\title{
Antioxidant Activities of Sonchus oleraceus L.
}

Sundara Mudiyanselage Maheshini Rangika Mawalagedera

\begin{abstract}
A thesis
submitted to the Victoria University of Wellington

in fulfilment of the requirements for the degree of

Doctor of Philosophy in Ecology and Biodiversity
\end{abstract}

Victoria University of Wellington

2014 


\begin{abstract}
Supernumerary free radicals and other reactive species can cause oxidative damage in animal cells, potentially leading to non-infectious diseases. Diets rich in low molecular weight antioxidants (LMWAs) may prevent or arrest the pathogenesis of these diseases. Leaves of Sonchus oleraceus L. may be an excellent dietary LMWA source for humans given their apparent strong antioxidant activities in vitro. However, different $S$. oleraceus plants vary in their antioxidant capacity. Nothing is known of possible environmental effects on antioxidant potential. Equally, the effects of cooking and gastrointestinal digestion are unknown. The goals of this research were: (i) to study the effects of plant age, locality, and abiotic stressors on antioxidant potential; (ii) to study the effects of cooking and in vitro gastrointestinal digestion on antioxidant activity and uptake in human cells; and (iii) to study extractable antioxidant activities of S. oleraceus cell suspension cultures in relation to abiotic stressors.
\end{abstract}

Antioxidant activities and levels of total phenolics, hydroxycinnamic acids and ascorbate increased as plants aged. An ecotype from Acacia Bay had a higher phenolic content and antioxidant activities than one from Oamaru; these differences were maintained across generations as well as in calli from in vitro cultures. This indicates heritability and genetic fidelity of antioxidant potential.

Chilling and salinity had variable effects on concentrations of phenolics and antioxidant activities in plants, and the combination of the two stressors was not synergistic. This indicates that these two stressors share signalling and response pathways. Stressorinduced increases in antioxidant activities of leaf extracts correlated with improved cellular antioxidant activities (CAA) inside HepG2 cells. Antioxidants were released from leaves following in vitro gastrointestinal digestion, which were then subsequently uptaken by $\mathrm{Caco} 2$ and HepG2 cells wherein they displayed CAAs. Thus, elevated levels of antioxidants in stressor-imposed plants provide potentially more antioxidant protection to live human cells.

Caftaric, chlorogenic and chicoric acids accounted for $92 \%$ of the phenolic compounds in S. oleraceus leaves. Of these, only chlorogenic acid was inducible by stressors, both in 
intact plants and in calli. In young stressor-applied plants, chlorogenic acid was enhanced to the levels achievable with plant ageing.

Boiling leaves prior to digestion did not diminish the caftaric and chlorogenic acid levels released through digestion, but chicoric acid levels were. Out of the nine phenolic compounds in leaves, only chicoric, chlorogenic and caftaric acids were released into the medium during in vitro gastrointestinal digestion. Digestion of leaves resulted in effective release of caftaric and chlorogenic acids from leaves but the levels of released chicoric acid were diminished by digestion.

This study offers insights into the factors that influence the antioxidant potential of $S$. oleraceus L. in vivo, in vitro, during cooking and in vitro gastrointestinal digestion. These results provide the foundation for: (1) encouraging the consumption of its fresh shoots as an antioxidant rich food; (2) further improving its antioxidant activities through manipulation of agronomy, ecotype and breeding; (3) developing its cell cultures as a commercial platform for phyto-antioxidant production aimed at formulating dietary supplements or food additives in biopharmaceutical industry. 


\section{ACKNOWLEDGEMENTS}

It is with deep gratitude that I express my sincere thanks to my supervisor Prof. Kevin S. Gould for the tremendous advice, encouragement, guidance and supervision extended to me throughout the research and made this thesis possible. Despite his busy schedule, he was always there to listen, motivate me and give feedback.

My secondary supervisor, Dr Arlene McDowell welcomed me into her lab at the School of Pharmacy, University of Otago which is greatly appreciated. I am truly thankful for her support and guidance provided for laboratory work and for her valuable feedback on the thesis.

My gratitude also goes to Dr Lesley Milicich, Derek Heath, Jack Cameron, Alan Howard (School of Biological Sciences, Victoria University of Wellington, New Zealand), Zongquan Ou, Julie Harwood, Len Stevenson, Mike Broughton and Kevin Crump (School of Pharmacy, University of Otago, New Zealand) for their assistance and guidance with laboratory work.

I wish to thank Kevin Gould lab group (Kate, Iggy, Luke, Karl and Gagan) for always providing fresh insights into problems and for just being there to answer my questions.

I am grateful for the funding by a New Zealand International Doctoral Research Scholarship, a Faculty Strategic Research Grant and three Wellington Botanical Society student grants which aided major and complementary financial requirements during past three years.

I am grateful for the moral support, friendly banter and concern shown by my adoptive family in New Zealand: Damayanthi, Prasad, Sandra, Trinh, Bruce, Kosala and Chathuri.

I would like to thank my parents and Uday for giving me their care, love and unprecedented understanding throughout my life. I could not have done it without their moral and financial support over all these years.

Finally, Waruna Thank you for making me your priority and putting up with me during past seven years. 


\section{TABLE OF CONTENTS}

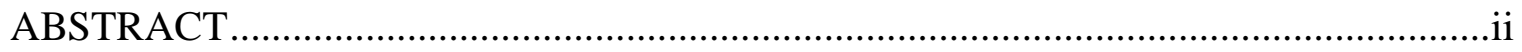

ACKNOWLEDGEMENTS ......................................................................................

TABLE OF CONTENTS .............................................................................................

LIST OF FIGURES ……………………...........................................................

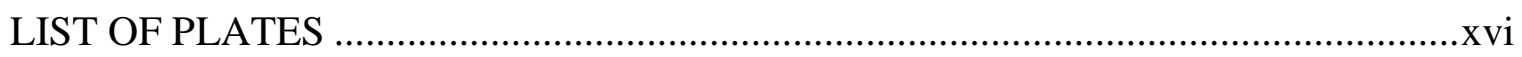

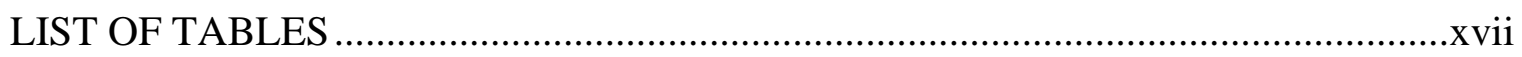

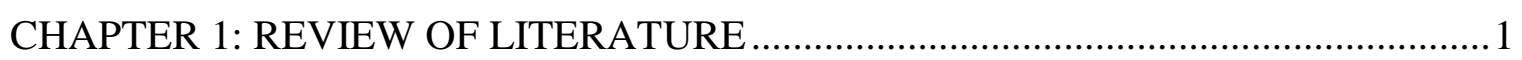

1.1 REACTIVE SPECIES AND ANTIOXIDANT DEFENCES …….........................

1.2 LOW MOLECULAR WEIGHT ANTIOXIDANTS OF DIETARY ORIGIN .....3

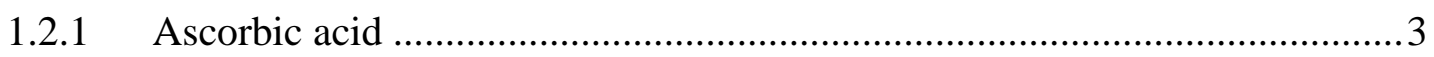

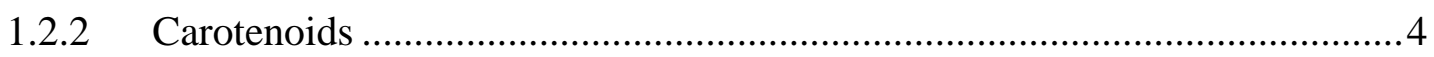

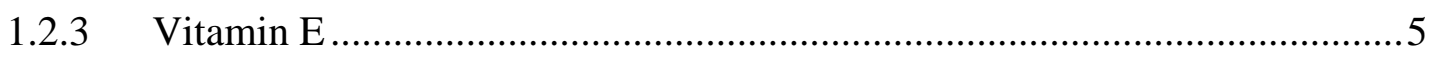

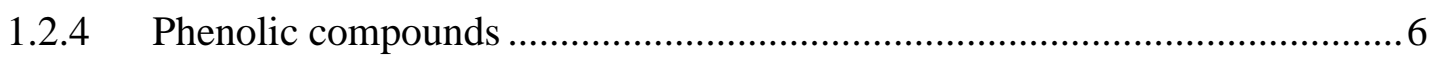

1.2.4.1 Phenolic acids .................................................................................

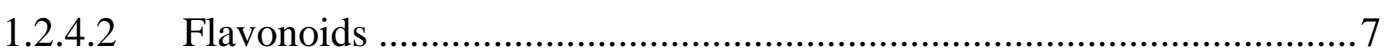

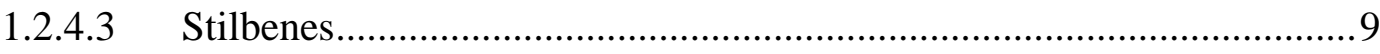

1.2.4.4 Antioxidant activities of phenolic compounds ...................................... 10

1.3 EVIDENCE FOR INFLUENCE OF DIETARY LMWAS ON OXIDATIVE STRESS-INDUCED DISEASES ……………………........................................ 12

1.4 THE BIOACCESSIBILITY, BIOAVAILABILITY, BIOACTIVITY AND STABILITY OF PHENOLIC COMPOUNDS …………………................................... 16 


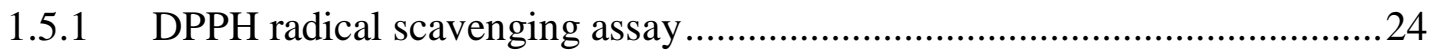

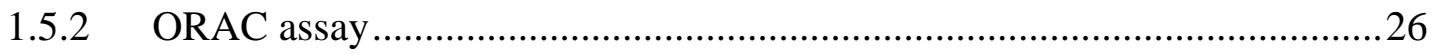

1.6 THE CELLULAR ANTIOXIDANT ACTIVITY (CAA) ASSAY ...................27

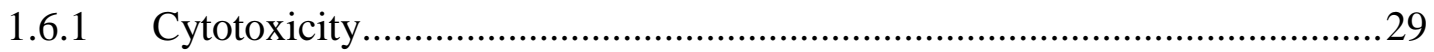

1.7 TRADITIONAL DIET OF MĀORI AND INCIDENCE OF COLORECTAL

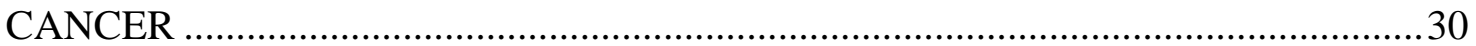

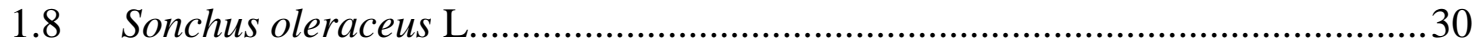

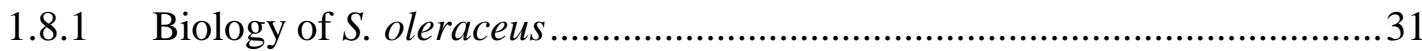

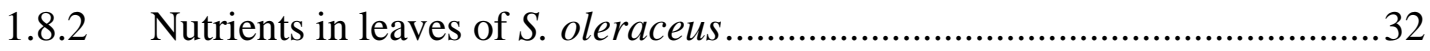

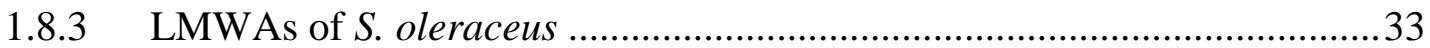

1.8.4 Variation in antioxidant potential of $S$. oleraceus ..................................... 34

1.9 EFFECT OF STRESS ON ANTIOXIDANT LEVELS IN PLANTS ................36

1.9.1 Drought stress on LMWA production in plants ..........................................38

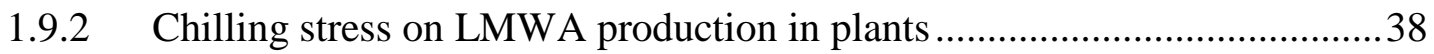

1.9.3 Light stress on LMWA production in plants ............................................ 38

1.9.4 Salinity stress on LMWA production in plants.......................................... 39

1.10 PLANT CELL CULTURE FOR THE PRODUCTION OF LMWAS............40

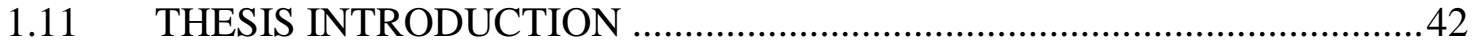

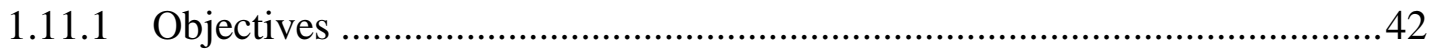

CHAPTER 2: GENERAL MATERIALS AND METHODS ..........................................4

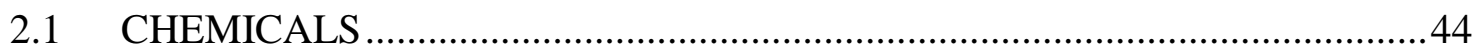




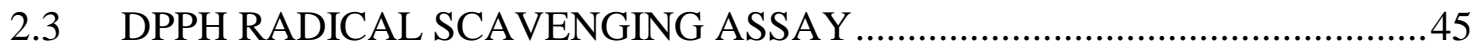

2.4 OXYGEN RADICAL ABSORBANCE CAPACITY ASSAY ..........................45

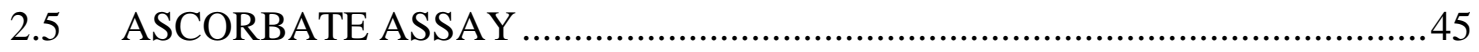

2.6 HUMAN CELL CULTURES (HepG2 and Caco2) .......................................46

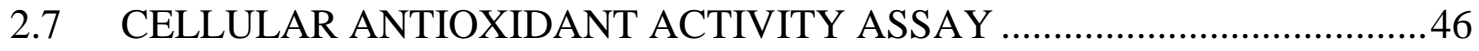

2.8 ONLINE REVERSE PHASE HPLC-DPPH RADICAL SCAVENGING .........47

CHAPTER 3: EFFECTS OF AGE, ECOTYPE, CHILLING AND SALINITY ON EXTRACTABLE ANTIOXIDANT ACTIVITIES OF Sonchus oleraceus L. .................48

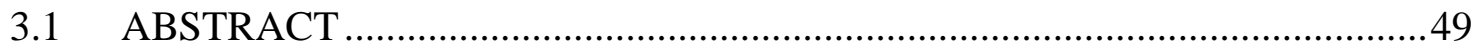

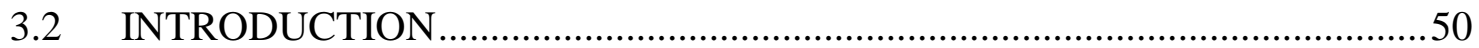

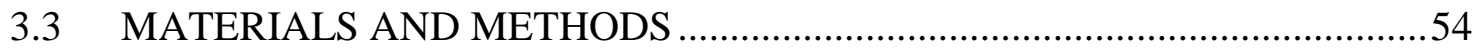

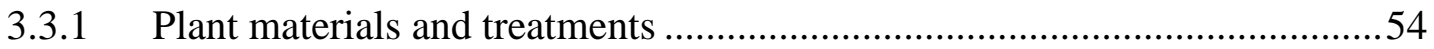

3.3.2 Chlorophyll fluorescence measurements ..................................................55

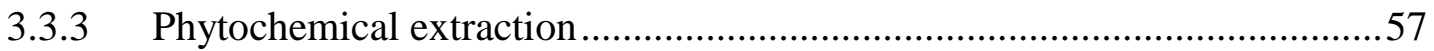

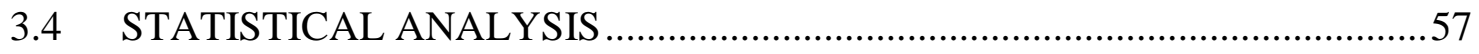

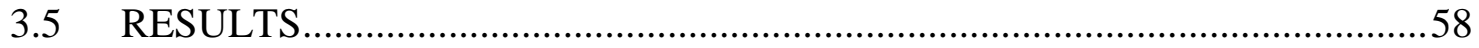

3.5.1 Hydroxycinnamic acids in S. oleraceus leaf extracts detected by HPLC ....58

3.5.2 Effect of age on extractable antioxidant activities, concentrations of total phenolic compounds and hydroxycinnamic acids ....................................................58

3.5.3 Effect of ecotype on extractable antioxidant activities, concentrations of total phenolic compounds and hydroxycinnamic acids .59 
3.5.4 Effects of stressors on extractable antioxidant activities, concentrations of total phenolic compounds and hydroxycinnamic acids

3.5.5 Effects of age, ecotype and stressors on ascorbate concentration .66

3.5.6 Effects of stressors on shoot, root and total dry biomass of plants.

3.5.7 Chlorophyll fluorescence measurements .68

3.5.7.1 Maximum efficiency of photosystem II .68

3.5.7.2 Light response curves for chlorophyll fluorescence .68

3.5.7.3 The parameters of light response curves for ETR .73

3.5.8 The stressor-induced variations in extractable antioxidant activities in leaves correlated with human cellular antioxidant activities .76

3.6 DISCUSSION .79

CHAPTER 4: EFFECTS OF COOKING AND IN VITRO GASTROINTESTINAL DIGESTION ON THE ANTIOXIDANT ACTIVITIES OF PHENOLIC COMPOUNDS IN Sonchus oleraceus L.

4.1 ABSTRACT .86

4.2 INTRODUCTION .87

4.3 MATERIALS AND METHODS

4.3.1 Chemicals

4.3.2 Plant Materials

4.3.3 Boiling .89

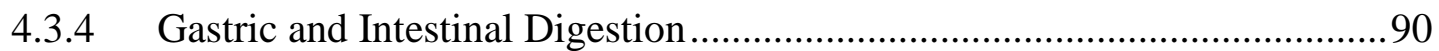

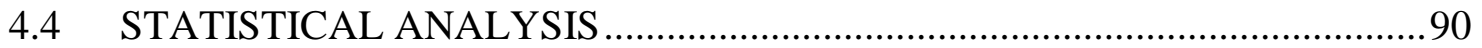

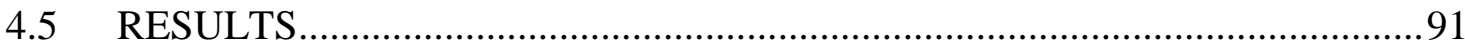


4.5.1 Antioxidant activities and concentrations of ascorbate and phenolic compounds from untreated raw leaf extracts

4.5.2 Antioxidant activities and concentrations of ascorbate and phenolic compounds after boiling and gastrointestinal digestion......

4.6 DISCUSSION 103

CHAPTER 5: EXTRACTABLE ANTIOXIDANT ACTIVITIES OF CELL SUSPENSION CULTURES OF Sonchus oleraceus L. IN RELATION TO ABIOTIC STRESSORS 108

5.1 ABSTRACT 109

5.2 INTRODUCTION. 110

5.3 MATERIALS AND METHODS 112

5.3.1 Chemicals

5.3.2 In vitro culture conditions

5.3.3 Establishment of in vitro plants

5.3.4 Establishment of callus culture

5.3.5 Establishment of cell suspension culture and culture conditions 113

5.3.6 Treatments 113

5.3.7 Phytochemical extraction 113

5.4 STATISTICAL ANALYSIS 114

5.5 RESULTS 115

5.5.1 In vitro plants, callus and suspension cultures of S. oleraceus L. 115

5.5.2 Biomass of cells from suspension cultures 116 
5.5.3 Effects of abiotic stressors on extractable antioxidant activities, concentrations of total phenolics, hydroxycinnamic acids and ascorbate

5.5.4 Ecotypes differ in extractable antioxidant activities, concentrations of total phenolics, hydroxycinnamic acids and ascorbate

5.5.5 Growth phases differ in extractable antioxidant activities, concentrations of total phenolics, hydroxycinnamic acids and ascorbate

5.5.6 Extractable antioxidant activities, and concentrations of total phenolics, hydroxycinnamic acids and ascorbate are lower in media than in calli.....

5.5.7 Comparison of LMWA concentrations in extracts from calli of suspension cultures and from leaves of greenhouse grown plants 126

5.6 DISCUSSION 128

CHAPTER 6: GENERAL DISCUSSION

6.1 CONCLUSIONS.

6.2 DISCUSSION

6.3 FUTURE DIRECTIONS 140

REFERENCES 142

APPENDIX A. 171

A.1 Optimum concentration of $\mathrm{NaCl}$ that enhances the DPPH radical scavenging activities of leaf extracts

A.2 Stressors that enhances the DPPH radical scavenging activities of leaf extracts .172

APPENDIX B 174

B.1 Effects of age, ecotype and stressor on antioxidant activity, total phenolic content, hydroxycinnamic acid content 174

B.2 Effects of age, ecotype and stressor on ascorbate concentration 175 
C.1 Optimum concentrations of NAA and BAP for callus initiation and growth ........ 176

C.2 Optimum concentrations of NAA and BAP for growth of suspension cultures ... 177 


\section{LIST OF FIGURES}

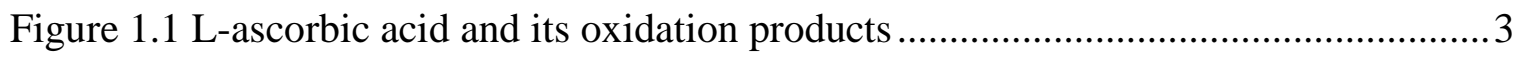

Figure 1.2 Structures of several carotenoids found in plants and animals........................

Figure 1.3 Basic structure of flavonoid molecule .......................................................

Figure 1.4 Oxidation-dependent changes in the structure of flavonoids .......................... 10

Figure 1.5 Percentage decrease in absorbance $\left(\mathrm{A}_{515 \mathrm{~nm}}\right)$ by DPPH against concentration of

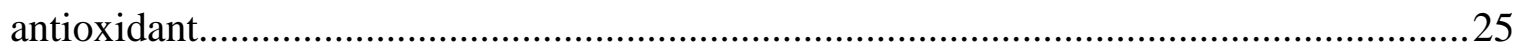

Figure 1.6 Fluorescence decay curve for antioxidant sample, blank and shaded area

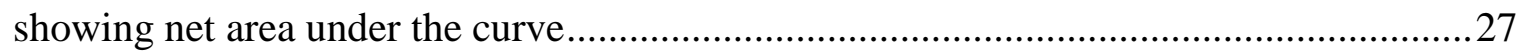

Figure 3.1 Effects of two combined abiotic stressors on extractable antioxidant activities

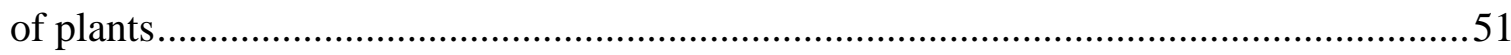

Figure 3.2 ANOVA interaction plots for additive effect of two stressors ........................52

Figure 3.3 ANOVA interaction plots when two stressors are either synergistic or antagonistic

Figure 3.4 Effects of age and ecotype on antioxidant activities and concentrations of LMWAs

Figure 3.5 Treatment effects on ORAC, DPPH radical scavenging and concentration of total phenolic compounds in ecotypes of Sonchus oleraceus L. at week 10, 12 and 14 ...63

Figure 3.6 Treatment effects on concentrations of hydroxycinnamic acids in ecotypes of Sonchus oleraceus L. at week 10, 12 and 14

Figure 3.7 RP-HPLC-DPPH chromatograms recorded for Sonchus oleraceus L. at week 10,12 , and 14, which had been exposed to treatments for two weeks

Figure 3.8 Concentration of ascorbate in ecotypes of Sonchus oleraceus L. with plant age and stressors .66 
Figure 3.9 Treatment effects on root, shoot and total dry biomass of ecotypes of Sonchus oleraceus $\mathrm{L}$. at week 14

Figure 3.10 Effects of age, ecotype and stressor on maximum efficiency of photosystem II (Fv/Fm) of Sonchus oleraceus L .68

Figure 3.11 Light response curves for quantum yield of PSII $\left(\Delta \mathrm{F} / \mathrm{F}_{\mathrm{m}}^{\prime}\right)$, nonphotochemical quenching (NPQ) and photochemical quenching $\left(\mathrm{q}_{\mathrm{P}}\right)$ and apparent electron transport rate (ETR) in leaves of ecotypes of Sonchus oleraceus L. at week 10, which had been exposed to treatments for two weeks. .70

Figure 3.12 Light response curves for quantum yield of PSII $\left(\Delta \mathrm{F} / \mathrm{F}_{\mathrm{m}}^{\prime}\right)$, nonphotochemical quenching (NPQ) and photochemical quenching $\left(\mathrm{q}_{\mathrm{P}}\right)$ and apparent electron transport rate (ETR) in leaves of ecotypes of Sonchus oleraceus L. at week 12, which had been exposed to treatments for two weeks. .71

Figure 3.13 Light response curves for quantum yield of PSII $\left(\Delta \mathrm{F} / \mathrm{F}_{\mathrm{m}}^{\prime}\right)$, nonphotochemical quenching (NPQ) and photochemical quenching $\left(\mathrm{q}_{\mathrm{P}}\right)$ and apparent electron transport rate (ETR) in leaves of ecotypes of Sonchus oleraceus L. at week 14, which had been exposed to treatments for two weeks.

Figure 3.14 Initial slope of light response curves for ETR $(\alpha)$ in leaves of ecotypes of Sonchus oleraceus L. with plant age and stressors .73

Figure 3.15 Maximum electron transport rate $\left(\mathrm{ETR}_{\max }\right)$ in leaves of ecotypes of Sonchus oleraceus $\mathrm{L}$. with plant age and stressors .74

Figure 3.16 Minimum saturating irradiance $\left(l_{\mathrm{k}}\right)$ in leaves of ecotypes of Sonchus oleraceus L. with plant age and stressors .75

Figure 3.17 Linear correlations between cellular antioxidant activities inside HepG2 cells with the extractable antioxidant activities .77

Figure 3.18 Linear correlations between cellular antioxidant activities inside HepG2 cells with the concentrations of LMWAs. .78

Figure 4.1 Reverse phase HPLC-DPPH chromatograms for methanolic extracts of Sonchus oleraceus L. raw untreated leaves. 
Figure 4.2 Changes in concentration of total phenolic compounds, DPPH radical scavenging activity and ORAC activity in Sonchus oleraceus L. leaves and in the bioaccessible fraction

Figure 4.3 Changes in concentrations of ascorbate and hydroxycinnamic acids in Sonchus oleraceus $\mathrm{L}$. leaves and in the bioaccessible fraction .95

Figure 4.4 Cellular antioxidant activity measured in HepG2 and Caco2 cells infused with the methanolic extracts of Sonchus oleraceus L. leaves and the bioaccessible fraction ...96

Figure 4.5 Correlation of cellular antioxidant activities between Caco2 and HepG2 cells infused with the bioaccessible fraction of Sonchus oleraceus L. leaves 97

Figure 4.6 Correlation between the concentration of hydroxycinnamic acids in the bioaccessible fraction and the cellular antioxidant activities.... .98

Figure 4.7 Reverse phase HPLC-DPPH chromatogram for methanolic extract of leaf digestate remaining after in vitro gastrointestinal digestion

Figure 4.8 Reverse phase HPLC-DPPH chromatograms recorded for bioaccessible fraction of Sonchus oleraceus L. leaves .99

Figure 4.9 Concentration of chlorogenic, ascorbic, chicoric and caftaric acids in Sonchus oleraceus L. raw and boiled leaves, and in the bioaccessible fraction 101

Figure 4.10 Proportionate contributions of three main hydroxycinnamic acids to the total phenolic acids in the bioaccessible fraction of Sonchus oleraceus L. raw and boiled leaves 101

Figure 4.11 Correlations between the concentration of hydroxycinnamic acids and the concentration of total phenolic compounds and antioxidant activities in the bioaccessible fraction of Sonchus oleraceus L. raw and boiled leaves 102

Figure 5.1 Changes in dry biomass of cells from suspension cultures of Sonchus oleraceus L 116

Figure 5.2 Changes in DPPH radical scavenging capacity in calli and media of ecotypes 118 
Figure 5.3 Changes in ORAC activity in calli and media of ecotypes

Figure 5.4 Changes in concentration of total phenolics in calli and media of ecotypes.. 120

Figure 5.5 Changes in concentration of chlorogenic acid in calli and media of ecotypes

Figure 5.6 Changes in concentration of caftaric acid in calli and media of ecotypes...... 122

Figure 5.7 Changes in concentration of chicoric acid in calli and media of ecotypes..... 123

Figure 5.8 Changes in concentration of ascorbate in calli and media of ecotypes 124

Figure 6.1 Process for validating a food plant as a valuable source of dietary LMWAs with evidence of health benefits

Figure A.1 Treatment effects on DPPH radical scavenging in methanolic extracts of leaves from 10, 12 and 14 week old plants of ACB and OAM ecotypes of Sonchus oleraceus L

Figure A.2 Effects of age and stressors on ORAC, DPPH radical scavenging, total phenolic content, in methanolic extracts of Sonchus oleraceus L

Figure B.1 Different hormone concentrations on callus initiation and callus dry biomass of Sonchus oleraceus L. after 21 days of culture 176

Figure B.2 Different hormone concentrations on dry biomass of Sonchus oleraceus L. suspension cultures after 21 days of culture 177 


\section{LIST OF PLATES}

Plate 1.1 Sonchus oleraceus L. whole plant and capitulum 31

Plate 3.1 Four week old Sonchus oleraceus L. plants growing in Victoria University of Wellington glasshouse 48

Plate 3.2 Shoot morphology of Sonchus oleraceus L. at week 10, 12 and 14, following two weeks of chilling, salinity and the combination of the two 62

Plate 4.1 Sonchus oleraceus L. leaves boiled for $5 \mathrm{~min}$ and digestate remaining after in vitro gastrointestinal digestion for $120 \mathrm{~min}$. .85

Plate 4.2 Paddle type dissolution apparatus (six-station Erweka DT 600 Dissolution Tester) .88

Plate 5.1 Light micrographs of Sonchus oleraceus L. cells in suspension cultures and a transverse section of a leaf from a greenhouse grown plant. 108

Plate 5.2 Sonchus oleraceus L. 07 day old, 21 day old in vitro plants and 21 day old callus cultures on Murashige and Skoog medium. 115

Plate 5.3 Suspension cultures of Sonchus oleraceus L. at 07 and 28 days. 116 


\section{LIST OF TABLES}

Table 1.1 List of selected free radicals and other reactive species .................................2

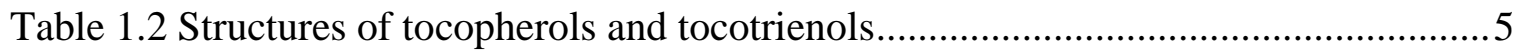

Table 1.3 Classification, occurrence and structure of selected phenolic acids in plants .....6

Table 1.4 Selected hydroxycinnamic acid derivatives and occurrence in plants................

Table 1.5 Classification, occurrence and structure of selected flavonoids naturally

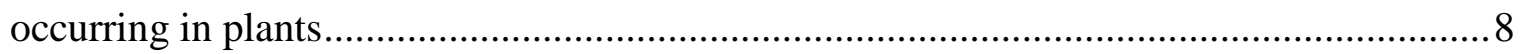

Table 1.6 Examples for selected glucoside derivatives of flavonoids naturally occurring in plants

Table 1.7 Classification and structure of selected derivatives of stilbenes in plants

Table 1.8 Selected epidemiological studies on dietary intake of phenolic compounds and cancer 13

Table 1.9 Selected randomized, controlled, crossover clinical feeding trial on effects of food and LMWAs on oxidative stress related diseases and conditions among humans.... 14

Table 1.10 Selected randomized, double-blind, placebo-controlled clinical feeding trial on influence of food and LMWAs on oxidative stress related diseases among humans .15

Table 1.11 Selected studies on bioaccessibility, bioactivity and stability of antioxidants from various food sources .17

Table 1.12 Compounds detected following in vitro gastrointestinal digestion of selected phenolic acids and their derivatives in food .18

Table 1.13 Compounds detected following in vitro gastrointestinal digestion of selected flavonoids and their derivatives in food.

Table 1.14 Compounds detected following in vitro gastrointestinal digestion of selected anthocyanins and their derivatives in food 20 
Table 1.15 Changes in metabolites detected following in vitro gastrointestinal digestion of selected phenolic compounds in food

Table 1.16 Changes in metabolites detected following in vitro digestion by colonic microflora or in situ digestion by rats of selected phenolic compounds in food

Table 1.17 Comparison of types of in vitro chemical antioxidant activity assays

Table 1.18 Cellular Antioxidant Activity in human hepatoma cells by selected phytochemicals

Table 1.19 Nutrient composition of S. oleraceus leaves collected from natural habitats in Spain

Table 1.20 Mineral elements in S. oleraceus leaves collected from natural habitats in Spain .33

Table 1.21 Composition and antioxidant activities of phenolic compounds from $S$. oleraceus . .34

Table 1.22 Antioxidant activities of methanolic extracts from S. oleraceus leaves collected from natural habitats throughout New Zealand .35

Table 1.23 Examples of primary reactive species, which are induced by abiotic and biotic stressors and their possible mechanism for induction 37

Table 1.24 Stress conditions that stimulate increased levels or activities of enzymatic antioxidants in plants .37

Table 1.25 Selected examples for effects of drought on increased LMWAs in plant species under experimental conditions

Table 1.26 Selected examples for effects of salinity on enhanced LMWAs in plant species under experimental conditions

Table 1.27 Selected examples for the effects of abiotic stresses on enhanced LMWAs in plant cell cultures under experimental conditions 
Table 3.1 Comparison of the regions from which the two ecotypes of Sonchus oleraceus L. were collected

Table 3.2 Definitions of fluorescence intensity parameters .56

Table 3.3 Definitions of fluorescence quenching parameters .56

Table 3.4 Retention times of phenolic compounds detected by HPLC and their content as a percentage of total peak area..... .58

Table 4.1 Antioxidant activities, concentrations of ascorbate and total phenolic compounds for methanolic extracts of Sonchus oleraceus L. raw leaves and blueberry fruit. 91

Table 4.2 Cellular antioxidant activities for methanolic extracts of Sonchus oleraceus L. raw leaves in HepG2 and Caco2 cells.

Table 5.1 Selected patents for production of phenolic compounds from plant cell suspension cultures.

Table 5.2 Selected commercial applications of plant cell suspension cultures for the production of LMWAs.

Table 5.3 Rates of cell dry biomass accumulation in suspension cultures of Sonchus oleraceus L

Table 5.4 Comparison of phytochemical concentrations in extracts from calli of suspension cultures and from leaves of greenhouse grown plants of ecotypes of Sonchus oleraceus $\mathrm{L}$. following treatments

Table 6.1 Simplified summary of results from Chapters $3-5$ showing factors affecting antioxidant activities in Sonchus oleraceus L. leaves and cell cultures 133

Table 6.2 Sonchus oleraceus L. leaves and common food categorized into six groups ranked by their extractable antioxidant activities.

Table 6.3 Comparison of concentrations of hydroxycinnamic acids extracted from calli of suspension cultures and leaves of greenhouse grown plants of Sonchus oleraceus L. and other selected plant species. 
Table 6.4 Effects of abiotic elicitors on concentrations of hydroxycinnamic acids extracted from calli of suspension cultures of Sonchus oleraceus L. and selected plant

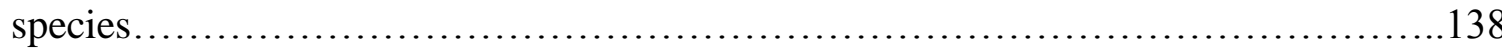




\section{CHAPTER 1: REVIEW OF LITERATURE}

\subsection{REACTIVE SPECIES AND ANTIOXIDANT DEFENCES}

A wide range of free radicals and other reactive species (Table 1.1) are capable of damaging the lipids, proteins, and DNA in plant and animal cells, and are associated with the development of various diseases. Of these reactive species the radical and non-radical derivatives of oxygen, collectively known as reactive oxygen species (ROS) are the most abundant type in plants and animals (Lushchak, 2011). ROS are either generated internally within the various tissues of organisms, or may be absorbed from external sources. ROS are formed internally by leakage of electrons to molecular oxygen in the photosynthetic and respiratory electron transport chains (Halliwell and Gutteridge, 2007). The formation of ROS in organisms can be induced externally by exposure to cigarette smoke, environmental pollutants, radiation, ultraviolet light, some chemicals and ozone (Halliwell and Gutteridge, 2007).

A system of antioxidant defences effectively neutralizes the ROS and counteracts their negative effects. However, when antioxidant defences are overwhelmed by the generation of supernumerary reactive species, tissues may be subjected to oxidative assault, resulting in damage to biomolecules. In humans, this can potentially lead to premature aging (Kregel and Zhang, 2007), inflammation (Federico et al., 2007), cancer (Halliwell, 2007), atherosclerosis (Singh and Jialal, 2006), diabetes (Baynes and Thorpe, 1999; Mehta et al., 2006), liver injury (Parola and Robino, 2001; Choi and James Ou, 2006), Alzheimer's disease (Mamelak, 2007), Parkinson's disease (Fahn, 1992), and coronary heart problems (Singal et al., 1998; Madamanchi et al., 2005).

The antioxidant defences in organisms comprise: (i) enzymes, which catalytically remove ROS; (ii) enzymes that regenerate oxidised antioxidants; (iii) proteins that minimise the availability of pro-oxidant ions such as iron and copper; (iv) proteins that protect biomolecules against oxidative damage; and (v) a variety of low molecular weight antioxidants (LMWAs), which scavenge ROS (Halliwell and Gutteridge, 2007). Humans synthesise some LMWAs in vivo; these include glutathione, $\alpha$-keto acids, sex hormones, melatonin, lipoic acid, coenzyme Q10, uric acid, histidine, and melanins. Others are 
derived from ingested food particularly derived from plants, and include tocopherols (vitamin E), ascorbic acid (vitamin C), carotenoids (vitamin A), and an assortment of phenolic and polyphenolic compounds (Halliwell and Gutteridge, 2007).

Table 1.1 List of selected free radicals and other reactive species

\begin{tabular}{|c|c|}
\hline Radicals & Non-radicals \\
\hline \multicolumn{2}{|c|}{ Reactive oxygen species (ROS) } \\
\hline - $\quad$ Superoxide $\left(\mathrm{O}_{2}^{-{ }^{-}}\right)$ & - Hydrogen peroxide $\left(\mathrm{H}_{2} \mathrm{O}_{2}\right)$ \\
\hline - $\quad$ Hydroxyl $\left(\mathrm{OH}^{\bullet}\right)$ & - Hypochlorous ( $\mathrm{HOCl})$ \\
\hline - $\quad$ Peroxyl $\left(\mathrm{RO}_{2}^{\circ}\right)$ & - $\quad$ Ozone $\left(\mathrm{O}_{3}\right)$ \\
\hline - $\quad$ Alkoxyl (RO') & - $\quad$ Singlet oxygen $\left({ }^{1} \mathrm{O}_{2}\right)$ \\
\hline - Hydroperoxyl $\left(\mathrm{HO}_{2}^{\circ}\right)$ & - $\quad$ Peroxynitrite $\left(\mathrm{ONOO}^{-}\right)$ \\
\hline \multicolumn{2}{|c|}{ Reactive nitrogen species } \\
\hline - $\quad$ Nitric oxide (NO') & - $\quad$ Nitrous acid $\left(\mathrm{HNO}_{2}\right)$ \\
\hline \multirow[t]{3}{*}{ - $\quad$ Nitrogen dioxide $\left(\mathrm{NO}_{2}{ }^{\circ}\right)$} & - $\quad$ Nitrosyl cation $\left(\mathrm{NO}^{+}\right)$ \\
\hline & - $\quad$ Nitroxyl anion $\left(\mathrm{NO}^{-}\right)$ \\
\hline & - $\quad$ Alkyl peroxynitriles (ROONO) \\
\hline
\end{tabular}

Reactive chlorine species

- $\quad$ Atomic chlorine $\left(\mathrm{Cl}^{\circ}\right)$

- Chlorine gas $\left(\mathrm{Cl}_{2}\right)$

- $\quad$ Bromine chloride $(\mathrm{BrCl})$

- Chlorine dioxide $\left(\mathrm{ClO}_{2}\right)$

Sulphur centered radicals

- $\quad$ Thiyl radicals $\left(\mathrm{RS}^{\circ}\right)$

- $\quad$ Perthiyl (RSS )

Carbon centred radicals

- Trichloromethyl $\left(\mathrm{CCl}_{3}{ }^{\circ}\right)$

Transition metal ions

- Iron ions $\left(\mathrm{Fe}^{2+}, \mathrm{Fe}^{3+}\right)$

- Copper ions $\left(\mathrm{Cu}^{2+}\right)$

- Manganese ions $\left(\mathrm{Mn}^{2+}\right)$ 


\subsection{LOW MOLECULAR WEIGHT ANTIOXIDANTS OF DIETARY ORIGIN}

\subsubsection{Ascorbic acid}

Animals lack the capacity to synthesise ascorbic acid, and therefore obtain it exclusively from their diet (Halliwell and Gutteridge, 2007). Because plants are the only natural dietary source of ascorbic acid for humans, efforts are underway to enhance ascorbic acid levels in plants through breeding and manipulation of growth conditions (Smirnoff, 2011). Several putative pathways of ascorbic acid biosynthesis occur simultaneously in plants (Smirnoff, 2011). In biological systems ascorbic acid functions as an antioxidant by donating electrons to neutralise ROS (Halliwell and Gutteridge, 2007). Donation of one electron by ascorbate forms the ascorbyl radical, which then disproportionates to monodehydroascorbate (MDHA). Further oxidation of MDHA produces dehydroascorbate (DHA). MDHA and DHA can be reduced to form ascorbate by energy dependent reactions, each catalysed by MDHA reductase (MDHAR) and DHA reductase (DHAR) enzymes; these reactions comprise the ascorbate-glutathione cycle (Figure 1.1).

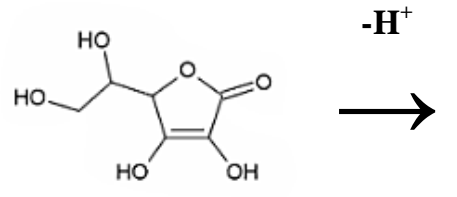

L-ascorbic acid<smiles>O=C1OC(C(O)CO)C([O-])=C1O</smiles>

ascorbate
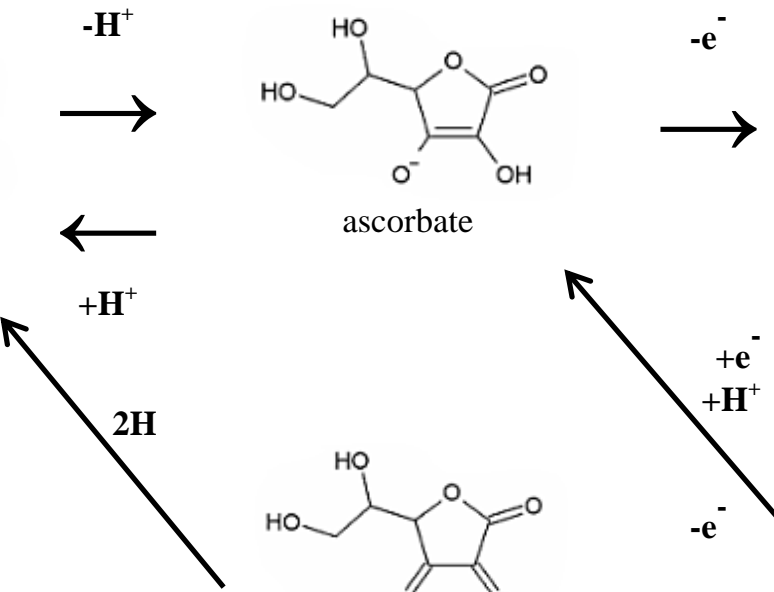

dehydroascorbate
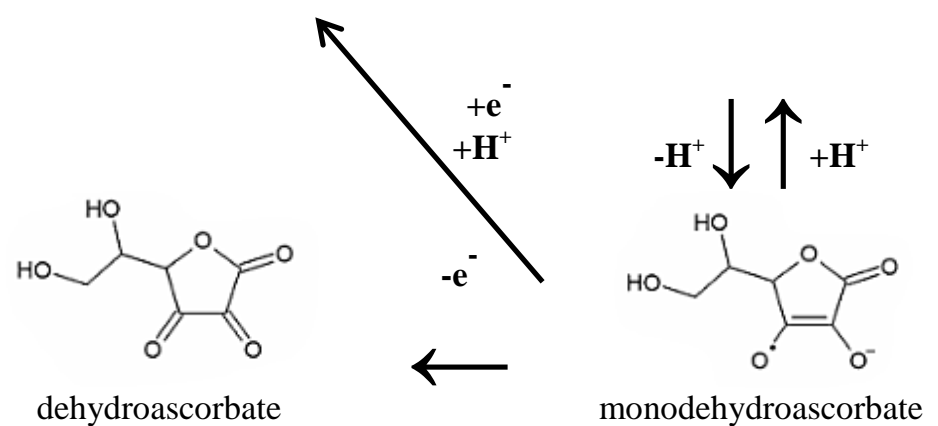

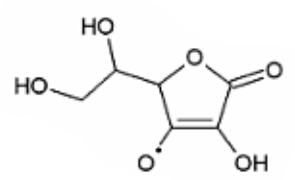

ascorbyl radical

Figure 1.1 L-ascorbic acid and its oxidation products

Source: Smirnoff (2011)

Sufficient supply of vitamin $\mathrm{C}$ has been associated with reduced onset of diseases such as Alzheimer's (Zandi et al., 2004), diabetes (Murthy et al., 1992), cardiovascular diseases (Diaz et al., 1997) and other oxidative stress disorders (Grassmann et al., 2002) possibly due to its antioxidant activity in vivo. 


\subsubsection{Carotenoids}

Carotenoids are a family of pigmented antioxidants such as $\alpha$-carotene, $\beta$-carotene, lycopene, lutein and zeaxanthin. They have a characteristic long chain of conjugated double bonds (Figure 1.2), with bilateral symmetry around the central double bond (Britton, 1995). Modification of the basic structure at the end groups by hydrogenation, dehydrogenation, cyclization, oxidation or any combination of these processes results in formation of derivatives with specific colours and antioxidant properties (Raoa and Raob, 2007).
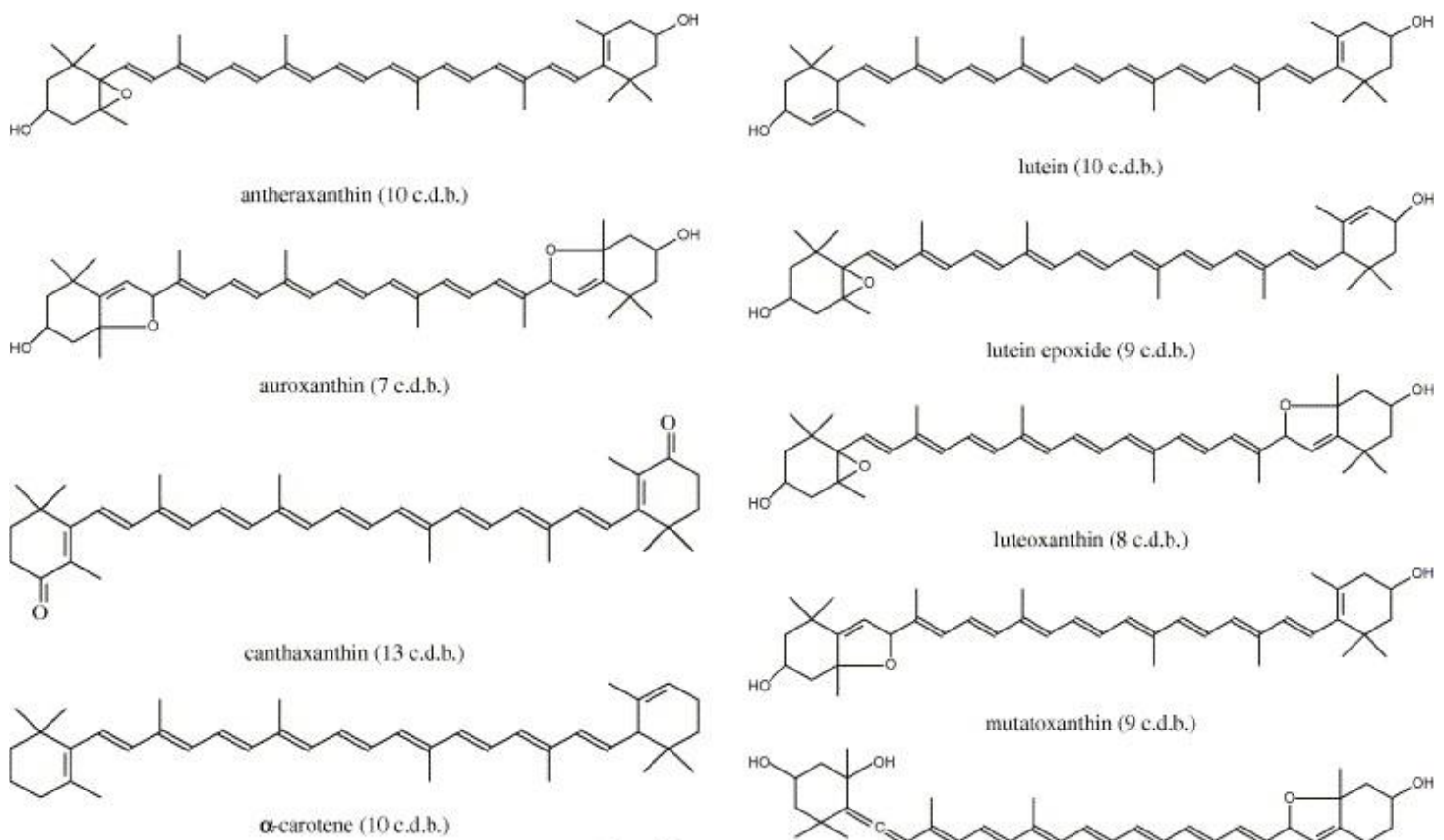<smiles>CC1=C(/C=C/C(C)=C/C=C/C(C)=C/C=C/C=C(C)/C=C/C=C(C)/C=C/C2=C(C)CCCC2(C)C)C(C)(C)CCC1</smiles><smiles>CC(C)=CCC/C(C)=C/CC/C(C)=C/C=C/C=C(C)/C=C/C=C/C=C(C)\C=C\C=C(/C)CC/C=C(\C)CCC=C(C)C</smiles>

ל-carotene (7 c.d.b.)<smiles>CC1=C(/C=C/C(C)=C/C=C/C(C)=C/C=C/C=C(C)/C=C/C=C(C)/C=C/C2=C(C)CC(O)CC2(C)C)C(C)(C)CCC1</smiles><smiles>C/C=C/C=C/C=C(C)/C=C/C=C(C)/C=C/C=C/C=C(C)/C=C/C=C(\C)C1C=C2C(C)(C)CC(O)CC2(C)O1</smiles><smiles>CC1=C2/C=C/C(C)=C/C=C/C(C)=C/C=C/C=C(C)/C=C/C=C(\C)C(C=C3C(C)(C)CC(O)CC3(C)C)C(C)(C1)CC(O)O2</smiles>

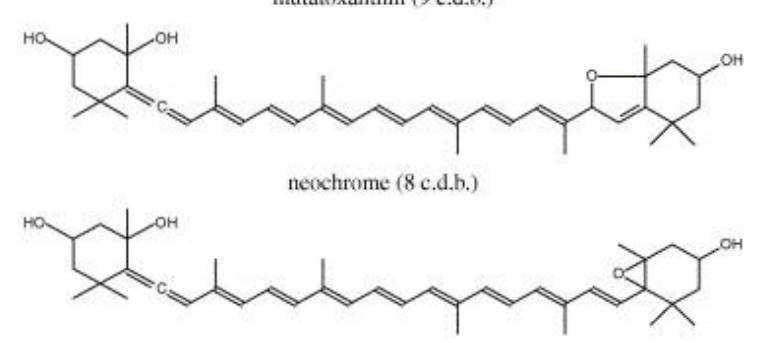

neoxanthin ( 9 c,d.b.)
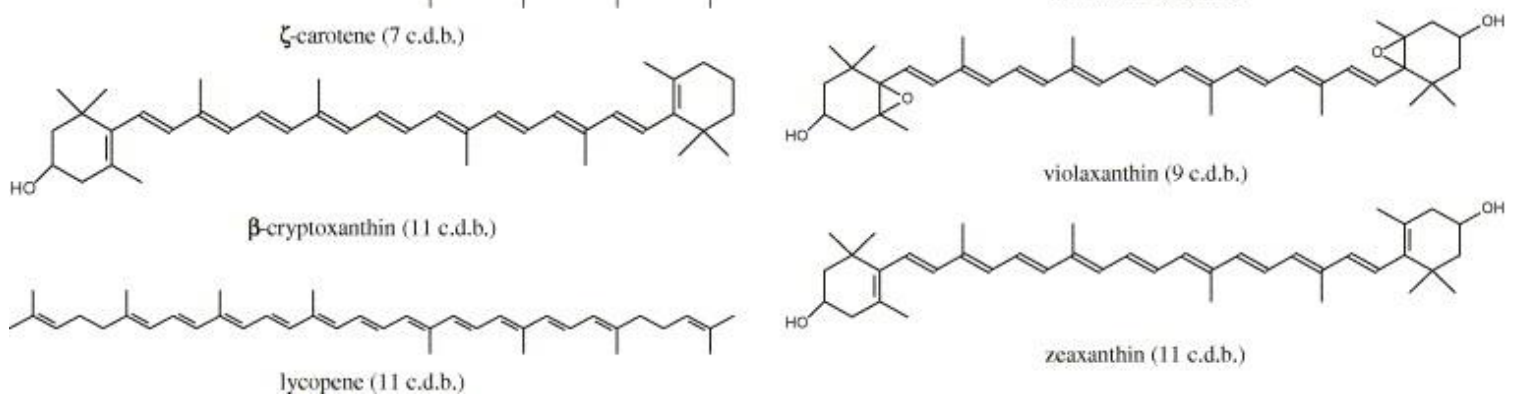

Figure 1.2 Structures of several carotenoids found in plants and animals

Source: Meléndez-Martínez et al. (2007) 
Fruits and vegetables constitute the major sources of carotenoids in the adult human diet (Johnson, 2002). Some carotenoids such as $\beta$-carotene and $\beta$-cryptoxanthin serve as the precursor for fat-soluble vitamin A (Maiani et al., 2009). Carotenoids are distributed in the membranes, lipoproteins, and adipocytes of the human body because of their lipophilic nature. Carotenoids display in vivo antioxidant properties by quenching ROS such as singlet oxygen (formed during lipid peroxidation). Quenching activity leaves the carotenoid structure intact, thus regeneration is not required (Sies and Stahl, 1995). Carotenoids were shown to have preventive activity against cardiovascular diseases (Ford and Giles, 2000) and UV-induced erythema (Stahl et al., 2001).

\subsubsection{Vitamin E}

Vitamin E refers to a group of lipid-soluble, naturally occurring antioxidants comprising $\alpha$-, $\beta$-, $\gamma$ - and $\delta$-tocopherol and $\alpha$-, $\beta$-, $\gamma$ - and $\delta$-tocotrienol (Table 1.2), which are capable of neutralising a variety of ROS (Halliwell and Gutteridge, 2007). Tocopherols and tocotrienols scavenge lipid peroxyl radicals and singlet oxygen, thereby preventing lipid peroxidation and subsequent oxidative injury in biological systems (Niki, 2013). Ingested tocopherols have been correlated with reduced indices of oxidative stress (Roberts II $e t$ al., 2007) in patients with cardiovascular disease (Rimm et al., 1993) and coronary artery disease (Devaraj et al., 2007).

Table 1.2 Structures of tocopherols and tocotrienols

Tocopherols




\subsubsection{Phenolic compounds}

Plants contain a large variety of phenolic compounds such as phenolic acids, flavonoids, stilbenes and their various derivatives. Phenolic compounds in plants are ubiquitous, diverse and are extremely important as compounds that affect pigmentation, astringency, antibacterial, anticancer, antioxidant and antiviral properties of plant derived products and foods (Jaganath and Crozier, 2010). Phenolic compounds in plants are synthesised from phenylalanine through the phenylpropanoid pathway (Halliwell and Gutteridge, 2007). Phenolic compounds are characterized by at least one hydroxyl group attached to a benzene ring (Halliwell and Gutteridge, 2007).

\subsubsection{Phenolic acids}

There are two major groups of phenolic acids: hydroxybenzoic acids and hydroxycinnamic acids (Table 1.3) and their associated derivatives. Derivatives of phenolic acids occur when they bind with cellulose, lignin, sugars and proteins through ester bonds (Halliwell and Gutteridge, 2007). Examples of hydroxycinnamic acid derivatives include: chlorogenic acid, which is an ester of caffeic acid and quinic acid; caftaric acid, which is an ester of caffeic acid and tartaric acid; and chicoric acid, which comprises of two caffeic acid molecules (Table 1.4).

Table 1.3 Classification, occurrence and structure of selected phenolic acids in plants

\begin{tabular}{|c|c|c|c|c|c|}
\hline Basic structure & Phenolic acid & R1 & $\mathbf{R 2}$ & R3 & Occurrence \\
\hline \multirow[t]{5}{*}{ Hydroxybenzoic acid } & Hydroxybenzoic & $\mathrm{H}$ & $\mathrm{OH}$ & $\mathrm{H}$ & \multirow{5}{*}{$\begin{array}{l}\text { Apples, cherries, grapefruit, } \\
\text { grapes, kiwi fruit, olives, } \\
\text { oranges, peaches, pears, } \\
\text { potatoes, wine (Tomás- } \\
\text { Barberán and Clifford, 2000) }\end{array}$} \\
\hline & Protocatechuic & $\mathrm{OH}$ & $\mathrm{OH}$ & $\mathrm{H}$ & \\
\hline & Vannilic & $\mathrm{OCH}_{3}$ & $\mathrm{OH}$ & $\mathrm{H}$ & \\
\hline & Syringic & $\mathrm{OCH}_{3}$ & $\mathrm{OH}$ & $\mathrm{OCH}_{3}$ & \\
\hline & Gallic & $\mathrm{OH}$ & $\mathrm{OH}$ & $\mathrm{OH}$ & \\
\hline \multirow{4}{*}{ Hydroxycinnamic acid } & Caffeic & $\mathrm{H}$ & $\mathrm{OH}$ & $\mathrm{H}$ & \multirow{4}{*}{$\begin{array}{l}\text { Apples, blueberries, cereal } \\
\text { bran, cherries, citrus species, } \\
\text { coffee, kiwi fruit, olives, } \\
\text { peaches, pears, potatoes, } \\
\text { tomatoes, white grapes, white } \\
\text { wine (Clifford, 1999) }\end{array}$} \\
\hline & Ferulic & $\mathrm{OH}$ & $\mathrm{OH}$ & $\mathrm{H}$ & \\
\hline & Cinnamic & $\mathrm{OCH}_{3}$ & $\mathrm{OH}$ & $\mathrm{H}$ & \\
\hline & Sinapic & $\mathrm{OCH}_{3}$ & $\mathrm{OH}$ & $\mathrm{OCH}_{3}$ & \\
\hline
\end{tabular}


Table 1.4 Selected hydroxycinnamic acid derivatives and occurrence in plants

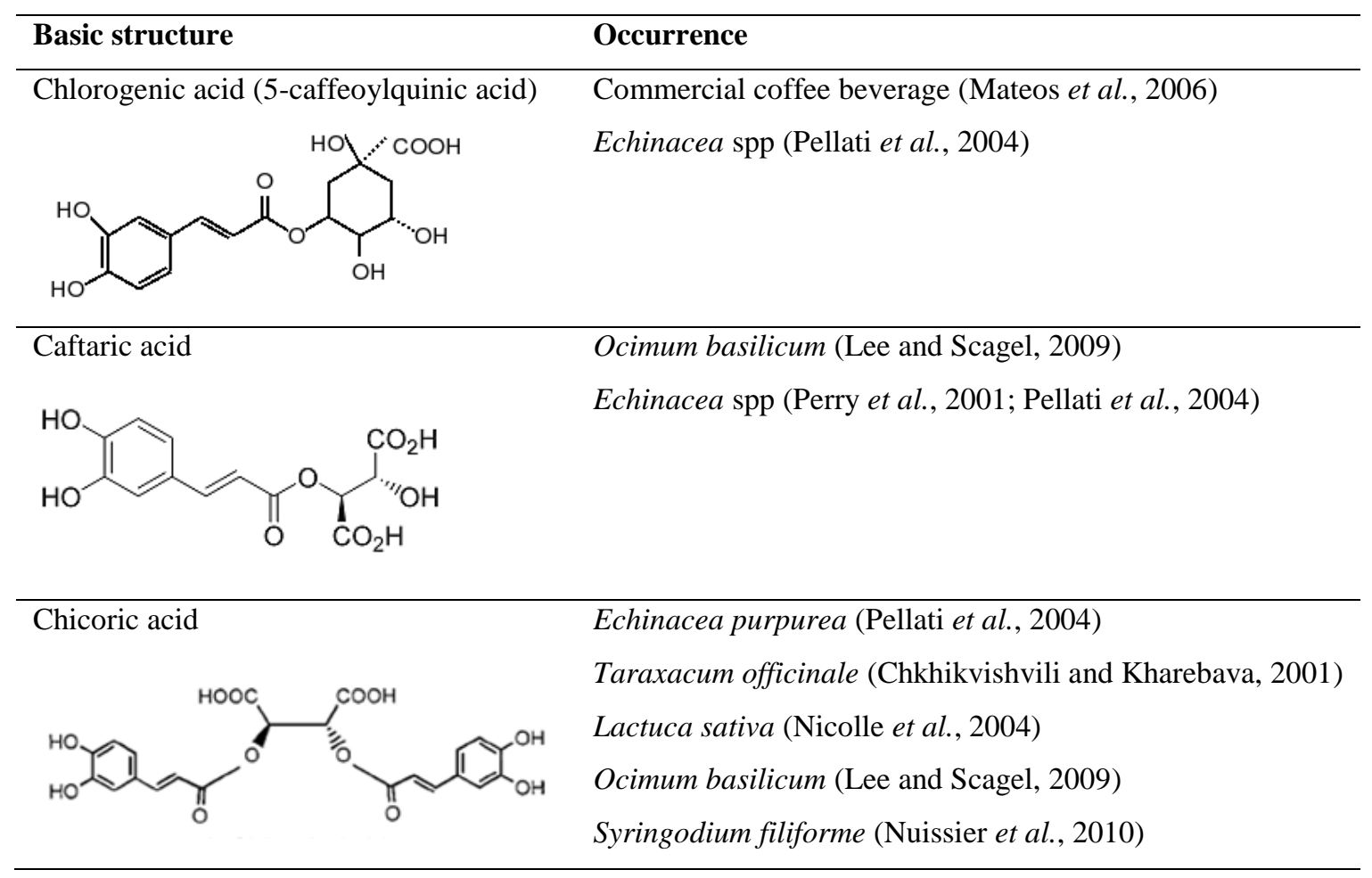

\subsubsection{Flavonoids}

Flavonoids (Figure 1.3) are characterized by two benzene rings (A and B), which are linked together by a $\gamma$-pyrone ring (C). Flavonoids are a broad class of LMWAs in plants through various modifications to the basic structure by the addition of hydroxyl, methyl or glycoside moieties (Tables 1.5 and 1.6). In plants, these compounds function as pigments, perform a number of regulatory roles in plant development and may provide protection against ultraviolet radiation, pathogens, and herbivores (Gould, 2004; Treutter, 2006).

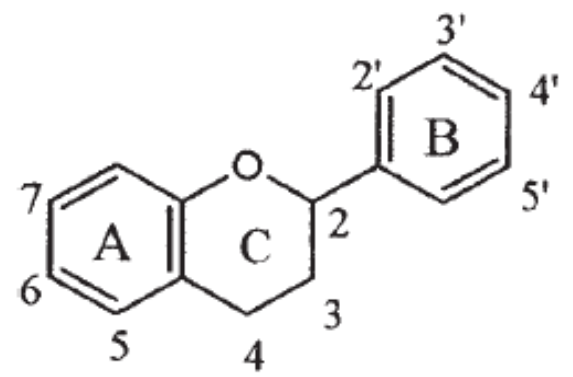

Figure 1.3 Basic structure of flavonoid molecule 
Table 1.5 Classification, occurrence and structure of selected flavonoids naturally occurring in plants

\begin{tabular}{|c|c|c|c|c|c|}
\hline $\begin{array}{l}\text { Classes and their basic } \\
\text { structure }\end{array}$ & Examples & R1 & $\mathbf{R 2}$ & $\mathbf{R 3}$ & Occurrence \\
\hline \multirow[t]{2}{*}{ Flavones } & Apigenin & $\mathrm{H}$ & $\mathrm{OH}$ & $\mathrm{H}$ & \multirow[t]{2}{*}{$\begin{array}{l}\text { Celery, citrus fruits, } \\
\text { parsley, red pepper, red } \\
\text { wine (Hollman and Arts, } \\
\text { 2000) }\end{array}$} \\
\hline & Luteolin & $\mathrm{H}$ & $\mathrm{OH}$ & $\mathrm{OH}$ & \\
\hline \multirow[t]{2}{*}{ Flavanones } & Hesperetin & $\mathrm{H}$ & $\mathrm{OCH}_{3}$ & $\mathrm{OH}$ & \multirow[t]{2}{*}{$\begin{array}{l}\text { Citrus fruits (Erlund, 2004; } \\
\text { Peterson et al., 2006a; } \\
\text { Peterson } \text { et al., 2006b) }\end{array}$} \\
\hline & Naringenin & $\mathrm{H}$ & $\mathrm{OH}$ & $\mathrm{H}$ & \\
\hline \multirow{3}{*}{ Flavonols } & Ouercetin & $\mathrm{H}$ & $\mathrm{OH}$ & $\mathrm{OH}$ & \multirow{3}{*}{$\begin{array}{l}\text { Apples, berries, black tea, } \\
\text { grapefruit, grapes, } \\
\text { olives, onions, red wine } \\
\text { (Hollman and Arts, 2000; } \\
\text { Erlund, 2004) }\end{array}$} \\
\hline & Kaempferol & $\mathrm{H}$ & $\mathrm{OH}$ & $\mathrm{H}$ & \\
\hline & Myricetin & $\mathrm{OH}$ & $\mathrm{OH}$ & $\mathrm{OH}$ & \\
\hline \multirow{4}{*}{ Flavan-3-ols } & Epicatechin & $\mathrm{H}$ & $\mathrm{H}$ & - & \multirow{4}{*}{$\begin{array}{l}\text { Apples, apricots, cherries, } \\
\text { green tea, black tea, } \\
\text { peaches, plums, red wine } \\
\text { (Hollman and Arts, 2000; } \\
\text { Monagas et al., 2005) }\end{array}$} \\
\hline & $\begin{array}{l}\text { Epicatechin } \\
\text { gallate }\end{array}$ & $\mathrm{H}$ & gallate & - & \\
\hline & Epigallocatechin & $\mathrm{OH}$ & $\mathrm{H}$ & - & \\
\hline & $\begin{array}{l}\text { Epigallocatechin } \\
\text { gallate }\end{array}$ & $\mathrm{OH}$ & gallate & - & \\
\hline \multirow[t]{4}{*}{ Anthocyanidins } & Peonidin & $\mathrm{OCH}_{3}$ & $\mathrm{OH}$ & $\mathrm{H}$ & \multirow{4}{*}{$\begin{array}{l}\text { Berries, blood oranges, red } \\
\text { cabbage, eggplant, grapes, } \\
\text { plums, red wine, rhubarb } \\
\text { (Clifford, 2000a) }\end{array}$} \\
\hline & Malvidin & $\mathrm{OCH}_{3}$ & $\mathrm{OH}$ & $\mathrm{OCH}_{3}$ & \\
\hline & Delphinidin & $\mathrm{OH}$ & $\mathrm{OH}$ & $\mathrm{OH}$ & \\
\hline & Cyanidin & $\mathrm{H}$ & $\mathrm{OH}$ & $\mathrm{OH}$ & \\
\hline \multirow[t]{3}{*}{ Isoflavones } & Genistein & $\begin{array}{l}5 \\
\mathrm{OH} \\
\end{array}$ & $\begin{array}{l}7 \\
\mathrm{OH}\end{array}$ & $\begin{array}{l}4 \\
\mathrm{OH}\end{array}$ & \multirow{3}{*}{$\begin{array}{l}\text { Bean, chick pea, cowpea, } \\
\text { mung bean, peanut, } \\
\text { soybean (Erlund, 2004) }\end{array}$} \\
\hline & Genistin & $\mathrm{OH}$ & $\begin{array}{l}O- \\
\text { gluc }\end{array}$ & $\mathrm{OH}$ & \\
\hline & Daidzein & & $\mathrm{OH}$ & $\mathrm{OH}$ & \\
\hline
\end{tabular}

gluc: glucose 
Table 1.6 Examples for selected glucoside derivatives of flavonoids naturally occurring in plants

\begin{tabular}{|c|c|c|c|c|c|}
\hline Glucoside derivatives of flavonoids & Examples & $\mathbf{R 1}$ & $\mathbf{R 2}$ & $\mathbf{R 3}$ & R4 \\
\hline \multirow{4}{*}{ } & $\begin{array}{l}\text { Luteolin-7- } O-\beta-\mathrm{D}- \\
\text { glucoside }\end{array}$ & $\mathrm{H}$ & $\mathrm{OH}$ & $\mathrm{H}$ & $\begin{array}{l}-\beta-D- \\
\text { gluc }\end{array}$ \\
\hline & $\begin{array}{l}\text { Apigenin-7-O- } \beta-\mathrm{D}- \\
\text { glucoside }\end{array}$ & $\mathrm{H}$ & $\mathrm{H}$ & $\mathrm{H}$ & $\begin{array}{l}-\beta-\mathrm{D}- \\
\text { gluc }\end{array}$ \\
\hline & $\begin{array}{l}\text { Kaempferol-3-O- } \beta-\mathrm{D} \text { - } \\
\text { glucoside }\end{array}$ & $\begin{array}{l}O-\beta-\mathrm{D}- \\
\text { gluc }\end{array}$ & $\mathrm{H}$ & $\mathrm{H}$ & $\mathrm{H}$ \\
\hline & $\begin{array}{l}\text { Quercetin-3-O- } \beta-\mathrm{D}- \\
\text { glucoside }\end{array}$ & $\begin{array}{l}O-\beta-\mathrm{D}- \\
\text { gluc }\end{array}$ & $\mathrm{OH}$ & $\mathrm{H}$ & $\mathrm{H}$ \\
\hline
\end{tabular}

gluc: glucose

\subsubsection{Stilbenes}

Stilbenes comprise a 1,2-diphenyl-ethylene backbone with two phenyl groups arranged in either cis or trans configuration (Table 1.7). Stilbenes are widely distributed in plants and particularly abundant in grapevine and peanuts (Versari et al., 2001; Hasan et al., 2012). Multiple health benefits such as anti-inflammatory, antitumor, and antioxidant activities have been postulated for stilbenes, particularly for resveratrol (Paredes-López et al., 2010). Stilbenes are also potent phytoalexins in plants.

Table 1.7 Classification and structure of selected derivatives of stilbenes in plants

\begin{tabular}{|c|c|c|c|c|c|}
\hline Basic structure & Examples & R1 & $\mathbf{R 2}$ & $\mathbf{R 3}$ & $\mathbf{R 4}$ \\
\hline & cis-Stilbene & $\mathrm{H}$ & $\mathrm{H}$ & $\mathrm{H}$ & $\mathrm{H}$ \\
\hline & cis-Resveratrol & $\mathrm{OH}$ & $\mathrm{OH}$ & $\mathrm{H}$ & $\mathrm{OH}$ \\
\hline & trans-Resveratrol & $\mathrm{OH}$ & $\mathrm{OH}$ & $\mathrm{H}$ & $\mathrm{OH}$ \\
\hline & $\begin{array}{l}\text { trans-Resveratrol-3-O- } \\
\text { glucoside }\end{array}$ & $O$-gluc & $\mathrm{OH}$ & $\mathrm{H}$ & $\mathrm{OH}$ \\
\hline $\mathrm{R} 2$ & & & & & \\
\hline
\end{tabular}


1.2.4.4 Antioxidant activities of phenolic compounds

The strong antioxidant activity of phenolic compounds is attributable to (i) their ready ability to donate protons or electrons; (ii) the property of the resultant radical to stabilize and delocalize unpaired electrons; and (iii) their ability to chelate with transition metal ions (Rice-Evans et al., 1996).

The antioxidant capacity of phenolic compounds varies according to the number and position of the hydroxyl groups (Rice-Evans et al., 1996; Pietta, 2000; Akdemir et al., 2001; Villaño et al., 2005). Hydroxyl groups on the B-ring donate hydrogen and an electron to ROS radicals, stabilizing them and giving rise to a relatively stable flavonoid radical (Figure 1.4). Among structurally homologous flavones and flavanones, radical scavenging increases according to the total number of $\mathrm{OH}$ groups (Cao et al., 1997).<smiles>CC(C)[C@@H](C)[C@H](O)C(=O)O</smiles>

a

b

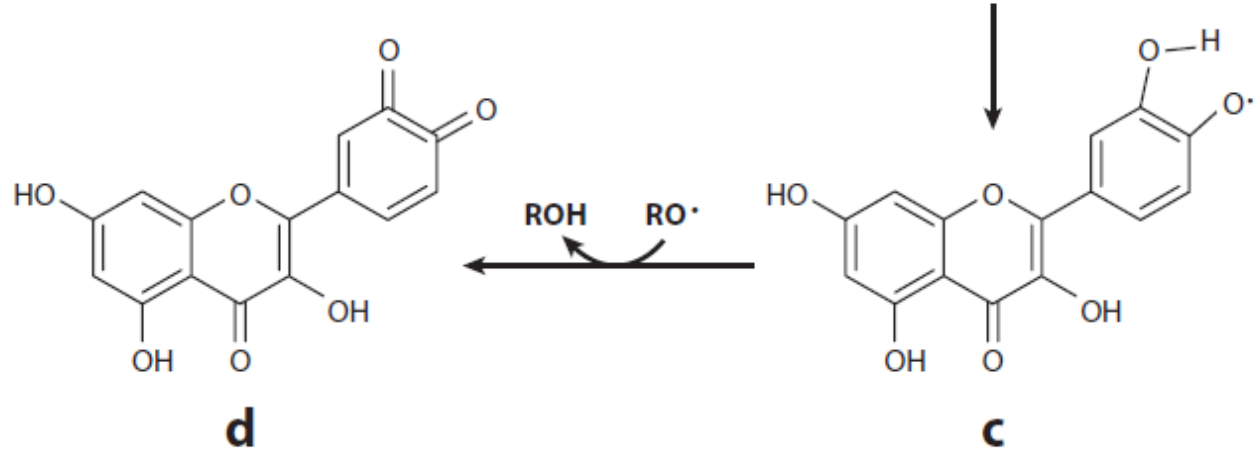

Figure 1.4 Oxidation-dependent changes in the structure of flavonoids; (a) flavonoid, (b) flavonoid radical stabilized by a hydrogen bond, (c) flavonoid phenoxy radical and (d) further oxidation of the flavonoid radical leads to the formation of an orthodiquinone, which is stable.

Source: Jacob et al. (2012) 
The antioxidant activities of phenolic compounds are not only governed by their degree of hydroxylation; but ortho hydroxylation on the benzene ring also influences radical scavenging (Burda and Oleszek, 2001; Nenadis et al., 2003). For example, ortho hydroxylated chlorogenic acid is $35 \%$ more potent than kaempferol in scavenging DPPH (2,2-diphenyl-1-picrylhydrazyl) radicals (Tabart et al., 2009).

Additionally, the antioxidant activities of flavonoids are influenced by the position and structural properties of the sugar moiety (Rice-Evans et al., 1996). The antioxidant properties of flavonoids decreases as the number of glycosidic moieties increases (Plumb et al., 1999b), and thus glycosylated flavonoids are lower in radical scavenging capacity than their corresponding aglycones (Shahidi et al., 1992).

In addition to scavenging ROS, phenolic compounds can also prevent ROS injury to cells. Phenolic compounds can modify the lipid packing order of cell membranes, which decreases the fluidity of the membranes sterically hindering the diffusion of ROS thus restricting peroxidation reactions in lipid membranes (Arora et al., 2000).

In addition to their function as antioxidants, phenolic compounds display various other properties, which are potentially beneficial for human health (Stevenson and Hurst, 2007). These include; antibacterial, anticarcenogenic, antimutagenic, antiallergic, antiinflammatory, antiviral and antiproliferative activities (Rao et al., 1995; Fernandez et al., 1998; De Mejía et al., 1999; Tuck and Hayball, 2002; Lee et al., 2005; Miles et al., 2005; Roy et al., 2007; Medeiros et al., 2008; Suárez et al., 2010). 


\subsection{EVIDENCE FOR INFLUENCE OF DIETARY LMWAS ON OXIDATIVE STRESS-INDUCED DISEASES}

Certain food sources and diets, which provide rich intakes of LMWAs correlate with low incidences of non-infectious diseases of the consumers, according to epidemiological evidence (Table 1.8) and clinical feeding trials (Tables 1.9 and 1.10). For example, epidemiological studies have shown that diets rich in phenolic compounds are associated with a reduction in the initiation and occurrence of some cancers (Table 1.8). However, caution is necessary in interpreting epidemiological data since such correlations do not necessarily imply causality. Clinical feeding trials are more appropriate than epidemiological studies, to draw specific conclusions regarding possible benefits of specific LMWAs. However, in clinical studies the individual effects of LMWAs are hard or impossible to isolate since in a whole organism there are many complicated effects, which occur simultaneously. Therefore mechanistic studies are required to understand specific cause and effect.

The majority of clinical feeding trials involving humans afflicted with oxidative stressrelated hypertension, inflammation, cardiovascular disease, cancer and atherosclerosis have shown that dietary intake of phenolic compounds such as fresh fruit and vegetables or in their concentrated forms is associated with reduced disease indices compared to the placebo group (Tables 1.9 and 1.10). The benefit of phenolic rich fruit and vegetable intake was seen in clinical trials where participants were under heavy oxidative stress and when the measured parameters were cardiovascular, plasma or bowel related low-density lipoprotein (LDL) oxidation and DNA damage (Tables 1.9 and 1.10). However in the few studies where dietary LMWAs intake did not reduce indicators of oxidative stress, the measures were done in sites such as lungs where the bioavailability of phenolic compounds are low (Cerda et al., 2005). Furthermore among relatively young and healthy participants the protective effects of dietary phenolic compounds were less observable and below the measurable lower limits since their cells were experiencing lower degree of oxidative stress (Chang et al., 2010). 
Table 1.8 Selected epidemiological studies on dietary intake of phenolic compounds and cancer

\begin{tabular}{|c|c|c|c|c|}
\hline Compound/s & Cancer & $\begin{array}{l}\text { Result/ } \\
\text { correlation }\end{array}$ & $\begin{array}{l}\text { Number of } \\
\text { human } \\
\text { subjects }\end{array}$ & Reference \\
\hline Flavones and flavanones & $\begin{array}{l}\text { Squamous cell } \\
\text { carcinoma }\end{array}$ & $\begin{array}{l}\text { Sig. inverse } \\
\text { association }\end{array}$ & $1061 / 1425 \mathrm{a}$ & $\begin{array}{l}\text { (Christensen } e t \\
\text { al., 2012) }\end{array}$ \\
\hline $\begin{array}{l}\text { Epicatechin catechin, quercetin, } \\
\text { and kaempferol }\end{array}$ & Lung & $\begin{array}{l}\text { Sig. inverse } \\
\text { association }\end{array}$ & $558 / 837$ a & $\begin{array}{l}\text { (Cui et al., } \\
\text { 2008) }\end{array}$ \\
\hline $\begin{array}{l}\text { Flavanones and } \\
\text { proanthocyanidins }\end{array}$ & Lung & $\begin{array}{l}\text { Sig. inverse } \\
\text { association }\end{array}$ & $34,708 \mathrm{~b}$ & $\begin{array}{l}\text { (Cutler et al., } \\
\text { 2008) }\end{array}$ \\
\hline $\begin{array}{l}\text { Flavonols, flavones, flavanones, } \\
\text { flavan-3-ols and anthocyanidins }\end{array}$ & Lung & $\begin{array}{l}\text { Sig. inverse } \\
\text { association }\end{array}$ & $2,590 \mathrm{~b}$ & $\begin{array}{l}\text { (Mursu et al., } \\
\text { 2008) }\end{array}$ \\
\hline $\begin{array}{l}\text { Cinnamic acids, } \\
\text { secoisolariciresinol and } \\
\text { coumestrol }\end{array}$ & Gastric & $\begin{array}{l}\text { Sig. inverse } \\
\text { association }\end{array}$ & $257 / 478 \mathrm{a}$ & $\begin{array}{l}\text { (Hernández- } \\
\text { Ramírez et al., } \\
\text { 2009) }\end{array}$ \\
\hline Flavonoids & Colorectal & $\begin{array}{l}\text { Sig. inverse } \\
\text { association }\end{array}$ & $424 / 401 \mathrm{a}$ & $\begin{array}{l}\text { (Wahle et al., } \\
\text { 2010) }\end{array}$ \\
\hline Flavonol and catechin & Colorectal & $\begin{array}{l}\text { Sig. inverse } \\
\text { association }\end{array}$ & $120,852 \mathrm{~b}$ & $\begin{array}{l}\text { (Simons et al., } \\
\text { 2009) }\end{array}$ \\
\hline Catechin & Rectal & $\begin{array}{l}\text { Sig. inverse } \\
\text { association }\end{array}$ & $120,852 \mathrm{~b}$ & $\begin{array}{l}\text { (Simons et al., } \\
\text { 2009) }\end{array}$ \\
\hline Flavones and flavanones & Adenocarcinoma & ns & $1061 / 1425 \mathrm{a}$ & $\begin{array}{l}\text { (Christensen } e t \\
\text { al., 2012) }\end{array}$ \\
\hline $\begin{array}{l}\text { Thearubigins, hesperetin, } \\
\text { naringenin, and myricetin }\end{array}$ & Lung & ns & $558 / 837$ a & $\begin{array}{l}\text { (Cui et al., } \\
\text { 2008) }\end{array}$ \\
\hline Flavones & Colorectal & ns & $120,852 \mathrm{~b}$ & $\begin{array}{l}\text { (Simons et al., } \\
\text { 2009) }\end{array}$ \\
\hline $\begin{array}{l}\text { Flavonols, flavones, flavanones, } \\
\text { flavan-3-ols and anthocyanidins }\end{array}$ & $\begin{array}{l}\text { Prostate and } \\
\text { colorectal }\end{array}$ & ns & $2,590 \mathrm{~b}$ & $\begin{array}{l}\text { (Mursu et al., } \\
\text { 2008) }\end{array}$ \\
\hline
\end{tabular}

Sig. : Significant

a: cohort study (disease cases /healthy cases)

b: population-based case-control studies

ns: not significant 
Table 1.9 Selected randomized, controlled, crossover clinical feeding trial on effects of food and

\section{LMWAs on oxidative stress related diseases and conditions among humans}

\begin{tabular}{|c|c|c|c|c|c|}
\hline $\begin{array}{l}\text { Diseases/ } \\
\text { conditions }\end{array}$ & $\begin{array}{l}\text { Number } \\
\text { of } \\
\text { patients }\end{array}$ & Food or LMWA & Measures & Result & Reference \\
\hline Atherosclerosis & 42 & Cocoa beverage & $\begin{array}{l}\text { Biomarkers of } \\
\text { atherosclerosis }\end{array}$ & $\begin{array}{l}\text { Significant } \\
\text { reduction }\end{array}$ & $\begin{array}{l}\text { (Monagas } e t \\
a l ., 2009)\end{array}$ \\
\hline $\begin{array}{l}\text { Cardiovascular } \\
\text { disease (CVD) } \\
\text { risk }\end{array}$ & 24 & $\begin{array}{l}\text { Orange juice } \\
\text { (hesperidin) }\end{array}$ & Blood pressure & $\begin{array}{l}\text { Significant } \\
\text { reduction }\end{array}$ & $\begin{array}{l}\text { (Morand et } \\
\text { al., 2011) }\end{array}$ \\
\hline $\begin{array}{l}\text { Oxidation of } \\
\text { human low- } \\
\text { density } \\
\text { lipoprotein (LDL) }\end{array}$ & 8 & $\begin{array}{l}\text { Olive oil } \\
\text { (phenolic } \\
\text { compounds) }\end{array}$ & LDL oxidation & $\begin{array}{l}\text { Significant } \\
\text { reduction }\end{array}$ & $\begin{array}{l}\text { (De La Torre- } \\
\text { Carbot et al., } \\
2010)\end{array}$ \\
\hline DNA oxidation & 182 & $\begin{array}{l}\text { Olive oil } \\
\text { (phenolic } \\
\text { compounds) }\end{array}$ & DNA oxidation & $\begin{array}{l}\text { Significant } \\
\text { reduction }\end{array}$ & $\begin{array}{l}\text { (Machowetz } \\
\text { et al., 2007) }\end{array}$ \\
\hline $\begin{array}{l}\text { Inflammation and } \\
\text { oxidative damage }\end{array}$ & 20 & $\begin{array}{l}\text { Almond ( } \alpha- \\
\text { tocopherol) }\end{array}$ & $\begin{array}{l}\text { Inflammation and LDL } \\
\text { oxidation }\end{array}$ & $\begin{array}{l}\text { Significant } \\
\text { reduction }\end{array}$ & $\begin{array}{l}\text { (Liu et al., } \\
\text { 2012) }\end{array}$ \\
\hline $\begin{array}{l}\text { Coronary artery } \\
\text { disease }\end{array}$ & 21 & $\begin{array}{l}\text { Walnut ( } \alpha- \\
\text { tocopherol and } \\
\alpha \text {-linolenic) }\end{array}$ & $\begin{array}{l}\text { Total cholesterol and } \\
\text { LDL cholesterol and } \\
\text { endothelium } \\
\text { vasodilation }\end{array}$ & $\begin{array}{l}\text { Significant } \\
\text { reduction }\end{array}$ & $\begin{array}{l}\text { (Ros et al., } \\
\text { 2004) }\end{array}$ \\
\hline $\begin{array}{l}\text { DNA damage and } \\
\text { repair }\end{array}$ & 28 & $\begin{array}{l}\text { Fruits and } \\
\text { vegetables }\end{array}$ & $\begin{array}{l}\text { DNA damage in } \\
\text { lymphocytes }\end{array}$ & ns & $\begin{array}{l}\text { (Chang et al., } \\
\text { 2010) }\end{array}$ \\
\hline
\end{tabular}

ns: not significant 
Table 1.10 Selected randomized, double-blind, placebo-controlled clinical feeding trial on influence of food and LMWAs on oxidative stress related diseases among humans

\begin{tabular}{|c|c|c|c|c|c|}
\hline Diseases & $\begin{array}{l}\text { Number } \\
\text { of } \\
\text { patients }\end{array}$ & Food or LMWA & Measures & Result & Reference \\
\hline $\begin{array}{l}\text { Chronic } \\
\text { inflammation }\end{array}$ & 106 & $\begin{array}{l}\text { Encapsulated fruit } \\
\text { and vegetable } \\
\text { powder } \\
\text { concentrate }\end{array}$ & $\begin{array}{l}\text { Chronic } \\
\text { inflammation } \\
\text { (DNA damage } \\
\text { in blood } \\
\text { lymphocytes) }\end{array}$ & $\begin{array}{l}\text { Significant } \\
\text { reduction }\end{array}$ & $\begin{array}{l}\text { (Cui et al., } \\
\text { 2012) }\end{array}$ \\
\hline $\begin{array}{l}\text { Inflammatory } \\
\text { bowel disease }\end{array}$ & 44 & Aloe vera & $\begin{array}{l}\text { Histological } \\
\text { disease activity }\end{array}$ & $\begin{array}{l}\text { More frequent } \\
\text { among treated } \\
\text { patients } \\
\text { Significant } \\
\text { reduction }\end{array}$ & $\begin{array}{l}\text { (Langmead } \\
\text { et al., 2004) }\end{array}$ \\
\hline CVD & 32 & Cranberry juice & $\begin{array}{l}\text { Plasma } \\
\text { antioxidant } \\
\text { capacity }\end{array}$ & $\begin{array}{l}\text { Significant } \\
\text { reduction } \\
\text { Significant } \\
\text { increase }\end{array}$ & $\begin{array}{l}\text { (Basu et al., } \\
\text { 2011) }\end{array}$ \\
\hline $\begin{array}{l}\text { CVD risk in } \\
\text { subjects with type } 2 \\
\text { diabetes }\end{array}$ & 48 & $\begin{array}{l}\text { Flavonoid rich } \\
\text { dietary } \\
\text { supplement }\end{array}$ & $\begin{array}{l}\text { CVD risk } \\
\text { factors }\end{array}$ & $\begin{array}{l}\text { Significantly } \\
\text { improved } \\
\text { Significant } \\
\text { reduction }\end{array}$ & $\begin{array}{l}\text { (Zibadi et } \\
\text { al., 2008) }\end{array}$ \\
\hline $\begin{array}{l}\text { Chronic obstructive } \\
\text { pulmonary disease }\end{array}$ & 30 & $\begin{array}{l}\text { Pomegranate } \\
\text { juice }\end{array}$ & $\begin{array}{l}\text { Clinical } \\
\text { symptoms of the } \\
\text { disease }\end{array}$ & ns & $\begin{array}{l}\text { (Cerda et } \\
\text { al., 2005) }\end{array}$ \\
\hline $\begin{array}{l}\text { Oxidative stress } \\
\text { related } \\
\text { hypertension and } \\
\text { endothelial } \\
\text { dysfunction }\end{array}$ & 69 & $\begin{array}{l}\text { Grape-seed } \\
\text { polyphenols }\end{array}$ & Blood pressure & ns & $\begin{array}{l}\text { (Ward et al. } \\
\text { 2005) }\end{array}$ \\
\hline
\end{tabular}

ns: not significant 


\subsection{THE BIOACCESSIBILITY， BIOAVAILABILITY， BIOACTIVITY AND STABILITY OF PHENOLIC COMPOUNDS}

For a phenolic compound to exert any beneficial biological effect, it must reach target tissues in chemically active form and at appropriate concentrations. Thus bioaccessibility, bioavailability, bioactivity and stability of an antioxidant-rich food source should be considered in order to fully utilize the possible health benefit of antioxidants in food plants. Bioaccessibility can be defined as the fraction of the ingested antioxidant(s) that is released and solubilised from the food matrix by gastrointestinal digestion and, which has the potential to be absorbed from the gastrointestinal tract into the intestinal epithelium (Hedren et al., 2002). In this context, the stability of an antioxidant refers to the ability of the compounds to retain their antioxidant properties following digestion (Dinnella et al., 2007). Bioavailability can be defined as the proportion of an administered dose that reaches the systemic circulation intact, and bioactivity is the ability to induce a biological response in an organism that consumes it (Finley, 2005).

The bioaccessibility of various components from foods has been studied using in vitro simulations of gastrointestinal digestion and absorption (Table 1.11). Similarly, the stability of LMWAs in food has been studied using in vitro antioxidant activity measurements of food products before and after simulated gastrointestinal incubation (Table 1.11). Recently, techniques have been developed to accommodate the three aspects of bioaccessibility, bioactivity and stability of food components using in vitro gastrointestinal simulations followed by cell culture models, which mimic uptake of LMWAs from the lumen of the gastrointestinal tract and the subsequent bioactivity within the cellular environment (Table 1.11). However, bioavailability also requires consideration of the complex effects of hepatic metabolism and activity of plasma enzymes on LMWAs following absorption from gastrointestinal tract. Therefore, to assess bioavailability, studies that mimic complex physiological conditions need to be done on human subjects due to the difficulty of designing in vitro models (Funes et al., 2009; Ranga Rao et al., 2010). 
Table 1.11 Selected studies on bioaccessibility, bioactivity and stability of antioxidants from various food sources

\begin{tabular}{|c|c|c|}
\hline Food & Technique $^{a}$ & Reference \\
\hline Solanum esculentum & 1 & (Toor et al., 2008) \\
\hline Camellia sinensis and Salvia officinalis & 1 & (Vermaak et al., 2009) \\
\hline Aronia melanocarpa & 2 & (Bermúdez-Soto et al., 2007) \\
\hline Punica granatum & 2 & (Pérez-Vicente et al., 2002) \\
\hline Rubus idaeus & 2 & (McDougall et al., 2005a) \\
\hline Prunus dulcis & 3 & (Mandalari et al., 2010) \\
\hline Malus domestica & 3 & (Bouayed et al., 2007) \\
\hline Prunus avium & 3 & (Fazzari et al., 2008) \\
\hline Fruits & 3 & (Tarko et al., 2009) \\
\hline Fruit juices & 3 & (Cilla et al., 2011) \\
\hline Vitis vinifera & 3 & (Tagliazucchi et al., 2010) \\
\hline Olea europaea & 3 & (Dinnella et al., 2007) \\
\hline Red wine & 3 & (Noguer et al., 2008) \\
\hline Vegetable juices & 3 & (Wootton-Beard et al., 2011) \\
\hline Rubus sp. & 4 & (Tavares et al., 2012) \\
\hline "Feijoada" whole meal ${ }^{\mathrm{b}}$ & 4 & (Faller et al., 2012) \\
\hline Agaricus bisporus, Lentinula edodes and Boletus edulis & 5 & (Soler-Rivas et al., 2009b) \\
\hline \multicolumn{3}{|l|}{ List of techniques used } \\
\hline \multicolumn{3}{|c|}{ 1. In vitro gastrointestinal simulation + in vitro chemical antioxidant activity measures } \\
\hline \multicolumn{3}{|c|}{ 2. In vitro gastrointestinal simulation + diffusion across cellulose membrane (D) } \\
\hline \multicolumn{3}{|c|}{ 3. In vitro gastrointestinal simulation $+\mathrm{D}+$ in vitro chemical antioxidant activity measures } \\
\hline \multicolumn{3}{|c|}{$\begin{array}{l}\text { 4. In vitro gastrointestinal simulation }+\mathrm{D}+\text { in vitro chemical antioxidant activity measures }+ \text { cellula } \\
\text { uptake and cellular antioxidant activity }(\mathrm{CAA}) \text { using human cell culture models }\end{array}$} \\
\hline In vitro gastrointestinal simulation + cellular uptake and & CAA using hu & man cell culture models \\
\hline
\end{tabular}

Not all phenolic compounds survive in vitro gastrointestinal digestion and their release and survival during digestion depends on the type of food that contained the compound (Tables 1.12 - 1.14). Additionally, not all compounds released in the bioaccessible fraction following in vitro gastrointestinal digestion were able to permeate across cellulose membranes or animal cell membranes (Tables 1.12 - 1.14). Passive absorption of phenolic compounds across cell membranes depends on the partition coefficient of the compound in question, polarity, size of the molecule and the moieties attached to the compound (Karakaya, 2004; Zhao and Moghadasian, 2010). For active absorption, the presence of specific transporters in cell membranes will be required (Ader et al., 1996). 
Table 1.12 Compounds detected following in vitro gastrointestinal digestion of selected phenolic acids and their derivatives in food

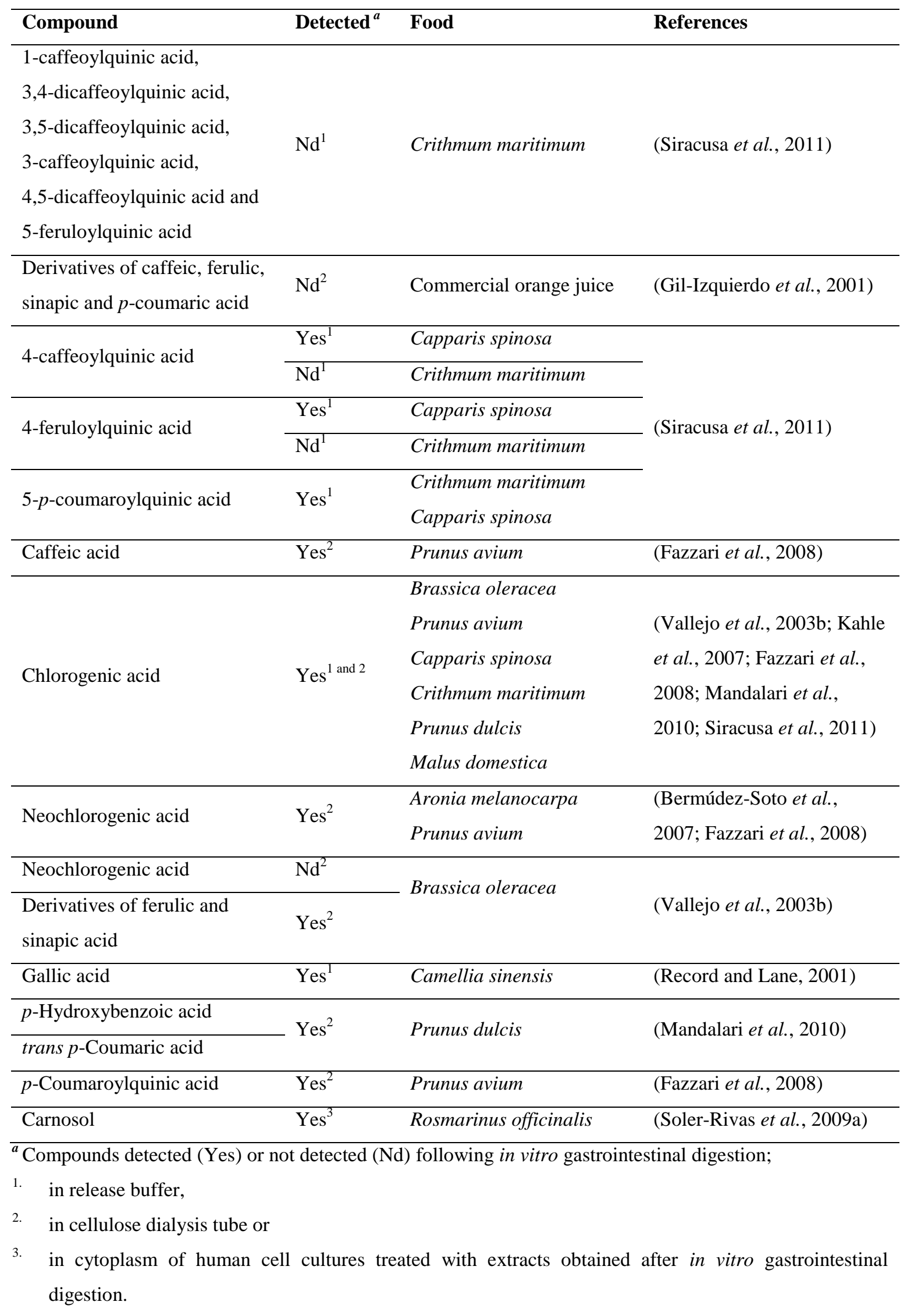


Table 1.13 Compounds detected following in vitro gastrointestinal digestion of selected flavonoids and their derivatives in food

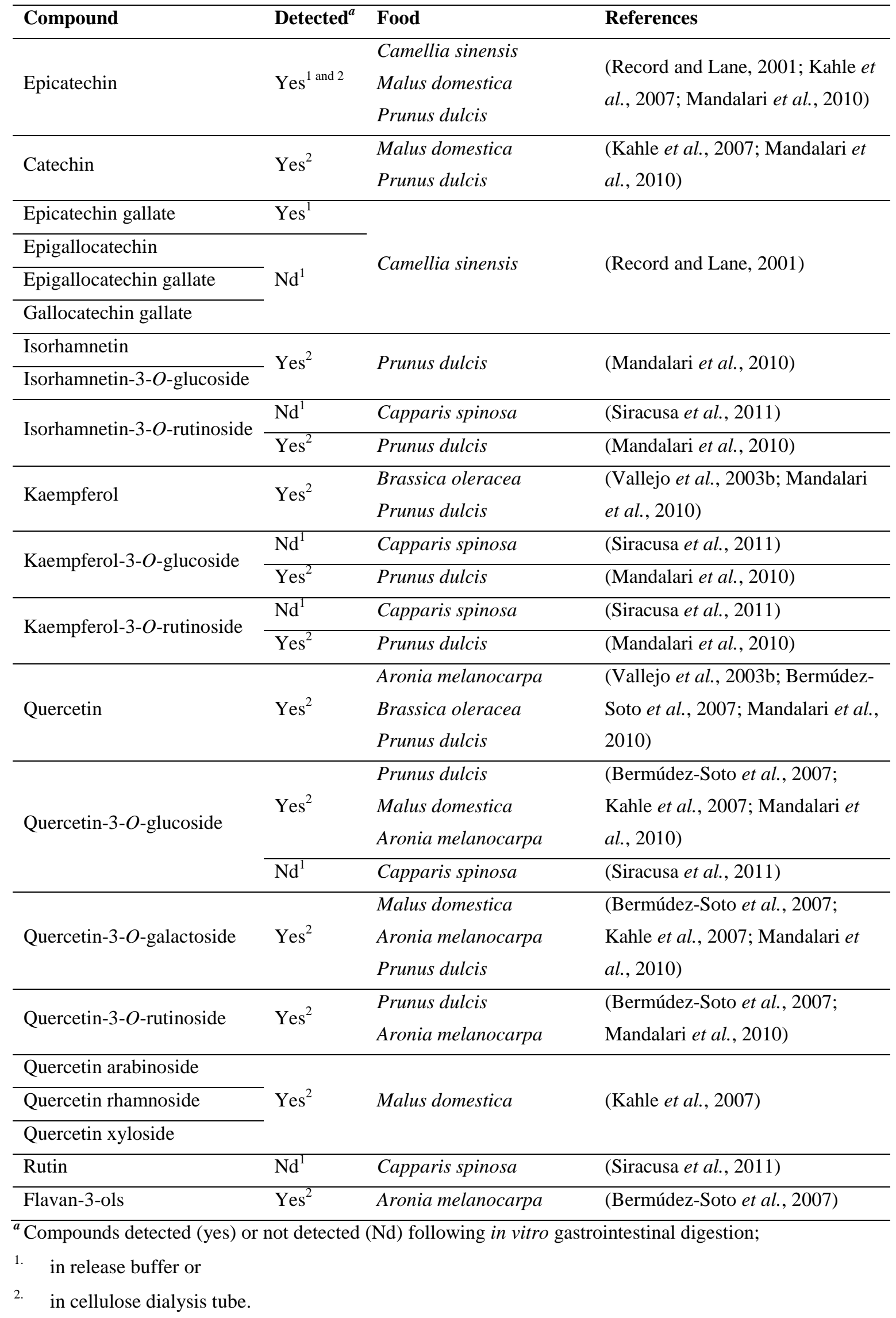


Table 1.14 Compounds detected following in vitro gastrointestinal digestion of selected anthocyanins and their derivatives in food

\begin{tabular}{|c|c|c|c|}
\hline Compound & Detected $^{a}$ & Food & References \\
\hline Cyanidin & \multirow{4}{*}{ Yes } & \multirow{3}{*}{ Aronia melanocarpa } & \multirow{3}{*}{$\begin{array}{l}\text { (Bermúdez-Soto et al., } \\
\text { 2007) }\end{array}$} \\
\hline Cyanidin-3-arabinoside & & & \\
\hline Cyanidin-3-galactoside & & & \\
\hline Cyanidin-3,5-diglucoside & & Punica granatum & (Pérez-Vicente et al., 2002) \\
\hline \multirow{4}{*}{ Cyanidin-3-glucoside } & \multirow{3}{*}{ Yes } & Aronia melanocarpa & (Pérez-Vicente et al., 2002; \\
\hline & & Punica granatum & Bermúdez-Soto et al., 2007; \\
\hline & & Prunus avium & Fazzari et al., 2008) \\
\hline & $\mathrm{Nd}$ & Red wine & (McDougall et al., 2005b) \\
\hline Cyanidin-3-rutinoside & Yes & Prunus avium & (Fazzari et al., 2008) \\
\hline Cyanidin-3-xyloside & Yes & Aronia melanocarpa & $\begin{array}{l}\text { (Bermúdez-Soto et al., } \\
\text { 2007) }\end{array}$ \\
\hline Delphidin-3-O-glucosides & \multirow{3}{*}{$\mathrm{Nd}$} & $\begin{array}{l}\text { Red wine } \\
\text { Punica granatum }\end{array}$ & $\begin{array}{l}\text { (Pérez-Vicente } \text { et al., 2002; } \\
\text { McDougall et al., 2005b) }\end{array}$ \\
\hline Delphinidin-3,5-diglucoside & & Punica granatum & (Pérez-Vicente et al., 2002) \\
\hline Delphinidin-3-O-coumaroylglucoside & & Red wine & (McDougall et al., 2005b) \\
\hline Malvidin-3-O-acetylglucoside & \multirow{3}{*}{ Yes } & \multirow{3}{*}{ Red wine } & \multirow{3}{*}{ (McDougall et al., 2005b) } \\
\hline Malvidin-3-O-coumaroylglucoside & & & \\
\hline Malvidin-3-O-glucosides & & & \\
\hline $\begin{array}{l}\text { Pelargonidin-3,5-diglucoside } \\
\text { Pelargonidin-3-glucoside }\end{array}$ & Yes & Punica granatum & (Pérez-Vicente et al., 2002) \\
\hline Peonidin-3-O-acetylglucoside & \multirow{2}{*}{$\mathrm{Nd}$} & \multirow{3}{*}{ Red wine } & \multirow{3}{*}{ (McDougall et al., 2005b) } \\
\hline Peonidin-3-O-coumaroylglucoside & & & \\
\hline Peonidin-3-O-glucosides & \multirow{2}{*}{ Yes } & & \\
\hline Peonidin-3-rutinoside & & Prunus avium & (Fazzari et al., 2008) \\
\hline Petundin-3-O-acetylglucoside & \multirow{3}{*}{$\mathrm{Nd}$} & \multirow{3}{*}{ Red wine } & \multirow{3}{*}{ (McDougall et al., 2005b) } \\
\hline Petundin-3-O-coumaroylglucoside & & & \\
\hline Petundin-3-O-glucosides & & & \\
\hline Naringenin & \multirow{4}{*}{ Yes } & \multirow{4}{*}{ Prunus dulcis } & \multirow{4}{*}{ (Mandalari et al., 2010) } \\
\hline Naringenin-7-O-glucoside & & & \\
\hline Eryodictiol & & & \\
\hline Eryodictiol-7- $O$-glucoside & & & \\
\hline
\end{tabular}


In vitro digestion by gastrointestinal enzymes and those produced by colonic microflora causes certain phenolic compounds to undergo chemical changes to form new compounds (Tables 1.15 and 1.16). In vitro digestion by colonic microbes resulted in the formation of wide variety of metabolites (Table 1.16) compared to digestion by gastrointestinal enzymes: pepsin, lipase and amylase (Table 1.15). Microflora in the gut can cause ringfission, degycosylation, methylation, deconjugation of phenolic compounds (Aura, 2008), while gastrointestinal enzymes are incapable of ring-fission and methylation.

Table 1.15 Changes in metabolites detected following in vitro gastrointestinal digestion of selected phenolic compounds in food

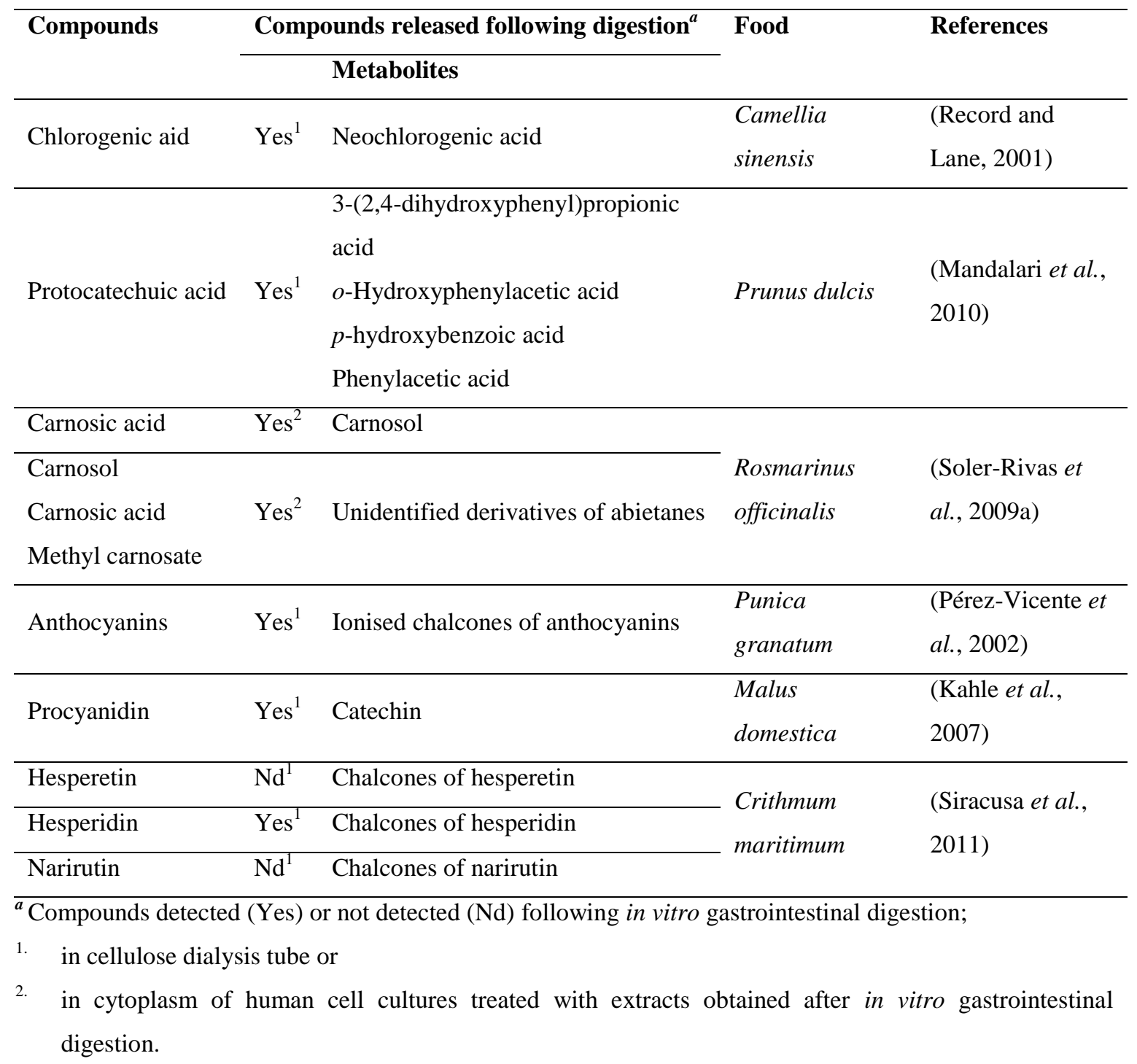


Phenolic compounds are largely absorbed through the jejunum and to a smaller extent, through the ileum and to a lesser degree in the stomach before reaching the microflora in the colon (Spencer et al., 1999; Clifford, 2000b; Mandalari et al., 2013). Furthermore the microbial conversion processes do not affect all compounds in a similar manner; for example, deglycosylation of flavonoids depends on the sugar moiety, while the chain length inversely influenced the conversion of proanthocyanidins into phenolic acids (Keppler and Humpf, 2005; Bazzocco et al., 2008).

Table 1.16 Changes in metabolites detected following in vitro digestion by colonic microflora or in situ digestion by rats of selected phenolic compounds in food

\begin{tabular}{|c|c|c|c|}
\hline \multirow[t]{2}{*}{ Compound } & \multicolumn{2}{|c|}{ Compounds released following digestion ${ }^{a}$} & \multirow[t]{2}{*}{ References } \\
\hline & $\begin{array}{l}\text { Original } \\
\text { compound }\end{array}$ & Metabolites & \\
\hline $\begin{array}{l}\text { Caffeic and Chicoric } \\
\text { acid }\end{array}$ & Yes $^{1}$ & $m$-hydroxyphenylpropionic acid & \multirow{2}{*}{$\begin{array}{l}\text { Echinacea purpurea } \\
(\mathrm{Ye}, 2009)\end{array}$} \\
\hline Caftaric acid & $\mathrm{Nd}^{1}$ & $m$-hydroxyphenylpropionic acid & \\
\hline \multirow{2}{*}{ Chlorogenic acid } & \multirow{2}{*}{$\mathrm{Yes}^{2}$} & Caffeic acid & Chlorogenic acid \\
\hline & & Quinic acid & (Plumb et al., 1999a) \\
\hline \multirow{4}{*}{ Gallic acid } & \multirow{4}{*}{ Yes $^{2}$} & 3-(4-Hydroxyphenyl)propionic acid & \multirow{18}{*}{$\begin{array}{l}\text { Flavonoids and } \\
\text { phenolic acids } \\
\text { (Serra } \text { et al., 2012) }\end{array}$} \\
\hline & & Phenylacetic acid & \\
\hline & & $p$-Hydroxyphenylacetic acid & \\
\hline & & Protocatechuic acid & \\
\hline Protocatechuic acid & $\mathrm{Yes}^{2}$ & Unchanged & \\
\hline Luteolin & $\mathrm{Yes}^{2}$ & 3-(2,4-Dihydroxyphenyl)propionic acid & \\
\hline \multirow{3}{*}{ Myricetin } & & 3-(2,4-Dihydroxyphenyl)propionic acid & \\
\hline & $\mathrm{Yes}^{2}$ & 3,4-Dihydroxyphenylacetic acid & \\
\hline & & Phenylacetic acid & \\
\hline \multirow{9}{*}{ Quercetin } & \multirow{9}{*}{$\mathrm{Yes}^{2}$} & 3-(3,4-Dihydroxyphenyl)propionic acid & \\
\hline & & 3,4-Dihydroxyphenylacetic acid & \\
\hline & & Homovainillic acid & \\
\hline & & $m$-Hydroxyphenylacetic acid & \\
\hline & & $o$-Hydroxyphenylacetic acid & \\
\hline & & $p$-Hydroxybenzoic acid & \\
\hline & & $p$-Hydroxyphenylacetic acid & \\
\hline & & Protocatechuic acid & \\
\hline & & Phenylacetic acid & \\
\hline Rutin & $\mathrm{Yes}^{3}$ & None & \multirow{2}{*}{$\begin{array}{l}\text { Hypericum perforatum } \\
(\mathrm{Ye}, 2009)\end{array}$} \\
\hline Quercetin galactoside & $\mathrm{Yes}^{3}$ & None & \\
\hline
\end{tabular}


Table 1.16 continued

\begin{tabular}{|c|c|c|c|}
\hline \multirow{8}{*}{ Quercetin rhamnoside } & \multirow{8}{*}{ Yes $^{2}$} & 3,4-Dihydroxyphenylacetic & \multirow{21}{*}{$\begin{array}{l}\text { Flavonoids and } \\
\text { phenolic acids } \\
\text { (Serra } \text { et al., 2012) }\end{array}$} \\
\hline & & Dihydroxyphenyl)propionic acid & \\
\hline & & m-Hydroxyphenylacetic acid & \\
\hline & & $o$-Hydroxyphenylacetic acid & \\
\hline & & Phenylacetic acid & \\
\hline & & $p$-Hydroxybenzoic acid & \\
\hline & & $p$-Hydroxyphenylacetic acid & \\
\hline & & Protocatechuic acid & \\
\hline \multirow{4}{*}{ Quercetin rutinoside } & \multirow{4}{*}{ Yes $^{2}$} & 3-(3,4-Dihydroxyphenyl)propionic acid & \\
\hline & & 3,4-Dihydroxyphenylacetic acid & \\
\hline & & $m$-Hydroxyphenylacetic acid & \\
\hline & & Phenylacetic acid & \\
\hline \multirow{3}{*}{ Kaempferol rutinoside } & \multirow{3}{*}{ Yes $^{2}$} & $o$-Hydroxyphenylacetic acid & \\
\hline & & Phenylacetic acid & \\
\hline & & $p$-Hydroxybenzioc acid & \\
\hline \multirow{6}{*}{ Naringenin } & \multirow{6}{*}{$\mathrm{Yes}^{2}$} & 3-(2,4-Dihydroxyphenyl)propionic acid & \\
\hline & & 3-(4-Hydroxyphenyl)propionic acid & \\
\hline & & $o$-Hydroxyphenylacetic acid & \\
\hline & & Phenylacetic acid & \\
\hline & & $p$-Hydroxyphenylacetic acid & \\
\hline & & Protocatechuic acid & \\
\hline
\end{tabular}

\footnotetext{
${ }^{a}$ Compounds detected (Yes) or not detected (Nd) following in vitro gastrointestinal digestion;

1. following in vitro fermentation using human, mouse or rat colonic microflora,

2. following in vitro digestion using extracts of human small intestine, liver, plasma and human colonic microflora, or

3. in plasma after in situ gastric administration to rats.
} 


\subsection{CHEMICAL ANTIOXIDANT ACTIVITY ASSAYS}

A number of chemical assays and in vitro cellular techniques have been used to measure antioxidant capacities of food and metabolites in a number of physiological matrices including gastrointestinal fluids, urine and plasma (Prior et al., 2005; Torres et al., 2008). These antioxidant activity assays can be classified into two types based on their reaction mechanism and type of radical scavenged (Table 1.17).

Table 1.17 Comparison of types of in vitro chemical antioxidant activity assays

\begin{tabular}{lll}
\hline Characteristic & \multicolumn{2}{c}{ Antioxidant activity assays } \\
\cline { 2 - 3 } & \multicolumn{1}{c}{ Hydrogen atom transfer (HAT) } & \multicolumn{1}{c}{ Single electron transfer (SET) } \\
mechanism & Ability of an antioxidant to quench free & Ability of an antioxidant to transfer single \\
& radicals by proton donation & electron, reducing the reactive species \\
\hline Type of & The antioxidant and substrate compete for & Assays measure the capacity of an \\
radical & thermally generated peroxyl radicals & antioxidant in the reduction of an oxidant, \\
scavenged & through the decomposition of azo- & which is then correlated with the \\
& compounds & antioxidant concentrations \\
\hline Examples & Oxygen radical absorbance capacity & 2, 2'-Azino-bis(3-ethylbenz-thiazoline-6- \\
& (ORAC) & sulfonic acid (ABTS) assay \\
& Total radical trapping antioxidant & Ferric ion reducing antioxidant power \\
& parameter (TRAP) & (FRAP) \\
& Crocin bleaching assays & DPPH radical scavenging assay
\end{tabular}

Further details on DPPH radical scavenging assay and ORAC (oxygen radical absorbance capacity) assay are detailed briefly (Sections 1.5.1 - 1.5.2) because they are most commonly used. They are also featured in the experimental sections of this thesis because the two techniques employ scavenging of two different radical species, at different temperature and $\mathrm{pH}$ conditions increasing the reliability of data (Sections 1.5.1 - 1.5.2).

\subsubsection{DPPH radical scavenging assay}

DPPH is a stable organic nitrogen radical with a non paired electron (Brand-Williams et al., 1995). In the presence of antioxidants (AH), which are capable of donating $\mathrm{H}$, the DPPH radical $\left(\mathrm{DPPH}^{\circ}\right)$ reduces to the stable non-radical DPPH (Equation 1.1). This 
reduction of the DPPH radical by an antioxidant causes the colour change (from violet to yellow), resulting in the loss of absorbance at $515 \mathrm{~nm}$.

$\mathrm{DPPH}^{\bullet}+\mathrm{AH} \rightarrow \mathrm{DPPH}+\mathrm{A}^{\bullet}$

Equation 1.1

The degree of absorbance loss is correlated with concentration of the antioxidant to calculate the $\mathrm{EC}_{50}$, which is the concentration of antioxidant that causes $50 \%$ loss of initial DPPH concentration (Figure 1.5). The $\mathrm{EC}_{50}$ of the sample can be expressed as equivalents of an appropriate standard such as ascorbic acid or trolox (commercial name for a vitamin E analogue).

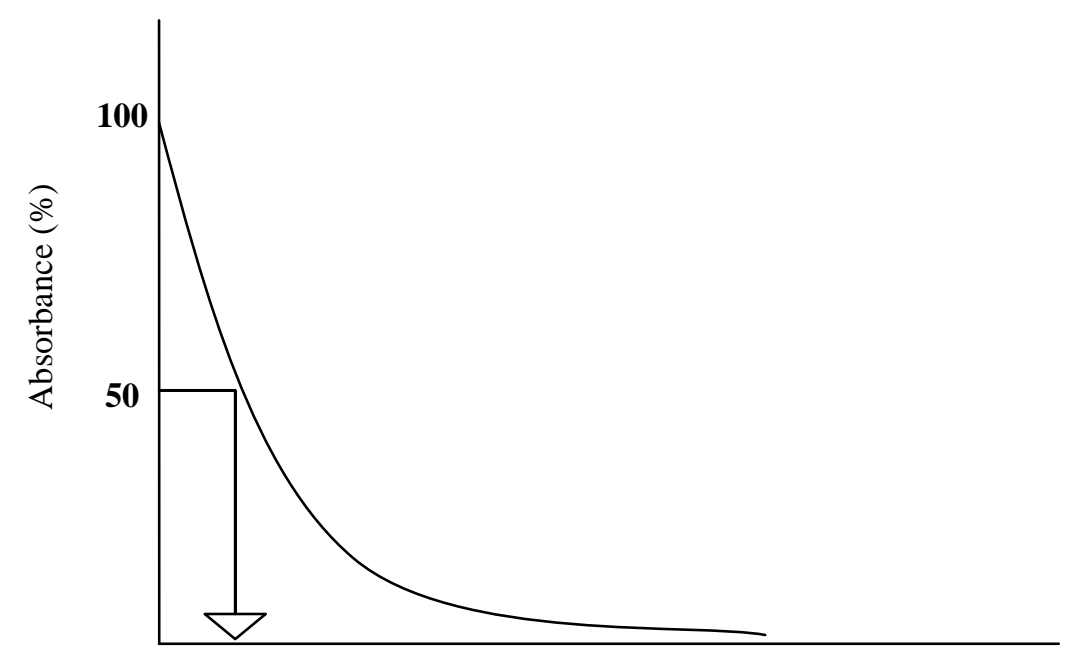

$\mathrm{EC}_{50}$

Antioxidant concentration $\left(\mathrm{mg} \mathrm{mL}^{-1}\right)$

Figure 1.5 Percentage decrease in absorbance $\left(\mathrm{A}_{515 \mathrm{~nm}}\right)$ by DPPH (2,2-diphenyl-1-picrylhydrazyl) against concentration of antioxidant, where $\mathrm{EC}_{50}$ denotes the concentration of antioxidant causing $50 \%$ loss of initial absorbance.

There are a few drawbacks to the use of the DPPH method. Importantly, the DPPH radical differs from the highly reactive and transient peroxyl radicals involved in lipid peroxidation in biological systems (Huang et al., 2005). Thus, antioxidants may display slower rate of scavenging towards the DPPH radical than towards peroxyl radicals (Ndhlala et al., 2010). Furthermore, steric inaccessibility of radical site of DPPH may result in an overestimation of the antioxidant capacity of those smaller molecules, which have better access to the DPPH radical, and vice versa (Goupy et al., 2002). For example, addition of two $\left(\mathrm{CH}_{2}\right)$ units to the molecular spacer of 3,5-Di-tert-butyl-4-hydroxybenzyl acid diminished its DPPH radical scavenging by 13-fold (Vol'eva et al., 2011). Therefore, 
efficient peroxyl radical scavengers can be inert in DPPH radical scavenging since they may have less access to the DPPH radical site (Goupy et al., 2002). Nonetheless, the DPPH assay is a simple, rapid technique, which does not require special equipment and provides useful information on the capacity of phytochemical sources in scavenging free radicals, aiding screening of potent antioxidant sources. Furthermore, the technique is routinely used in assays of the antioxidant potential of foodstuffs (Huang et al., 2005).

\subsubsection{ORAC assay}

ORAC measures antioxidant inhibition of peroxyl radical induced oxidations and thus reflects radical chain breaking antioxidant activity by $\mathrm{H}^{+}$transfer (Dávalos et al., 2003). A synthetic free radical generator is thermally decomposed, supplying a continuous flux of peroxyl radicals $\left(\mathrm{ROO}^{\circ}\right)$, which oxidises a fluorescent probe $(\mathrm{PH})$ and reducing fluorescence intensity (Equation 1.2 and 1.3). The antioxidants $(\mathrm{AH})$ inhibit the oxidation of the fluorescent probe by competing for peroxyl radicals, thus maintaining the fluorescence intensity (Equation 1.4 and 1.5).

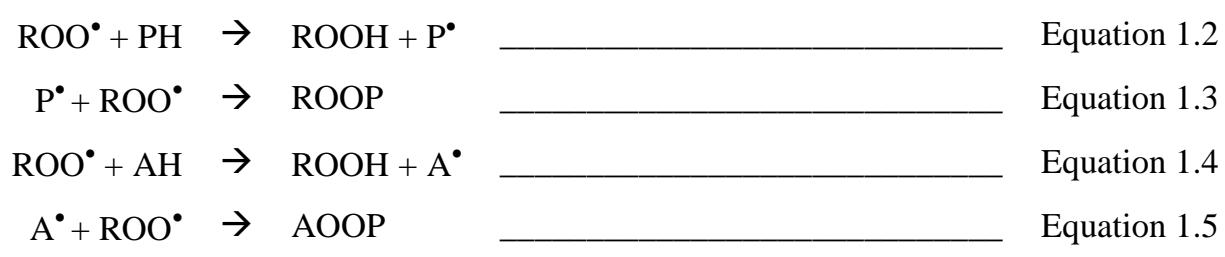

Fluorescence decay curves (Figure 1.6) reflect the protective effect of the antioxidants in the sample and can be numerically quantified as net integrated areas under the fluorescence decay curves (AUC). A standard curve is generated using the net AUC for concentrations gradient of trolox, and the trolox equivalents of the sample are calculated from the standard curve. 


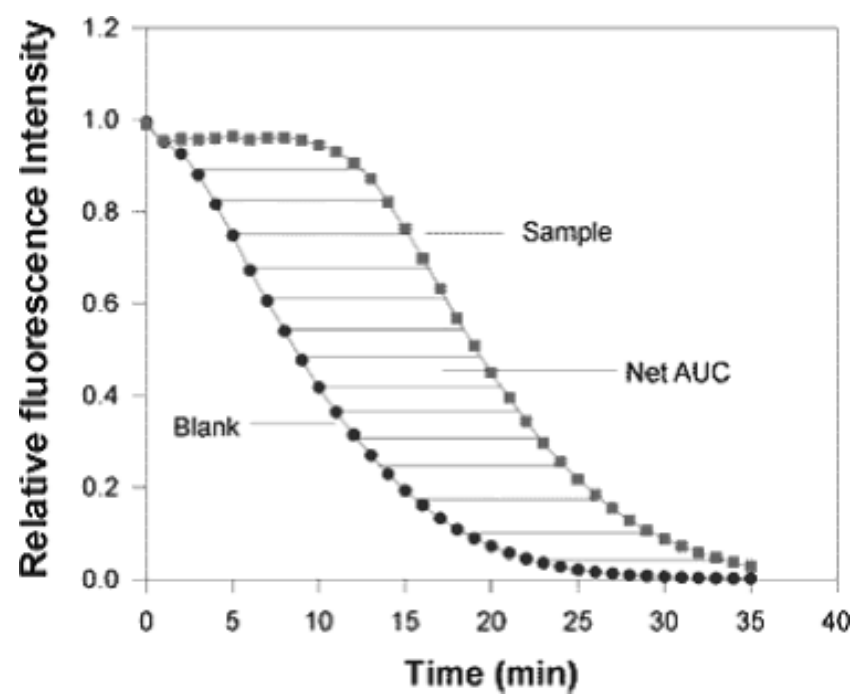

Figure 1.6 Fluorescence decay curve for antioxidant sample, blank (without antioxidant) and shaded area showing net area under the curve (AUC)

Source: Gillespie et al. (2007)

The ORAC assay is technically more complex compared to the DPPH radical scavenging assay, requiring temperature control throughout the assay period and a fluorometer to monitor fluorescence during the $1 \mathrm{~h}$ of analysis. The ORAC assay can be automated, reducing inter-assay variability by reducing errors and time spent in manual handling. In contrast to the DPPH assay, ORAC measures the scavenging of biologically relevant peroxyl radicals at physiologically relevant $\mathrm{pH}(7.4)$ and temperature $\left(37{ }^{\circ} \mathrm{C}\right)$, which simulates the antioxidant reactions involving lipids in biological systems (Ou et al., 2001; Huang et al., 2005). The ORAC values are more representative of total radical scavenging capacity since the ORAC values encompass the rate and time taken for scavenging the radicals by an antioxidant source into a single value. This is because the AUC of the florescence decay curve in ORAC is dependent on decaying rate and time taken for complete decay (Ou et al., 2001; Huang et al., 2005).

\subsection{THE CELLULAR ANTIOXIDANT ACTIVITY (CAA) ASSAY}

Extractable antioxidant activities measured by in vitro chemical assays (such as ORAC and DPPH) does not necessarily correlate positively with their in vivo antioxidant effects. The CAA assay is an in vitro technique that is used to evaluate the uptake, metabolism, and distribution of LMWAs in human hepatoma cells (Spencer et al., 2004). Therefore, the CAA assay has several advantages over traditional chemical antioxidant activity 
assays. The CAA assay has been used to quantify antioxidant activities of isolated antioxidant compounds (Wolfe and Liu, 2008), as well as those in fruits (Wolfe and Liu, 2007; Wolfe et al., 2008), vegetables (Song et al., 2010) and foliar extracts (McDowell et al., 2011).

It is important when determining the health benefit of antioxidants in an ingested food matrix to evaluate their ability to be absorbed through the stomach and intestine into systemic circulation, to reach target tissues, and to exert physiological effects. However, monitoring the lumen of the human intestines and adjunct blood vessels and the target tissues in vivo, can be complex. Therefore, the development of suitable models that mimic human metabolism is useful for bioavailability and bioactivity studies (Grajek, 2005; Wolfe and Liu, 2007; Wolfe et al., 2008; Wolfe and Liu, 2008; Song et al., 2010; McDowell et al., 2011). Cell lines such as L-02 (human normal hepatocytes) and HepG2 (human hepatoma cells) have most frequently been used for this work, since the liver is the central organ where the metabolism and detoxification takes place in humans. Human HepG2 cells are well differentiated experimental models that display biochemical responses comparable to the hepatocytes, and have been used successfully to evaluate cytotoxic and antioxidant potential of pure chemicals and plant extracts in the CAA assay (Wolfe and Liu, 2007; Wolfe et al., 2008; Wolfe and Liu, 2008; Song et al., 2010; McDowell et al., 2011).

The CAA values positively correlated to ORAC antioxidant activities and total phenolic content in fruits such as Vaccinium corymbosum, Rubus fruticosus, Fragaria ananassa, Rubus idaeus and Vaccinium macrocarpon (Wolfe et al., 2008) and in vegetables such as Beta vulgaris, Capsicum annuum and Brassica oleracea var. italica (Song et al., 2010). The CAA assay has been conducted on foliar extracts of Sonchus oleraceus, for which the antioxidants were shown to be effectively absorbed into HepG2 cells and display antioxidant activity in the cytoplasm (McDowell et al., 2011).

The low CAAs of certain LMWAs may be due to their poor or slower uptake into HepG2 cells. The CAA assay using pure compounds has shown that quercetin had the highest activity, while ascorbic acid was 100-fold lower in the CAA assay compared to quercetin (Table 1.18). 
Table 1.18 Cellular Antioxidant Activity (CAA) in human hepatoma cells by selected phytochemicals listed from highest to lowest CAA

\begin{tabular}{lc}
\hline Antioxidant & $\mathbf{E C}_{\mathbf{5 0}}(\boldsymbol{\mu M})^{\boldsymbol{a}}$ \\
\hline Quercetin & $5.1 \pm 0.2$ \\
\hline Kaempferol & $6.3 \pm 0.2$ \\
\hline Epigallocatechin gallate & $15.8 \pm 0.4$ \\
\hline Myricetin & $15.4 \pm 0.5$ \\
\hline Luteolin & $23.1 \pm 1.0$ \\
\hline Gallic acid & $335 \pm 26$ \\
\hline Caffeic acid & $525 \pm 38$ \\
\hline Ascorbic acid & $>500$ \\
\hline \multicolumn{2}{c}{ Source: Wolfe and Liu $(2007)$}
\end{tabular}

${ }^{a} \mathrm{EC}_{50}$ reflects the median effective antioxidant concentration eliciting 50\% CAA, obtained from dose-CAA response curves.

\subsubsection{Cytotoxicity}

High intakes of dietary LMWAs may have cytotoxic effects on human tissues. For example, the flavonoids luteolin, hydroxygenkwanin, and kaempferol possess significant in vitro cytotoxic effects on cultured L-02 and HepG2 cells ( $\mathrm{Li}$ et al., 2008). The cytotoxic effect of quercetin on HepG2 cells was dose- and time-dependant (Meyers et al., 2003; Wolfe et al., 2003). In contrast, chlorogenic acid and (-)-epicatechin were not toxic on HepG2 cells, within the tested upper limit of $1000 \mu \mathrm{M}$ (Meyers et al., 2003).

Measures of cytotoxicity of isolated phenolic compounds are higher than those for fruit and vegetable extracts, which naturally contain those compounds. For example, doses exceeding $6 \mu \mathrm{g} \mathrm{mL}^{-1}$ of quercetin were cytotoxic on HepG2 cells, while most fruits and vegetables required doses of greater than $150 \mathrm{mg} \mathrm{mL}^{-1}$ to be cytotoxic (Wolfe and Liu, 2007; Wolfe et al., 2008; Song et al., 2010; McDowell et al., 2011; Faller et al., 2012). The reason could be that the concentration of a specific LMWA in fruits and vegetables is lower, therefore to reach cytotoxic levels higher doses of a whole food is required compared to the pure compound alone. 


\subsection{TRADITIONAL DIET OF MĀORI AND INCIDENCE OF COLORECTAL CANCER}

In New Zealand, a lower incidence of colorectal cancer has been reported for Māori than for non-Māori New Zealanders, according to colonoscopy records (from 2001 to 2005 involving 3000 participants) and statistics (from International Agency for Research on Cancer from 1980 to 1998 for nearly 4 x $10^{6}$ individuals). The prevalence of colorectal adenomas was $50 \%$ less in Māori than in non-Māori New Zealanders of European origin (Ferguson et al., 1995; Thomson, 2002; Dickson et al., 2010). These lower colorectal cancer rates in Māori occur, despite higher prevalence of oncogenic risk factors for colorectal cancers among Māori (Ferguson et al., 1995; Thomson, 2002). Such oncogenic risk factors among Māori are: higher intakes of red meat, saturated fat and alcohol, higher food portion sizes, a higher prevalence of obesity and lower proportions of individuals who consume the recommended daily servings of fruit and vegetables. To explain this apparent paradox, it has been postulated that specific food plants, which are favoured especially by Māori might offer protection against the onset of colorectal cancers. Of the 51 food plants eaten by New Zealanders, four were eaten significantly more frequently by Māori than by European and Pacific Island descended New Zealanders (Ferguson et al., 1995). These foods were sow thistle (Sonchus oleraceus), silverbeet (Beta vulgaris var. cicla), watercress (Nasturtium offcinale) and sweet potato (Ipomoea batatas); of these, methanolic extracts of sow thistle, silverbeet and watercress showed antimutagenic properties possibly leading to cancer prevention (Botting et al., 1999). However sow thistle was indicated as the most frequently eaten plant food among Māori according to a survey of about 2000 Māori respondents, (Rush et al., 2010).

\subsection{Sonchus oleraceus L.}

The Sonchus oleraceus (the smooth sow thistle known as "puha" by Māori) and possibly S. asper and S. kirkii were predominantly boiled or sometimes steamed before consumption in the traditional Māori diet (Whyte et al., 2001; Cambie and Ferguson, 2003b). S. oleraceus has also been used in traditional medical practices of Hawaiian islands to treat a wide variety of disorders via both external application and internal administration (Leonard, 1998). 


\subsubsection{Biology of S. oleraceus}

S. oleraceus L. (Compositae) is an annual herb (Holm and Center, 1977). It is native to Europe, North Africa, and Asia, and successfully grows and reproduces over a diverse range of habitats (Holm and Center, 1977). The older leaves form a basal rosette close to the ground, but later-formed leaves are on the flowering stem, which terminates in an inflorescence (Plate 1.1). The first leaves are orbicular with a slightly serrate margin. The mature leaves are pinnatifid with irregularly-toothed margins, and become increasingly lobed with maturity, reaching $10-25 \mathrm{~cm}$ in length. Bolting occurs when plants have $20-$ 25 leaves (Cici et al., 2009). After the appearance of the first floral buds, rapid elongation of internodes increases the plant height to $1 \mathrm{~m}$ or more (Holm and Center, 1977). The self-compatible flowers develop achenes one week after flowering. The average number of seeds per capitulum is around 140, and the mean number of capitula per plant is 4.4 (Cici et al., 2009).

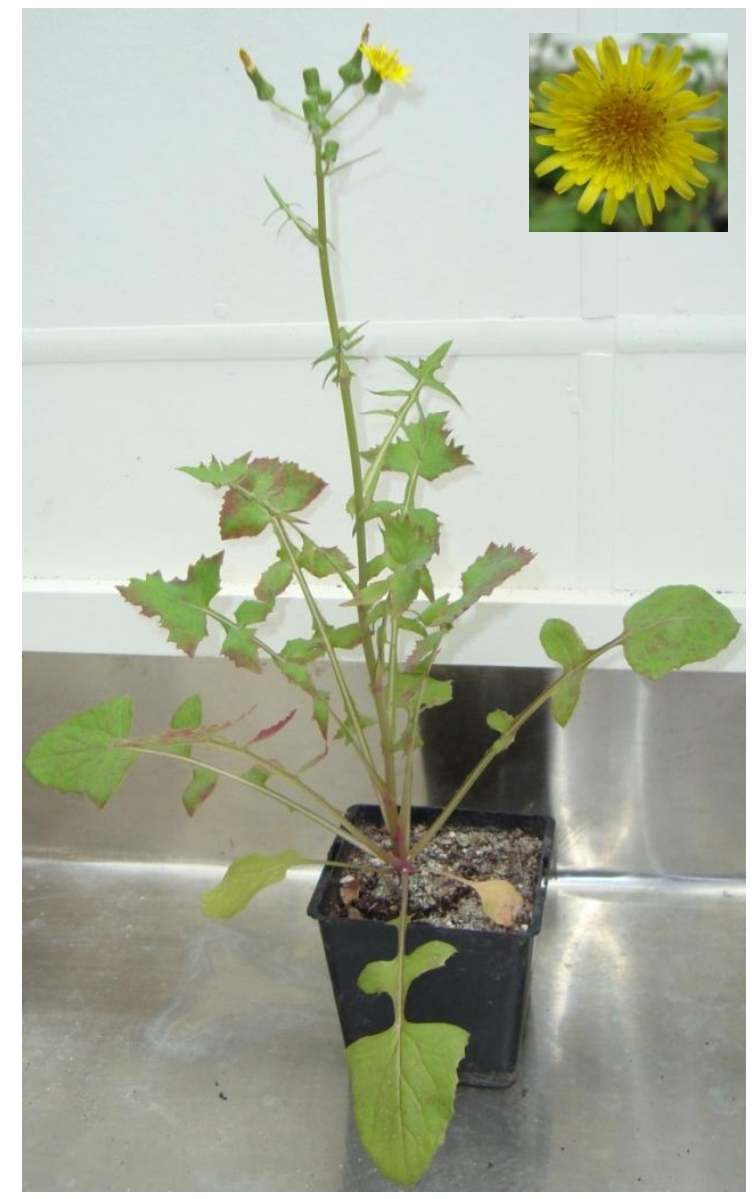

Plate 1.1 Sonchus oleraceus whole plant and capitulum (inset) 
S. oleraceus seeds germinate approximately two weeks after sowing and require light for germination (Hutchinson et al., 1984). Maximum germination rates are observed in trays filled with sand: potting mixture mixed in 1:1 ratio (Ellwood, 2007). Their germination is not greatly influenced by temperature (Chauhan et al., 2006). The maximum germination occurred from seeds sown at the soil surface, while increasing osmotic potential and $\mathrm{pH}$ (by $160 \mathrm{mM} \mathrm{NaCl}$ and $\mathrm{pH} 10$ ) resulted in low germination percentage (Chauhan et al., 2006).

\subsubsection{Nutrients in leaves of S. oleraceus}

Leaves of S. oleraceus contain vitamin C, carotenoids, oxalic acid (Table 1.19), various elements (Table 1.20) and short chain fatty acids (Mercadante and Rodriguez-Amaya, 1990; Guil-Guerrero et al., 1998; Liu et al., 2002). The concentration of vitamin C and carotenoids in S. oleraceus leaves were 20 - and three-fold lower respectively than those present in tomato on the same dry weight basis (Table 1.19).

Table 1.19 Nutrient composition of S. oleraceus leaves collected from natural habitats in Spain

\begin{tabular}{lc}
\hline Component & $\begin{array}{c}\text { Content }\left(\mathbf{g ~ k g}^{-1} \mathbf{D W}\right)^{\boldsymbol{a}} \\
(\text { Mean } \pm \text { SD })\end{array}$ \\
\hline Water $^{1}$ & $872.4 \pm 14.0$ \\
\hline Protein & $31.7 \pm 1.5$ \\
\hline Digestible carbohydrates & $18.2 \pm 1.4$ \\
\hline Fibre & $32.5 \pm 2.4$ \\
\hline Lipids & $7.5 \pm 0.9$ \\
\hline Ash & $29.9 \pm 1.8$ \\
\hline Oxalic acid $^{2}$ & $1.3 \pm 0.3$ \\
\hline Vitamin C $^{3}$ & $0.8 \pm 0.1$ \\
\hline Carotenoids $^{4}$ & $0.2 \pm 0.0$ \\
\hline Energy $^{5}$ & $1098 \pm 155$
\end{tabular}

Source: Guil-Guerrero et al. (1998)

${ }^{a}$ except for water and energy

$\mathrm{g} \mathrm{kg}^{-1} \mathrm{FW}$

4.4 ,

16.4 and

0.6 accordingly in Solanum esculentum (Guil-Guerrero and Rebolloso-Fuentes, 2009).

5. $\mathrm{kJ} \mathrm{kg}^{-1} \mathrm{DW}$ 
Table 1.20 Mineral elements ( $\left.\mathrm{mg} \mathrm{kg}^{-1} \mathrm{DW}\right)$ in $S$. oleraceus leaves collected from natural habitats in

\begin{tabular}{lc}
\multicolumn{2}{c}{ Spain } \\
\hline Mineral elements & Content (mean \pm SD) \\
\hline $\mathrm{Na}$ & $2582 \pm 282$ \\
\hline $\mathrm{K}$ & $6225 \pm 783$ \\
\hline $\mathrm{Ca}$ & $324 \pm 102$ \\
\hline $\mathrm{Mg}$ & $759 \pm 99$ \\
\hline $\mathrm{P}$ & $580 \pm 96$ \\
\hline $\mathrm{Fe}$ & $38 \pm 4$ \\
\hline $\mathrm{Cu}$ & $3 \pm 1$ \\
\hline $\mathrm{Zn}$ & $8 \pm 2$ \\
\hline $\mathrm{Mn}$ & $12 \pm 2$ \\
\hline $\mathrm{S}$ & \\
\hline
\end{tabular}

Source: Guil-Guerrero et al. (1998)

\subsubsection{LMWAs of $S$. oleraceus}

Vegetative shoots of S. oleraceus are exceptionally rich in LMWAs; DPPH radical scavenging capacities of methanol-soluble extracts prepared from leaves of S. oleraceus were found to be four-fold greater than those for blueberry (Vaccinium corymbosum) extracts on dry weight basis (Gould et al., 2006). Cauline leaves of S. oleraceus held higher levels of extractable antioxidants than did rosette leaves (Ellwood, 2007). DPPH radical scavenging capacities of methanolic extracts were greater than aqueous and ethanolic extracts of leaves (Yin et al., 2007). S. oleraceus leaf extracts are more potent in LMWA activity than are related species, S. asper and S. kirkii (Ellwood, 2007).

Measurements of antioxidant activity in methanolic extracts of S. oleraceus leaves correlate to the presence of phenolic compounds (Simopoulos, 2004). In one study, caffeic acid derivatives were the major phenolic compounds present $(0.8 \% \mathrm{DW})$, while luteolin-7-glucoside and apigenin-7-glucoside collectively accounted for $0.2 \%$ DW (Table 1.21). In addition, flavonoids (luteolin, apigenin, kaempferol and quercetin) and their glucoside derivatives were identified from whole plant extracts (Table 1.21). Recently caftaric acid has also been identified from leaf methanolic extracts (Ou et al., 2012). Table 1.16 lists the DPPH radical scavenging activities of flavonoids and their derivatives in $S$. oleraceus extracts, where scavenging activities of glycosidic derivatives were lower than their original flavonoid aglycones (Yin et al., 2007; Yin et al., 2008). 
The $S$. oleraceus foliar extracts were only cytotoxic on HepG2 cells at concentrations exceeding $100 \mathrm{mg} \mathrm{DW} \mathrm{mL} \mathrm{m}^{-1}$ (McDowell et al., 2011). This indicates their safety for consumption as sources of dietary LMWAs.

Table 1.21 Composition and antioxidant activities of phenolic compounds from leaf extracts of $S$.

oleraceus

\begin{tabular}{|c|c|c|c|}
\hline \multirow[t]{2}{*}{ Phenolic compounds } & \multirow{2}{*}{$\begin{array}{c}\text { Concentration }^{a} \\
\text { Mean } \pm \text { SE } \\
\left(\mathrm{mg} \mathrm{g}^{-1} \text { leaf } \mathrm{DW}\right)\end{array}$} & \multicolumn{2}{|c|}{$\begin{array}{c}\mathrm{DPPH}^{b} \text { scavenging } \\
\mathrm{EC}_{50}{ }^{c}\end{array}$} \\
\hline & & $(\mu \mathbf{M})$ & $\left(\mu \mathrm{g} \mathrm{mL} \mathbf{L}^{-1}\right)$ \\
\hline Caffeic acid derivatives & $2.6 \pm 0.3$ & $\mathrm{nq}$ & $\mathrm{nq}$ \\
\hline Chlorogenic acid & $1.5 \pm 0.2$ & $\mathrm{nq}$ & $\mathrm{nq}$ \\
\hline Chicoric acid & $12.5 \pm 1.3$ & $\mathrm{nq}$ & $\mathrm{nq}$ \\
\hline Luteolin-7-O- $\beta$-D-glucoside & $3.6 \pm 0.4$ & 131 & 61 \\
\hline Apigenin-7-O- $\beta$-D-glucoside & $1.7 \pm 0.2$ & 206 & 89 \\
\hline Luteolin & nd & 42 & 12 \\
\hline Apigenin & nd & 144 & 39 \\
\hline Kaempferol & nd & 45 & 13 \\
\hline Quercetin & nd & 36 & 11 \\
\hline Kaempferol-3-O- $\beta$-D-glucoside & nd & 100 & 45 \\
\hline Quercetin-3-O- $\beta$-D-glucoside & nd & 47 & 22 \\
\hline
\end{tabular}

${ }^{a}$ S. oleraceus leaves collected from natural habitats in Italy (Gatto et al., 2011)

${ }^{b}$ 2,2-diphenyl-1-picrylhydrazyl radical

${ }^{c}$ Antioxidant activities of isolated phenolic compounds from whole plants of S. oleraceus collected from natural habitats in South Korea (Yin et al., 2008)

nq: not quantified

nd: not detected

\subsubsection{Variation in antioxidant potential of $S$. oleraceus}

S. oleraceus shows geographical variation in extractable antioxidant activity (Simopoulos, 2004; Schaffer, 2005; Ellwood, 2007). The antioxidant activity and polyphenol content of $S$. oleraceus leaves collected from wild populations in Spain, Greece and Italy varied two-fold (Schaffer, 2005). For plants naturalised in different parts of New Zealand, the antioxidant activity varied four-fold (Ellwood, 2007; Table 1.22). Plant growth conditions, too, may affect the antioxidant status of S. oleraceus leaves. In 
one study, the antioxidant activity as measured by the DPPH assay was found to be higher in greenhouse grown plants than in those collected from the field, however, reasons for this effect were not identified (Ellwood, 2007). The antioxidant activity parent plants correlated to those of the F1 offspring for selfed plants, indicating heritability of antioxidant traits (Ellwood, 2007). Thus it is likely that combinations of genetic and environmental factors contribute to variability in LMWA in S. oleraceus. It is possible to enhance the LMWA activities in S. oleraceus by imposing abiotic stresses, since there are numerous examples of this in other species (Section 1.9).

Table 1.22 Antioxidant activities of methanolic extracts from S. oleraceus leaves collected from natural habitats throughout New Zealand listed according to descending order of antioxidant capacity

\begin{tabular}{lc}
\hline Location & $\begin{array}{c}\text { DPPH }^{\text {a }} \text { radical scavenging capacity } \mathbf{E C}_{\mathbf{5 0}} \\
\left(\mathbf{m g} \text { leaf } \mathbf{~ D W ~} \mathbf{~}^{\mathbf{1}}\right)\end{array}$ \\
\hline Alexandra $^{1}$ & $42.4 \pm 2.0$ \\
\hline Akaroa $^{2}$ & $42.7 \pm 1.2$ \\
\hline Dunedin $^{3}$ & $47.6 \pm 3.3$ \\
\hline Acacia Bay $^{4}$ & $48.9 \pm 4.9$ \\
\hline Otago Peninsula $^{3}$ & $50.2 \pm 1.6$ \\
\hline Kuratau Dam $^{4}$ & $50.6 \pm 2.0$ \\
\hline Arrowtown $^{1}$ & $52.1 \pm 8.0$ \\
\hline Rotoaira Forest $^{4}$ & $59.9 \pm 5.8$ \\
\hline Halfmoon Bay $^{5}$ & $60.1 \pm 20.1$ \\
\hline Roxburg $^{1}$ & $61.3 \pm 7.0$ \\
\hline Tokaanu $^{4}$ & $62.8 \pm 4.6$ \\
\hline Oamaru $^{3}$ & $62.9 \pm 2.5$ \\
\hline Mokai $^{4}$ & $63.4 \pm 7.5$ \\
\hline
\end{tabular}

Source: Ellwood (2007)

a2,2-diphenyl-1-picrylhydrazyl

${ }^{1}$ Central Otago, ${ }^{2}$ Cantebury, ${ }^{3}$ Coastal Otago,,${ }^{4}$ Central North Island and ${ }^{5}$ Stewart Island. 


\subsection{EFFECT OF STRESS ON ANTIOXIDANT LEVELS IN PLANTS}

ROS production in plants is an unavoidable by-product of aerobic metabolic processes such as photosynthesis and respiration. ROS serve a useful function as secondary messengers in signal transduction cascades (Mittler et al., 2004; Foyer and Noctor, 2005; Miller et al., 2008). However, in excess, they have the same capacity to adversely affect plant cell components as they do in humans. Many studies have shown that plants subjected to UV radiation, ozone, drought, salinity and temperature accumulate supernumerary free radicals and ROS (Mittler, 2002; Foyer and Noctor, 2003; Tausz et al., 2004). In addition, pathogens and herbivore wounding are known to trigger the production of ROS (Orozco-Cardenas and Ryan, 1999); these apoplastic ROS mediate pathogen recognition by plants, which ultimately may lead to enhanced disease resistance (Lamb and Dixon, 1997; Grant et al., 2000). ROS-yielding processes such as the Mehler reaction in chloroplasts, the glycolate oxidase reaction in peroxisomes and electron leakage in mitochondria are enhanced by such environmental conditions (Table 1.23).

Plants have evolved numerous mechanisms to limit the production of ROS during photosynthesis under excess excitation energy. For example, leaf anatomical adaptations (Mittler et al., 2001), photoprotective pigments (Gould, 2004), and biochemical pathways such as water-water cycle can all retard rates of ROS production (Asada, 1999). However, when stressors generate ROS in excess of the plants' capacity to quench them, they bring about signal transduction cascades, which induce the production of both enzymatic (Table 1.24) and LMWAs (Sections 1.9.1 - 1.9.4), ultimately resulting in enhanced stress tolerance (Mano and Komatsuda, 2002).

Abiotic stresses upregulate key enzymes such as phenylalanine-ammonia-lyase (PAL), chalcone synthase (CHS), flavanone 3-hydroxylase (F3H), and flavonol synthase (FLS) of phenylpropanoid and flavonoid pathway; leading to elevated levels of phenolic compounds in the tissues under stress (Leyva et al., 1995; Janas et al., 2000; Niggeweg et al., 2004; Løvdal et al., 2010). Further details on enhancement of LMWAs in plants by abiotic stresses such as drought, chilling, salinity and light are detailed briefly (Sections 1.9.1 - 1.9.4) because these stresses are featured in the experimental sections of this thesis. 
Table 1.23 Examples of primary reactive species, which are induced by abiotic and biotic stressors and their possible mechanism for induction

\begin{tabular}{|c|c|c|}
\hline Stressor & Reactive species & Mechanisms \\
\hline Strong light & $\mathrm{O}_{2}^{\cdot-}, \mathrm{H}_{2} \mathrm{O}_{2},{ }^{1} \mathrm{O}_{2}$ & $\begin{array}{l}\text { Enhanced Mehler activity; photorespiration; triplet chlorophyll } \\
\text { excitation }\end{array}$ \\
\hline Heat & $\mathrm{O}_{2}^{\cdot-}, \mathrm{H}_{2} \mathrm{O}_{2}, \mathrm{NO}^{\bullet}$ & $\begin{array}{l}\text { Impairment of photosynthetic and mitochondrial electron transport; } \\
\text { enzyme inhibition; increased membrane permeability }\end{array}$ \\
\hline Cold & $\mathrm{O}_{2}^{\circ}, \mathrm{H}_{2} \mathrm{O}_{2}$ & $\begin{array}{l}\text { Enhanced Mehler activity; suppression of Calvin cycle enzymes; } \\
\text { reduced antioxidant activity; decreased membrane fluidity }\end{array}$ \\
\hline $\begin{array}{l}\text { UV-B } \\
\text { radiation }\end{array}$ & $\mathrm{OH}^{\circ}, \mathrm{O}_{2}{ }^{--}, \mathrm{H}_{2} \mathrm{O}_{2}$ & Inhibition of PSII reaction centre enzymes; possibly fission of $\mathrm{H}_{2} \mathrm{O}_{2}$ \\
\hline Drought & $\mathrm{O}_{2}^{\cdot-}, \mathrm{H}_{2} \mathrm{O}_{2}, \mathrm{NO}^{\bullet}$ & $\begin{array}{l}\text { Inhibition of rubisco; uncoupling of electron transport from ATP } \\
\text { synthesis; enhanced Mehler activity; photoinhibition; inhibition of } \\
\text { mitochondrial antioxidants; enhanced root respiration }\end{array}$ \\
\hline Wounding & $\mathrm{O}_{2}^{\cdot-}, \mathrm{H}_{2} \mathrm{O}_{2}, \mathrm{NO}^{\circ}$ & $\begin{array}{l}\text { Elicitation by cell wall fragments; interference by with redox systems on } \\
\text { plasma membrane }\end{array}$ \\
\hline Salinity & $\mathrm{O}_{2}^{\cdot-}, \mathrm{H}_{2} \mathrm{O}_{2}, \mathrm{NO}^{\circ}$ & $\begin{array}{l}\text { Stomatal closure, causing } \mathrm{NADP}^{+} \text {deficit and } \mathrm{O}_{2} \text { reduction in } \\
\text { mitochondria; suppression of Calvin cycle enzymes, by enhanced } \\
\text { Mehler reaction and ion leakage through damaged membranes }\end{array}$ \\
\hline Patho & $\mathrm{O}_{2}^{\cdot-}, \mathrm{H}_{2} \mathrm{O}_{2}, \mathrm{NO}^{\bullet}$ & cell wall per \\
\hline
\end{tabular}

Source: Reproduced after permission from Gould (2003)

Table 1.24 Stress conditions that stimulate increased levels or activities of enzymatic antioxidants in plants

\begin{tabular}{lll}
\hline Antioxidant enzymes & Functions & Stress conditions \\
\hline Ascorbate peroxidase & Convert $\mathrm{H}_{2} \mathrm{O}_{2}$ to water. & $\begin{array}{l}\text { Drought, high } \mathrm{CO}_{2} \text {, high light intensity, } \\
\text { ozone, paraquat }\end{array}$ \\
\hline Catalase & Convert $\mathrm{H}_{2} \mathrm{O}_{2}$ to water and oxygen & Chilling \\
\hline Glutathione peroxidase & Glutathione peroxidase & Chilling, drought, high $\mathrm{CO}_{2}$, ozone, \\
and reductase & decomposes $\mathrm{H}_{2} \mathrm{O}_{2}$ and glutathione & paraquat \\
& reductase regenerates glutathione. & \\
\hline Superoxide dismutase & Converts superoxide anion & ${\text { Chilling, high } \mathrm{CO}_{2}, \text { high light, increased }}$ \\
& radicals to $\mathrm{H}_{2} \mathrm{O}_{2}$. & $\mathrm{O}_{2}$, ozone, paraquat, $\mathrm{SO}_{2}$ \\
\hline
\end{tabular}

Sources: Buchanan et al. (2000); Halliwell and Gutteridge (2007) 


\subsubsection{Drought stress on LMWA production in plants}

There is a large body of evidence to indicate that LMWAs accumulate in plants in response to drought stress. Particularly phenolic compounds have the ability to mitigate effects of oxidative stress from water deficit either by scavenging ROS directly or by reducing light energy received by chloroplasts. This helps photosystems of drought stressed plants to process radiation without the formation of ROS (Bilger et al., 2001). The response of the antioxidant system to water deficit varies among plant species and varieties, and may change with development of the plant, as well as the duration and intensity of the stress (Table 1.25).

\subsubsection{Chilling stress on LMWA production in plants}

The enhancement of antioxidant capacity and level of phenolic compounds in response to cold stress has been observed in many species (Solecka et al., 1999; Janas et al., 2000; Rivero et al., 2001; Kirakosyan et al., 2003; Pennycooke et al., 2005; Olenichenko et al., 2006; Liu et al., 2007; Koc et al., 2010). The hawthorn species (Crataegus laevigata and C. monogyna) upregulated different phenolics (such as vitexin-2"-O-rhamnoside, acetylvitexin-2"- $O$-rhamnoside, hyperoside, quercetin) at different magnitudes in response to identical conditions of cold stress (Kirakosyan et al., 2003) indicating that species and varieties differ in their antioxidants defences facing the same stress.

\subsubsection{Light stress on LMWA production in plants}

Increasing light intensities enhanced the accumulation of phenolic compounds in species such as Populus trichocarpata, Solanum esculentum, Vitis vinifera and Punica granatum (Dumas et al., 2003; Warren et al., 2003; Pereira et al., 2006; Gautier et al., 2008; Schwartz et al., 2009). Anthocyanins in particular, accumulate in vacuoles under high light, where they contribute to light screening, pigmentation and photoprotection among other functions (Gould, 2004; Hernández et al., 2009). Increased ascorbic acid levels were associated with increasing light intensities in Solanum esculentum (Lee and Kader, 2000; Dumas et al., 2003). 
Table 1.25 Selected examples for effects of drought on increased low molecular weight antioxidants

(LMWAs) in plant species under experimental conditions

\begin{tabular}{lll}
\hline Enhanced LMWAs & Plant species & References \\
\hline Phenolic compounds & & \\
Chlorogenic acid & Hypericum perforatum & (Gray et al., 2003; Nacif de Abreu and Mazzafera, \\
Quercetin & Hypericum brasiliense & 2005; Zobayed et al., 2007) \\
Rutin & \\
Quercetin glucoside & \\
$\begin{array}{l}\text { 1,5-dihydroxyxanthone } \\
\text { Hypericin }\end{array}$ & \\
Chlorogenic acid & Crataegus sp. \\
Epicatechin & \\
Catechin & \\
\hline$\underline{\alpha-T o c o p h e r o l ~}$ & & \\
\hline
\end{tabular}

\begin{tabular}{ll} 
Arbutus unedo & (Munné-Bosch and Peñuelas, 2004; Šircelj et al., 2005) \\
\hline $\begin{array}{l}\text { Triticum aestivum } \\
\text { Festuca arundinacea }\end{array}$ & (Bartoli et al., 1999; Herbinger et al., 2002) \\
Agrostis palustris & \\
\hline Rosmarinus officinalis & (Munné-Bosch et al., 1999) \\
\hline Lavandula stoechas & (Munné-Bosch et al., 2001)
\end{tabular}

\begin{tabular}{|c|c|c|}
\hline \multicolumn{3}{|l|}{ Ascorbate } \\
\hline & Arbutus unedo & (Munné-Bosch and Peñuelas, 2004; Šircelj et al., 2005) \\
\hline & Rosmarinus officinalis & (Munné-Bosch et al., 1999; Munné-Bosch and Alegre, \\
\hline & Salvia officinalis & 2003) \\
\hline & Melissa officinalis & \\
\hline
\end{tabular}

$\underline{\text { Carotenoids }}$

Rosmarinus officinalis (Munné-Bosch et al., 1999)

Triticum aestivum (Bartoli et al., 1999; Herbinger et al., 2002)

\subsubsection{Salinity stress on LMWA production in plants}

Numerous studies have indicated that plants subjected to salinity, in addition to regulating water and ionic relations; enhanced LMWAs in their tissues to remove excess ROS. The type of LMWAs accumulated and effective range of salinity is specific to plant species (Table 1.26). 
Table 1.26 Selected examples for effects of salinity on enhanced low molecular weight antioxidants (LMWAs) in plant species under experimental conditions

\begin{tabular}{|c|c|c|c|}
\hline Enhanced LMWAs & Species & $\begin{array}{l}\mathrm{NaCl} \text { concentration } \\
(\mathrm{mM})\end{array}$ & References \\
\hline \multicolumn{4}{|l|}{ Phenolic compounds } \\
\hline Polyphenolic content & Cakile maritime & 100 and 400 & (Ksouri et al., 2007) \\
\hline $\begin{array}{l}\text { Isoorientin, orientin, rutin and } \\
\text { vitexin }\end{array}$ & Fagopyrum esculentum & $10,50,100$, and 200 & (Lim et al., 2012) \\
\hline Oleuropein & Olea europaea & $75-125$ & $\begin{array}{l}\text { (Petridis et al., } \\
\text { 2012) }\end{array}$ \\
\hline \multirow[t]{2}{*}{ Ascorbate } & Catharanthus roseus & $50-100$ & (Jaleel et al., 2007) \\
\hline & Solanum esculentum & Saline water & (Raffo et al., 2006) \\
\hline \multicolumn{4}{|l|}{ Carotenoids } \\
\hline Lycopene & Capsicum аппиит & $15-30$ & $\begin{array}{l}\text { (Navarro et al., } \\
\text { 2006) }\end{array}$ \\
\hline Carotenoid & Fagopyrum esculentum & 50 and 100 & (Lim et al., 2012) \\
\hline Tocopherols & Solanum esculentum & $50-150$ & (Incerti et al., 2008) \\
\hline
\end{tabular}

Enhancement of LMWAs due to abiotic stresses is not limited to intact plants but extends to in vitro cultured plant cells, as demonstrated for various plant species (Section 1.10; Table 1.27). Further, extraction of LMWAs from cell cultures have numerous advantages over extraction from whole plants (Section 1.10), thus S. oleraceus cell cultures may provide an effective and efficient means of LMWAs production.

\subsection{PLANT CELL CULTURE FOR THE PRODUCTION OF LMWAS}

Plant cell culture may be a viable option for the commercial scale extraction of antioxidants from $S$. oleraceus, avoiding the substantial variation of antioxidant content across plant material itself. Ideally, S. oleraceus cell cultures would continuously produce phenolic antioxidants, while the content could be controlled by manipulating culture conditions and imposing abiotic stressors. Abiotic stressors has been used successfully, to enhance LMWAs in experimental plant cell cultures of other species (Table 1.27), and the harvestable product has been manipulated by changing the source of explant, growth conditions, and nutrient medium composition. Many plant metabolites have been 
produced via cell culture production at the industrial scale, such as anthocyanins, berberines, carthamin, ginsenosides, rosmarinic acid, scopolamine, shikonin and taxol (Sajc et al., 2000; Verpoorte et al., 2002; Kolewe et al., 2008; Wilson and Roberts, 2012).

Table 1.27 Selected examples for the effects of abiotic stresses on enhanced low molecular weight antioxidants (LMWAs) in plant cell cultures under experimental conditions

\begin{tabular}{|c|c|c|c|}
\hline Enhanced LMWAs & Species & Abiotic elicitor & References \\
\hline \multicolumn{4}{|l|}{ Phenolic compounds } \\
\hline $\begin{array}{l}\text { Flavonoids, flavonols and } \\
\text { saponins }\end{array}$ & Glycine max & $\mathrm{NaCl}(10 \mathrm{mM})$ & $\begin{array}{l}\text { (Radhakrishnan et al., } \\
\text { 2012) }\end{array}$ \\
\hline $\begin{array}{l}p \text {-coumaric acid and 2-3-O- } \\
\text { glucosylresveratrol }\end{array}$ & Vitis vinifera & $\begin{array}{l}\text { Hydrostatic pressure } \\
(40 \mathrm{MPa})\end{array}$ & (Cai et al., 2011) \\
\hline Taxol & Taxus yunnanensis & $\mathrm{La}^{3+}(5.8 \mu \mathrm{M})$ & (Wu et al., 2001) \\
\hline \multirow[t]{2}{*}{ Saponins } & Panax ginseng & $\begin{array}{l}\text { Ultrasound }\left(0.1 \mathrm{~W} \mathrm{~cm}^{-3}\right. \\
\text { at } 38.5 \mathrm{kHz})\end{array}$ & (Wu and Lin, 2002) \\
\hline & Panax notoginseng & $\begin{array}{l}\text { Hydrostatic pressure } \\
(670 \mathrm{kPa})\end{array}$ & (Zhang et al., 1995) \\
\hline Anthocyanins & Vitis vinifera & $\begin{array}{l}\text { Pulsed electric field } \\
\left(0.32 \mathrm{~J} \mathrm{~kg}^{-1}\right)\end{array}$ & (Saw et al., 2012) \\
\hline Ascorbate & $\begin{array}{l}\text { Arabidopsis thaliana } \\
\text { Nicotiana tabacum }\end{array}$ & $\begin{array}{l}\text { Methyl jasmonate }^{1}(50 \\
\mu \mathrm{M})\end{array}$ & (Wolucka et al., 2005) \\
\hline
\end{tabular}

\section{$\underline{\text { Carotenoids }}$}

$\beta$-carotene and violaxanthin $\quad$ Ipomoea batatas $\quad \mathrm{NaCl}(100-200 \mathrm{mM}) \quad$ (Kim et al., 2012)

\begin{tabular}{llll}
\cline { 2 - 3 } Zeaxanthin & Scutellaria baicalensis & $\mathrm{NaCl}(100 \mathrm{mM})$, & (Tuan et al., 2013)
\end{tabular}

$\operatorname{ABA}^{2}(200 \mu \mathrm{M})$

\section{Tocopherols}

a-tocopherol Carthamus tinctorius $\quad \mathrm{NaCl}(0.9-1.2 \mathrm{M}) \quad$ (Chavan et al., 2011)

\footnotetext{
1. methyl jasmonate mediate biotic and abiotic stress responses in plant cells

2. Abscisic acid can simulate osmotic stress
} 
Plant cell cultures are often preferred over whole plants for the extraction of phytochemicals at a commercial scale, since commercial extraction requires phytochemicals from sources, which are not limited by compound availability, compound variability, seasonal availability, species abundance and variable growth rate of the intact plants (Wilson and Roberts, 2012). Additionally, the extraction of phytochemicals from plant cell cultures may be a more economical option, since chemical synthesis is complex and costly (Zhang et al., 1995; Sajc et al., 2000). In a few cases, cell cultures have been found to produce higher levels of secondary metabolites than the differentiated mother plant itself (Rao and Ravishankar, 2002).

\subsection{THESIS INTRODUCTION}

S. oleraceus may be able to protect human cells from oxidative stress given their superb extractable antioxidant activities. However to substantiate this claim, further studies on the antioxidant properties of $S$. oleraceus are needed. Thus, the broad aim of this research was to study the antioxidant activities of $S$. oleraceus leaves based on following specific objectives:

\subsubsection{Objectives}

1. To study the effects of age of a plant, its original locality, and the imposition of abiotic stressors on the extractable antioxidant activities of S. oleraceus leaves; and the effects of stressor-induced leaf variations on cellular antioxidant activities of cultured human cells.

2. To study the effects of cooking and in vitro gastrointestinal digestion on extractable antioxidant activities and in vitro cellular antioxidant activities of $S$. oleraceus leaves.

3. To study extractable antioxidant activities of S. oleraceus cell suspension cultures in relation to abiotic stressors. 
This dissertation is divided into three main chapters to test the above hypotheses, each corresponding to a stand-alone publication, and therefore a certain extent of overlap between background information is inevitable.

Chapter 2 outlines the general materials and methodology that were followed in Chapters 3 - 5. Chapter 3 identifies the variables that affect the extractable and cellular antioxidant activities of $S$. oleraceus leaves. Chapter 4 presents the effects of cooking and in vitro gastrointestinal digestion on extractable and cellular antioxidant activities of phenolic compounds in S. oleraceus leaves. Finally, Chapter 5 presents a protocol that allows continuous extraction of phenolic antioxidants from the $S$. oleraceus cell suspension cultures where the production varied with abiotic stressor applied. Chapter 6 presents general discussion based on findings from previous chapters and possible future directions. 


\section{CHAPTER 2: GENERAL MATERIALS AND METHODS}

\subsection{CHEMICALS}

2,2'-Azobis(2-amidino-propane) dihydrochloride (AAPH) and chlorogenic acid were purchased from Sapphire Bioscience (Hamilton, New Zealand). 2,2'-Azobis(2methylpropionamididine) dihydrochloride (ABAP), 2',7'-dichlorofluorescin diacetate (DCFH-DA), 2,2-diphenyl-1-picrylhydrazyl (DPPH), caftaric acid, chicoric acid, Dulbecco's modified Eagle's medium (DMEM), fluorescein disodium, Folin-Ciocalteu reagent, Hank's balanced salt solution (HBSS), pepsin from porcine gastric mucosa, pancreatin from porcine pancreas, phosphate buffered saline solution (PBS) and quercetin dihydrate were purchased from Sigma-Aldrich (St Louis, MO). 6-Hydroxy-2,5,7,8tetramethylchroman-2-carboxylic acid (Trolox) and sodium carbonate $\left(\mathrm{Na}_{2} \mathrm{CO}_{3}\right)$ were purchased from Thermo Fisher Scientific Australia (Scoresby, Australia). Tannic acid was purchased from Carl Roth Gmbh (Karlsruhe, Germany). Ascorbate assay kit (700420) from Cayman Chemical Company (Ann Arbor, MI, USA). Quercetin was kindly provided by Plant and Food Research, Chemistry Department, University of Otago, Dunedin, New Zealand. Solvents were of HPLC grade. Human hepatocellular carcinoma (HepG2) cells were gratefully obtained from the Pathology Department at the University of Otago, Dunedin, New Zealand. Human epithelial colorectal adenocarcinoma cells (Caco2) cells were kindly provided by Victoria University of Wellington, Wellington, New Zealand.

\subsection{TOTAL PHENOLICS ASSAY}

Total phenolics were measured using the Folin-Ciocalteu method, modified after Waterhouse (2001). Duplicate 1:2 serial dilutions of samples or a $0-60 \mu \mathrm{M}$ tannic acid standard series were introduced into the wells of 96 well plates. Each well held a $25 \mu \mathrm{L}$ sample, standard or blank $\left(\mathrm{ddH}_{2} \mathrm{O}\right)$, plus $125 \mu \mathrm{L}$ of $0.1 \mathrm{M}$ Folin-Ciocalteu reagent. Plates were incubated in the dark on an orbital shaker $(10 \mathrm{rpm})$ at room temperature for $3 \mathrm{~min}$, and then $125 \mu \mathrm{L} 0.6 \mathrm{M} \mathrm{Na}_{2} \mathrm{CO}_{3}$ added to each well and incubated for a further $30 \mathrm{~min}$. Absorbance at $760 \mathrm{~nm}$ was read using an EnSpire 2300 multimode reader (PerkinElmer, 
San Jose, CA). Total phenolic concentrations were expressed as mg tannic acid equivalents $\mathrm{g}^{-1}$.

\subsection{DPPH (2,2-diphenyl-1-picrylhydrazyl) RADICAL SCAVENGING ASSAY}

DPPH radical scavenging capacity was measured for duplicate serial dilutions of the samples as described by Philpott et al. using 1mM Trolox as the standard (Philpott et al., 2003). A $200 \mu \mathrm{L}$ aliquot of $100 \mu \mathrm{M}$ DPPH in methanol was added to $50 \mu \mathrm{L}$ sample or standard, incubated in darkness on an orbital shaker for $30 \mathrm{~min}$, and absorbance measured at $515 \mathrm{~nm}$. Antioxidant activity was estimated as the reciprocal of $\mathrm{EC}_{50}$, the concentration of sample or standard which resulted in a $50 \%$ reduction in $\mathrm{A}_{515}$.

\subsection{OXYGEN RADICAL ABSORBANCE CAPACITY (ORAC) ASSAY}

The ORAC-fluorescein assay, adapted for manual handling, was performed on serial dilutions of samples in black 96-well plates (Dávalos et al., 2003). Into each well were dispensed $120 \mu \mathrm{L}$ of $117 \mathrm{nM}$ fluorescein disodium in $75 \mathrm{mM}$ phosphate buffer at $\mathrm{pH} 7.4$, and $20 \mu \mathrm{L}$ of sample or Trolox in the same phosphate buffer. Plates were incubated at 37 ${ }^{\circ} \mathrm{C}$ for $5 \mathrm{~min}$, and then $60 \mu \mathrm{L}$ of $40 \mathrm{mM}$ AAPH added to generate peroxyl radicals. Wells were excited at $485 \mathrm{~nm}$, and fluorescence emission at $538 \mathrm{~nm}$ was read at minute intervals over $1 \mathrm{~h}$ using an EnSpire 2300 multimode reader, with $5 \mathrm{~s}$ shaking between readings. The areas under fluorescence decay curves (AUC) of samples were calculated, from which the AUC of the antioxidant-free blank (75 mM phosphate buffer) was subtracted. ORAC values for samples were expressed as $\mu$ mol Trolox equivalents $\mathrm{g}^{-1}$ using regression equations between net AUC and Trolox concentration.

\subsection{ASCORBATE ASSAY}

Ascorbate concentration was measured using the ascorbate assay kit (700420) from Cayman Chemical Company (Ann Arbor, MI, USA). The samples were resuspended in methanol: $\mathrm{ddH}_{2} \mathrm{O}$ : diethylenetriaminepentaacetic acid DTPA (75: 22: 2.5, v/v/v) to obtain $0.05 \%(\mathrm{w} / \mathrm{v})$ dilution. The concentration of ascorbate was measured using serial dilutions of samples in black 96-well plates. Into each well were dispensed $50 \mu \mathrm{L}$ of DTPA, and 50 $\mu \mathrm{L}$ of sample or ascorbate standard. Then $100 \mu \mathrm{L}$ of reconstituted ascorbate substrate was 
added to all wells excluding sample background wells. Ascorbate assay buffer $100 \mu \mathrm{L}$ was added to sample background wells. The plates were incubated in darkness at $25{ }^{\circ} \mathrm{C}$ for $10 \mathrm{~min}$, and then $50 \mu \mathrm{L}$ of ascorbate developer to all the wells. The plates were incubated in darkness at $25{ }^{\circ} \mathrm{C}$ for $5 \mathrm{~min}$, and well contents were excited at $345 \mathrm{~nm}$, and fluorescence emission at $425 \mathrm{~nm}$ was read using an EnSpire 2300 multimode reader. Ascorbate concentrations of samples were expressed as ascorbate $\mathrm{mg} \mathrm{g}^{-1}$.

\subsection{HUMAN CELL CULTURES (HepG2 and Caco2)}

Human HepG2 cells were grown in DMEM growth medium supplemented with $10 \%$ heat inactivated FBS, $0.2 \mathrm{M}$ GlutaMAX and $0.1 \mathrm{mg} \mathrm{mL}^{-1}$ penicillin-streptomycin. Human Caco2 cells were grown in complete DMEM medium (containing high glucose supplemented with $10 \%$ heat inactivated FBS, $10 \mathrm{~mL} \mathrm{~L}^{-1}$ nonessential amino acids, 2 mmol L ${ }^{-1}$ L-glutamine, $0.5 \mathrm{mg} \mathrm{L}^{-1}$ amphotericin $\mathrm{B}, 50 \mathrm{mg} \mathrm{L}^{-1}$ gentamicin, $15 \mathrm{mmol} \mathrm{L}^{-1}$ HEPES and $\left.44 \mathrm{mmol} \mathrm{L}^{-1} \mathrm{NaHCO}\right)$.

Both HepG2 and Caco2 cell cultures were maintained in $75 \mathrm{~cm}^{2}$ flasks at $37{ }^{\circ} \mathrm{C}$ in a humidified atmosphere with $5 \% \mathrm{CO}_{2}$. Cells were routinely passaged every 2-3 d, upon reaching $90 \%$ confluency (when $90 \%$ of the growth surface of the flask is occupied by cells). The cells were passaged by removing media and incubating with trypsin for $15 \mathrm{~min}$ and adding fresh media. The HepG2 cells used for subsequent experiments were between passages 12 and 20 while Caco 2 cells were between passages 21 and 30 .

\subsection{CELLULAR ANTIOXIDANT ACTIVITY (CAA) ASSAY}

The CAA assay was performed according to Wolfe and Liu (2007). Human HepG2 and Caco 2 cells were seeded at $6 \times 10^{4}$ per well on a 96 well flat-bottom plate in $100 \mu \mathrm{L}$ of DMEM, and incubated at $37{ }^{\circ} \mathrm{C}$ for $24 \mathrm{~h}$. DMEM was removed, and the cells were washed with PBS. Samples, were (evaporated and) diluted with DMEM, and $50 \mu \mathrm{L}$ of 25 $\mathrm{mM}$ DCFH-DA was added to $50 \mu \mathrm{L}$ of the diluted extracts, to yield final concentrations of $1,3,10$ and $30 \mathrm{~g} \mathrm{~L}^{-1}$ of samples. Cells were treated for $1 \mathrm{~h}$ with samples or quercetin dihydrate standard (at 5, 10, 15 and $20 \mu \mathrm{M}$ final concentration) in DCFH-DA. A $100 \mu \mathrm{L}$ aliquot of $600 \mu \mathrm{M}$ ABAP in HBSS was applied to the cells after PBS wash. The emission fluorescence at $538 \mathrm{~nm}$ (following excitation at $485 \mathrm{~nm}$ ), was measured at $37{ }^{\circ} \mathrm{C}$ every 5 
min for $1 \mathrm{~h}$ using a Fluoroskan Ascent microplate fluorometer (Thermo Electron, Franklin, MA).

CAA values were calculated as the integral of fluorescence emission using the following equation:

CAA unit $=100-\left(\int \mathrm{SA} / \int \mathrm{CA}\right) \times 100$,

where $\int \mathrm{SA}$ and $\int \mathrm{CA}$ is the integrated area under the curve of fluorescence versus time for sample and control curves, respectively (Wolfe and Liu, 2007).

\subsection{ONLINE REVERSE PHASE HPLC-DPPH RADICAL SCAVENGING}

The HPLC method reported by Yin et al. was modified and used to separate and quantify phenolics in samples (Yin et al., 2008; Ou et al., 2013). We used an Agilent Technologies 1200 series HPLC system (Agilent Technologies, Palo Alto, CA) equipped with a quaternary pump and a diode array detector. Briefly, samples were injected at $4{ }^{\circ} \mathrm{C}$ into a reverse phase Alltima C18 column $(3 \mu \mathrm{m} 150 \times 2.1 \mathrm{~mm})$. Elution $\left(0.2 \mathrm{~mL} \mathrm{~min}^{-1}\right)$ was performed using a solvent system comprising 1\% formic acid (A) and 100\% acetonitrile (B) using a gradient starting with $95 \% \mathrm{~A}$, reducing to $85 \%$ at $15 \mathrm{~min} ; 76 \%$ at $27 \mathrm{~min}$, $70 \%$ at $40 \mathrm{~min}, 20 \%$ from 41 to $45 \mathrm{~min}$ and $95 \%$ from 46 to $55 \mathrm{~min}$. The absorption spectra at $320 \mathrm{~nm}$ were recorded. The HPLC-separated analytes were reacted postcolumn, with the DPPH reagent $(250 \mu \mathrm{M})$ dissolved in $100 \%$ acetonitrile: $0.1 \mathrm{M}$ sodium citrate buffer $(50: 50, \mathrm{v} / \mathrm{v})$ at $\mathrm{pH} 7.6$ and pumped at $0.2 \mathrm{~mL} \mathrm{~min}^{-1}$. The induced bleaching was detected photometrically as a negative peak at $518 \mathrm{~nm}$. Identification of main peaks in samples were confirmed by co-eluting with authentic compounds. 
CHAPTER 3: EFFECTS OF AGE, ECOTYPE, CHILLING AND SALINITY ON EXTRACTABLE ANTIOXIDANT ACTIVITIES OF Sonchus oleraceus $\mathbf{L}$.

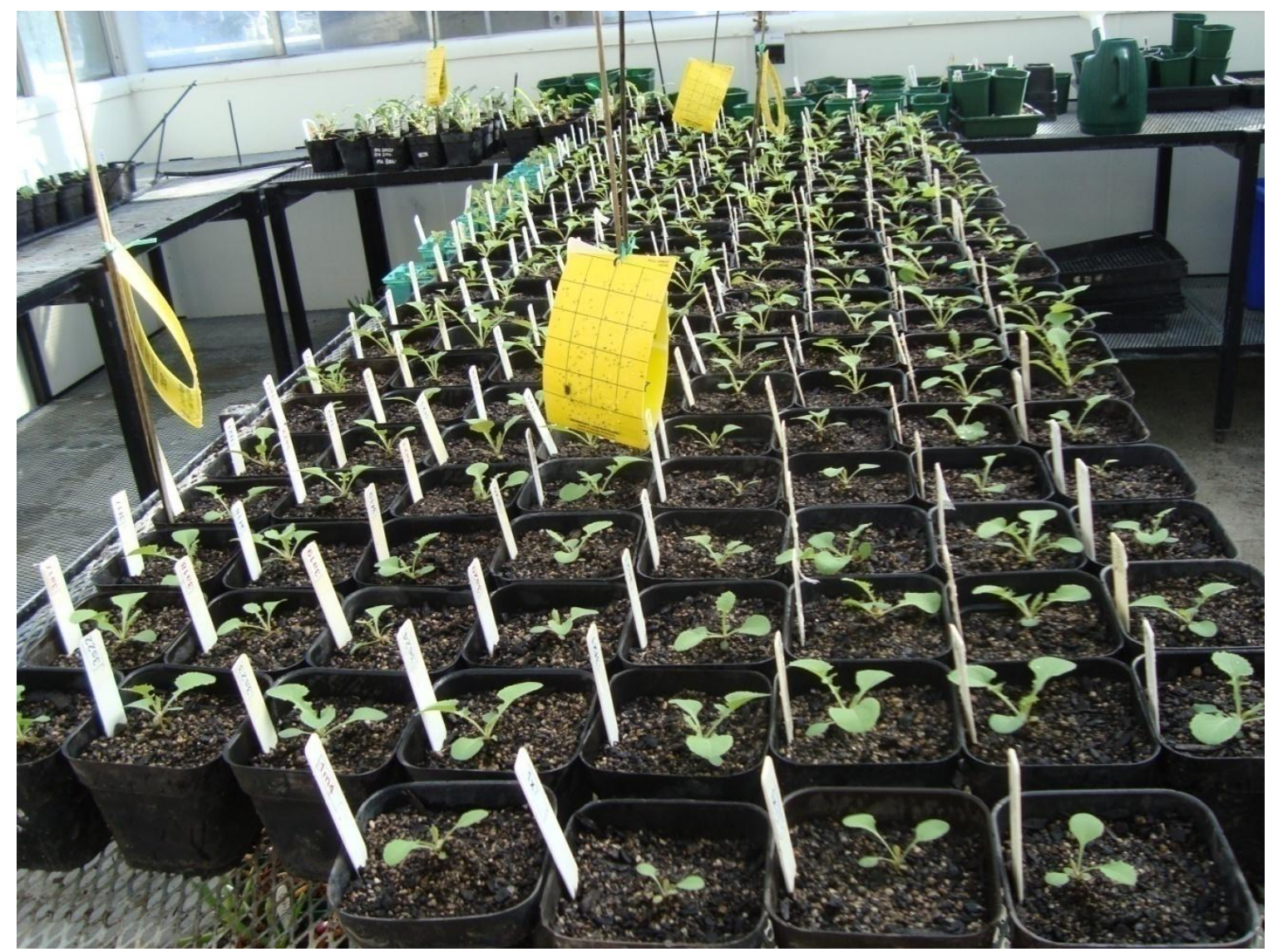

Plate 3.1 Four week old Sonchus oleraceus L. plants growing in Victoria University of Wellington glasshouse. 


\subsection{ABSTRACT}

Leaves of Sonchus oleraceus L., a traditional component of the Māori diet in New Zealand, are rich in phenolics and show high antioxidant potential in vitro. Extractable antioxidant activities show considerable variation among plants, which may be due to variation in their growing environments and/or genotype, but the precise reasons for this variation are unknown. To study possible environmental effects on antioxidant activity, two ecotypes from Acacia Bay (ACB) and Oamaru (OAM) in New Zealand were exposed to chilling, salinity and their combination for two weeks commencing 8, 10 and 12 weeks after germination. Chlorophyll fluorescence parameters, extractable and cellular antioxidant activities, ascorbate and total phenolic contents were measured, and HPLC profiles obtained for methanolic extracts of leaves. None of the treatments significantly diminished the maximum quantum efficiency of photosystem II but rapid light response curves for chlorophyll fluorescence indicated acclimation to stressors after two weeks. Antioxidant activities and total phenolic content were higher in older plants compared to younger plants in both ecotypes, irrespective of the treatment. The ACB ecotype had a higher phenolic concentration and antioxidant activities compared to OAM, and these levels were maintained from F1 to F2 generation. Chlorogenic acid was enhanced in youngest plants by exposing plants to chilling, salinity and their combination. The cellular antioxidant activities in HepG2 cells correlated linearly with stressor-induced extractable antioxidant activities and LMWAs concentrations from the youngest plants. My data indicate that the imposition of stressors on already potent ecotypes can augment the extractable antioxidant potential in S. oleraceus. Further, these stressor-induced changes were transferable to human cells in vitro.

KEYWORDS: Sonchus oleraceus, antioxidant, phenolics, chilling, salinity 


\subsection{INTRODUCTION}

Māori have long used the smooth sow thistle, Sonchus oleraceus L., both as a leafy vegetable and for medicinal purposes (Section 1.7). The leaves of S. oleraceus are rich in phenolic compounds and thus exceptionally high in extractable antioxidant activities (Section 1.8.3). S. oleraceus shoots showed variation in DPPH radical scavenging activities among plants collected from different locations in New Zealand (Section 1.8.4; Ellwood, 2007). In addition to genotypic variation, some of the variability in LMWA activity is likely attributable to differences in development stage, growth environment and the degree to which plants are subjected to abiotic stressors. However, the exact causes of this variation are unknown.

In other plant species, age-related increases in phenolic compounds and antioxidant activities are associated with increasing capacities of mature plants to invest resources in secondary metabolic processes, whereas in young plants, limited resources are demanded for primary metabolic processes required for growth (Fritz et al., 2001; Barton, 2007). For example, the concentration of phenolics and antioxidant activities increased with age in species such as Brassica oleracea, Cosmos caudatus and Lactuca sativa (Vallejo et al., 2003a; Oh et al., 2011; Mediani et al., 2012).

Intraspecific differences in extractable LMWA activities and phenolic concentration may be attributable to differences in concentration and activity of enzymes involved in the phenylpropanoid pathway. Differences in phenolic concentration and antioxidant activity among cultivars have been reported for species, such as Fragaria ananassa, Rosa sp., Solanum tuberosum, Rubus idaeus, Vaccinium corymbosum and Solanum esculentum (Ehlenfeldt and Prior, 2001; Vinokur et al., 2006; Reddivari et al., 2007; Tulipani et al., 2008; Løvdal et al., 2010; Krüger et al., 2011).

There are numerous examples in which a single abiotic stressor (Section 1.9) was used to elevate phenolic levels and antioxidant activities in vegetative shoots of different species (Smirnoff, 1993; Bartoli et al., 1999; Munné-Bosch et al., 1999; Munné-Bosch and Alegre, 2000; Zhang and Schmidt, 2000; Munné-Bosch and Alegre, 2002; Kirakosyan et al., 2003; Munné-Bosch and Peñuelas, 2004; Šircelj et al., 2005). However, far fewer 
studies have examined the effects of combinations of these stressors on antioxidant levels (Figure 3.1; Mittler, 2006).

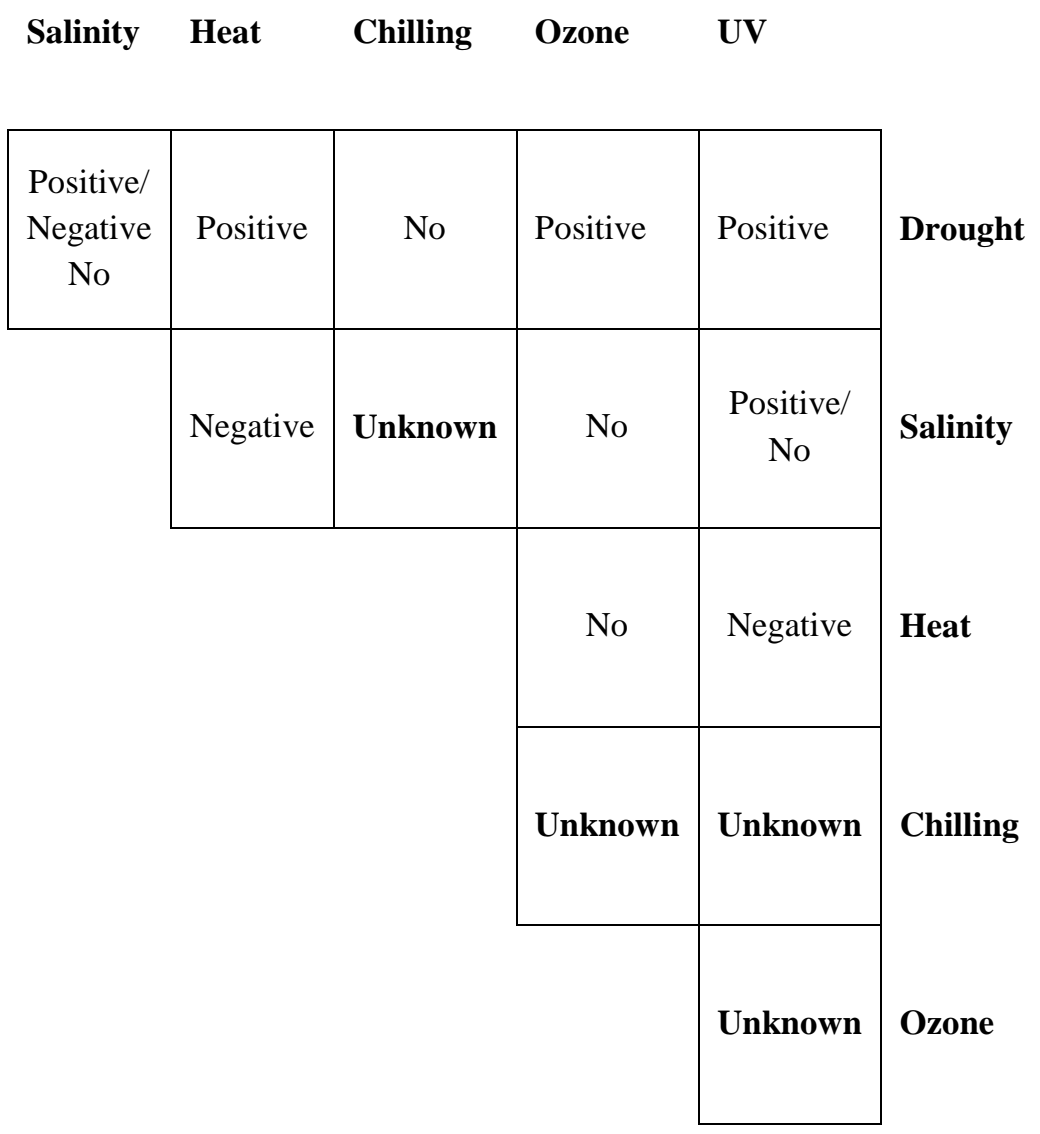

No : no change by the combination compared to single stressor

Negative : negative interaction (decrease owing to the combination compared to single stressor)

Positive : positive interaction (increase owing to the combination compared to single stressor)

Unknown : effect of stressor combination unknown

Figure 3.1 Effects of two combined abiotic stressors on extractable antioxidant activities of plants Sources: Pääkkönen et al. (1998); Aroca et al. (2003); Koti et al. (2007); Maggio et al. (2007); Shen et al. (2010); Silva et al. (2010); Hartikainen et al. (2012); Ahmed et al. (2013a); Ahmed et al., (2013b)

Plant responses to a combination of stressors may be complex, not simply the sum of effects of individual stressors. In laboratory experiments and field conditions involving different species, stressor combinations have been found to yield additive, antagonistic, synergistic effects on plant physiological, phytochemical or yield responses, and cannot be predicted through plants responses to the individual stressor. Additive effects are defined as when the two stressors together cause a response equal to the effects caused by 
two stressors individually (i.e. simple addition of each individual response), therefore can be either positive or negative (Figure 3.2). Synergistic interaction occurs when two stressors together produce an effect greater than the sum of their individual effects (Figure 3.3A). Antagonistic interaction occurs when two stressors together produce an effect lower than the sum of their individual effects (Figure 3.3B). Additionally, the potential effects of stressor combination could also vary depending on the relative level of each of the different stressors combined (Mittler, 2006).

A0: without stressor A

B0: without stressor B

A1: with stressor A

B1: with stressor B
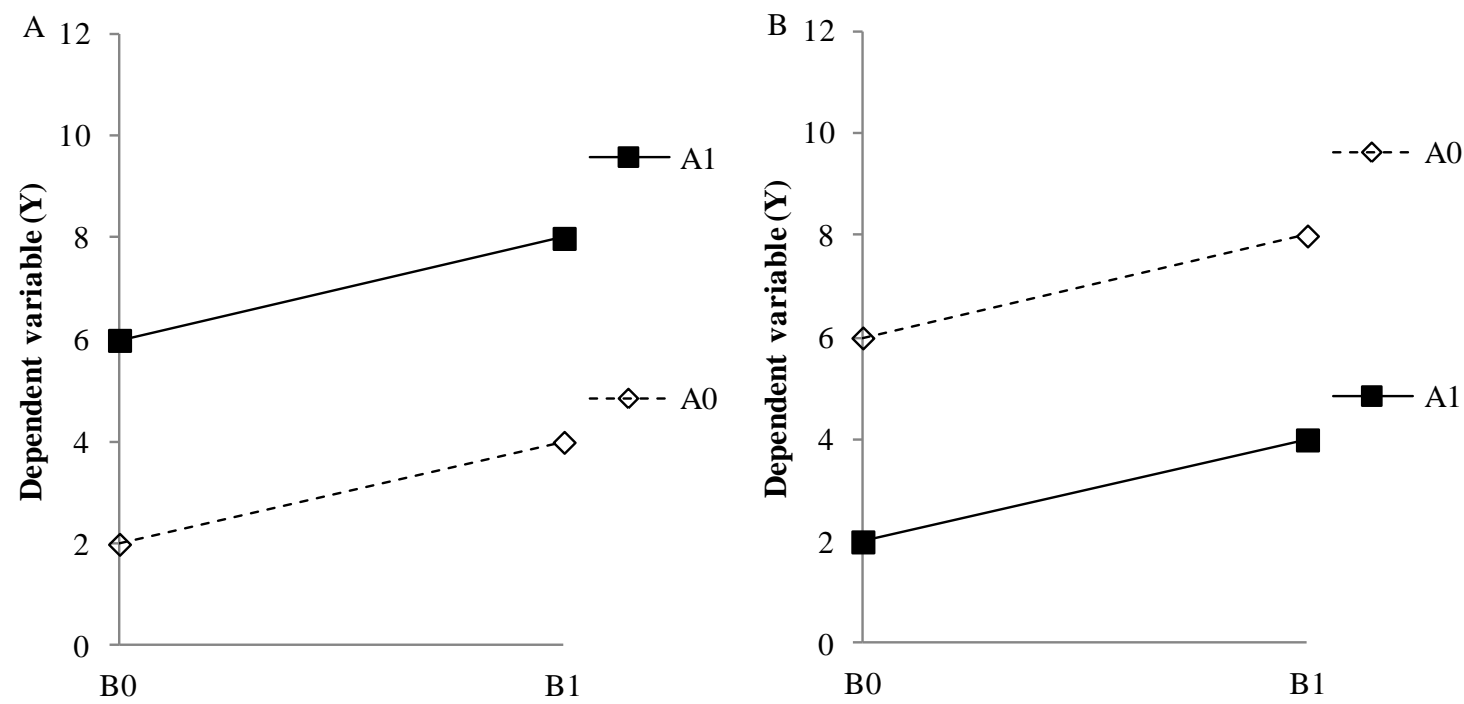

Figure 3.2 ANOVA interaction plots for additive effect of two stressors (A1 and B1) together produce an effect equal to the sum of their individual stressor effects on the dependent variable (Y), which could be either (A) positive or (B) negative.

Source: Dunne (2010) 
A0: without stressor A

B0: without stressor B

A1: with stressor A

B1: with stressor B
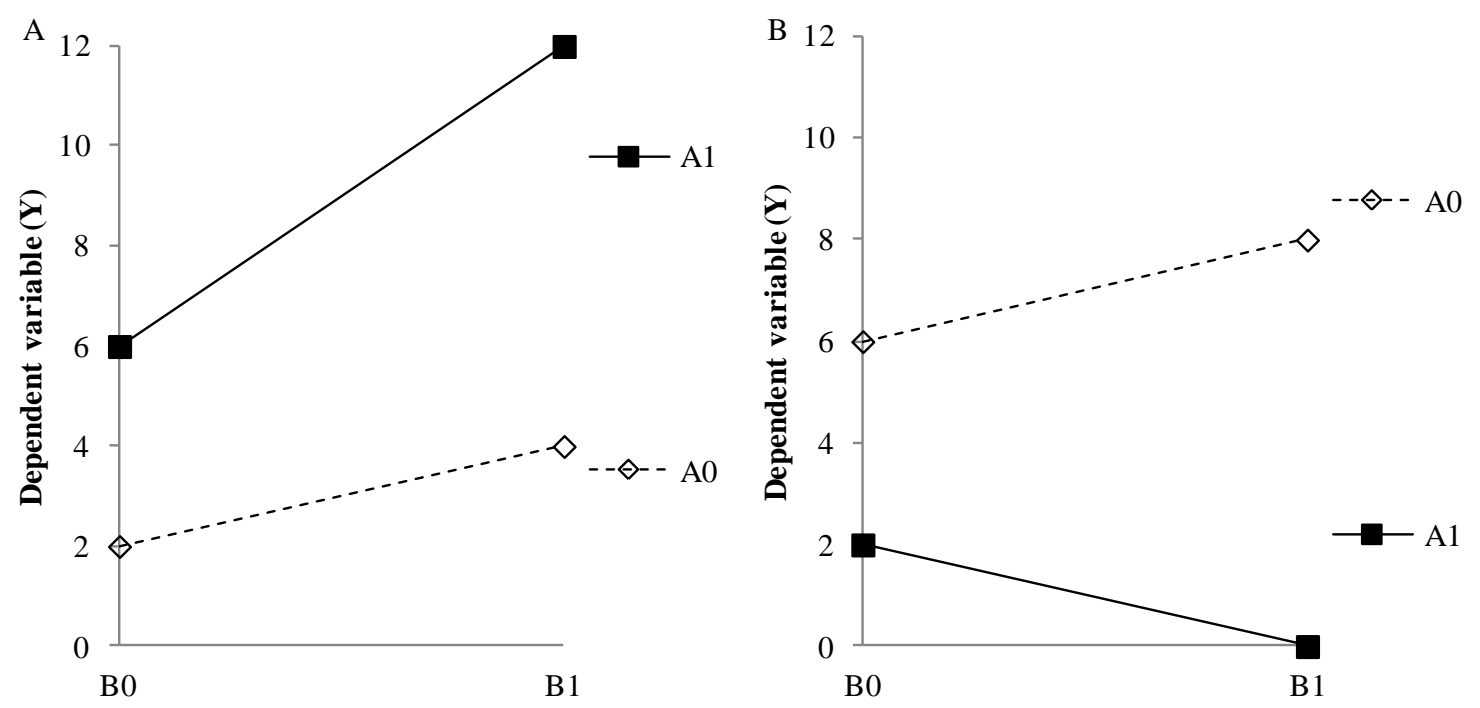

Figure 3.3 ANOVA interaction plots when two stressors (A1 and B1) together produce either (A) synergistic or (B) antagonistic on the dependent variable (Y).

Source: Dunne (2010)

Assays for extractable antioxidant activities alone are not themselves sufficient for us to conclude that those plants that possess the highest antioxidant levels would provide the greatest protection against effects of ROS in the cells of the consumer (Section 1.6). Nevertheless, associations between chemical measures of leaf antioxidant activities and CAA of S. oleraceus have not yet been studied. It is not known whether variation in the phenolic content and recorded antioxidant capacity in leaf extracts is accurately reflected in terms of the cellular antioxidant boost supplied to living human cells.

It was hypothesized that extractable LMWA activities of S. oleraceus leaves vary depending on age of a plant, its original locality, and the imposition of abiotic stressors; and stressor-induced variations correlates with cellular antioxidant activities in cultured human cells. Using ecotypes of $S$. oleraceus already known to possess potent LMWA activities, I describe here the effects of applying chilling and salinity treatments, both alone and in combination, on the levels of phenolic compounds in the leaves. In preliminary trials (Appendix A.1-A.2), these two stressors were shown to have the greatest potential for manipulating phenolic compound concentration. 


\subsection{MATERIALS AND METHODS}

\subsubsection{Plant materials and treatments}

Two ecotypes of Sonchus oleraceus were grown from seeds obtained from selfed F1 generation plants, which were themselves raised from seeds collected from wild populations at Acacia Bay and Oamaru in New Zealand (hereafter the ecotypes are abbreviated as ACB and OAM, respectively). These two ecotypes were selected due to their difference original growing environments (Table 3.1) and in antioxidant activities, where ACB was 1.6 times more efficient in scavenging DPPH radicals than OAM (Ellwood, 2007). OAM originated from a colder region than ACB (Table 3.1).

Table 3.1 Comparison of the regions from which the two ecotypes of Sonchus oleraceus L. were collected

\begin{tabular}{lcc}
\hline & \multicolumn{2}{c}{ Ecotypes } \\
\cline { 2 - 3 } & ACB & OAM \\
\hline Location & Acacia Bay & Oamaru \\
& Central North Island & Coastal South Island \\
\hline Coordinates & $\mathrm{S} 38^{\circ} 42^{\prime}$, E $176^{\circ} 02^{\prime}$ & S $45^{\circ} 05^{\prime}$, E $170^{\circ} 58^{\prime}$ \\
\hline Temperature $\left({ }^{\mathbf{0}} \mathbf{C}\right)^{1}$ & $12.4 \pm 0.1$ & $9.4 \pm 0.1$ \\
\hline Humidity $(\%)^{\mathbf{1}}$ & $82.7 \pm 0.2$ & $78.4 \pm 0.3$
\end{tabular}

Source: NIWA (2012)

${ }^{1}$ Annual average for measurements at $3 \mathrm{~h}$ interval

The plants were grown in individual pots $(12 \times 12 \times 15 \mathrm{~cm})$ containing a 1:1 mixture of potting mix: sand inside an unheated glasshouse under natural light at Victoria University of Wellington campus during January to March 2011 (summer). Two ecotypes and four treatments (stressors) were combined to give eight treatments for which each had eight replicates. Treatments were imposed for $14 \mathrm{~d}$ on 8,10 and 12 week old plants to test the effect of plant age on the responsiveness to abiotic stressors. Control plants were watered with tap water at $150 \mathrm{~mL} \mathrm{day}^{-1}$. For the chilling treatment, plants were repeatedly held at $5{ }^{\circ} \mathrm{C}$ for $12 \mathrm{~h}$ overnight and returned to the glasshouse during the day. Salinity was imposed by irrigating with $150 \mathrm{~mL} \mathrm{day}^{-1}$ of $50 \mathrm{mM} \mathrm{NaCl}$. The fourth group of plants was given both the chilling and salinity treatments. 
The fully expanded youngest leaves from nodes 5 and 6 on each plant were selected on weeks 10, 12 and 14, for chlorophyll fluorescence measurements and then harvested for subsequent phytochemical analysis.

\subsubsection{Chlorophyll fluorescence measurements}

The maximum photosynthetic efficiency of PS II was measured in leaves dark-adapted for 8 h using a PAM 2500 chlorophyll fluorometer (Heinz Walz GmbH, 2008, Germany). The minimum level of fluorescence $\left(\mathrm{F}_{\mathrm{o}}\right)$ was determined under low measuring-light irradiance $\left(<0.05 \mu \mathrm{mol} \mathrm{m} \mathrm{s}^{-2}\right)$, and then $\mathrm{F}_{\mathrm{m}}$ (maximum fluorescence) determined using a saturating pulse $\left(12,000 \mu \mathrm{mol} \mathrm{m} \mathrm{m}^{-2} \mathrm{~s}^{-1}\right.$ for $\left.0.8 \mathrm{~s}\right)$. From those parameters, values of $\mathrm{F}_{\mathrm{v}} / \mathrm{F}_{\mathrm{m}}$ (the maximum quantum efficiency of PSII in the dark-adapted state) were approximated, where variable fluorescence $\left(\mathrm{F}_{\mathrm{v}}\right)$ was calculated as $\mathrm{F}_{\mathrm{m}}-\mathrm{F}_{\mathrm{o}}$ (Table 3.2).

To obtain rapid light response curves, the leaves were irradiated with white actinic light supplied by the fluorometer. Steady state fluorescence $\left(\mathrm{F}^{\prime}{ }_{\mathrm{o}}\right)$ was measured under a light ramp comprising 11 intensities from 0 to $3000 \mu \mathrm{mol} \mathrm{m} \mathrm{m}^{-2}$ at $30 \mathrm{~s}$ interval. The maximum fluorescence $\left(\mathrm{F}_{\mathrm{m}}^{\prime}\right)$ was recorded using saturating light pulses superimposed on the actinic light (Table 3.2). Accordingly, $\Delta \mathrm{F} / \mathrm{F}_{\mathrm{m}}^{\prime}$ (effective quantum yield) was obtained where $\Delta \mathrm{F}$ (variable fluorescence) was calculated as $\mathrm{F}_{\mathrm{m}}^{\prime}-\mathrm{F}_{\mathrm{o}}^{\prime}$ (Table 3.2). Non photochemical quenching (NPQ) was calculated as $\left(\mathrm{F}_{\mathrm{m}}-\mathrm{F}_{\mathrm{m}}^{\prime}\right) / \mathrm{F}_{\mathrm{m}}^{\prime}$, where $\mathrm{F}_{\mathrm{m}}$ is the maximum fluorescence measured during light curve. $\mathrm{q}_{\mathrm{P}}$ (photochemical quenching) was calculated as $\left(\mathrm{F}_{\mathrm{m}}^{\prime}-\mathrm{F}_{\mathrm{t}}\right) /\left(\mathrm{F}_{\mathrm{m}}{ }_{\mathrm{m}}-\mathrm{F}_{\mathrm{o}}{ }_{\mathrm{o}}\right)$, where $\mathrm{F}_{\mathrm{t}}$ defined as steady state yield of fluorescence in the light (Table 3.2 - 3.3). Apparent rate of photosynthetic electron transport of photosystem II (ETR) was calculated as $\Delta \mathrm{F}_{\mathrm{v}} / \mathrm{F}_{\mathrm{m}}^{\prime} \times 0.5 \times 0.84 \times \mathrm{PAR}$, (where PAR is photosynthetically active radiation, $400-700 \mathrm{~nm}$; 0.84 is the ETR factor, the fraction of absorbed PAR by green leaves and 0.5 is the fraction of quanta distributed to PS II). 
Table 3.2 Definitions of fluorescence intensity parameters

\begin{tabular}{lll}
\hline Symbol & Fluorescence intensity & Definition \\
& parameter & \\
\hline $\mathrm{F}_{\mathrm{o}}$ & Minimum fluorescence & Fluorescence intensity with all PS II reaction centres open while \\
& (dark adapted leaf) & the photosynthetic membrane is in the non-energized state. \\
\hline $\mathrm{F}_{\mathrm{m}}$ & Maximum fluorescence & Fluorescence intensity with all PSII reaction centres closed all \\
& (dark adapted leaf) & nonphotochemical quenching processes are at a minimum. \\
\hline $\mathrm{F}_{\mathrm{v}}$ & Variable fluorescence & Maximum variable fluorescence in the state when all non- \\
& (dark adapted leaf) & photochemical processes are at a minimum, calculated as ( $\left.\mathrm{F}_{\mathrm{m}}-\mathrm{F}_{\mathrm{o}}\right)$. \\
\hline $\mathrm{F}^{\prime}{ }_{\mathrm{o}}$ & Minimum fluorescence & Fluorescence intensity with PS II reaction centres open in any \\
& (light adapted leaf) & light adapted state. \\
\hline $\mathrm{F}^{\prime}{ }_{\mathrm{m}}$ & Maximum fluorescence & Maximum fluorescence intensity with saturating pulse in any light \\
& (light adapted leaf) & adapted state. \\
\hline $\mathrm{F}_{\mathrm{t}}$ & Steady state fluorescence & Fluorescence immediately before a saturating pulse. \\
& (light adapted leaf) & \\
\hline$\Delta \mathrm{F}$ & Variable fluorescence & Maximum variable fluorescence in any light adapted state, \\
& (light adapted leaf) & calculated as ( $\mathrm{F}_{\mathrm{m}}^{\prime}-\mathrm{F}_{\mathrm{o}}^{\prime}$ ).
\end{tabular}

Source: Maxwell and Johnson (2000)

Table 3.3 Definitions of fluorescence quenching parameters

\begin{tabular}{lll}
\hline $\begin{array}{l}\text { Fluorescence quenching } \\
\text { parameters }\end{array}$ & Definition & Calculation \\
\hline $\begin{array}{l}\text { Maximum quantum efficiency } \\
\text { (dark adapted leaf) }\end{array}$ & $\begin{array}{l}\text { The maximum potential quantum efficiency of PSII in } \\
\text { the dark adapted state. }\end{array}$ & $\mathrm{F}_{\mathrm{v}} / \mathrm{F}_{\mathrm{m}}$ \\
\hline $\begin{array}{l}\text { Effective quantum efficiency } \\
\text { (light adapted leaf) }\end{array}$ & The proportion of the light absorbed by the chlorophyll & $\Delta \mathrm{F} / \mathrm{F}_{\mathrm{m}}^{\prime}$ \\
\hline NPQ & associated with PSII that is used in photochemistry. & \\
(Non photochemical quenching) & Quantum yield of regulated non-photochemical energy & $\left(\mathrm{F}_{\mathrm{m}}-\mathrm{F}_{\mathrm{m}}^{\prime}\right) /$ \\
\hline loss in PS II as heat. & $\mathrm{F}_{\mathrm{m}}^{\prime}$ \\
\hline (Photochemical quenching) & The proportion of the PSII reaction centers that are open. & $\left(\mathrm{F}_{\mathrm{m}}^{\prime}-\mathrm{F}_{\mathrm{t}}\right) /$ \\
\hline
\end{tabular}

Source: Genty et al. (1989)

The curve fit option in the PamWin-3 software, which has been derived by Eilers and Peeters' mechanistic model (Eilers and Peeters, 1988) was used to obtain three parameters from the ETR versus PAR curves:(i) efficiency of light capture in the light limiting region indicated by the initial slope of the curve $(\alpha)$; (ii) maximum 
photosynthetic capacity indicated by the plateau in ETR at light saturation $\left(\mathrm{ETR}_{\max }\right)$; and (iii) light saturation coefficient of the curve $\left(l_{k}\right)$.

\subsubsection{Phytochemical extraction}

Leaves were removed and bisected longitudinally, one half to be used for phytochemical analysis and the other to determine dry matter percentage (all results presented on dry weight basis). The remainder of the plant was separated into shoot and root systems and oven dried at $70{ }^{\circ} \mathrm{C}$ for $12 \mathrm{~h}$ to obtain dry biomass.

Material intended for phytochemical analysis was snap frozen in liquid nitrogen, ground to a fine powder, and dissolved in methanol: $\mathrm{ddH}_{2} \mathrm{O}$ : acetic acid $(70: 23: 7, \mathrm{v} / \mathrm{v} / \mathrm{v})$ to obtain a $10 \%(\mathrm{w} / \mathrm{v})$ slurry. Aliquots were centrifuged at $24000 \mathrm{~g}$ for $5 \mathrm{~min}$, and supernatants stored under nitrogen at $-20{ }^{\circ} \mathrm{C}$. Phytochemical analyses were performed within $7 \mathrm{~d}$ of extraction.

The chemicals used are listed in Section 2.1. The analysis of total phenolic content, 2,2diphenyl-1-picrylhydrazyl (DPPH) radical scavenging activities, oxygen radical absorbance capacity (ORAC) assay, Cellular Antioxidant Activity (CAA) assay, ascorbate content and online reverse phase HPLC-DPPH radical scavenging were performed as described in Sections 2.2-2.8.

\subsection{STATISTICAL ANALYSIS}

A three-way analysis of variance (ANOVA) with Tukey's post hoc test was performed to identify effects of age, ecotype and abiotic stressors. Mixed repeated measures ANOVA was performed on light response curve data and Bonferroni post hoc tests. Probit analysis was performed for CAA dose-response data. Correlation analysis was performed between CAA and extractable antioxidant activities, total phenolic content, ascorbate content and hydroxycinnamic acid concentrations. Significances were defined at $P<0.05$. All analyses were performed using SPSS 18.0 statistical software. 


\subsection{RESULTS}

\subsubsection{Hydroxycinnamic acids in S. oleraceus leaf extracts detected by HPLC}

HPLC profiles revealed that caftaric, chicoric and chlorogenic acids were the most abundant antioxidants in methanolic leaf extracts of $S$. oleraceus (Table 3.4). These hydroxycinnamic acids collectively accounted for $84-93 \%$ of the phenolic compounds detected by HPLC-DPPH chromatograms (Table 3.4).

Table 3.4 Retention times (RT) of phenolic compounds detected by HPLC at $320 \mathrm{~nm}$ and their content as a percentage of total peak area

\begin{tabular}{clcc}
\hline Peak & Compound & RT (min) & \% total $^{\mathbf{1}}$ \\
\hline 1 & Caftaric acid & $11.4 \pm 0.1$ & $10.7 \pm 1.3$ \\
\hline 2 & Chlorogenic acid & $14.4 \pm 0.1$ & $18.3 \pm 1.6$ \\
\hline 3 & Unknown & $14.9 \pm 0.1$ & $0.5 \pm 0.1$ \\
\hline 4 & Unknown & $18.3 \pm 1.3$ & $0.9 \pm 0.2$ \\
\hline 5 & Unknown & $26.5 \pm 0.1$ & $0.2 \pm 0.1$ \\
\hline 6 & Chicoric acid & $27.1 \pm 0.1$ & $59.7 \pm 1.5$ \\
\hline 7 & Unknown & $28.4 \pm 0.1$ & $3.5 \pm 0.2$ \\
\hline 8 & Unknown & $29.1 \pm 0.1$ & $1.9 \pm 0.4$ \\
\hline 9 & Unknown & $31.0 \pm 0.3$ & $4.3 \pm 0.6$
\end{tabular}

${ }^{1}$ Retention time (mean $\left.\pm \mathrm{SE}, n=192\right)$

${ }^{2}$ Means \pm SE, $n=192$

\subsubsection{Effect of age on extractable antioxidant activities, concentrations of total phenolic compounds and hydroxycinnamic acids}

Of the three factors studied (age, ecotype and stressor), plant age had the largest effect on extractable antioxidant activities; a three-fold increase was seen at week 12 compared to week 10 as measured by both ORAC and DPPH assays $(P<0.001$; Figure 3.4A,B). Plant age had the largest effect on total phenolic content; two-fold higher at week 12 compared to week $10(P<0.001$; Figure 3.4C). These increases occurred irrespective of ecotype and across all treatments (Figure 3.4A-C). 
The extractable concentrations of caftaric, chicoric and chlorogenic acids were 50\% higher at week 12 compared to week 10 in both ecotypes irrespective of the stressor applied $(P<0.001$; Figures 3.4D-F).

\subsubsection{Effect of ecotype on extractable antioxidant activities, concentrations of total phenolic compounds and hydroxycinnamic acids}

Differences between ecotypes were the next largest effect on ORAC activity and content of total phenolics and hydroxycinnamic acids in S. oleraceus leaves (Figure 3.4). For flowering individuals, the ORAC activities were between 40 and 50\% higher in ACB than in OAM $(P=0.01$; Figure 3.4A). Similarly, DPPH radical scavenging activities of ACB were 1.2-fold higher than those of OAM $(P=0.06$; Figure 3.4B). Total phenolic contents were between $20 \%$ and $30 \%$ higher in ACB than OAM in older plants $(P<0.001$; Figure 3.4C). In youngest plants, $\mathrm{ACB}$ and $\mathrm{OAM}$ were similar in antioxidant activities and total phenolic content (Figure 3.4A-C). ACB leaves contained $20-40 \%$ more caftaric, chicoric and chlorogenic acids than OAM leaves specially when the plants were young $(P$ $<0.001$; Figure 3.4D-F). 


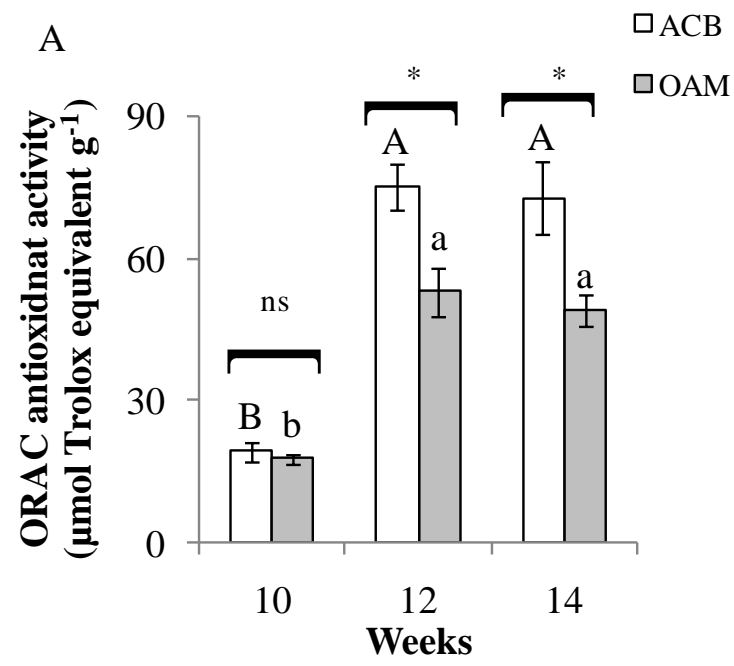

$\mathrm{D} \quad \square \mathrm{ACB}$
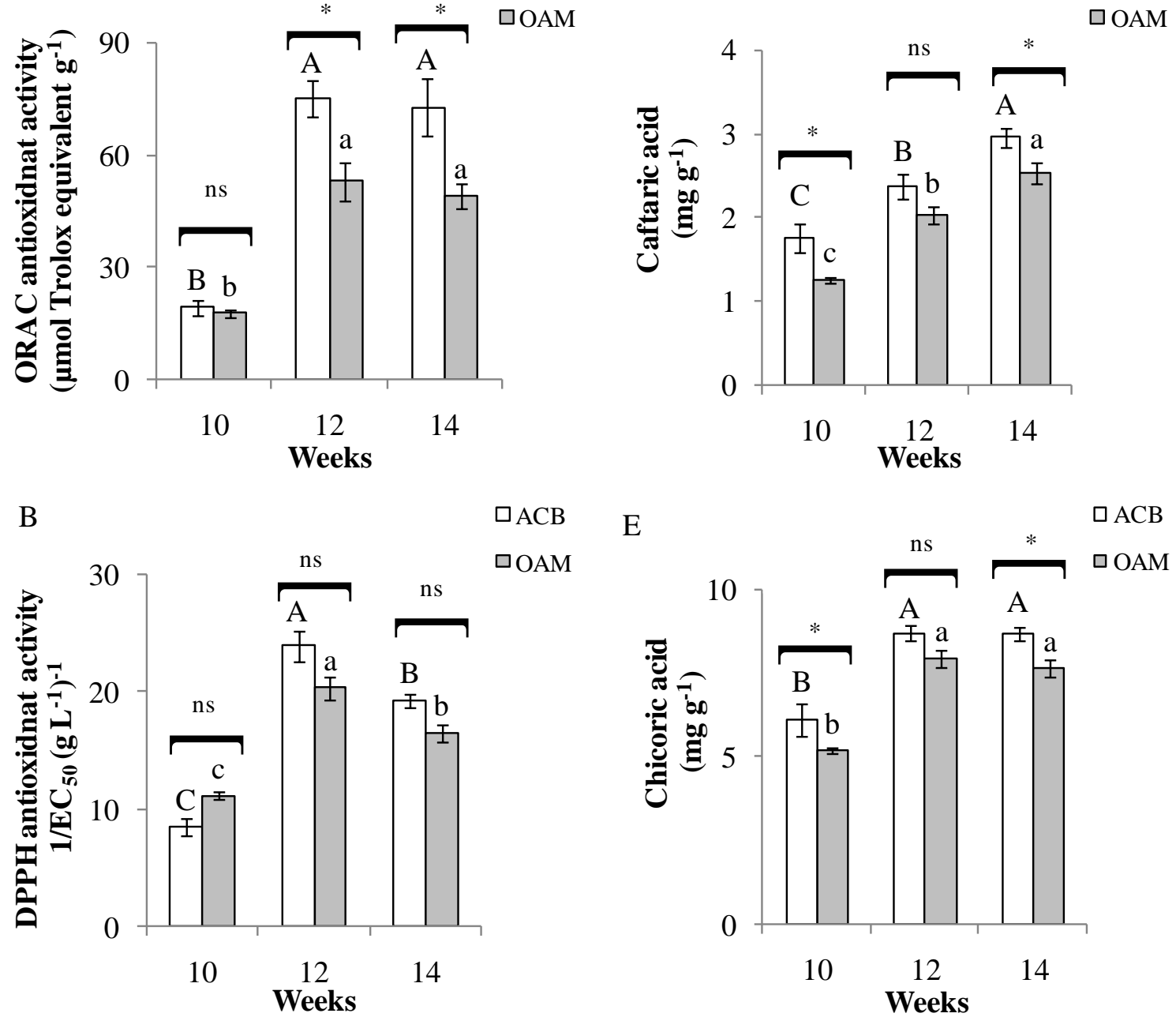

$\mathrm{E}$
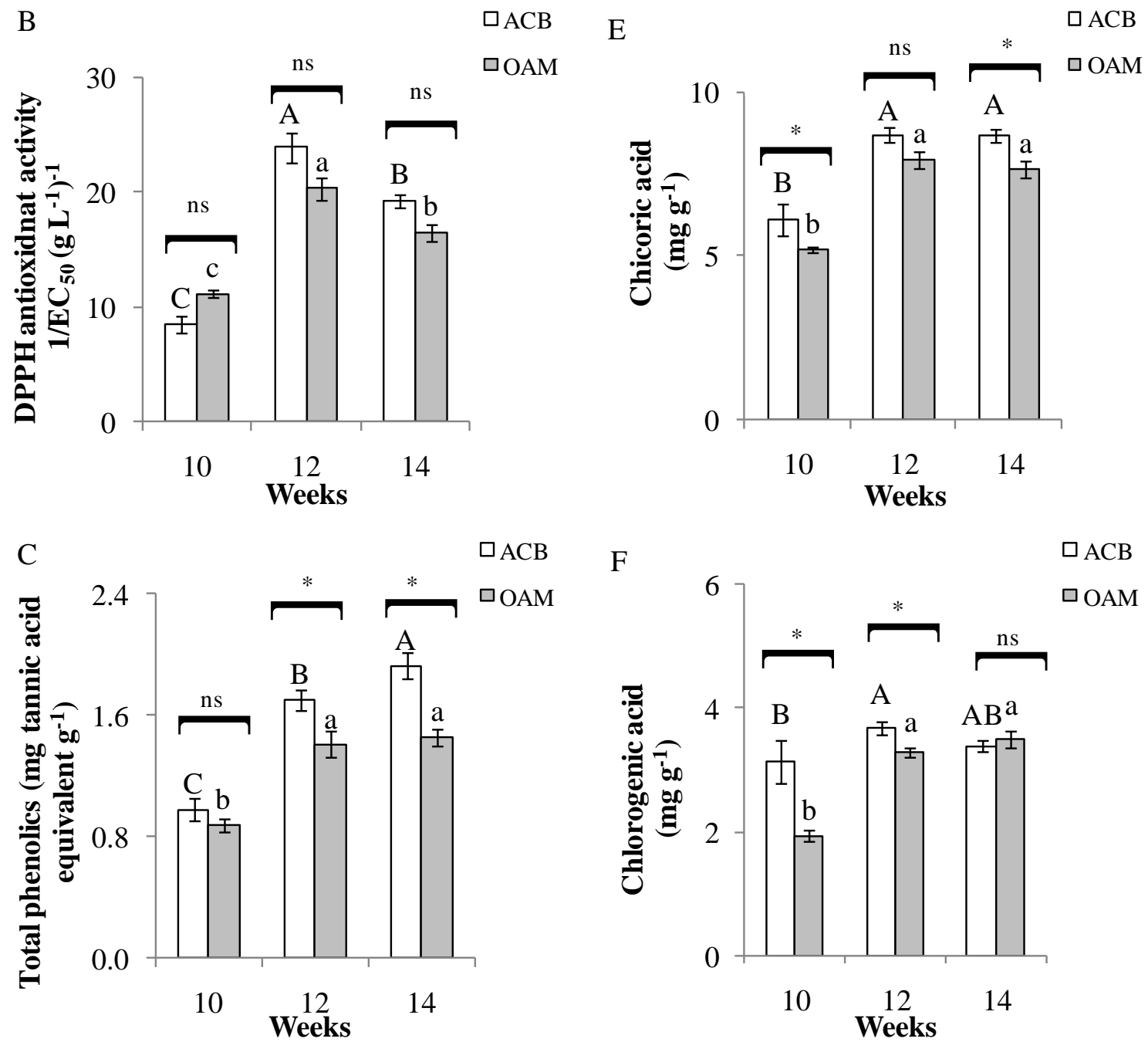

Figure 3.4 Effects of age and ecotype on (A) ORAC activity, (B) DPPH radical scavenging, concentrations of (C) total phenolics, (D) caftaric, (E) chicoric and (F) chlorogenic acids in methanolic extracts of leaves of ACB and OAM ecotypes of Sonchus oleraceus L. Means \pm SE $(n=$ 32). Bars with different letters of the same case indicate significant differences among plant ages within an ecotype $(P<0.05)$. *Significant difference between ecotypes $(P<0.05)$. ns: Ecotypes not significantly different $(P>0.05)$. 
The plants were vegetative at week 10, but were flowering in weeks 12 and 14 (Plate 3.2 A-C).
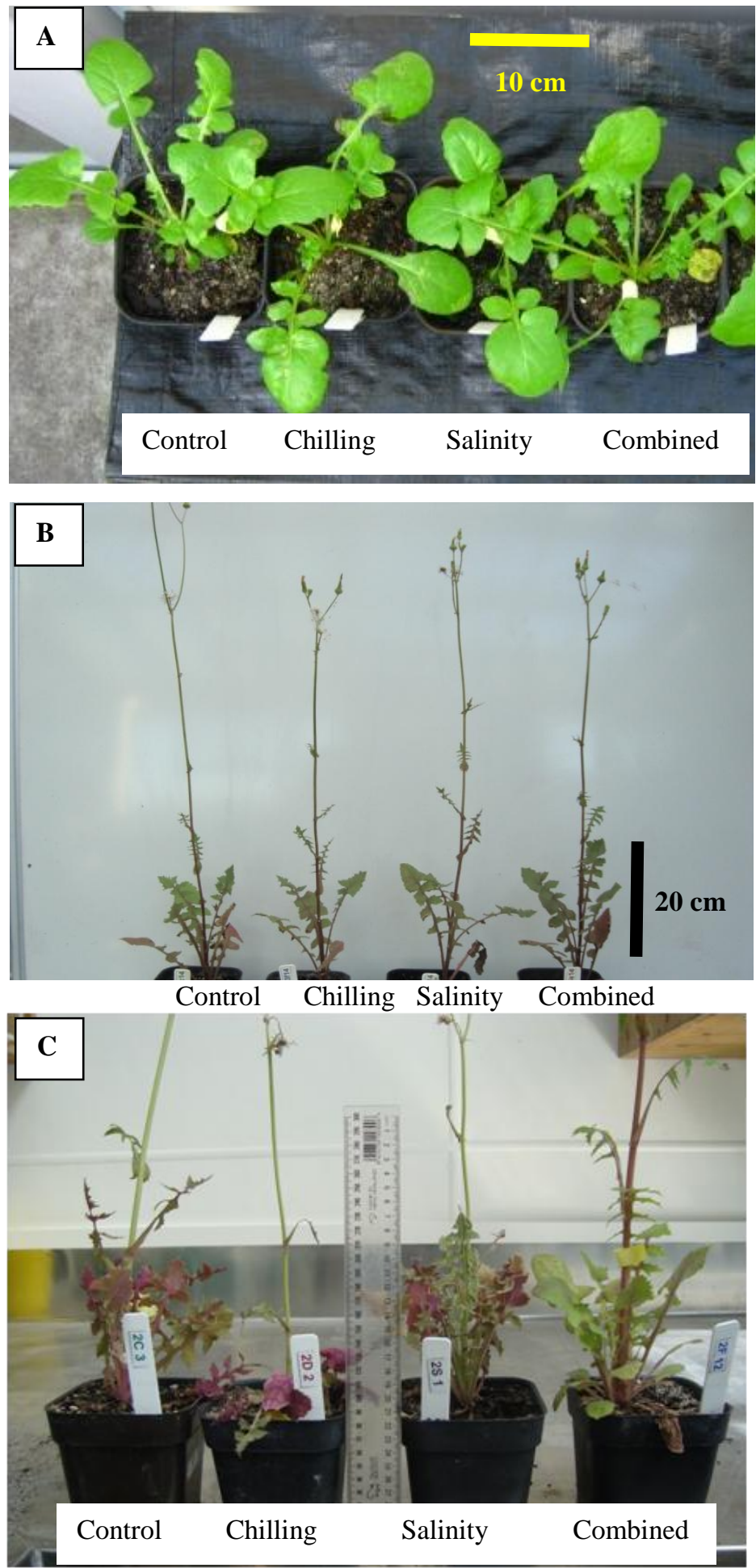

Plate 3.2 Shoot morphology of Sonchus oleraceus L. at week (A) 10, (B) 12 and (C) 14, following two weeks of chilling, salinity and the combination of the two. Representative plants for each treatment are shown. 


\subsubsection{Effects of stressors on extractable antioxidant activities, concentrations of total phenolic compounds and hydroxycinnamic acids}

ORAC activities were not influenced by any of the stressor treatments $(P=0.72$; Figure 3.5A) but DPPH radical scavenging activities were $(P<0.05$; Figure 3.5B). Plants treated with chilling and salinity alone did not differ from the control plants in DPPH radical scavenging. However, when chilling and salinity were applied in combination to flowering plants, the DPPH radicals were scavenged $20 \%$ less efficiently compared to the control in both ecotypes (Figure 3.5B).

Concentrations of total phenolics were not affected by chilling and salinity alone compared to the control, across ecotypes and plant ages $(P=0.01$; Figure $3.5 \mathrm{C})$. However when chilling and salinity were applied in combination to older plants, the concentration of total phenolics was enhanced compared to the control in both ecotypes (Figure 3.5C).

Concentrations of caftaric $(P=0.92)$ and chicoric acids $(P=0.47)$ were not influenced by any of the treatments (Figure 3.6A,B). Stressors significantly increased chlorogenic acid concentration $(P<0.001$; Figure 3.6C). Salinity and combined treatment doubled chlorogenic acid concentration compared to the control in both ecotypes (Figure 3.6C). Chilling increased chlorogenic acid concentration by three-fold in both ecotypes, but only in vegetative plants (Figure 3.6C). HPLC profiles of leaf methanolic extracts did not reveal any new peaks resulting from the stressor treatment, indicating that no new compounds had been formed (Figure 3.7). 


\section{A}

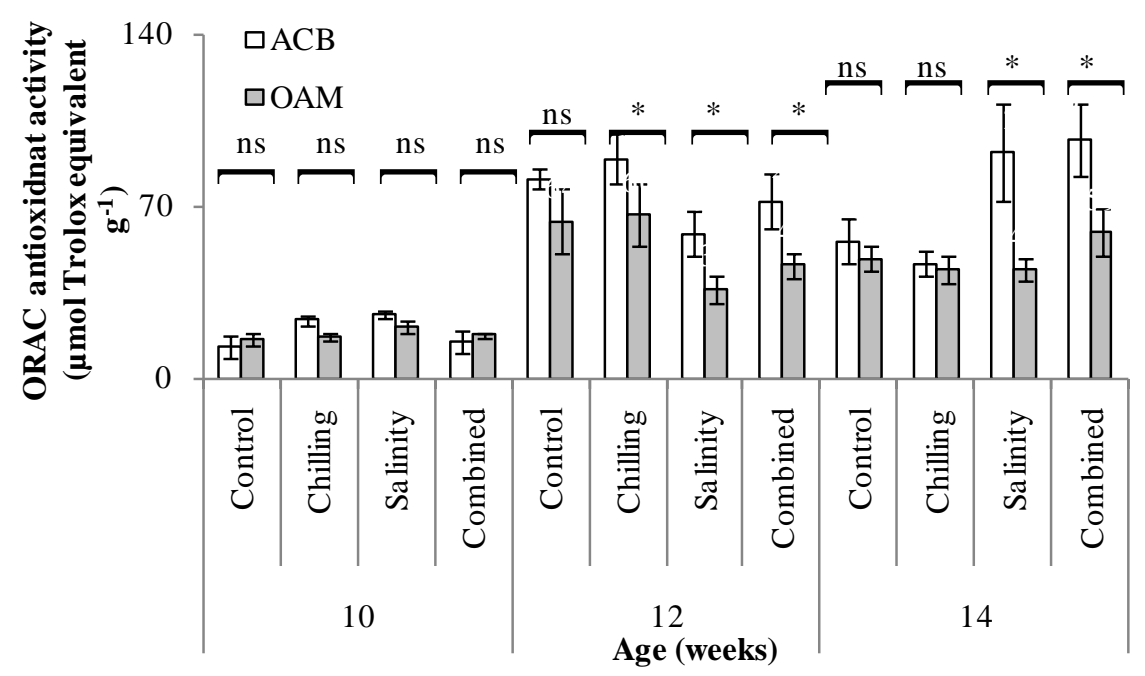

B
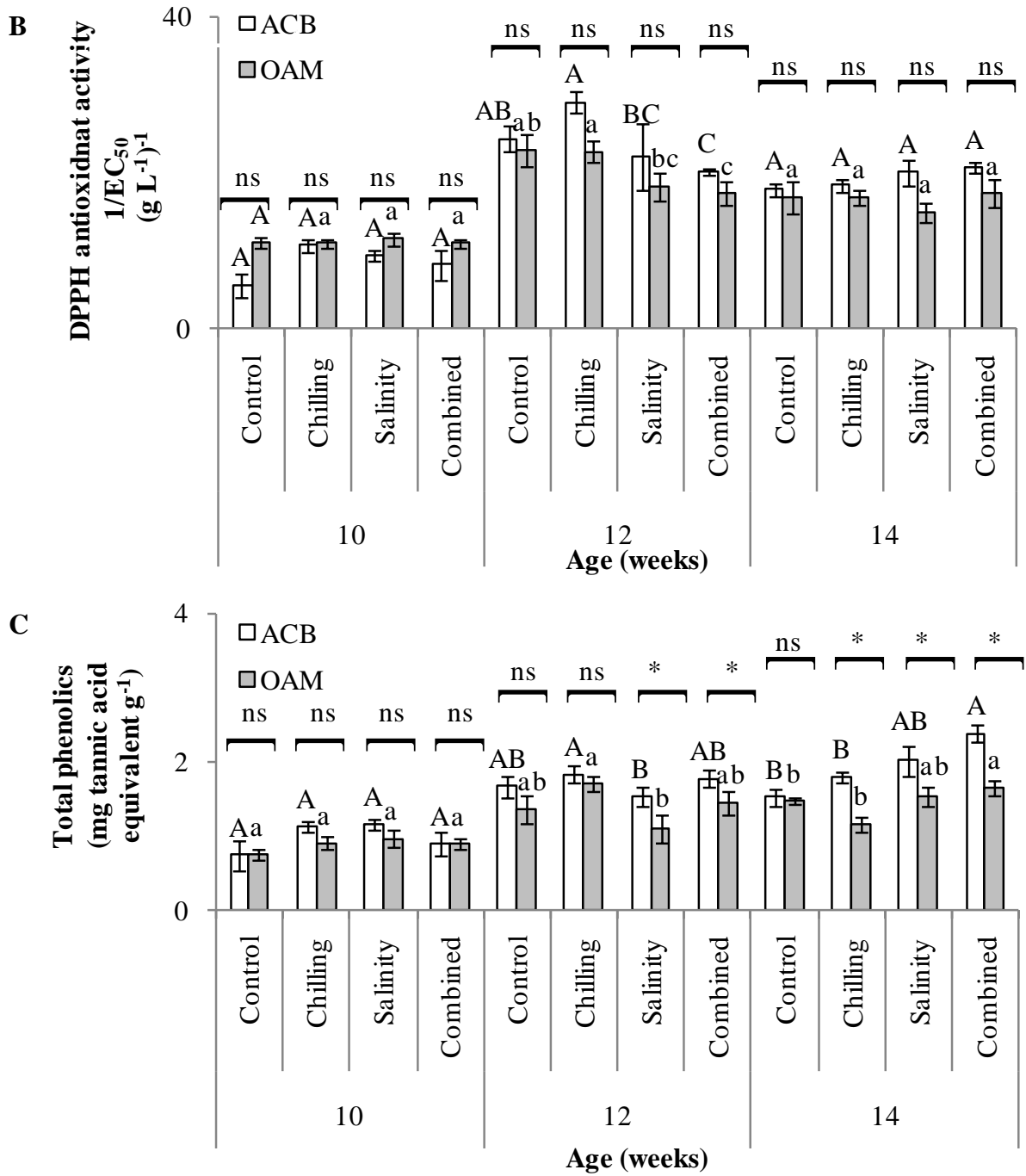

Figure 3.5 Treatment effects on (A) ORAC, (B) DPPH radical scavenging and (C) concentration of total phenolic compounds in methanolic extracts of leaves of ACB and OAM ecotypes of Sonchus oleraceus $\mathrm{L}$. at week 10, 12 and 14, which had been exposed to treatments for two weeks: control, chilling, salinity and the combination of the two. Means $\pm \mathrm{SE}(n=8)$. Bars with different letters of the same case indicate significant differences across treatments within an ecotype at each week $(P<0.05)$. *Significant difference between ecotypes $(P<0.05)$. ns: Ecotypes not significantly different $(P>0.05)$. 
A

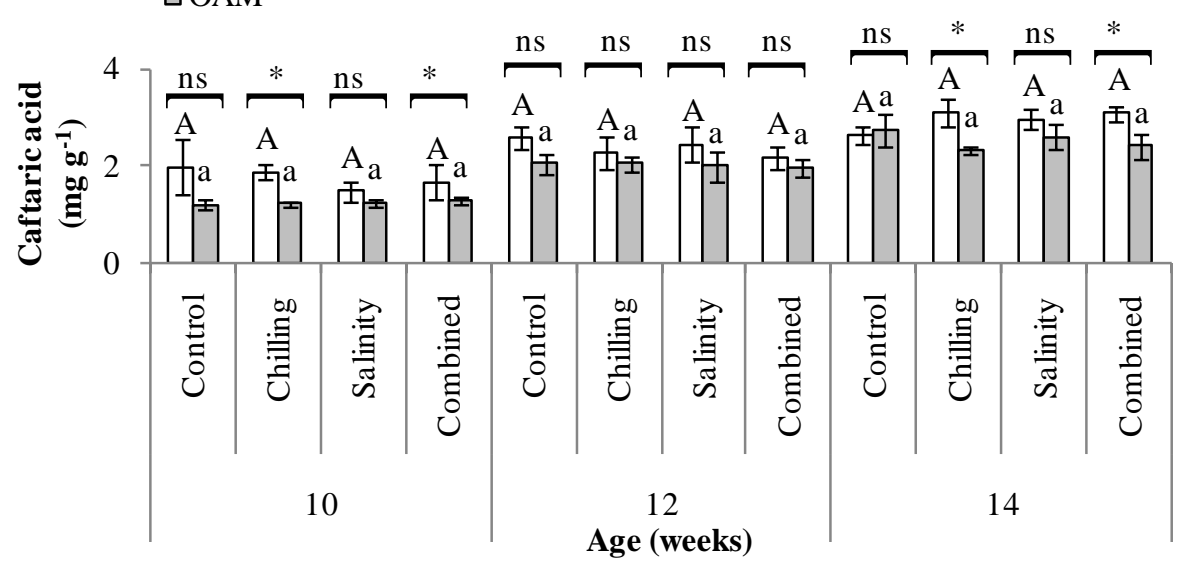

B

\section{$\square \mathrm{ACB}$}

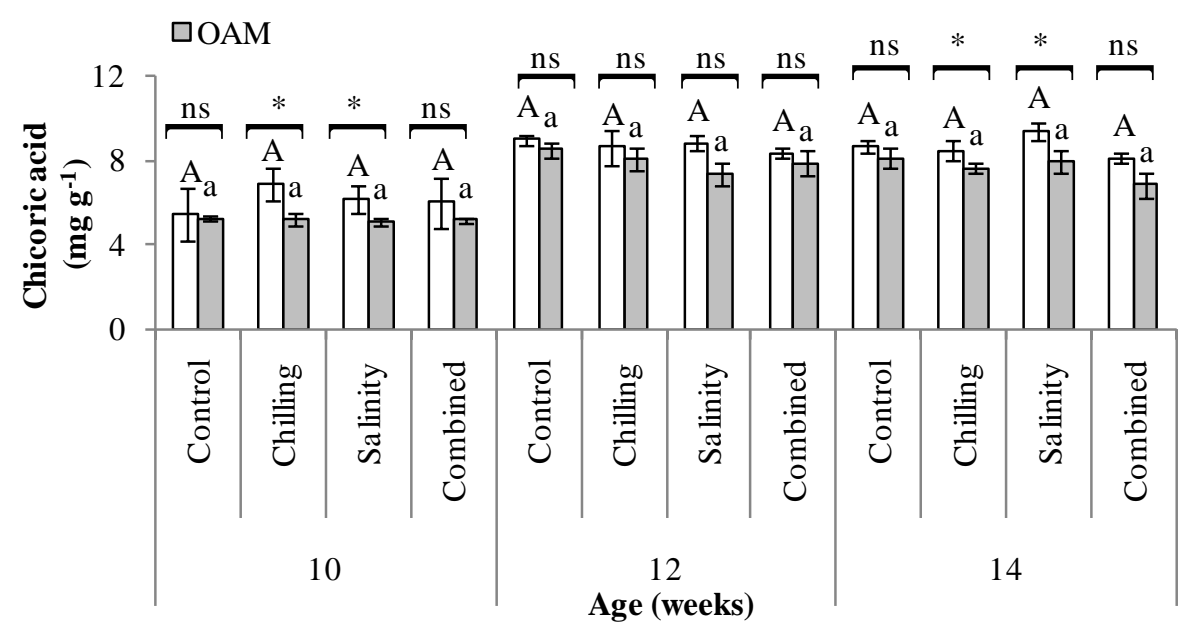

C

\section{$\square \mathrm{ACB}$}

$\square \mathrm{OAM}$

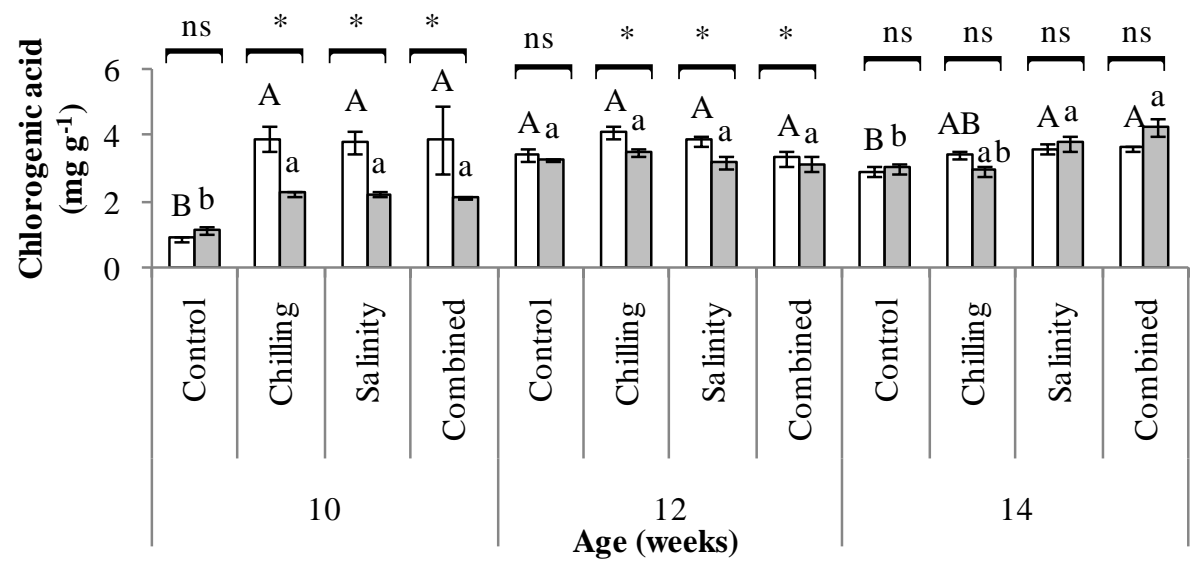

Figure 3.6 Treatment effects on (A) caftaric (B) chicoric and (C) chlorogenic acid concentrations in methanolic extracts of leaves of ACB and OAM ecotypes of Sonchus oleraceus L. at week 10, 12 and 14, which had been exposed to treatments for two weeks: control, chilling, salinity and the combination of the two. Means \pm SE $(n=8)$. Bars with different letters of the same case indicate significant differences across treatments within an ecotype at each week $(P<0.05)$. *Significant difference between ecotypes $(P<0.05)$. ns: Ecotypes not significantly different $(P>0.05)$. 

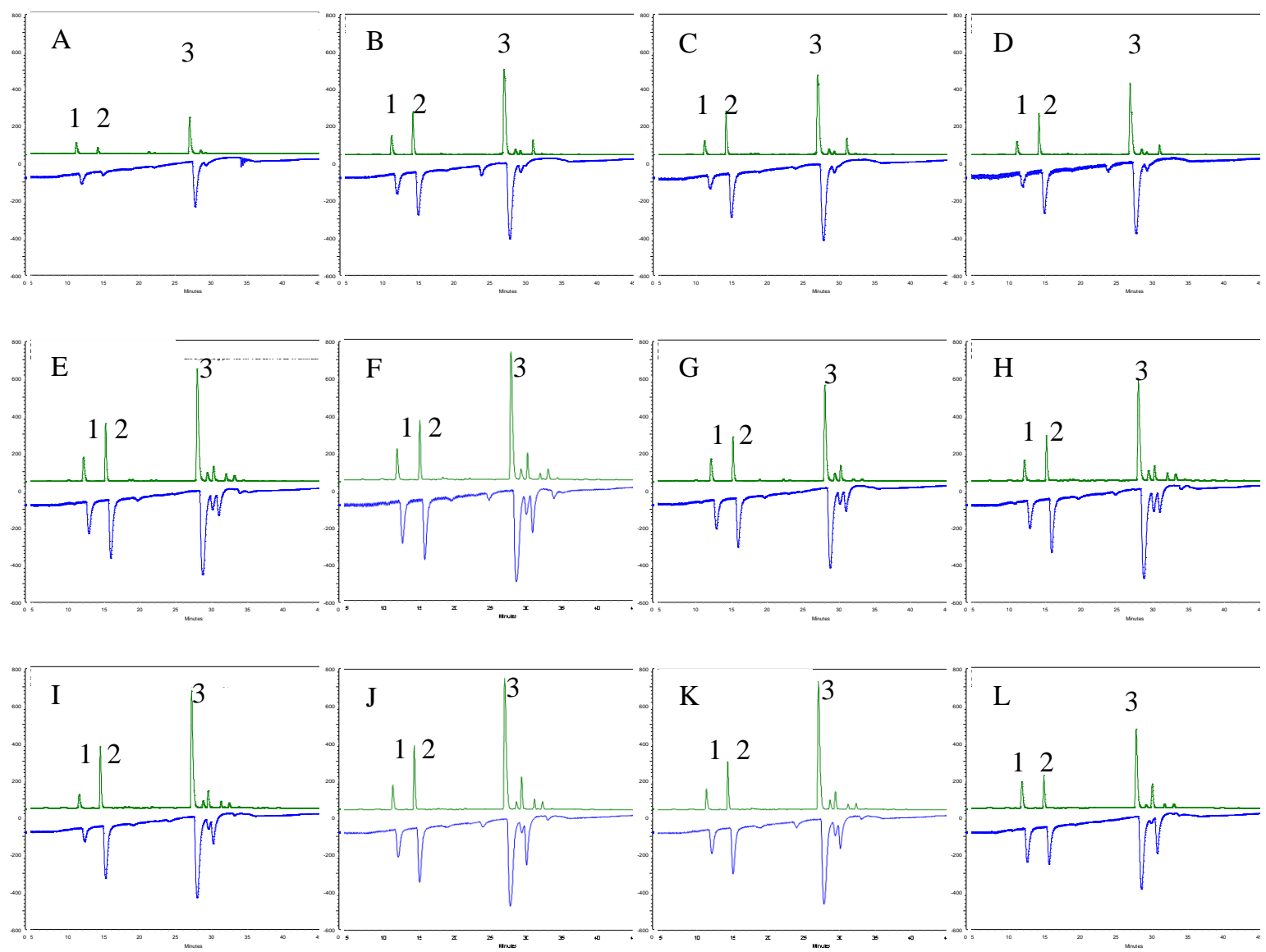

Figure 3.7 RP-HPLC-DPPH chromatograms recorded for ACB methanolic extracts of leaves of Sonchus oleraceus L. at week 10 (A-D), 12 (E-H), and 14 (I-L), which had been exposed to treatments for two weeks: control (A,E,I), chilling (B,F,J), salinity (C,G,K) and the combination of the two (D,H,L). Phenolics (green line) measured at $320 \mathrm{~nm}$; DPPH radical scavenging (blue line) at $518 \mathbf{~ n m}$. Peaks: 1, caftaric acid, 2, chlorogenic acid and 3, chicoric acid. 


\subsubsection{Effects of age, ecotype and stressors on ascorbate concentration}

Plant age had the largest effect on ascorbate concentration; a three-fold increase was observed at week 12 compared to week 10 in both ecotypes $(P<0.001$; Figure 3.8A). The ACB had $30-60 \%$ higher leaf ascorbate concentration than OAM $(P<0.001$; Figure 3.8). Stressors did not significantly affect leaf ascorbate level concentrations $(P=0.65$; Figure 3.8).

A

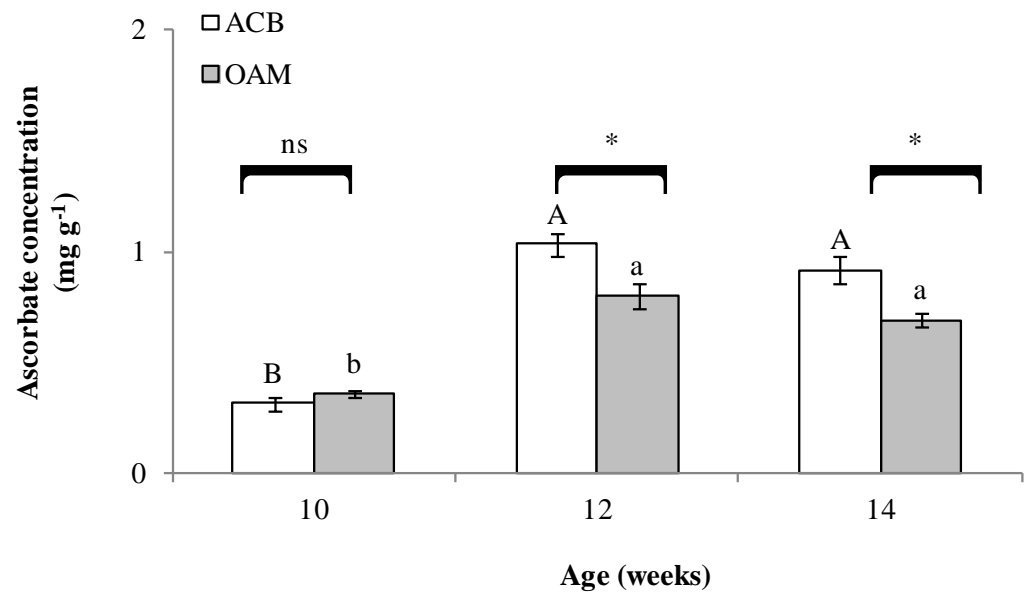

B

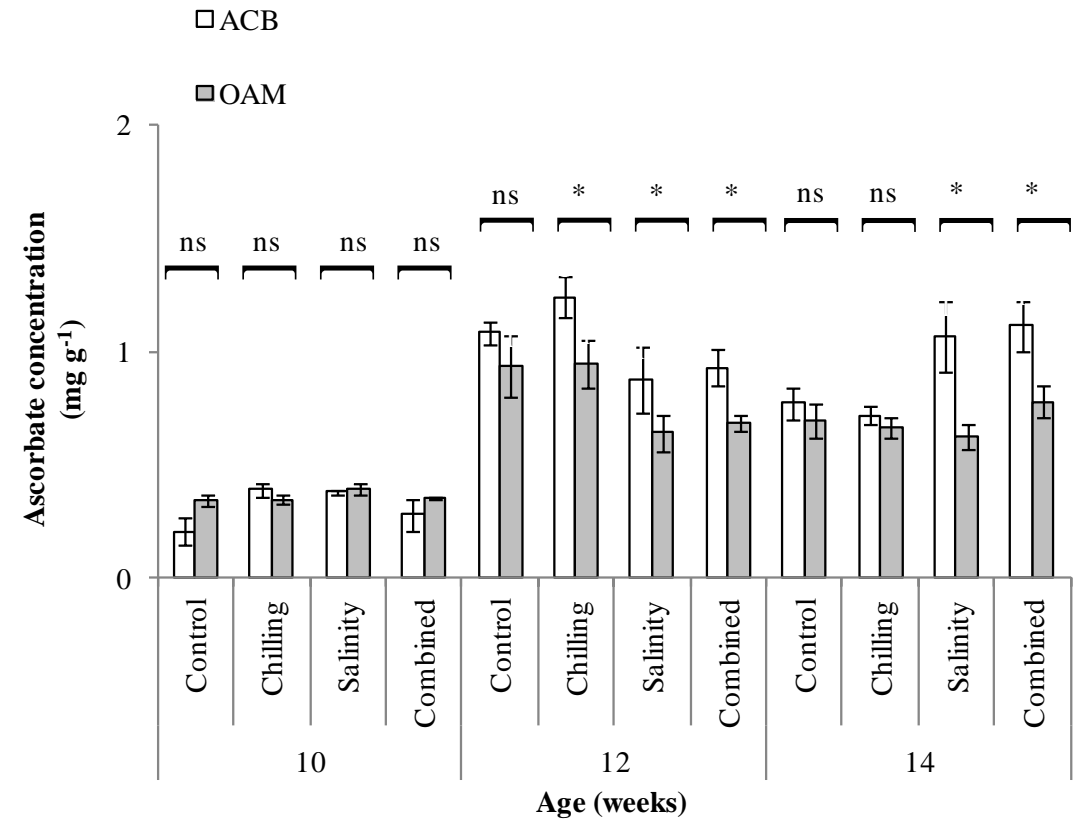

Figure 3.8 Concentration of ascorbate in methanolic extracts of leaves of ACB and OAM ecotypes of Sonchus oleraceus L. with (A) plant age and (B) stressors at week 10, 12 and 14, which had been exposed to treatments for two weeks: control, chilling, salinity and the combination of the two. Means $\pm \mathrm{SE}(n=32$ and $n=8)$. Bars with different letters of same case indicate significant differences within an ecotype $(P<0.05)$.* Significant difference between ecotypes $(P<0.05)$. ns: Ecotypes not significantly different $(P>0.05)$. None of the treatments was statistically significant $(P>0.05)$. 


\subsubsection{Effects of stressors on shoot, root and total dry biomass of plants.}

None of the stressors significantly influenced the dry biomass of roots $(P=0.86$; Figure 3.9A), shoots $(P=0.15$; Figure 3.9B $)$ or total plant $(P=0.86$; Figure 3.9C). However stressors created differences in plant morphology. Older plants subjected to stressors were shorter, had broader stems and more red leaves compared to the controls (Plate 3.2 B-C).
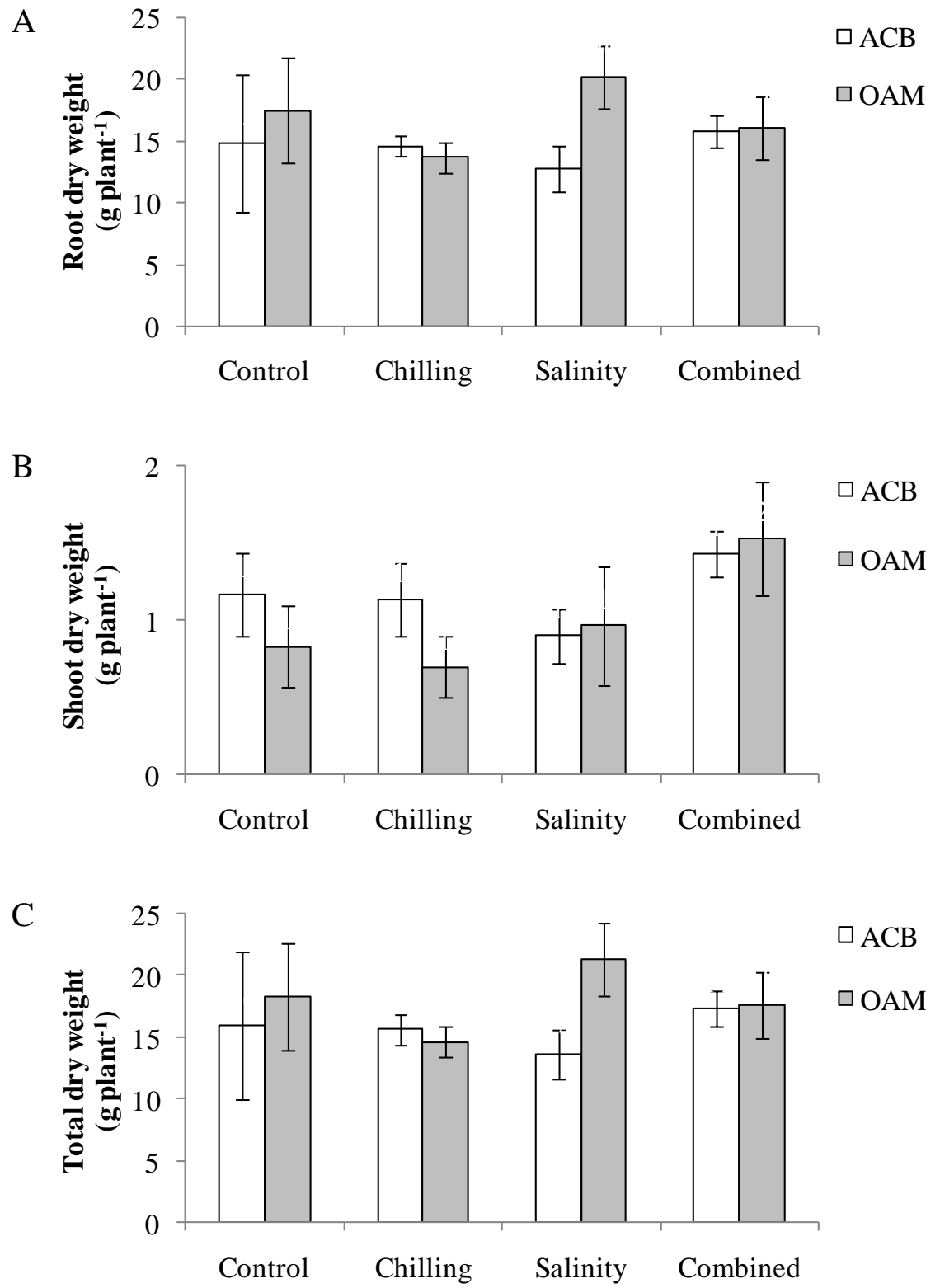

Figure 3.9 Treatment effects on (A) root, (B) shoot and (C) total dry biomass of ACB and OAM ecotypes of Sonchus oleraceus $\mathrm{L}$. at week 14. Means $\pm \mathrm{SE}(n=8)$. None of the treatments significantly altered the dry biomass $(P<0.05)$. 


\subsubsection{Chlorophyll fluorescence measurements}

\subsubsection{Maximum efficiency of photosystem II}

Maximum efficiency of photosystem II $\left(\mathrm{F}_{\mathrm{v}} / \mathrm{F}_{\mathrm{m}}\right)$ values of leaves averaged $0.81 \pm 0.00$ for all data and none was lower than $0.79 \pm 0.00$ (Figure 3.10).

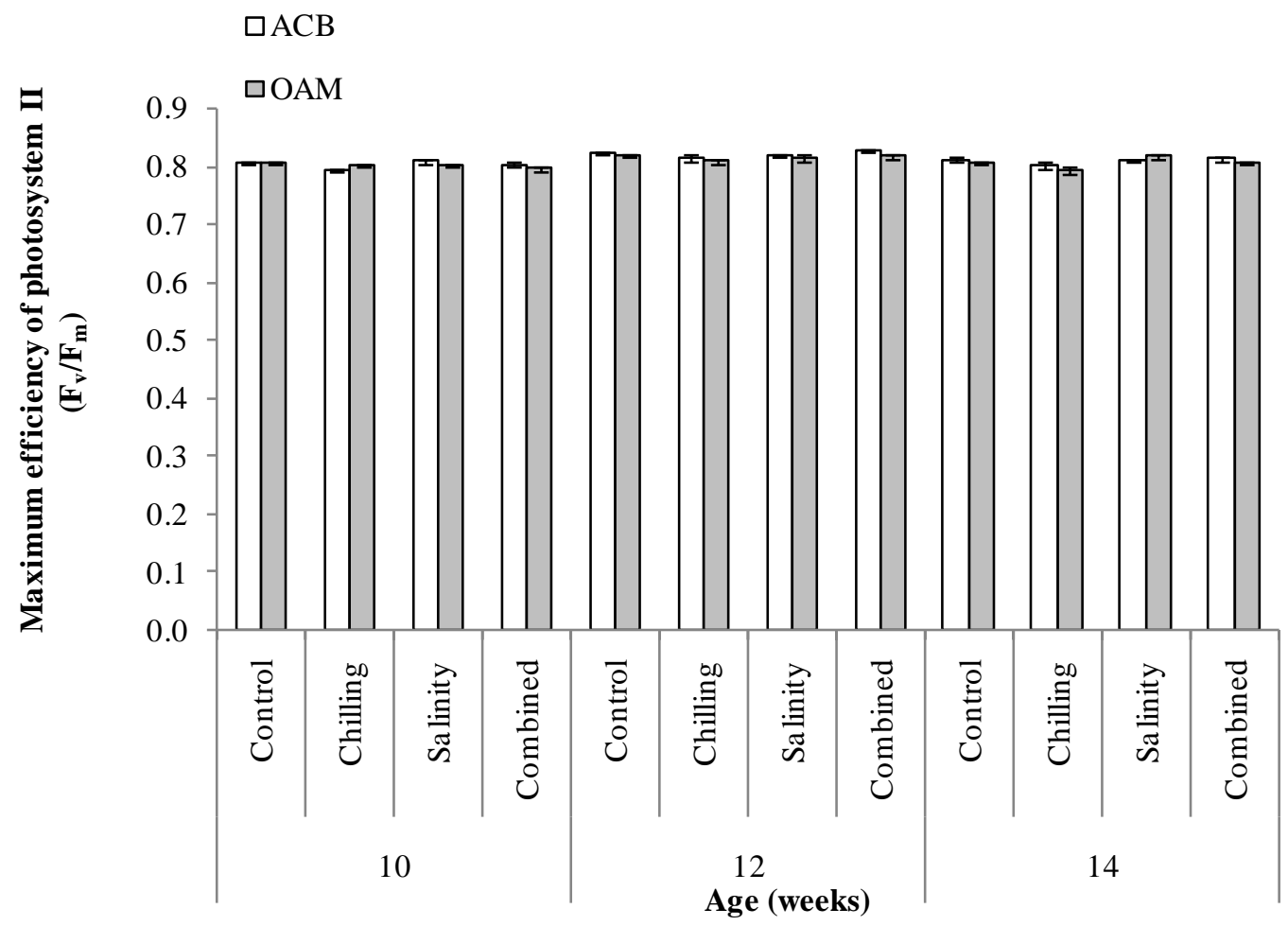

Figure 3.10 Treatment effects on maximum efficiency of photosystem II $\left(F_{v} / F_{m}\right)$ of leaves of $A C B$ and OAM ecotypes of Sonchus oleraceus $\mathrm{L}$. at week 10, 12 and 14, which had been exposed to treatments for two weeks: control, chilling, salinity and the combination of the two. Means $\pm \mathrm{SE}(n=8)$. None of the treatments was statistically significant $(P>0.05)$.

\subsubsection{Light response curves for chlorophyll fluorescence}

Ecotypes did not significantly influence the parameters $\Delta \mathrm{F}_{\mathrm{v}} / \mathrm{F}_{\mathrm{m}}^{\prime}, \mathrm{NPQ}, \mathrm{q}_{\mathrm{P}}$ and ETR as derived using rapid light response curves $(P>0.5$; Figures $3.11-3.13)$.

Light response curves for $\Delta \mathbf{F} / \mathbf{F}^{\prime}{ }_{\mathbf{m}}$ : There were only small effects of stressors on the effective quantum yields of the plants, which became less pronounced as plants aged $(P=$ 
0.002; Figures 3.11A,B - 3.13A,B). The rate of decline of $\Delta \mathrm{F} / \mathrm{F}^{\prime}{ }_{\mathrm{m}}$ with increasing light intensity was lower for plants subjected to stressors than for the respective controls in both ecotypes (Figure 3.11A,B).

Light response curves for NPQ: NPQ values were highest in flowering plants across ecotypes and all stressors $(P=0.01$; Figures 3.11C,D - 3.13C,D). NPQ curves did not differ significantly among stressors $(P=0.11$; Figures 3.11C,D - 3.13C,D).

Light response curves for $\mathbf{q}_{\mathbf{p}}$ : For both ecotypes, the impact of stressors was greatest on the youngest plants, and became less prominent as plants aged $(P<0.001$; Figures 3.11E,F - 3.13E,F). Rate of decrease in qp with increasing light intensity was lower for stressor-imposed plants than the control in both ecotypes (Figures 3.11E,F - 3.12E,F). However, these effects due to stressors varied between ecotypes.

Light response curves for ETR: Influences of stressors on light response curves for ETR were more pronounced in younger than in older plants; in the oldest plants none of the stressors had any impact in both ecotypes $(P<0.001$; Figures $3.11 \mathrm{G}, \mathrm{H}-3.13 \mathrm{G}, \mathrm{H})$. Rates of increase in ETR with light were greater for stressor treated plants than for controls (Figure 3.11G,H). As plants aged, the rate of increase in ETR with increasing light diminished across both ecotypes and among all stressors (Figures 3.11G,H $3.13 \mathrm{G}, \mathrm{H})$. 

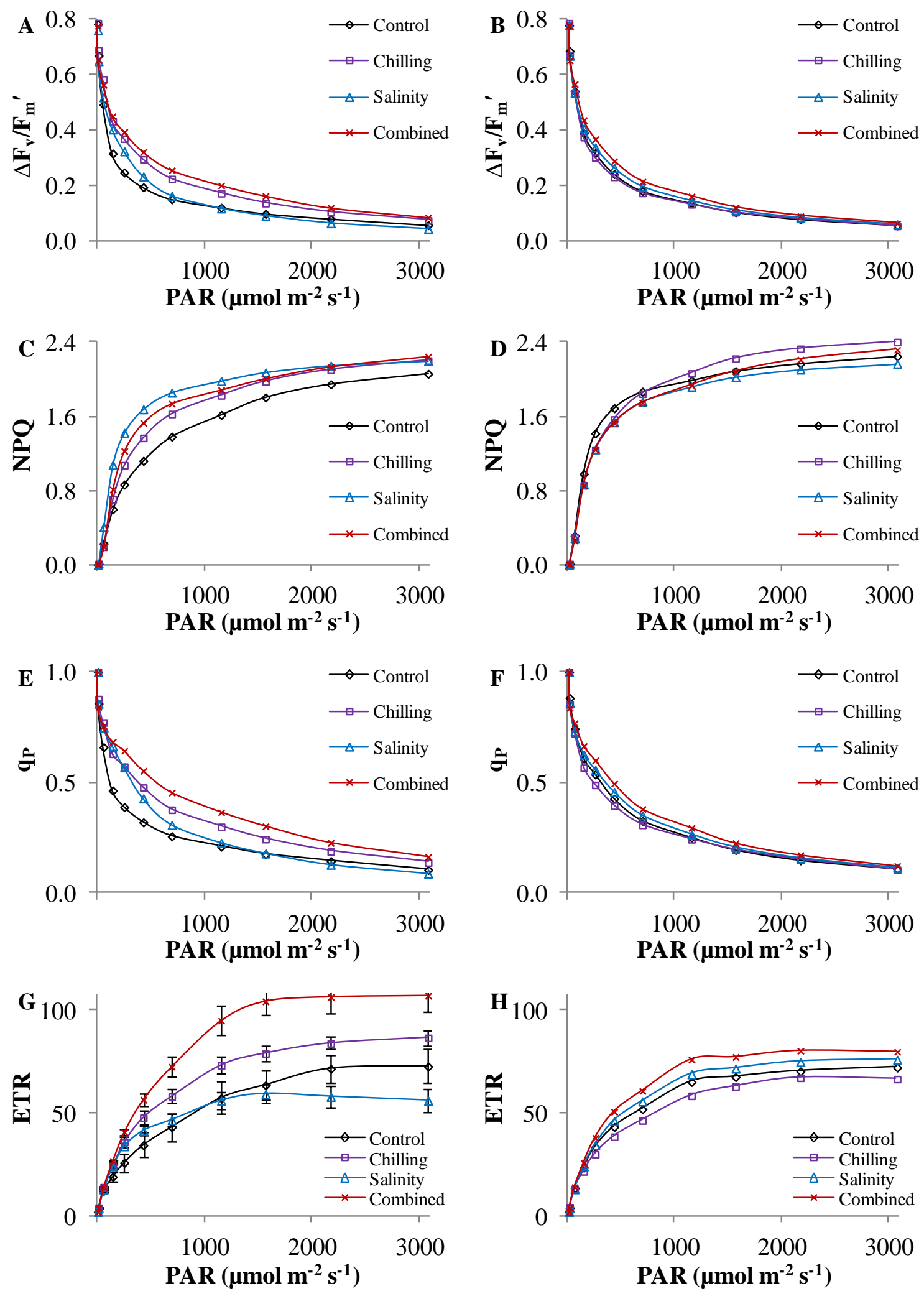

Figure 3.11 Light response curves for quantum yield of PSII $\left(\Delta \mathrm{F} / \mathrm{F}^{\prime}{ }_{\mathrm{m}} ; \mathrm{A}, \mathrm{B}\right)$, nonphotochemical quenching (NPQ; C,D) and photochemical quenching $\left(q_{\mathrm{P}} ; \mathrm{E}, \mathrm{F}\right)$ and apparent electron transport rate (ETR; G,H) in leaves of ACB (A,C,E,G) and OAM (B,D,F,H) ecotypes of Sonchus oleraceus L. at week 10, which had been exposed to treatments for two weeks: control, chilling, salinity and the combination of the two. Means $\pm \operatorname{SE}(n=8)$. 

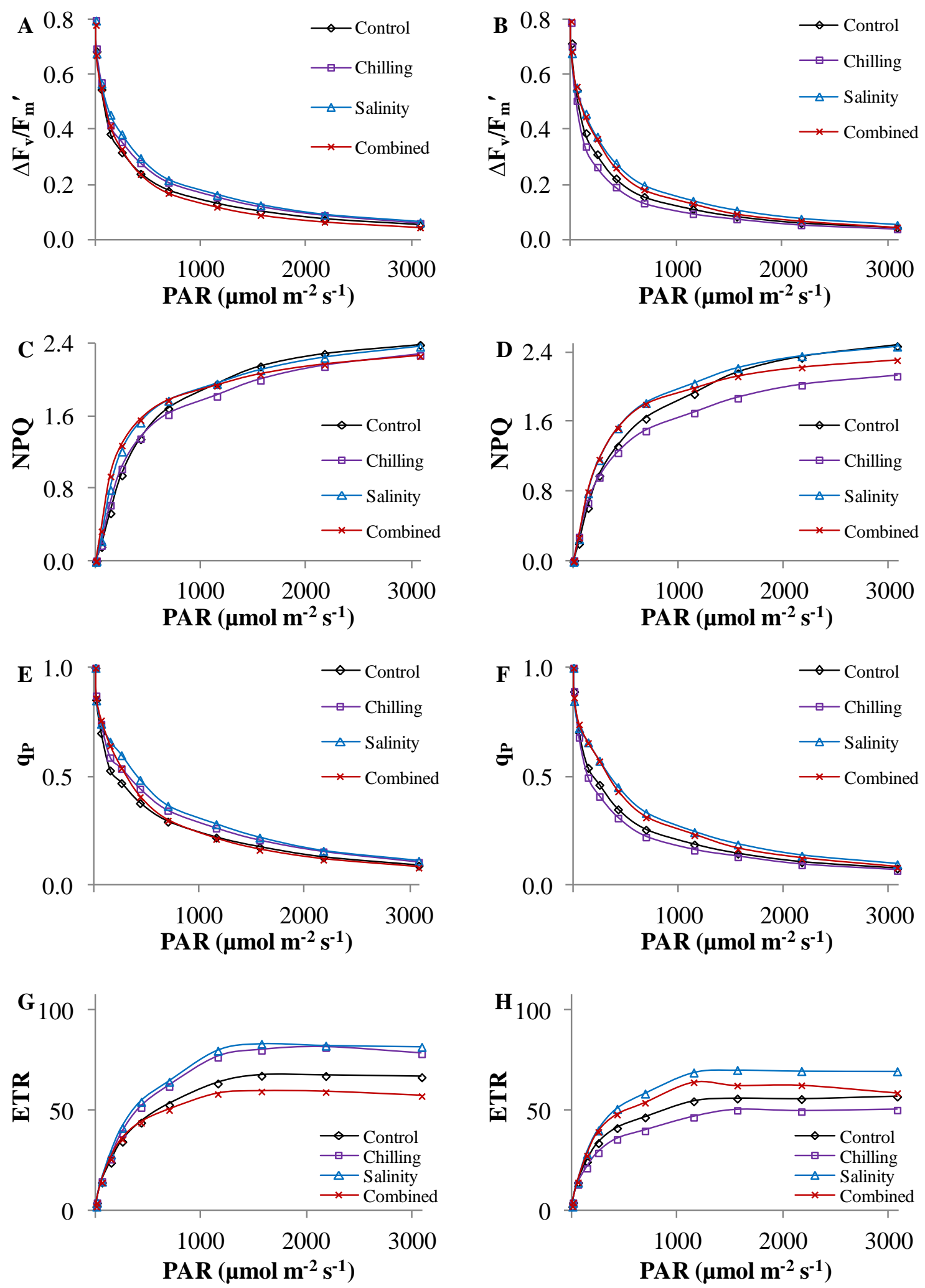

Figure 3.12 Light response curves for quantum yield of PSII $\left(\Delta F / F^{\prime}{ }_{m} ; A, B\right)$, nonphotochemical quenching (NPQ; C,D) and photochemical quenching $\left(q_{\mathrm{P}} ; \mathrm{E}, \mathrm{F}\right)$ and apparent electron transport rate (ETR; G,H) in leaves of ACB (A,C,E,G) and OAM (B,D,F,H) ecotypes of Sonchus oleraceus L. at week 12, which had been exposed to treatments for two weeks: control, chilling, salinity and the combination of the two. Means $\pm \operatorname{SE}(n=8)$. 

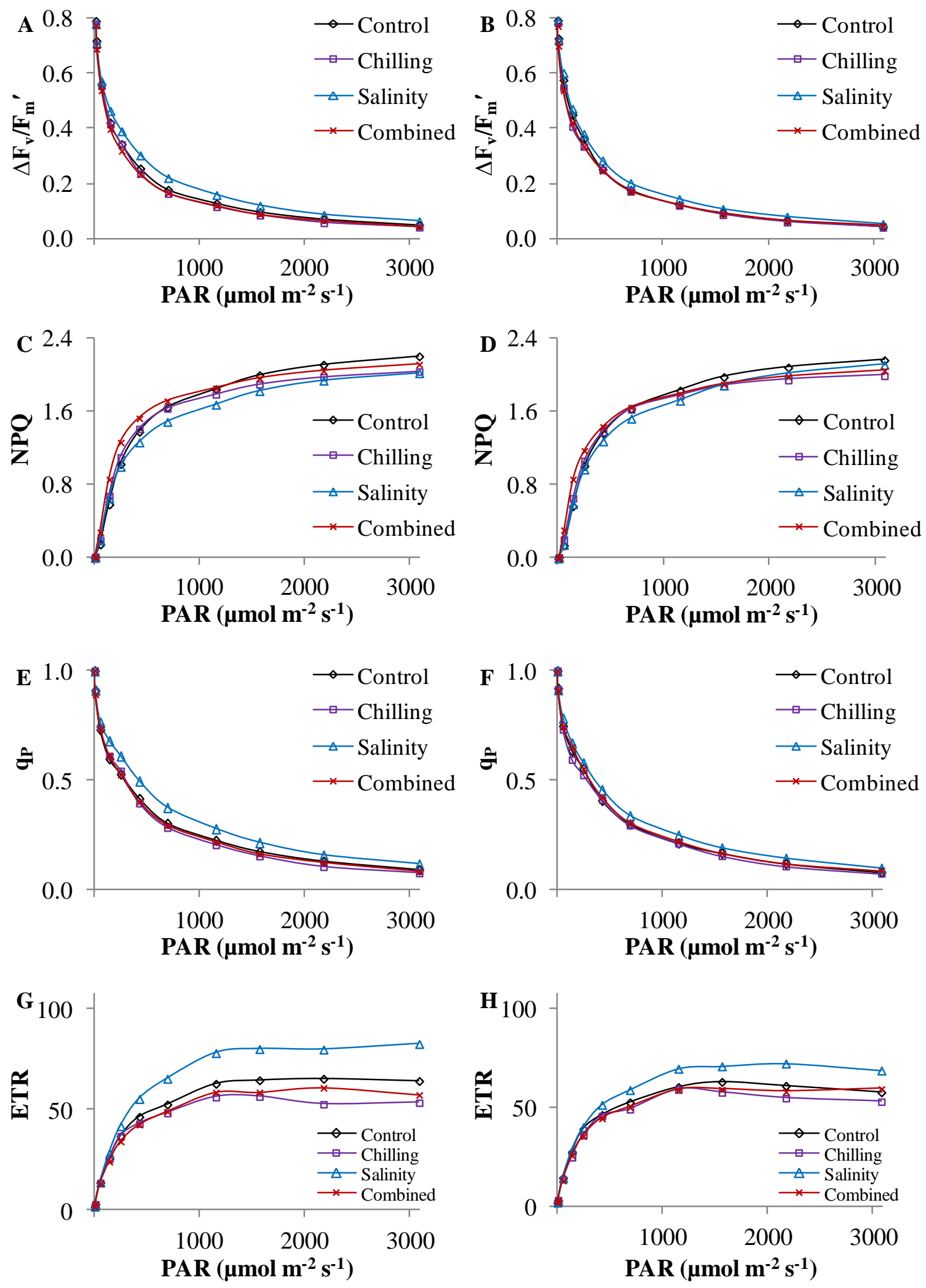

Figure 3.13 Light response curves for quantum yield of PSII $\left(\Delta \mathrm{F} / \mathrm{F}^{\prime}{ }_{\mathrm{m}} ; \mathrm{A}, \mathrm{B}\right)$, nonphotochemical quenching (NPQ; C,D) and photochemical quenching $\left(q_{\mathrm{P}} ; \mathrm{E}, \mathrm{F}\right)$ and apparent electron transport rate (ETR; G,H) in leaves of ACB (A,C,E,G) and OAM (B,D,F,H) ecotypes of Sonchus oleraceus L. at week 14, which had been exposed to treatments for two weeks: control, chilling, salinity and the combination of the two. Means $\pm \operatorname{SE}(n=8)$. 
3.5.7.3 The parameters of light response curves for ETR

Initial slope of light response curves for ETR ( $\alpha)$ : $\alpha$ was higher in older plants than young plants irrespective of ecotype or stressor $(P<0.001$; Figure 3.14A). $\alpha$ between ecotypes were not different $(P=0.94$; Figure 3.14). Stressors had variable impacts on $\alpha$ between ecotypes $(P<0.01)$. Chilling and the stressor combination on ACB resulted in higher $\alpha$ than control plants irrespective of their age (Figure 3.14B). Stressors did not significantly alter $\alpha$ in OAM (Figure 3.14B).

A

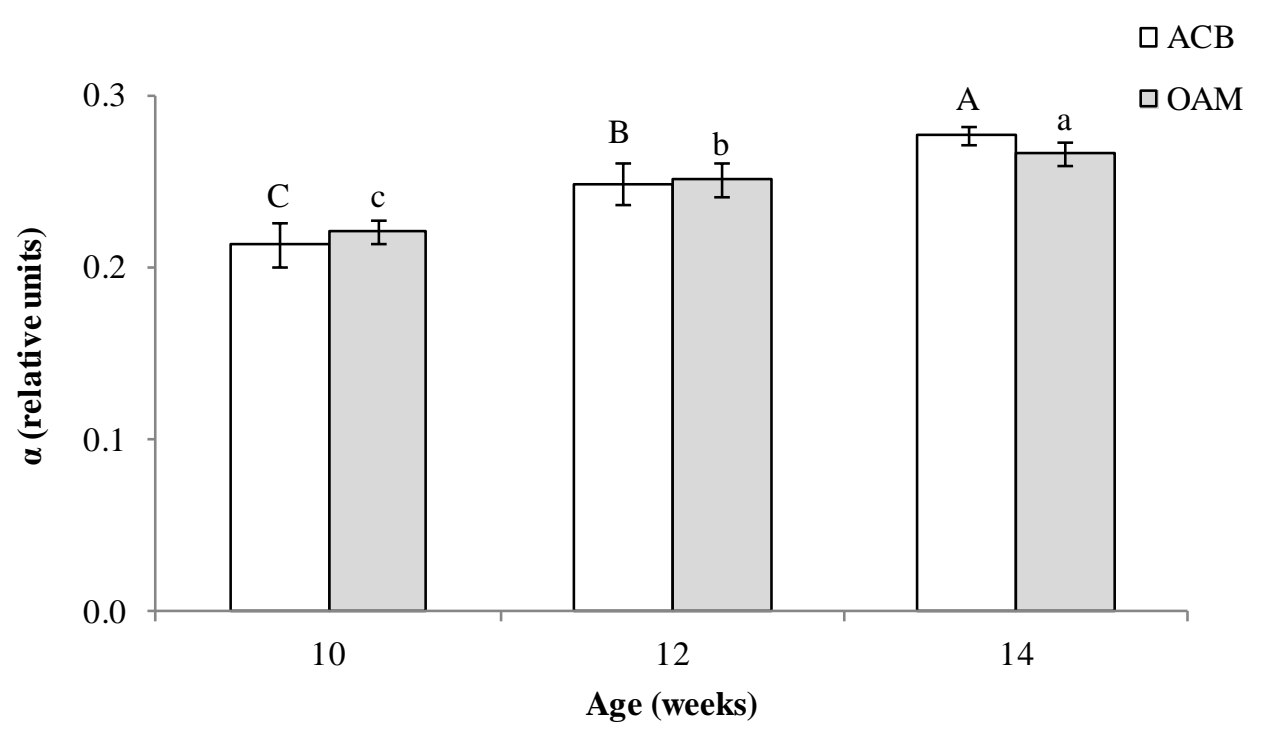

B

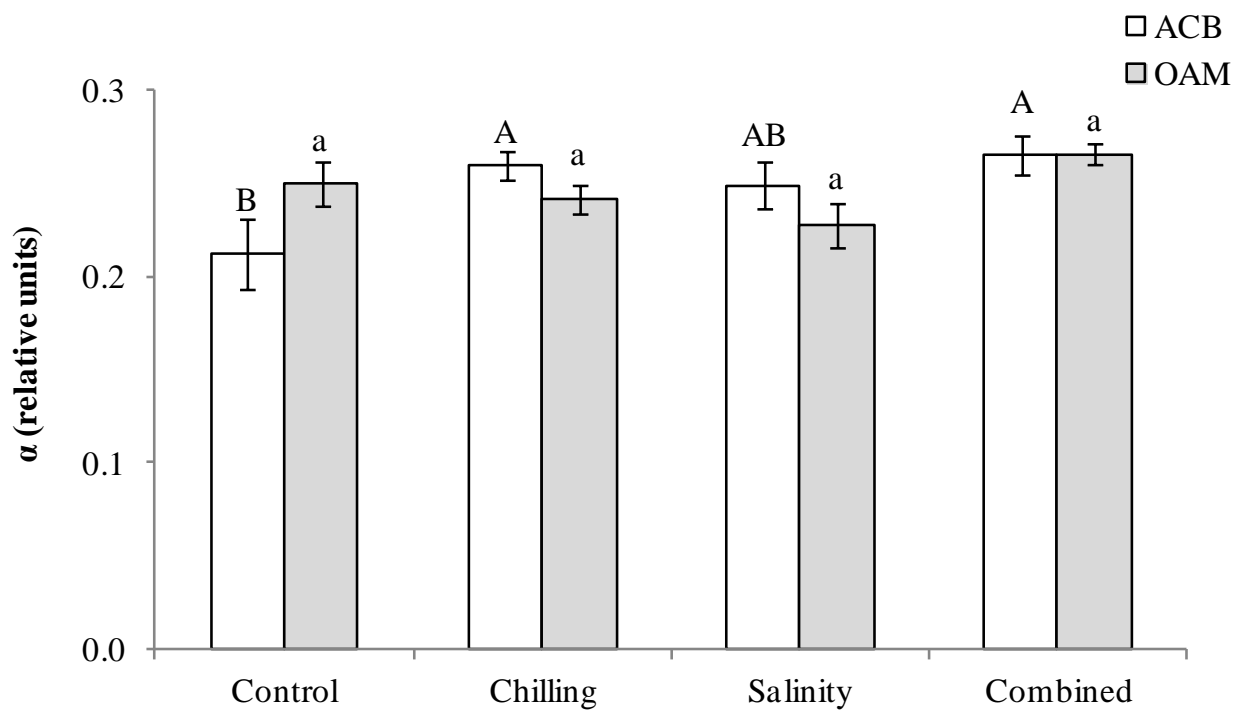

Figure 3.14 Initial slope of light response curves for ETR $(\alpha)$ in leaves of ACB and OAM ecotypes of Sonchus oleraceus L. with (A) plant age and (B) stressors. Means \pm SE $(n=32$ and $n=24)$. Bars with different letters of same case indicate significant differences within an ecotype $(P<0.05)$. 
Maximum electron transport rate $\left(\mathbf{E T R}_{\max }\right)$ : The $\mathrm{ETR}_{\max }$ of OAM diminished as plants aged for all the treatments, but not in ACB $(P<0.001$; Figure $3.15 \mathrm{~A})$. The $\mathrm{ETR}_{\max }$ were not different between ecotypes $(P=0.32$; Figure 3.15A). Stressors had variable impacts on $\mathrm{ETR}_{\max }$ between ecotypes $(P<0.001)$. Salinity treated OAM plants had lower ETR $\mathrm{Eax}_{\max }$ than control, while in ACB stressor treated plants were not significantly different from the control (Figure 3.15B).

A $\square \mathrm{ACB}$
100
$\square \mathrm{OAM}$

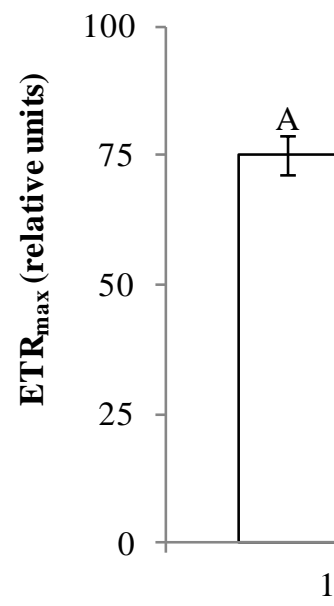

10

12

14

Age (weeks)

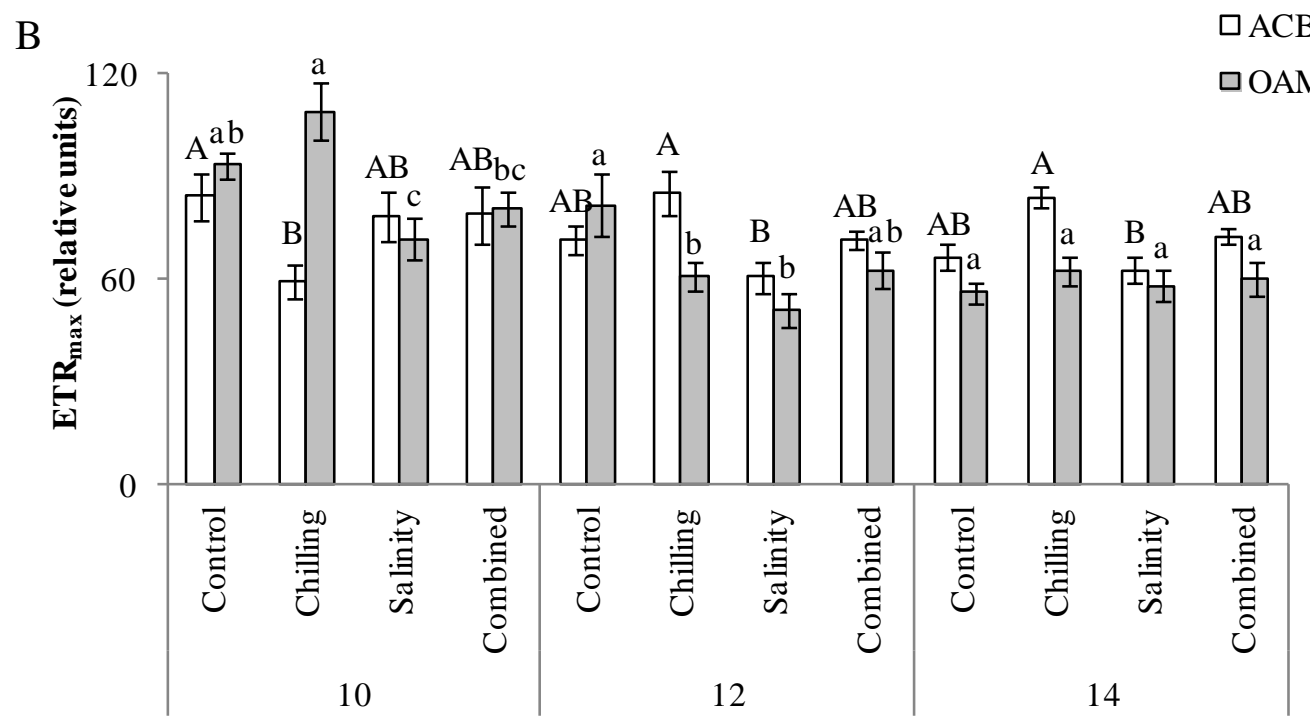

Age (weeks)

Figure 3.15 Maximum electron transport rate $\left(E T R_{\max }\right)$ in leaves of $\mathrm{ACB}$ and $\mathrm{OAM}$ ecotypes of Sonchus oleraceus $\mathrm{L}$. with (A) plant age and (B) stressors at week 10, 12 and 14, which had been exposed to treatments for two weeks: control, chilling, salinity and the combination of the two. Means $\pm \mathrm{SE}$ ( $n=32$ and $n=8$ ). Bars with different letters of same case indicate significant differences within an ecotype at each week $(P<0.05)$. 
Minimum saturating irradiance $\left(l_{k}\right)$ : The $l_{k}$ declined as plants aged $(P<0.001$; Figure $3.16 \mathrm{~A})$. The $\mathrm{l}_{\mathrm{k}}$ for two ecotypes differed in young plants $(P=0.04$; Figure $3.16 \mathrm{~B})$. The $\mathrm{l}_{\mathrm{k}}$ of young ACB control plants was three-fold higher than that of the average recorded for rest of the data $(P<0.001$; Figure $3.16 \mathrm{~B})$.

A

$\square \mathrm{ACB}$

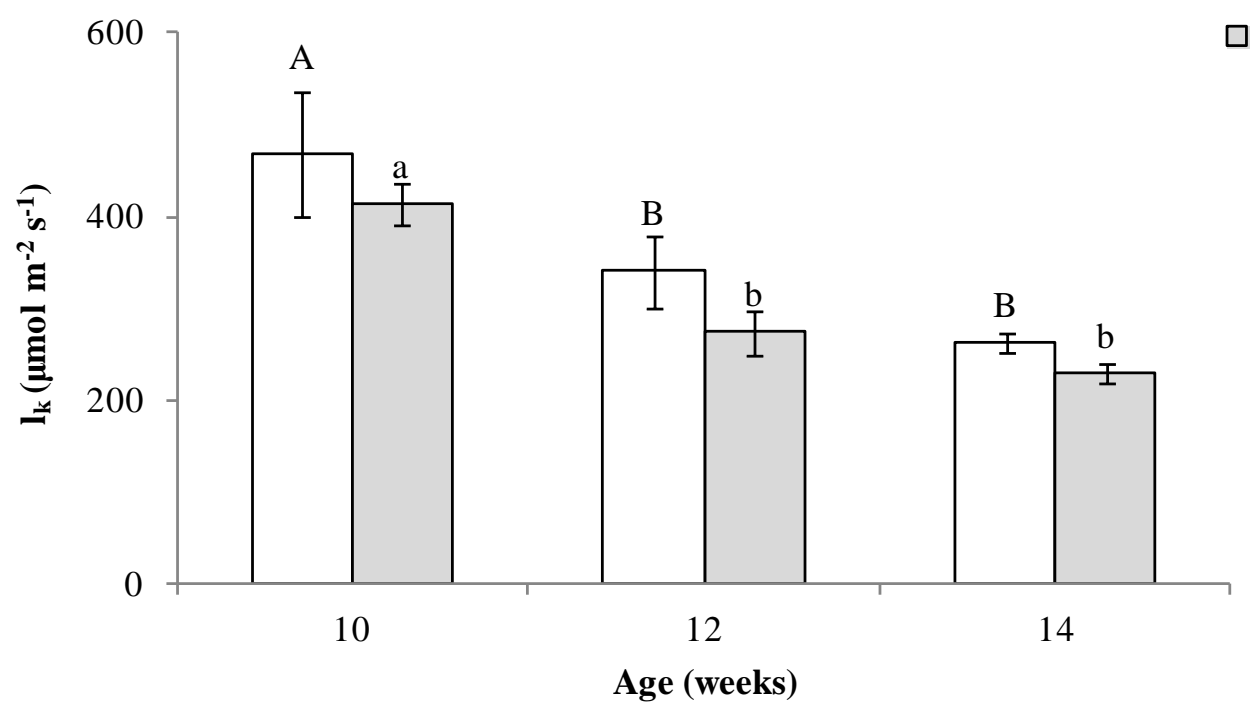

B

$\square \mathrm{ACB}$

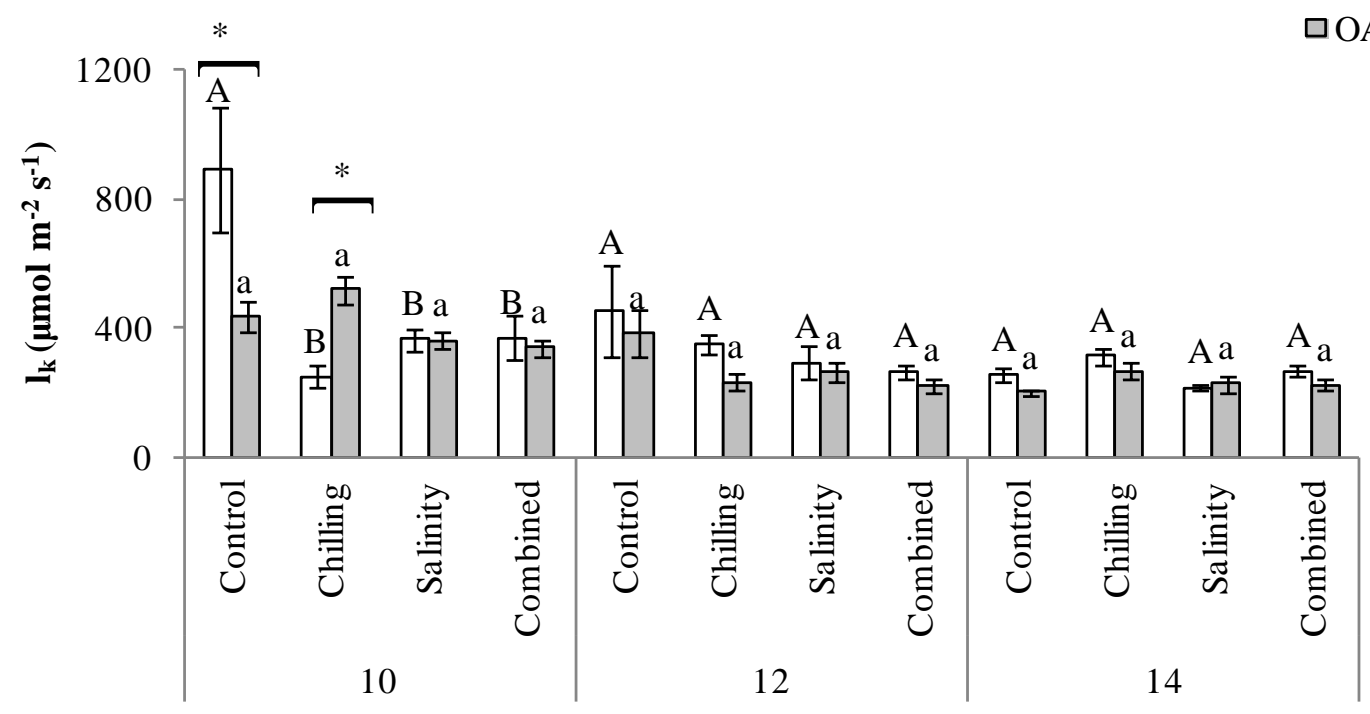

Age (weeks)

Figure 3.16 Minimum saturating irradiance $\left(l_{k}\right)$ in leaves of ACB and OAM ecotypes of Sonchus oleraceus $\mathrm{L}$. with (A) plant age and (B) stressors at week 10, 12 and 14, which had been exposed to treatments for two weeks: control, chilling, salinity and the combination of the two. Means $\pm \operatorname{SE}(n=$ 32 and $n=8$ ). Bars with different letters of same case indicate significant differences within an

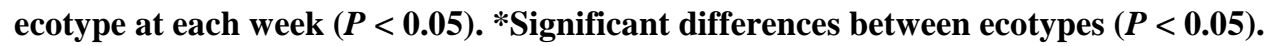




\subsubsection{The stressor-induced variations in extractable antioxidant activities in leaves correlated with human cellular antioxidant activities}

In order to see whether the differences in phenolic composition after stressors translated into antioxidant advantages inside human cells, HepG2 cells were infused with leaf extracts from youngest $S$. oleraceus plants that had been exposed to treatments for two weeks. Significant linear correlations between the CAA values in HepG2 cells and leaf extracted antioxidant activities and concentrations of total phenolics existed (Figure 3.17). Antioxidant activities measured by the ORAC assay better correlated with CAA values (Figure 3.17A) than did those obtained by the DPPH technique (Figure 3.17B). Concentrations of chlorogenic acid, chicoric acid and ascorbate of leaf methanolic extracts significantly linearly correlated with CAA values (Figure 3.18A-C). However, concentrations of caftaric acid did not significantly correlate with CAA (Figure 3.18D). 
A

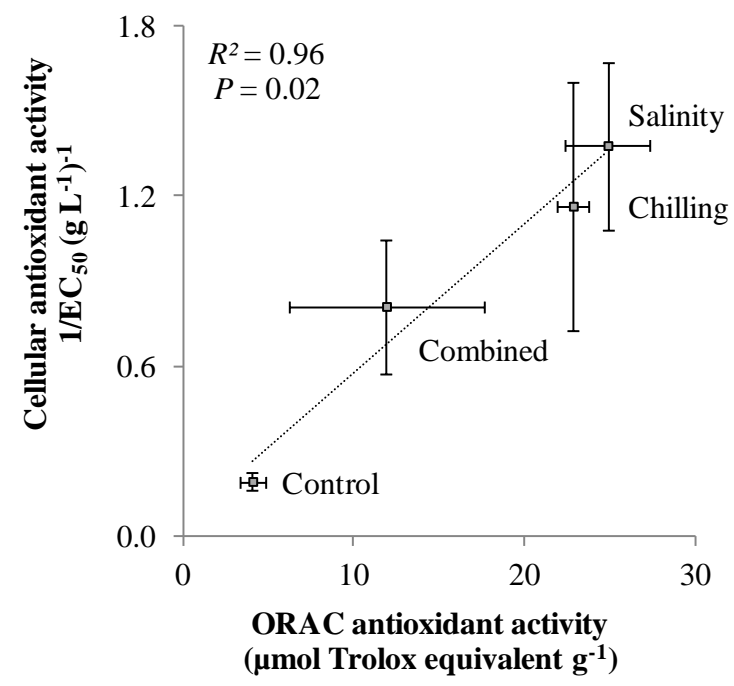

C

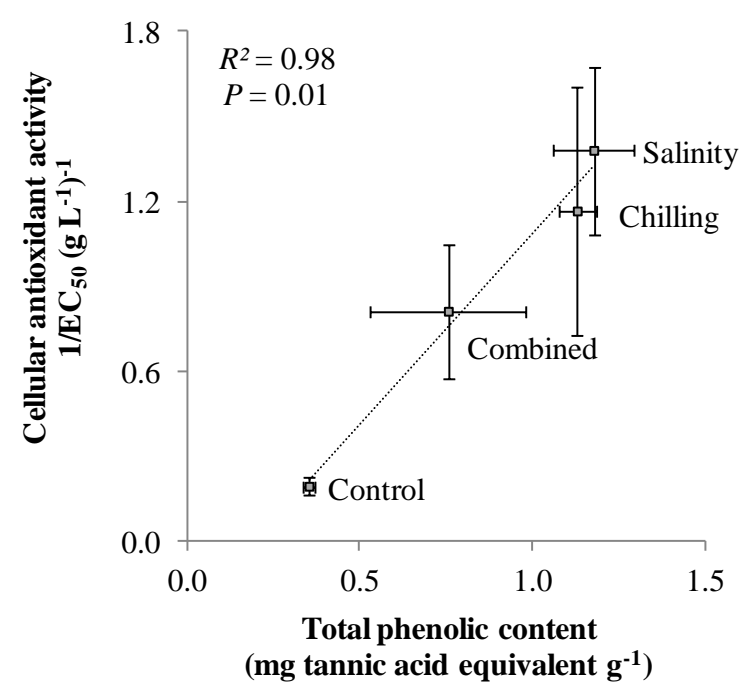

B

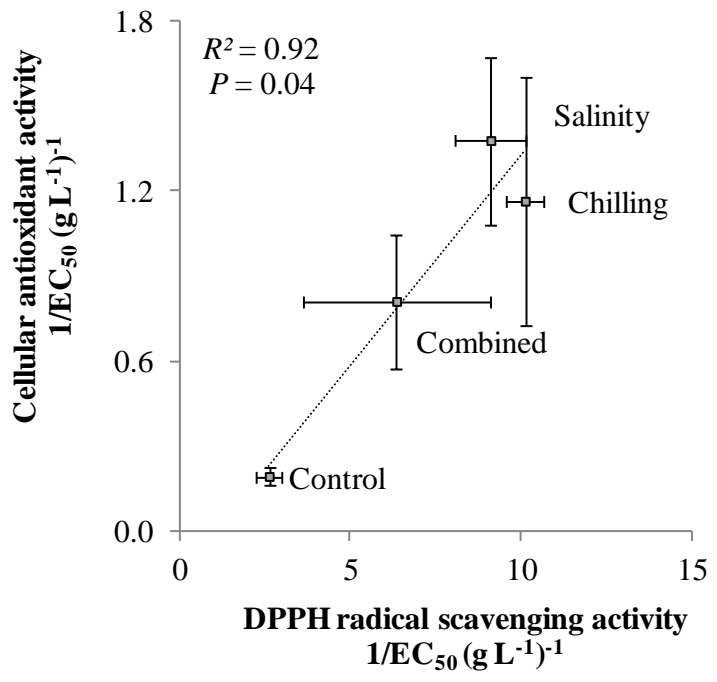

Figure 3.17 Linear correlations between cellular antioxidant activities inside HepG2 cells infused with leaf extracts of ACB ecotype of Sonchus oleraceus $\mathrm{L}$. at week 10, which had been exposed to two weeks of chilling, salinity and the combination of the two, with the extractable antioxidant activities measured by (A) ORAC and (B) DPPH techniques and (C) the concentration of total phenolic compounds. Means \pm SE $(n=5)$. 
A

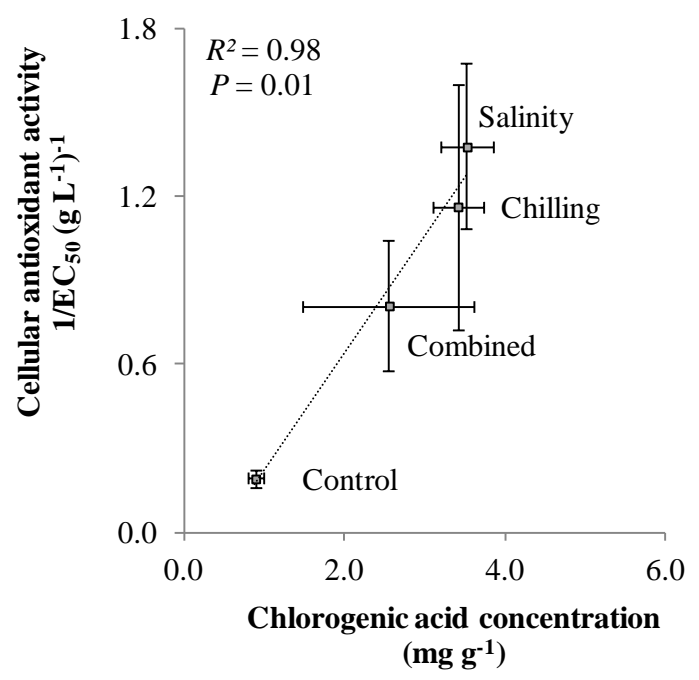

$\mathrm{C}$

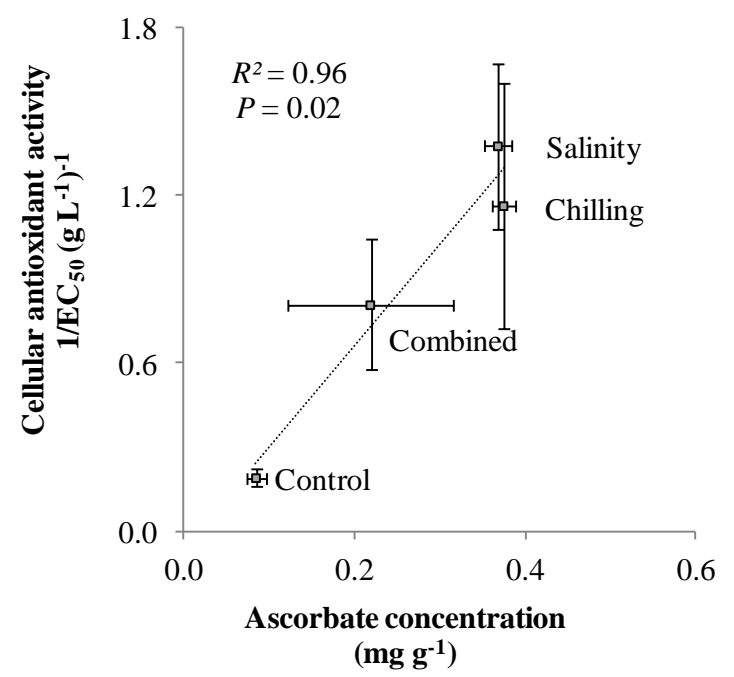

B

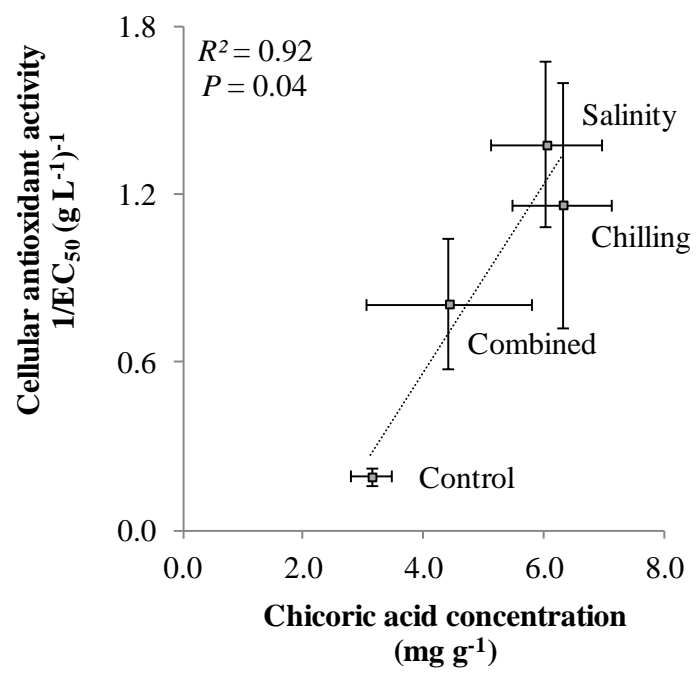

$\mathrm{C}$

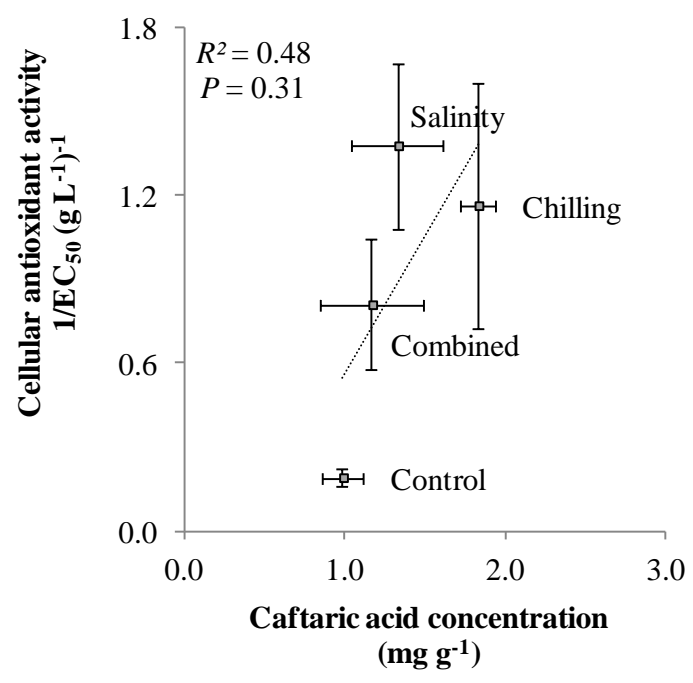

Figure 3.18 Linear correlations between cellular antioxidant activities inside HepG2 cells infused with leaf extracts of ACB ecotype of Sonchus oleraceus $\mathrm{L}$. at week 10, which had been exposed to two weeks of chilling, salinity and the combination of the two, with the concentrations of: (A) chlorogenic acid, (B) chicoric acid, (C) ascorbate and (D) caftaric acid. Means \pm SE $(n=5)$. 


\subsection{DISCUSSION}

My study has confirmed that differences among plant age, ecotypes and growing conditions can lead to variation in extractable antioxidant activities of S. oleraceus. Of the three factors, plant maturation had the largest effect on content of hydroxycinnamic acids, total phenolics and on antioxidant activities, followed by ecotype, while stressors had minor effects. Older plants were richer in ascorbate, hydroxycinnamic acids and had higher antioxidant activities. Of the two ecotypes tested, ACB had the stronger antioxidant potential than OAM and was richer in ascorbate and phenolic acid concentration. Applications of chilling, salinity and their combination significantly increased concentrations of chlorogenic acid in leaves of young plants from both ecotypes. Furthermore this study confirmed that the concentration of chlorogenic acid, chicoric acid, total phenolics and chemical estimates of antioxidant capacity of the leaf extracts from the youngest plants, correlate well with cellular measures of antioxidant activities within cultured human HepG2 cells. These results indicate that it is indeed possible to manipulate antioxidant levels in S. oleraceus through the judicious use of high yielding ecotypes, the harvesting of mature plants, and the imposition of moderate stressors. Moreover, the data suggest that improvements in the antioxidant status of leaf cells may translate to higher antioxidant protection in cultured human cells.

The transition from vegetative to reproductive growth was associated with an increase in the leaf accumulated ascorbate, hydroxycinnamic acids and other phenolic compounds, and antioxidant activities. Such increases occurred irrespective of the treatment applied to the plants and the ecotype (Figures 3.4 and 3.8A). This may be explained by accelerated secondary metabolism during reproduction, which is often accompanied by an enhanced production of phenylpropanoid compounds (Acamovic and Brooker, 2005; Papageorgiou et al., 2008; Franz et al., 2011). In other species, too, phenolic compounds have been shown to increase to their maximum levels at flowering; for example, chlorogenic acid in Hypericum origanifolium (Çirak et al., 2007), total phenolic content in Mentha pulegium (Karray-Bouraoui et al., 2010), rutin, quercetin, isoquercetin, hypericin, and hyperforin in various Hypericum spp (Abreu et al., 2004; Ayan et al., 2006; Çirak et al., 2006; Couceiro et al., 2006). 
That the combined chilling and salinity treatments did not show synergistic effects (Figures 3.5 and 3.6) suggests there may be a common mechanism for minimising damage that involves the activation and transcription of genes for phenolic biosynthesis by both chilling and salinity (Mittler, 2006; Tattersall et al., 2007; Chattopadhyay et al., 2011). Crosstalk between chilling- and salinity-stressor pathways has been reported previously, and is explainable since both stressors generate ROS due to osmotic stress (Bohnert and Sheveleva, 1998; Chinnusamy et al., 2007), and they induce different but overlapping suites of genes (Narusaka et al., 2004; Fujita et al., 2006; Liu et al., 2008; Fraire-Velázquez et al., 2011). In Helianthus annuus, for example, of the genes that were activated by chilling or by salinity, $63 \%$ were similar for both stressors. In A. thaliana similar miRNA accumulated under both cold and salt stressors (Liu et al., 2008). Thus, common responses stimulated by both stressors (Fernandez et al., 2008) may have abolished possible additive or synergistic accumulations of phenolic acids as might have been predicted by the responses to each stressor individually.

Chilling and salinity, when applied separately, did not influence the concentration of total phenolics or ORAC antioxidant activities in S. oleraceus (Figure 3.5A,C). In other species chilling and salinity enhanced the biosynthesis of phenolic compounds; for example, chilling increased ferulic acid in Glycine $\max$ and caffeoyl derivatives in Solanum esculentum, while root zone $\mathrm{NaCl}$ salinity increased chlorogenic and chicoric acids in Echinacea angustifolia, and caffeic acid derivatives in Olea europaea (Janas et al., 2000; Montanari et al., 2008; Ben Ahmed et al., 2009; Remorini et al., 2009; Løvdal et al., 2010). It is noteworthy that prolonged exposure to these stressors caused acclimatory responses, which resulted in polymerisation of synthesised phenolic compounds and incorporation into the cell wall (Janas et al., 2000; López Pérez et al., 2007). It is, therefore, possible that in S. oleraceus, too, prolonged exposure to stressors resulted in incorporation of phenolic compounds into cell wall phenylpropanoid compounds, which rendered them undetectable through the Folin-Ciocalteu method using methanolic leaf extracts (Pociecha et al., 2008). Certainly, acclimation to stressors in $S$. oleraceus was indicated by higher rates for NPQ curves (Figures 3.11C,D - 3.13C,D) which indicated strong xanthophyll cycle activities, which presumably enabled the stressor-imposed plants to maintain lower declining rates for $\Delta \mathrm{F} / \mathrm{F}_{\mathrm{m}}^{\prime}, \mathrm{q}_{\mathrm{P}}$ and ETR curves with increasing PAR compared to controls (Figures 3.11A,B,E-G - 3.13A,B,E-G). Similar observations were made in: cold acclimated Triticum aestivum and Secale cereal, 
salinity treated Sonneratia alba and Rhizophora stylosa and fruiting stressed Malus domestica (Oquist et al., 1993; DeEll and Toivonen, 2003; Kitao et al., 2003; Wünsche et $a l ., 2005)$. In my experiments, none of the treatments significantly damaged the PS II complexes in $S$. oleraceus, as indicated by $\mathrm{F}_{\mathrm{v}} / \mathrm{F}_{\mathrm{m}}$ values, which were within $0.80-0.83$ (Figure 3.10), a typical range for unstressed C3 plant species (Adams III et al., 2006). Even if photosystems of $S$. olearaceus were initially damaged by chilling and salinity, they could have recovered prior to the measurements of $F_{v} / F_{m}$ through rapid replacement of damaged D1 protein (Kornyeyev et al., 2002; Andersson and Aro, 2004; Strauss et al., 2007). Alternatively, they may have been protected by the direct scavenging activities of accumulated antioxidants or through utilizing the excess energy from light harvesting complexes for phenylpropanoid biosynthesis (Grace and Logan, 2000; Niggeweg et al., 2004; Mondolot et al., 2006; Hernández and Van Breusegem, 2010).

Chilling, salinity and their combination upregulated chlorogenic acid production in $S$. oleraceus leaves, while caftaric and chicoric acids were not affected, indicating stressors had a variable effect on the accumulation of these hydroxycinnamic acids (Figure 3.6). Although chilling and salinity have been shown previously to induce the expression and activity of phenylalanine ammonia-lyase (PAL), the subsequent synthesis of each phenolic compound was not influenced to the same degree, as documented for Echinacea angustifolia (Montanari et al., 2008), Lactuca sativa (Oh et al., 2009), Matricaria chamomilla (Kováčik et al., 2007), Glycine max (Janas et al., 2000), Olea europaea (Ortega-García et al., 2008) transgenic Nicotiana tabacum (Howles et al., 1996), and numerous other species (Blount et al., 2000; Blount et al., 2002). This is because in addition to PAL, various other enzymes are involved in the phenylpropanoid pathway. After PAL, cinnamic acid 4-hydroxylase $(\mathrm{C} 4 \mathrm{H})$, hydroxylates cinnamic acid into 4coumaric acid (Blount et al., 2002), which is then esterified into different hydroxycinnamic acids through a number of biosynthetic steps by specific cytochrome P450 monooxygenases (Hahlbrock and Scheel, 1989; Ehlting et al., 2006). Transcription and activity of genes for the cytochrome P450 monooxygenases are influenced by different stressors to variable degrees, as documented for Arabidopsis thaliana (Narusaka et al., 2004; Ehlting et al., 2006) resulting in the biosynthesis of different hydroxycinnamic acids in different quantities (Blount et al., 2002). 
Here, the effects of all three stressors on ascorbate concentration was not significantly different from the control (Figure 3.8B), which may be due to the null nett effect of stressor-enhanced transcription and activity of enzymes: ascorbate peroxidase (APX), Lgalactono-1,4-lactone dehydrogenase (GLDH), monodehydroascorbate reductase (MDHAR) and dehydroascorbate reductase (DHAR). GLDH is a key enzyme that regulates ascorbate biosynthesis, APX oxidises ascorbate while MDHAR and DHAR catalyses the regeneration of ascorbate from its oxidised forms in ascorbate-glutathione cycle (Wang and Frei, 2011). For example, salinity increased transcription and activity of enzymes catalysing the biosynthesis, recycling and oxidation of ascorbate in Solanum esculentum and Fragaria ananassa (Keutgen and Pawelzik, 2007; Sgherri et al., 2007; Sgherri et al., 2008).

It is clear, that the antioxidant potential of $S$. oleraceus ecotypes is heritable across generations; a strong genetic component contributes to the variation of antioxidant activities among S. oleraceus ecotypes overriding the effects of abiotic stressors. Leaf extracts from the ACB ecotype were on average 1.2 times more potent scavengers of DPPH radicals than were those of OAM irrespective of the treatment (Figure 3.4B). These plants were the F2 progeny of selfed plants, the parents of which showed 1.6-fold higher DPPH radical scavenging by ACB than by OAM leaf extracts (Ellwood, 2007). These higher antioxidant activities were associated with higher concentrations of phenolic compounds (Figures 3.4D-F). This may have arisen via differential expression of the PAL multigene family across plant accessions (Emmons and Peterson, 2001) and thus changing the concentrations of synthesised phenolics among members of the same species. Cultivar and ecotype differences in phenolic compound concentration have been reported for various species (Ehlenfeldt and Prior, 2001; Reddivari et al., 2007; Løvdal et al., 2010; Krüger et al., 2011), including S. oleraceus (Schaffer, 2005; Ellwood, 2007).

ACB plants had more leaf ascorbate than OAM plants (Figure 3.8A). This may be explained by higher rates ascorbate biosynthesis and recycling in ACB compared to OAM. Reinforcing this idea, varieties of Diospyros kaki, Solanum esculentum, Setaria italica and Triticum aestivum that accumulated more ascorbate had higher transcription and activities of enzymes: GLDH, MDHAR, DHAR compared to low ascorbate-yield varieties (Sreenivasulu et al., 2000; Bartoli et al., 2005; Zushi and Matsuzoe, 2007). Discovery of ecotypes rich in ascorbate is important due to its potent antioxidant 
activities and multiple health benefits for humans (Section 1.1.1). The DPPH radical scavenging capacity of ascorbate was 15 times more efficient than quercetin (LoNostro et al., 2000).

Chlorogenic and chicoric acid concentrations in S. oleraceus leaves positively linearly correlated with CAA values in HepG2 cells (Figure 3.18A,B) while caftaric acid did not (Figure 3.18D). This may be explained by higher lipophilicity and lower polarity of chlorogenic and chicoric acid than caftaric acid, which better facilitates the absorbance into HepG2 cells and therefore their antioxidant activities within the cells. The lipophilicity estimated as the $\log$ of octanol-water partition coefficient $\left(\log K_{\mathrm{ow}}\right)$ of chicoric acid $\left(\log \mathrm{K}_{\mathrm{ow}}=3\right.$ ), is three-fold higher than that of caftatric acid $\left(\log \mathrm{K}_{\mathrm{ow}}=1\right)$, thus lowering the ability of caftaric acid to cross cell membranes compared to chicoric acid (Iranshahi and Amanzadeh, 2008). Chlorogenic acid, too, is less polar and more lipophilic than caftaric acid since the polarity of the quinic acid moiety in chlorogenic acid is lower than the tartaric acid moiety in caftaric acid (Clifford et al., 2003; Pellati et al., 2004). Because higher lipophilicity ensures better transport of these across cell membranes (Burdette et al., 2002; Wu et al., 2007; Zhang et al., 2008), these compounds are better antioxidants in cellular compartments compared to caftaric acid. Confocal laser scanning microscopy has confirmed that phenolic compounds in S. oleraceus leaf extracts are indeed absorbed into HepG2 cells (rather than being bound to external cell membranes) whereupon they exhibit antioxidant activities (McDowell et al., 2011).

Total phenolic concentration and extractable antioxidant activities in S. oleraceus leaf extracts correlated well with CAA values in HepG2 cells (Figure 3.17). This indicates that phenolic compounds may have been largely responsible for the cellular antioxidant activities of $S$. oleraceus. Similarly, in other crops rich in phenolic compounds, strong correlations between ORAC values and CAA measures have been observed (Wolfe et al., 2008). However in crops with lower phenolic antioxidant activities, the correlations between ORAC and CAA were not significant (Eberhardt et al., 2005; Song et al., 2010).

The DPPH radical scavenging activities of leaf extracts and CAAs showed a lesser degree of correlation than that between ORAC and CAAs values (Figure 3.17A,B). This may be because both ORAC and CAA assays measure the ability of antioxidants to scavenge peroxyl radicals generated by a free radical generator at physiologically relevant 
conditions of $37{ }^{\circ} \mathrm{C}$ and $\mathrm{pH} 7.4$ (Section 4.5-4.6). In contrast, the DPPH assay measures the scavenging by antioxidants of the localised free electron on the DPPH molecule, which bears very little resemblance with biologically relevant conditions (Prior et al., 2005).

In summary, the variation of LMWA activities in S. oleraceus is largely associated with plant ageing, followed by ecotype that appears to be heritable. There are also some beneficial effects of the abiotic environment. Furthermore, an extractable antioxidant activities of leaf extracts correlates well with the cellular antioxidant activities inside HepG2 cells. In conclusion, leaves with highest antioxidant activities and concentrations of LMWAs were obtained at week 12 from $\mathrm{ACB}$, and exposure to cold night temperatures further augmented the levels. Agronomic recommendations that can be formulated from this study to obtain harvestable leaves rich in antioxidants are: use of selfed seeds from superior ecotypes across cropping cycles, harvesting leaves from flowering plants, and coinciding harvesting period with the incidences of low night temperatures. 
CHAPTER 4: EFFECTS OF COOKING AND IN VITRO GASTROINTESTINAL DIGESTION ON THE ANTIOXIDANT ACTIVITIES OF PHENOLIC COMPOUNDS IN Sonchus oleraceus L.

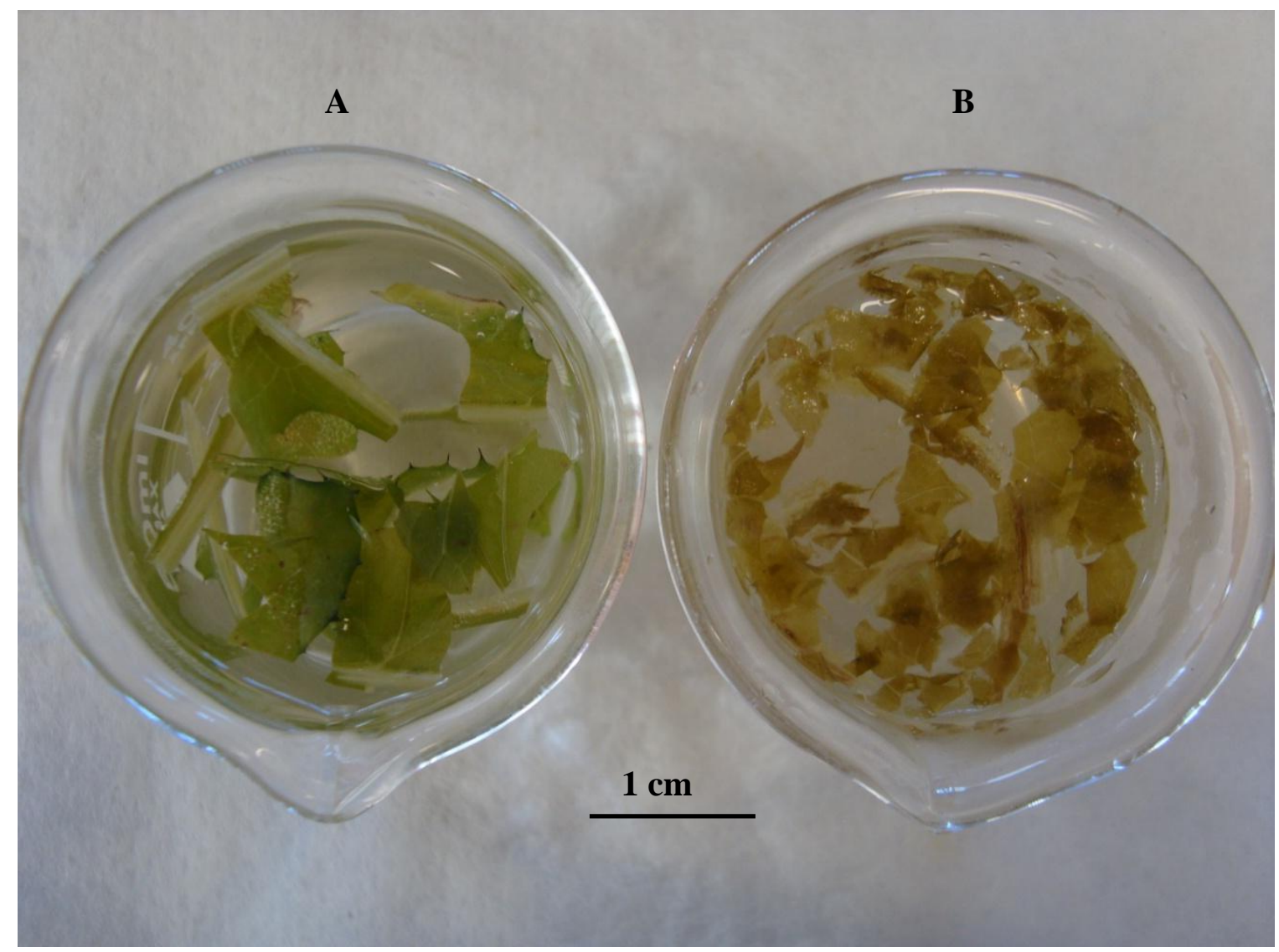

Plate 4.1 Sonchus oleraceus L. leaves (A) boiled for 5 min and (B) digestate remaining after in vitro gastrointestinal digestion for $120 \mathrm{~min}$. 


\subsection{ABSTRACT}

Leaves of Sonchus oleraceus L., a traditional component of the Māori diet in New Zealand, are rich in phenolics and show potent extractable antioxidant activities. However, the stability and antioxidant activities of these compounds after cooking and gastrointestinal digestion are unknown. Extractable antioxidant activities, HPLC profiles, the concentration of ascorbate and phenolic compounds, and cellular antioxidant activities in Caco2 and HepG2 cells were measured in raw and boiled S. oleraceus leaves and in their bioaccessible fraction obtained after gastric and intestinal digestion. Boiling significantly diminished the concentration of ascorbate, chicoric acid and oxygen radical absorbance capacity (ORAC), but did not affect 2,2-diphenyl-1-picrylhydrazyl (DPPH) radical scavenging activity or concentrations of total phenolic compounds, caftaric and chlorogenic acids in the bioaccessible fraction compared to raw leaves. After $30 \mathrm{~min}$ gastric digestion, ORAC and DPPH activities, and total phenolic concentration in the bioaccessible fraction approached those measured from untreated leaves. Phenolics released from gastric digestion were absorbed into Caco2 and HepG2 cells and exerted antioxidant activity. Intestinal digestion of leaf residues after gastric digestion released further antioxidants. During gastrointestinal digestion only chicoric, chlorogenic, and caftaric acid were stable out of nine antioxidants present in untreated leaves. That these key phenolics are released from leaves by digestion, and are absorbed into human cells wherein they exert antioxidant activity, indicates that $S$. oleraceus leaves may be suitable as an excellent dietary antioxidant source.

KEYWORDS: Sonchus oleraceus, antioxidant stability, gastrointestinal digestion, phenolics, HepG2 cells 


\subsection{INTRODUCTION}

The sow thistle, Sonchus oleraceus L. has traditionally been eaten by Māori as a leafy vegetable after boiling for 5 - 30 minutes (Cambie and Ferguson, 2003; Whyte et al, 2001). S. oleraceus produces leaves that contain exceptionally high concentrations of ascorbic acid and other phenolic compounds (Guil-Guerrero et al., 1998; Simopoulos, 2004). Indeed, S. oleraceus leaves held the highest concentration of phenolic compounds among 16 edible leafy plant species chosen from the Italian cuisine (Conforti et al., 2009). The in vitro antioxidant activities of $S$. oleraceus leaves were two times higher than those of spinach, which ranked first in antioxidant activity among 27 vegetables common in human diet (Song et al., 2009). However, the antioxidant potential measured by chemical assays (Chapter 3.0; Section 3.5) does not necessarily translate into antioxidant activity in vivo; the compounds need to retain their antioxidant activities through the processes of cooking, gastrointestinal digestion, absorption, and transport to the target tissues (Chapter 1.0; Section 1.4). Nothing has been documented about the fate of antioxidants in S. oleraceus leaves during the cooking and digestion processes. It is not known whether they are released from the leaf matrix under physiological conditions of the digestive tract, nor whether the antioxidant activities are retained.

In other leafy vegetables, cooking has been found either to increase or decrease the concentrations of available phenolic compounds. Some cell wall-bound phenolic compounds can be liberated during cooking because high temperatures dissociates the covalent, ester, ether, or acetal bonds that held them; thus, the concentrations of phenolic compounds and their associated antioxidant capacities may increase beyond the levels prior to cooking (Robbin, 2003). For example, cooking liberated more phenolic compounds increasing the antioxidant capacity of citrus (Seok-Moon et al., 2004). Alternatively, cooking might decrease the levels of some phenolic compounds because heat can either polymerise or decompose the aromatic rings, thereby denaturing the compounds.

Efforts to simulate gastrointestinal digestion have had variable effects on the apparent bioaccessibilty of phenolic compounds in diets (Section 1.4; Tables $1.12-1.14$ ). In vitro gastrointestinal digestion released either more or lower levels of phenolic compounds than the levels that were extracted from the food prior to digestion (Rodríguez-Roque et 
al., 2013; Tagliazucchi et al., 2010). The increases were attributed to the release of phenolic compounds bound to proteins and carbohydrates in the food matrix through acid hydrolysis in the gastric phase and enzymatic hydrolysis in gastric and intestinal phases (Rodríguez-Roque et al., 2013). For example, caffeic and chlorogenic acids, hesperidin, naringenin and rutin levels were higher following in vitro gastrointestinal digestion of fruit juices. However, following in vitro gastrointestinal digestion, sinapic acid levels from fruit juice diminished, while flavonoid levels remained constant for grapes (Laurent et al., 2007).

Monitoring gastrointestinal digestion and uptake of LMWAs into human cells in vivo can be complex, and therefore models that simulate human gastrointestinal digestion and uptake have often been employed (Section 1.4; Table 1.11 and Section 1.6). Consequently, dissolution testing can be used to evaluate the bioaccessibility of LMWAs. In vivo gastric and intestinal conditions can be reproduced in dissolution tests by employing a paddle type dissolution apparatus (Plate 4.2) and following the protocol for conventional release solid dosage forms (Anon,(1988; Hu, 1998; Mann and Pygall, 2012). Following in vitro gastrointestinal digestion, the bioaccessible fraction is obtained by either filtration or centrifugation of the simulated gastrointestinal solution (MoredaPiñeiro et al., 2011). After dissolution testing, the cell models can be employed to study the in vivo antioxidant activities of the antioxidant compounds in the bioaccessible fraction (Section 1.6).

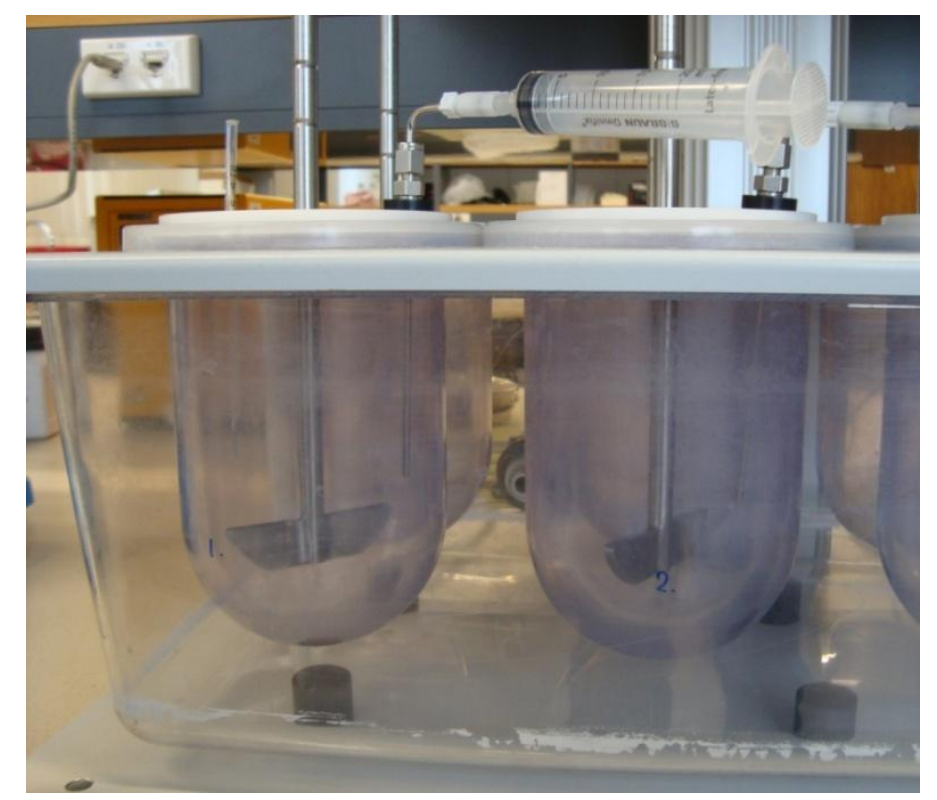

Plate 4.2 Paddle type dissolution apparatus (six-station Erweka DT 600 Dissolution Tester) 
Here, we identify and quantify the ascorbate, hydroxycinnamic acids, total phenolics and antioxidant activities of raw and boiled S. oleraceus leaves during in vitro gastrointestinal digestion, and then employ the CAA assay to identify cellular uptake and antioxidant activity of the raw, digested leaves. It was hypothesized that in vitro cellular and chemical antioxidant activities of $S$. oleraceus leaves survive cooking and in vitro gastrointestinal digestion, and are absorbed into human cells wherein they exert antioxidant activities.

\subsection{MATERIALS AND METHODS}

\subsubsection{Chemicals}

Pepsin from porcine gastric mucosa and pancreatin from porcine pancreas were purchased from Sigma-Aldrich (St Louis, MO). All other chemicals are listed at Section 2.1 .

\subsubsection{Plant Materials}

S. oleraceus were grown as described in Section 3.3.1 from seeds collected from a natural population at Acacia Bay in North Island of New Zealand. The plants were grown for 84 days during January to April 2011. The leaves from nodes 5 and 6 were removed from 48 plants. Leaves were bisected longitudinally, one half (untreated control) was used for phytochemical analysis and the other for gastrointestinal digestion. For comparisons of antioxidant activities, fresh blueberry fruits (Vaccinium corymbosum) were purchased from a local supermarket (sourced from Blueberries Waikato, Ohaupo, New Zealand). Material intended for phytochemical analysis was prepared according to Section 3.3.3.

\subsubsection{Boiling}

Leaf portions were subdivided equally, and one half was boiled in water at $100{ }^{\circ} \mathrm{C}$ for 5 min to study the effects of cooking, and the other half used raw. 


\subsubsection{Gastric and Intestinal Digestion}

Artificial gastric juice and intestinal fluid were prepared as described in the British Pharmacopoeia (1988) and dissolution test performed according to the protocol for conventional release solid dosage forms (Anon, 1988). Gastric juice contained $34.2 \mathrm{mM}$ $\mathrm{NaCl}, 92.4 \mu \mathrm{M}$ pepsin and $80 \mathrm{mM} \mathrm{HCl}$ at $\mathrm{pH}$ 1.2. Intestinal fluid was made using $50 \mathrm{mM}$ $\mathrm{KH}_{2} \mathrm{PO}_{4}, 15.4 \mathrm{mM} \mathrm{NaOH}, 1.1 \mathrm{~g} \mathrm{~L}^{-1}$ of pancrease powder, and adjusted to $\mathrm{pH}$ 7.5. Digestion was performed in a six-station Erweka DT 600 Dissolution Tester (Plate 4.2; Erweka International AG, Basel, Switzerland) at $37{ }^{\circ} \mathrm{C}$ with a paddle speed of $50 \mathrm{rpm}$. Boiled and raw leaf portions cut into approximately $1 \mathrm{~cm}^{2}$ pieces $(9 \mathrm{~g})$ were incubated in $900 \mathrm{~mL}$ artificial gastric juice for $1 \mathrm{~h}$, and then the digestate was resuspended in $900 \mathrm{~mL}$ intestinal fluids for $1 \mathrm{~h}$. Aliquots of the fluids were withdrawn 5, 15, 30, and 60 min into each digestion, centrifuged at $24000 \mathrm{~g}$ for $5 \mathrm{~min}$, and supernatant stored at $-20{ }^{\circ} \mathrm{C}$ under nitrogen. A blank prepared using the same chemicals but without the leaf material was treated identically.

The analysis of total phenolics, DPPH radical scavenging activities, ORAC Assay, Cellular Antioxidant Activity (CAA) assay and online reverse phase HPLC-DPPH radical scavenging were performed as described in Sections $2.2-2.8$.

\subsection{STATISTICAL ANALYSIS}

Differences in antioxidant activities and antioxidant concentrations attributable to boiling and digestion were evaluated using repeated measures ANOVA with Bonferroni post hoc tests $(P<0.05)$. Correlations were established by simple linear regressions $(P<0.05)$. Comparisons of linear regression were performed by ANCOVA $(P<0.05)$. Probit analysis was performed for CAA dose-response data. All analysis was performed using SPSS 18.0 statistical software. 


\subsection{RESULTS}

\subsubsection{Antioxidant activities and concentrations of ascorbate and phenolic compounds from untreated raw leaf extracts}

As measured by the DPPH assay, the antioxidant activities of methanolic extracts of fresh, untreated $S$. oleraceus leaves were on average four times greater than those of blueberry fruit on a dry weight comparison (ANOVA; $P<0.001$; Table 4.1). In contrast, measurements of the same extracts using the ORAC assay were only 1.3 -fold greater $(P=$ 0.5; Table 4.1). Concentration of total phenolic compounds, expressed as tannic acid equivalents, were 1.3 times higher in the $S$. oleraceus leaf extracts than in blueberries $(P$ $=0.14$; Table 4.1). The extracts from blueberries were three times more concentrated in ascorbate than $S$. oleraceus leaves $(P<0.001$; Table 4.1). Antioxidants from the methanolic extracts of fresh, untreated leaves entered the HepG2 and Caco2 cells and exhibited antioxidant activity in situ (Table 4.2).

Table 4.1 Antioxidant activities as measured by DPPH and ORAC, and concentrations of ascorbate and total phenolic compounds for methanolic extracts of Sonchus oleraceus L. raw leaves and blueberry fruit ${ }^{a}$

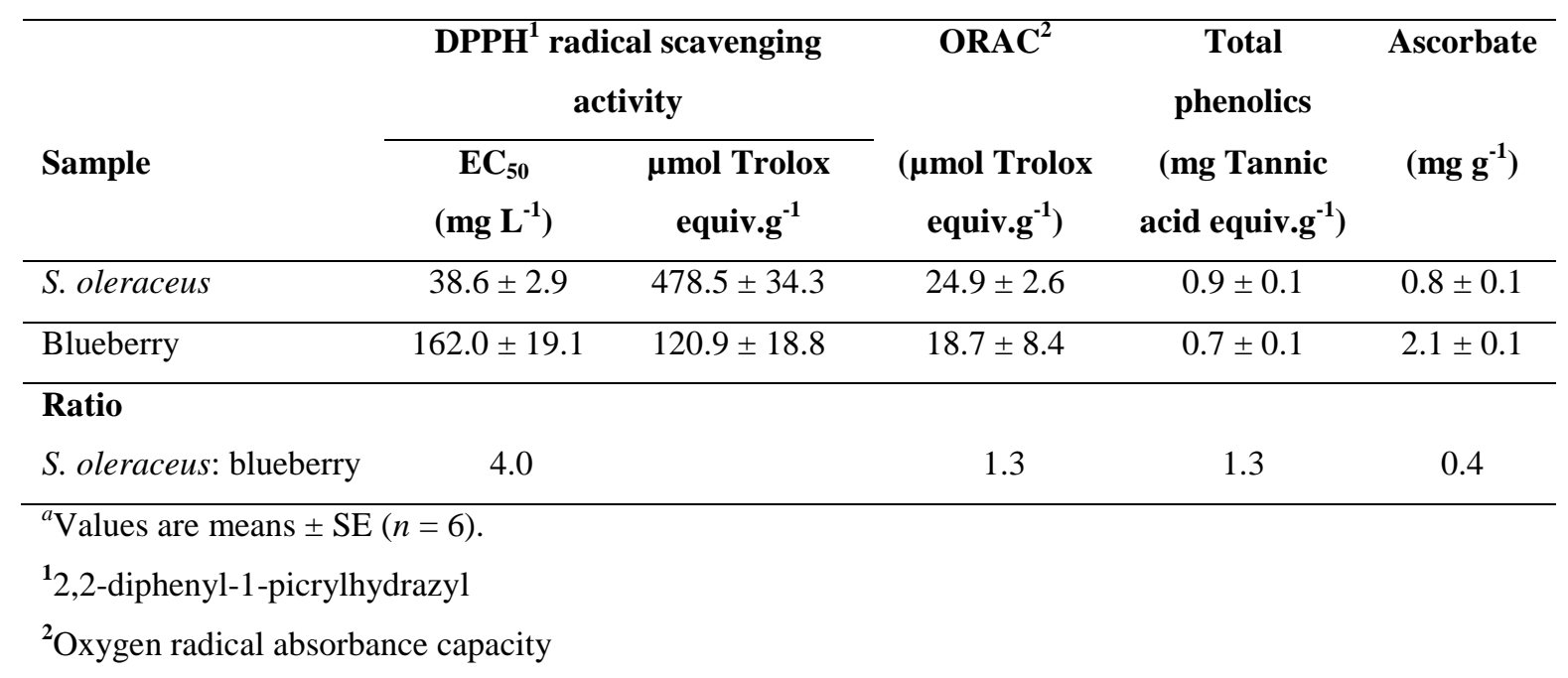


Table 4.2 Cellular antioxidant activities (CAA) for methanolic extracts of Sonchus oleraceus $\mathrm{L}$. raw leaves in HepG2 and Caco2 cells ${ }^{a}$

\begin{tabular}{lcc}
\hline Cell line & \multicolumn{2}{c}{ CAA } \\
\cline { 2 - 3 } & $\mathbf{E C}_{\mathbf{5 0}}\left(\mathbf{g ~ L ~}^{\mathbf{- 1}}\right)$ & $\left(\boldsymbol{\mu}\right.$ mol quercetin equivalent. $\left.\mathbf{g}^{-\mathbf{1}}\right)$ \\
\hline HepG2 & $0.4 \pm 0.1$ & $30.2 \pm 2.7$ \\
\hline Caco2 & $1.4 \pm 0.1$ & $3.9 \pm 0.1$ \\
\cline { 2 - 3 } Values are means $\pm \mathrm{SE}(n=6)$. &
\end{tabular}

HPLC profiles of the untreated leaf extracts revealed nine peaks at $320 \mathrm{~nm}$ that had corresponding DPPH radical scavenging activities (Figure 4.1). Of those, the hydroxycinnamic acids were present at the highest concentrations; caftaric, chlorogenic and chicoric acids eluted at 11.6, 14.5 and $27.0 \mathrm{~min}$, respectively, at concentrations of 3.5 $\pm 0.5,2.2 \pm 0.2$ and $9.5 \pm 0.6 \mathrm{mg} \mathrm{g}^{-1}$. These compounds were identified from their retention times in comparison with previous reports, and by co-elution with authentic standards (Ou et al., 2013).

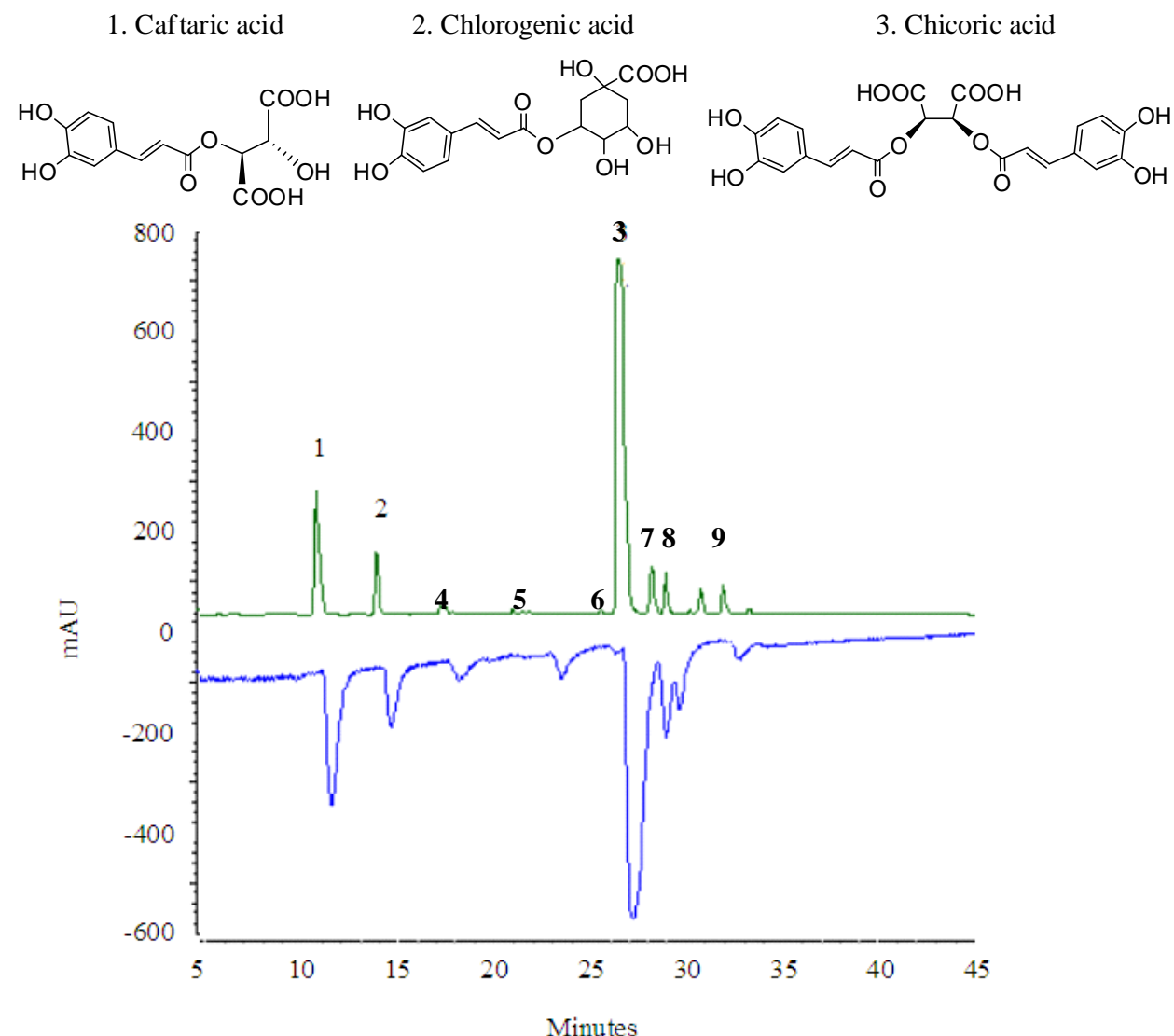

Figure 4.1 Reverse phase HPLC-DPPH chromatograms for methanolic extracts of Sonchus oleraceus L. raw untreated leaves. Phenolic acids (green line) measured at 320 nm; DPPH radical scavenging (blue line) at 518 nm. Peaks: 1, caftaric acid; 2, chlorogenic acid; 3, chicoric acid and 4 - 9, unknown. 


\subsubsection{Antioxidant activities and concentrations of ascorbate and phenolic compounds after boiling and gastrointestinal digestion}

Boiling S. oleraceus leaves for $5 \mathrm{~min}$ at $100{ }^{\circ} \mathrm{C}$ did not significantly alter concentrations of total phenolics (ANOVA; $P=0.14$ ) or antioxidant activities measured as DPPH $(P=$ $0.84)$ or ORAC activities $(P=0.99)$ in their methanolic extracts of untreated leaves (Figure 4.2). Boiling diminished concentrations of ascorbate $(P=0.03)$ and total hydroxycinnamic acids $(P=0.03)$ in methanolic extracts compared to raw leaves (Figure $4.3)$.

The bioaccessible fraction from both boiled and raw leaves held comparable concentrations of total phenolics (Figure 4.2A). However, raw leaves released more ascorbate (Figure 4.3A) and total hydroxycinnamic acids (Figure 4.3B) than boiled leaves into the bioaccessible fraction obtained through gastrointestinal digestion.

ORAC values of the bioaccessible fraction were lower for boiled than for raw leaves following digestion in both gastric and intestinal conditions $(P<0.001$; Figure 4.2C). In contrast, DPPH activities were higher for boiled than for raw leaves following gastric digestion $(P=0.05$; Figure 4.2B), but were comparable following subsequent intestinal digestion.

Importantly, the antioxidants in the bioaccessible fraction from raw leaves were absorbed into HepG2 (Figure 4.4A) and Caco2 cells (Figure 4.4B). Their CAA in HepG2 $(P=$ $0.01)$ and Caco2 cells $(P<0.001)$ were greater the longer leaves had been digested. The CAA values approached levels comparable to those from methanolic extracts of ground, untreated leaves just after 5 min of gastric digestion (Figure 4.4). Interestingly, the CAA values after 60 min of gastric digestion were three-fold greater than those of raw leaves in both cell types. Significant positive linear correlation exists for the CAA values obtained for the bioaccessible fraction between the two cell types (Figure 4.5). Increases in CAA in both cell types correlated linearly with the increases in hydroxycinnamic acid concentration in the bioaccessible fraction of raw leaves (Figure 4.6). 
A

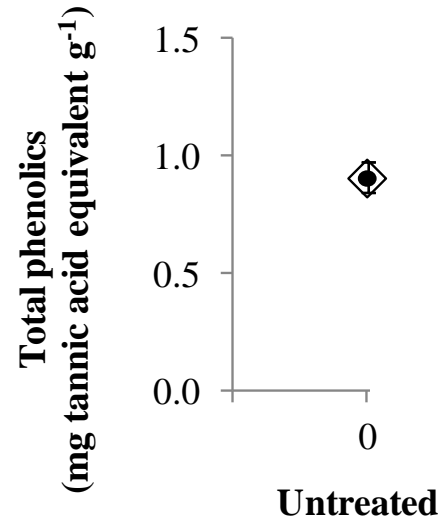

B

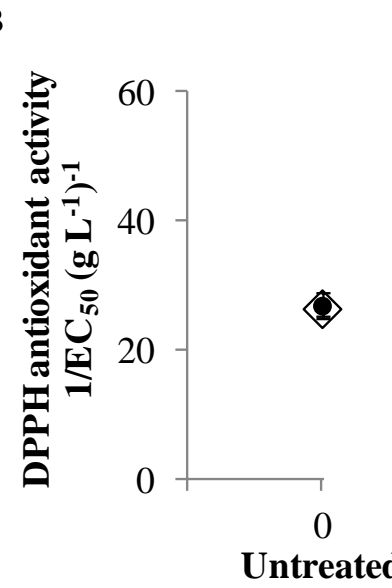

C

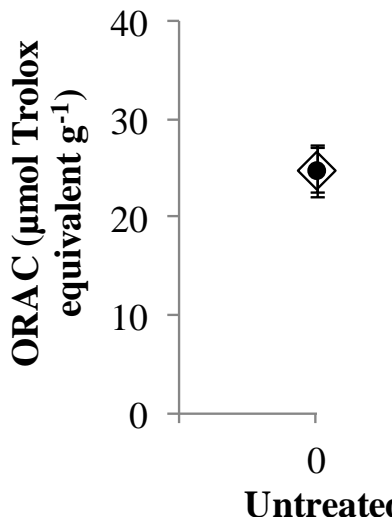

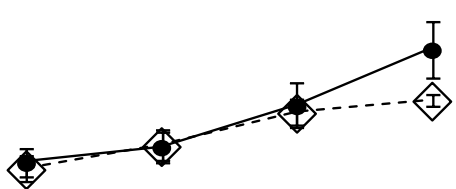
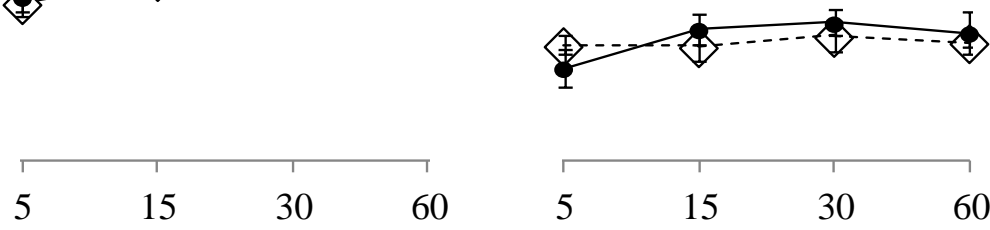

Gastric

Duration of digestion (min)

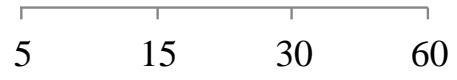

Intestinal

- Raw leaves

$--\vartheta-$ Boiled leaves

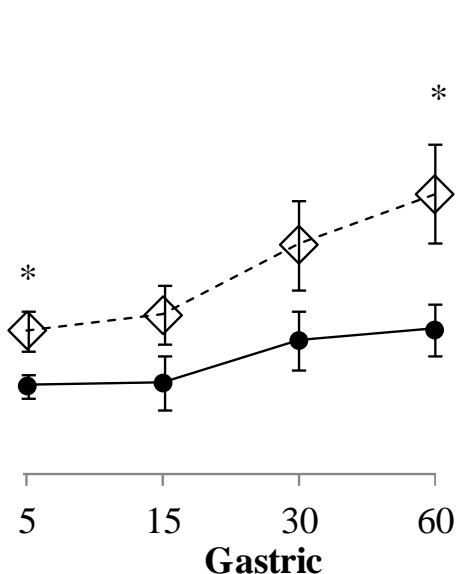

—- Raw leaves

$--\diamond-$ Boiled leaves

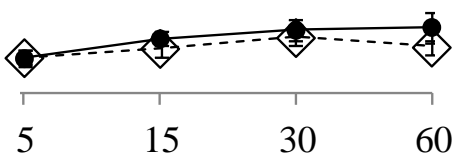

Duration of digestion (min)

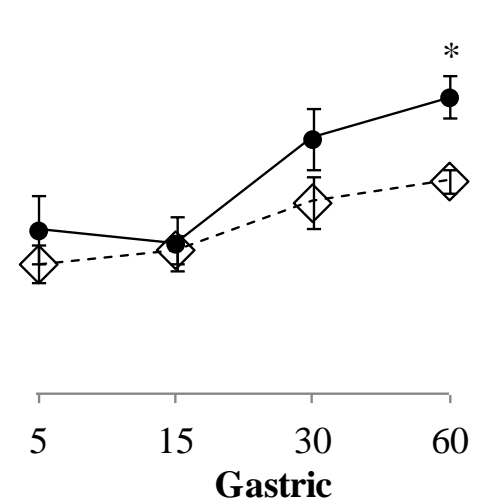

- - Raw leaves

$--\diamond-$ Boiled leaves
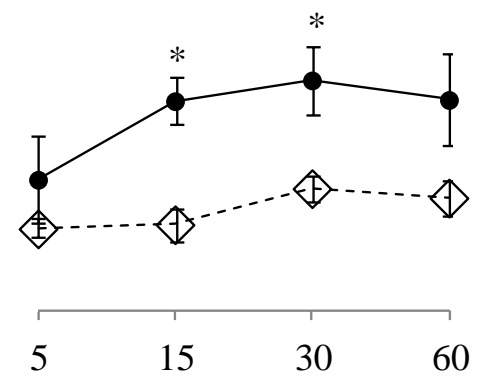

Duration of digestion (min)

Figure 4.2 Changes in (A) concentration of total phenolic compounds, (B) DPPH radical scavenging activity and (C) ORAC activity in the methanolic extracts of Sonchus oleraceus L. leaves and in the bioaccessible fraction during in vitro gastric and subsequent intestinal digestion. Means \pm SE $(n=6)$. *Significant difference between raw and boiled extracts at $P<0.05$. 
A

$\multimap$ Raw leaves

1

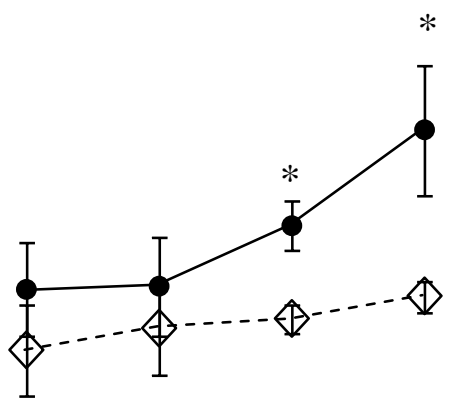

$-\diamond-$ Boiled leaves

\section{Untreated}

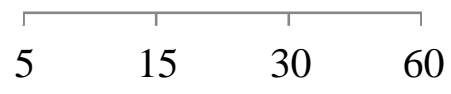

Gastric

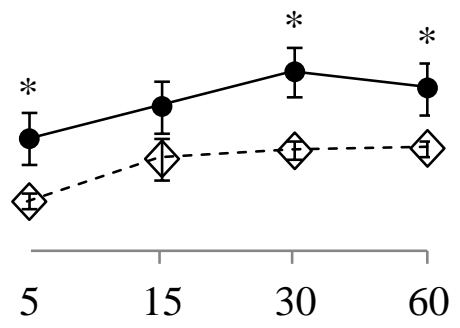

Intestinal

\section{Duration of digestion (min)}
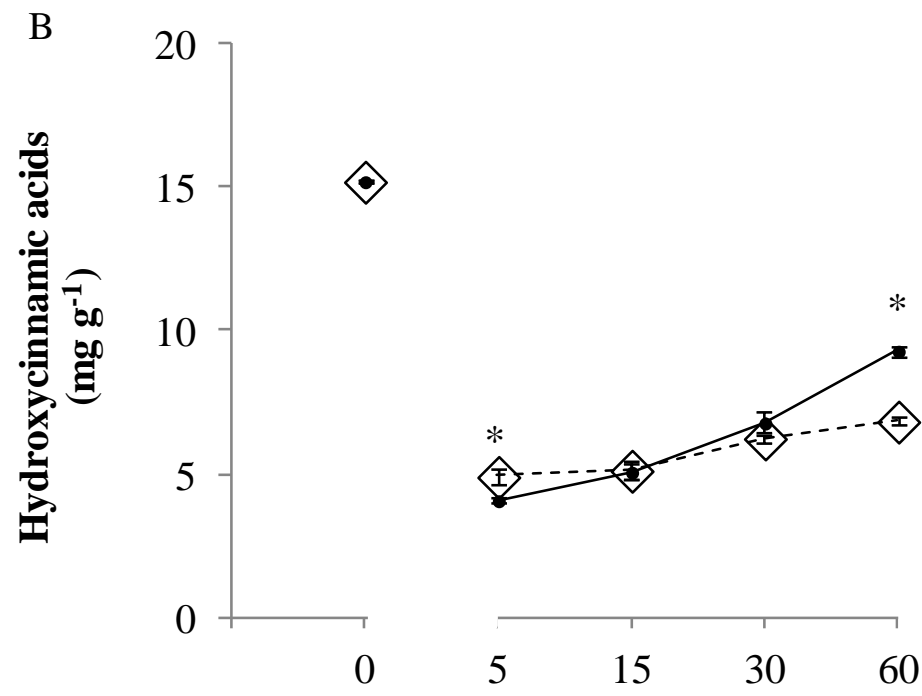

Untreated

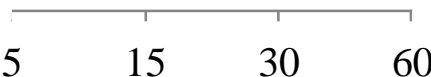

Gastric

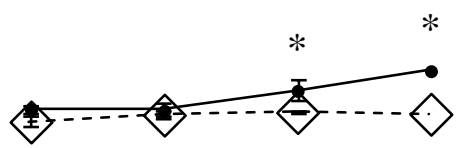

$\longrightarrow$ Raw leaves

$--\diamond-$ Boiled leaves

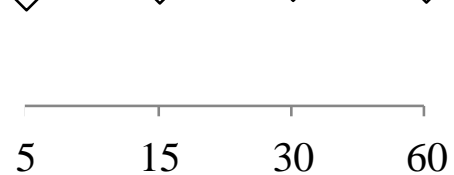

Intestinal

\section{Duration of digestion (min)}

Figure 4.3 Changes in concentrations of (A) ascorbate and (B) hydroxycinnamic acids in the methanolic extracts of Sonchus oleraceus $\mathrm{L}$. leaves and in the bioaccessible fraction during in vitro gastric and subsequent intestinal digestion. Means \pm SE $(n=6) .{ }^{*}$ Significant difference between raw and boiled extracts at $P<0.05$. 

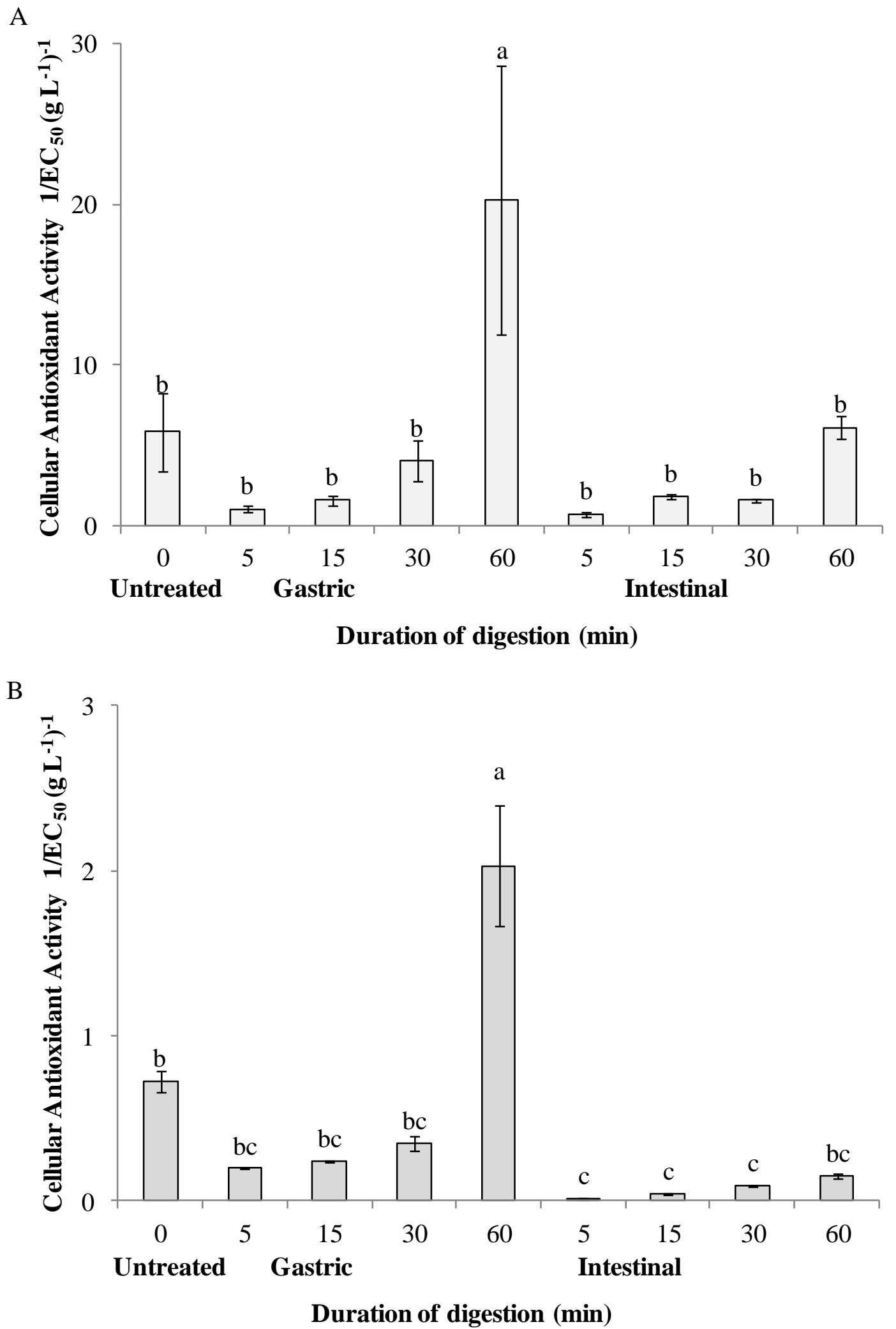

Figure 4.4 Cellular antioxidant activity measured in (A) HepG2 and (B) Caco2 cells infused with the methanolic extracts of Sonchus oleraceus L. raw leaves and the bioaccessible fraction following in vitro gastric and subsequent intestinal digestion. Means \pm SE $(n=6)$. Bars with different letters are significantly different $(P<0.05)$. 


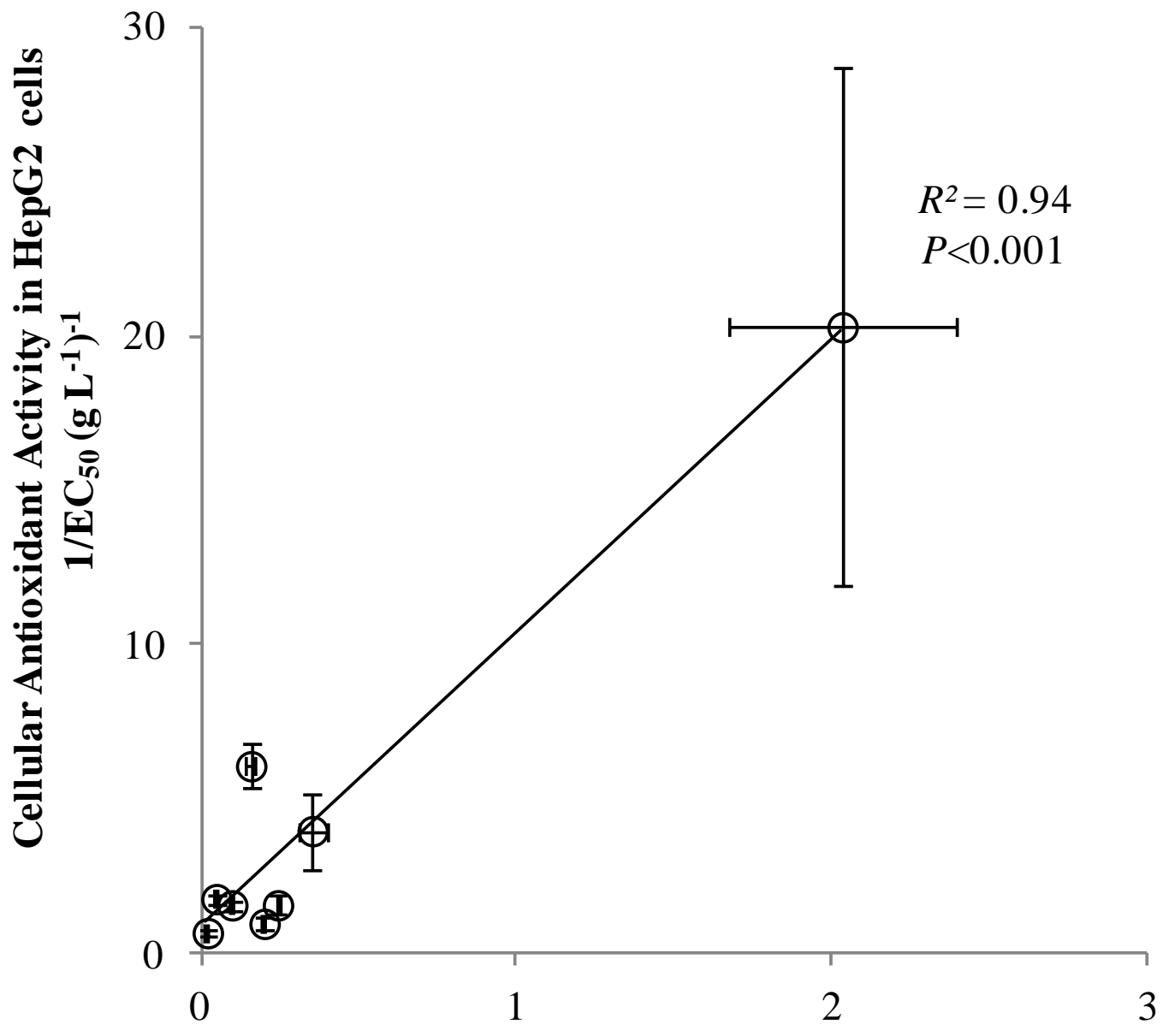

Cellular Antioxidant Activity in Caco2 cells

$1 / \mathrm{EC}_{50}\left(\mathrm{~g} \mathrm{~L}^{-1}\right)^{-1}$

Figure 4.5 Correlation of cellular antioxidant activities between Caco2 and HepG2 cells infused with the bioaccessible fraction following in vitro gastric and intestinal digestion of Sonchus oleraceus $\mathbf{L}$. raw leaves. Data are means $\pm \mathrm{SE}(n=6)$ for $5,15,30,60 \mathrm{~min}$ of gastric and 5, 15, 30 and 60 min intestinal digestion. 
A

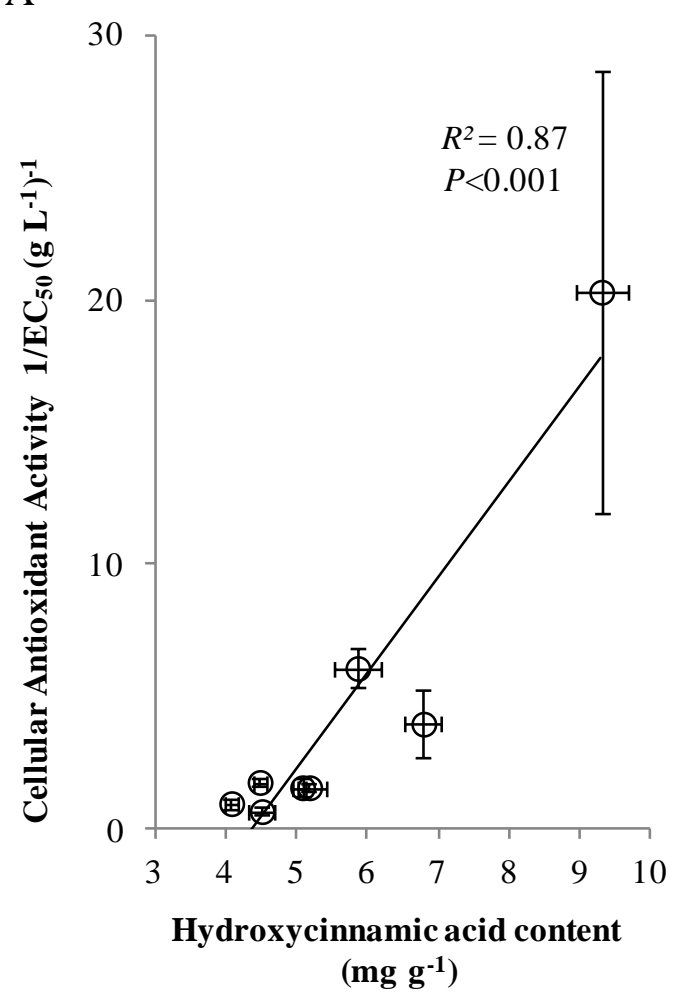

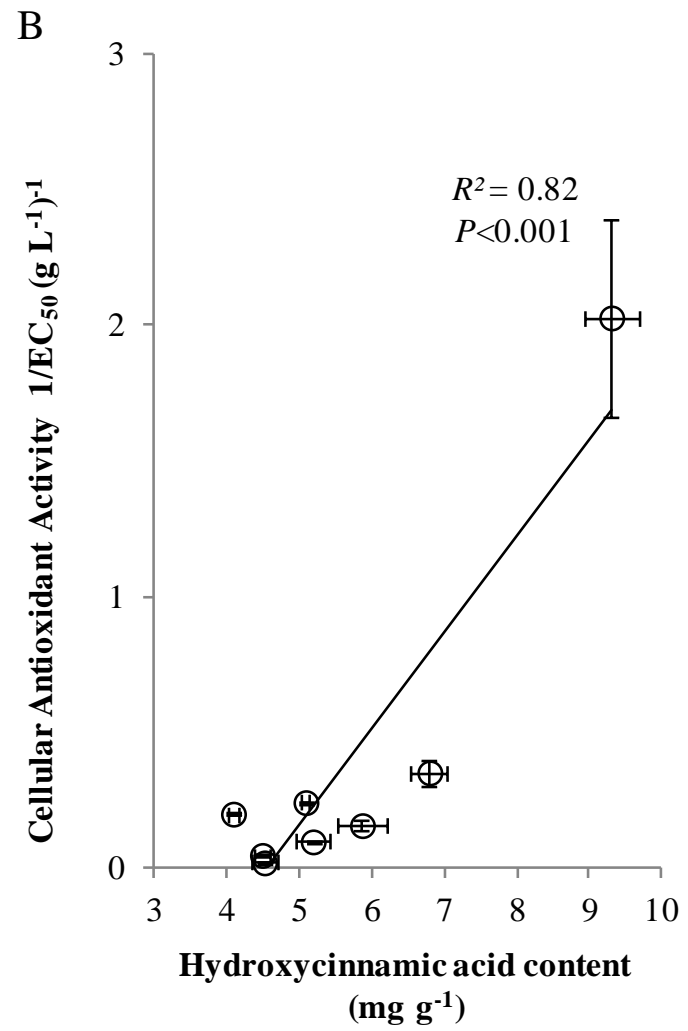

$\left(\mathbf{m g ~ g}^{-1}\right)$

Figure 4.6 Correlation between the concentration of hydroxycinnamic acids in the bioaccessible fraction and the cellular antioxidant activities measured in cells: (A) HepG2 and (B) Caco2, infused with the bioaccessible fraction following in vitro gastric and intestinal digestion of Sonchus oleraceus L. raw leaves. Data are means $\pm S E(n=6)$ for $5,15,30$ and $60 \mathrm{~min}$ of gastric and 5, 15, 30 and $60 \mathrm{~min}$ intestinal digestion.

As evidenced by HPLC-DPPH chromatograms (Figure 4.1), gastrointestinal digestion apparently degraded six of the nine antioxidants present in methanolic extracts of untreated leaves and none remained in the digestate at the end of gastrointestinal digestion (Figure 4.7). Only caftaric, chlorogenic and chicoric acid were prominent in HPLC profiles collected from the bioaccessible fraction during gastric and intestinal digestion of leaf material (Figure 4.8 A-B). These three compounds had associated DPPH radical scavenging activity shown by the magnitude of the negative peak in the HPLC chromatograms. 


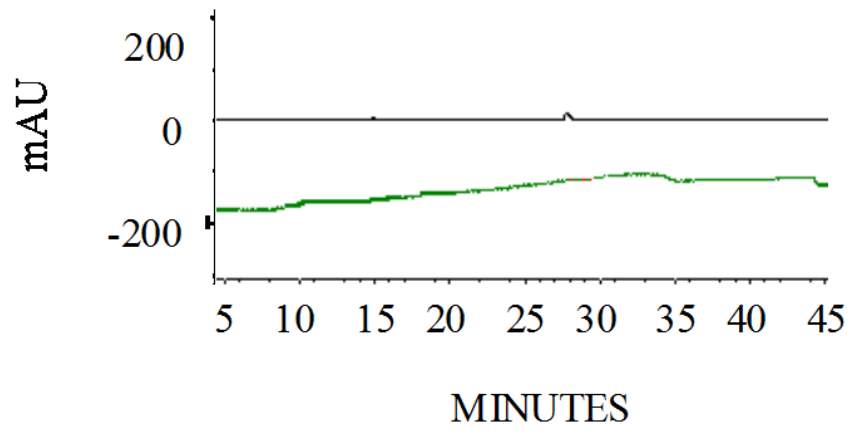

Figure 4.7 Reverse phase HPLC-DPPH chromatogram for methanolic extract of leaf digestate remaining after in vitro gastric and subsequent intestinal digestion of Sonchus oleraceus L. leaves. Phenolic acids (black line) measured at $320 \mathrm{~nm}$; DPPH radical scavenging (green line) at $518 \mathrm{~nm}$.

A

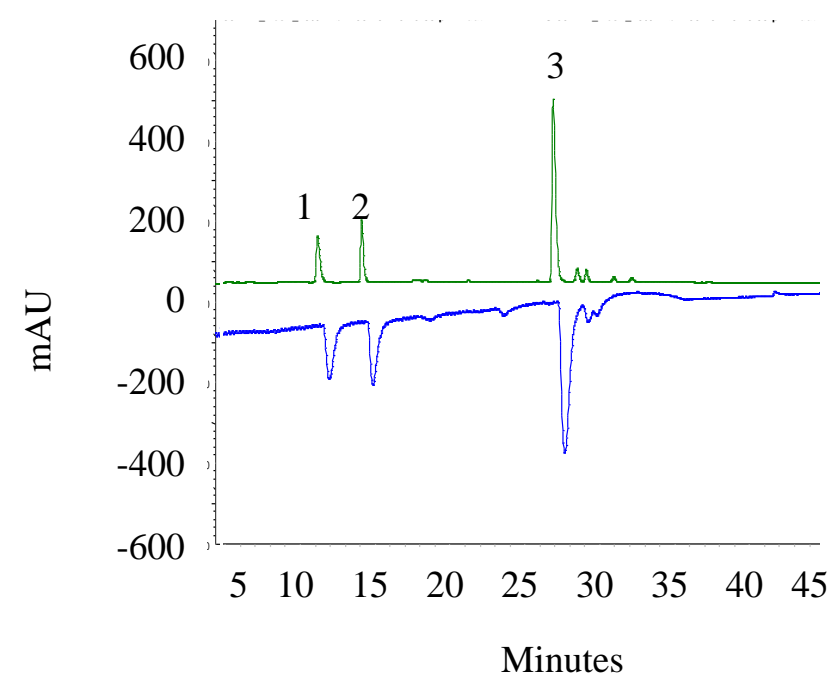

B

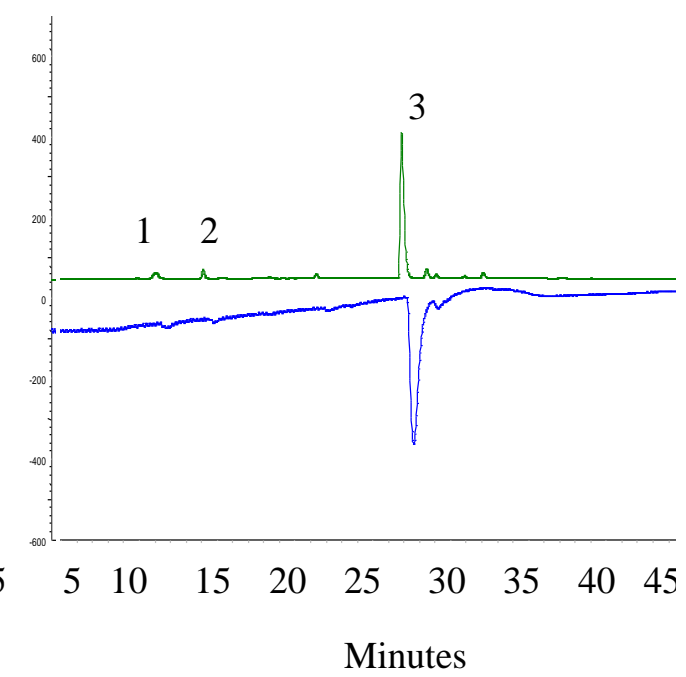

Figure 4.8 Reverse phase HPLC-DPPH chromatograms recorded for bioaccessible fraction of Sonchus oleraceus L. raw leaves, 60 minutes after in vitro (A) gastric and (B) intestinal digestion. Phenolics (green line) measured at $320 \mathrm{~nm}$; DPPH radical scavenging (blue line) at $518 \mathrm{~nm}$. Peaks: 1, caftaric acid; 2 , chlorogenic acid and 3 , chicoric acid. 
Gastrointestinal digestion of leaves resulted in the release of all the chlorogenic acid (ANOVA; $P=0.29$; Figure 4.9A) and ascorbate content $(P=0.41$; Figure $4.9 \mathrm{~B})$, which were initially present in their leaves regardless of boiling. The level of chicoric acid released through gastrointestinal digestion was significantly lower than those extracted from untreated leaves $(P<0.001$; Figure 4.9C).

The chicoric acid levels released through digestion by boiled leaves were lower than for raw leaves $(P=0.004$; Figure 4.9C). However, the release of chlorogenic acid $(P=0.14$; Figure 4.9A) and caftaric acid $(P=0.24$; Figure 4.9D) by digestion was similar for boiled and raw leaves. The bioaccessible fraction held a higher proportion of caftaric and chlorogenic acids when using boiled rather than raw leaves (Figure 4.10).

The concentrations of total hydroxycinnamic acids in the bioaccessible fraction positively linearly correlated with the increases in: total phenolic concentrations (Figure 4.11A) and antioxidant capacities determined by ORAC (Figure 4.11B) and DPPH assays (Figure 4.11C), for both raw and boiled leaves. Linear regression coefficients for DPPH radical scavenging versus the hydroxycinnamic acids in the bioaccessible fractions differed between boiled and raw leaves; the gradient for boiled leaves was five-fold higher than for raw leaves (ANCOVA; $P<0.001$; Figure 4.11C). 
A

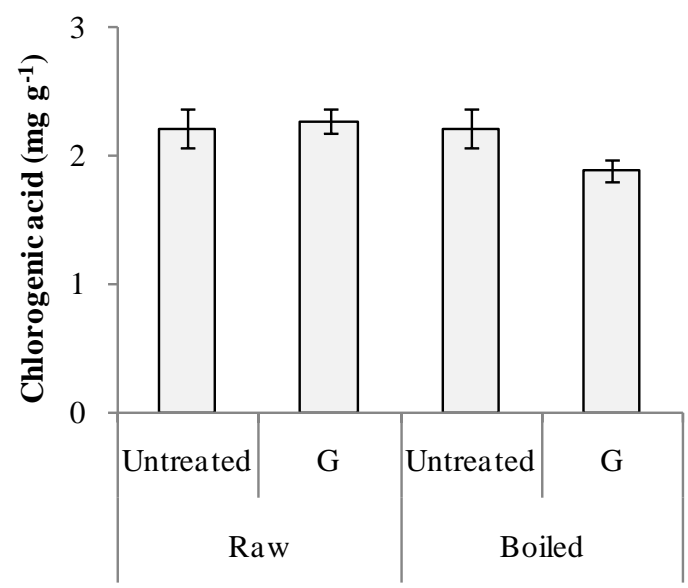

$\mathrm{C}$

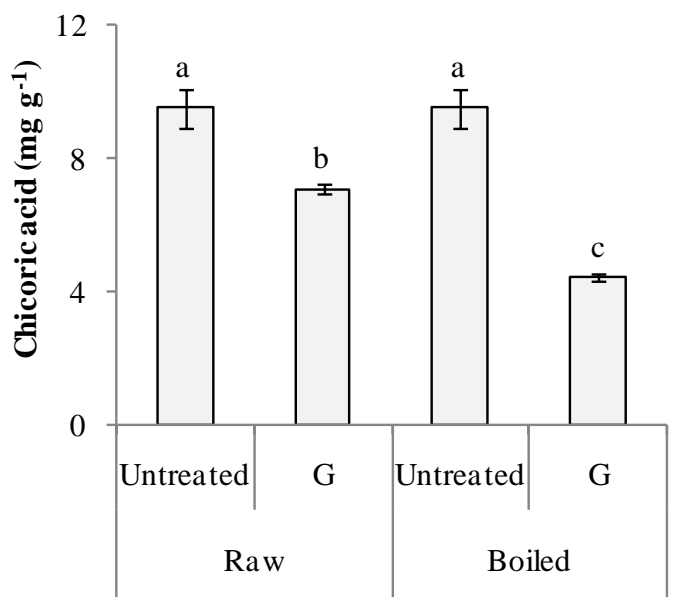

B

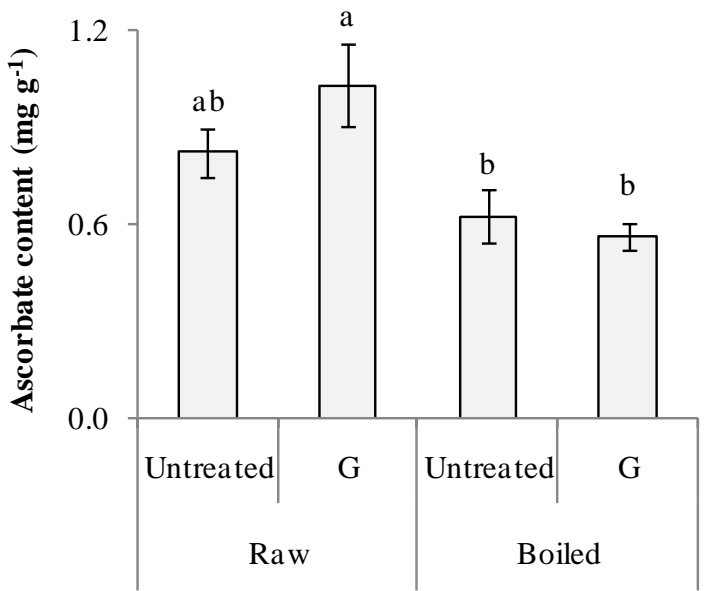

$\mathrm{D}$

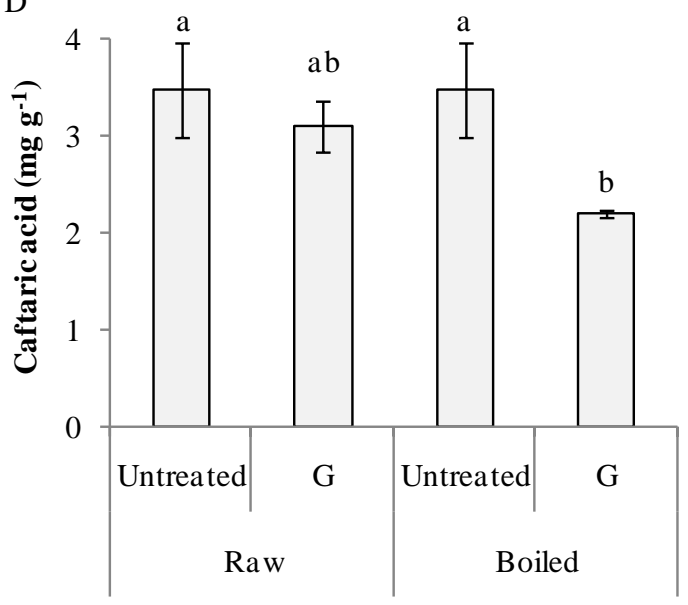

Figure 4.9 Concentration of (A) chlorogenic, (B) ascorbic, (C) chicoric and (D) caftaric acids in the methanolic extracts of Sonchus oleraceus L. raw and boiled leaves, and in the bioaccessible fraction following in vitro gastrointestinal digestion (G). Means \pm SE (n=6). Bars with different letters are significantly different $(P<0.05)$.

A

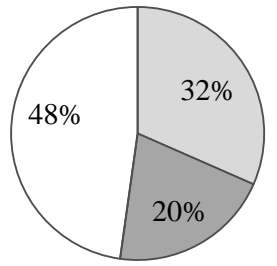

Raw leaves

$\square$ Caftaric acid

$\square$ Chlorogenic acid

$\square$ Chicoric acid
B

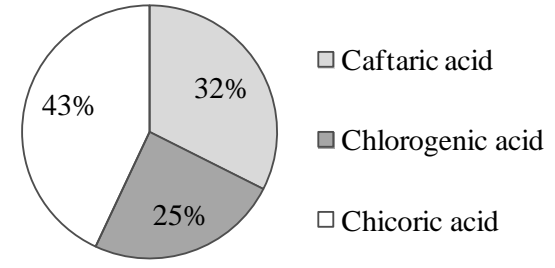

Figure 4.10 Proportional contributions of three main hydroxycinnamic acids to the total phenolic acids in the bioaccessible fraction of Sonchus oleraceus L. raw and boiled leaves 


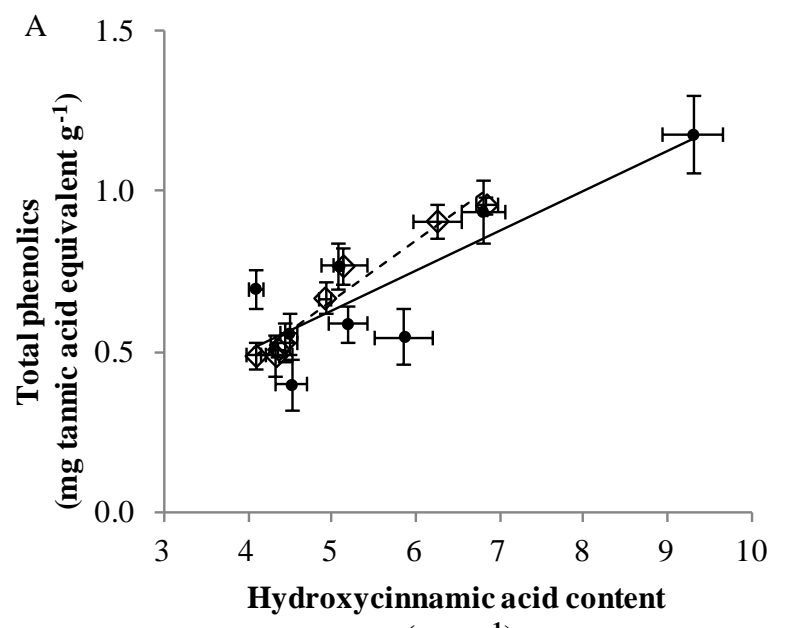

- Raw leaves

$\diamond \quad$ Boiled leaves

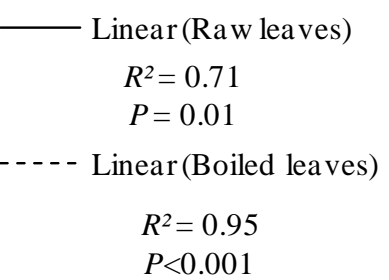
(mg g $\left.{ }^{-1}\right)$

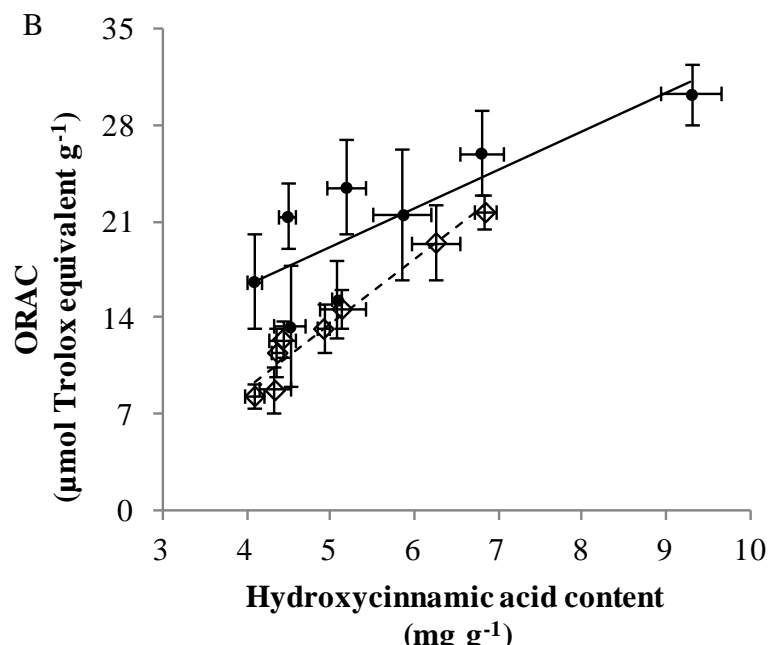

- Rawleaves

$\diamond \quad$ Boiled leaves
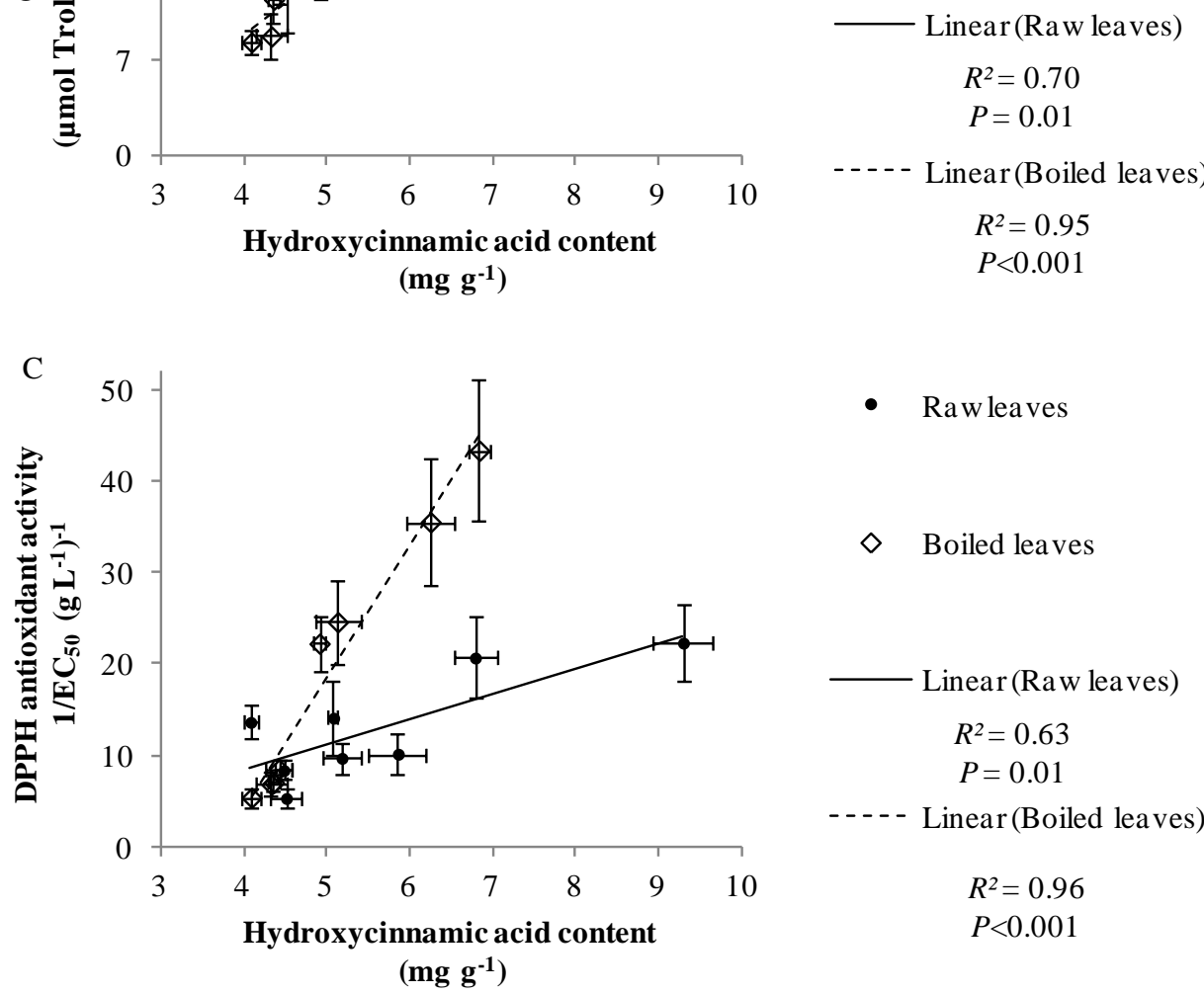

- Rawleaves

$\diamond \quad$ Boiled leaves

- Linear(Raw leaves)

$$
\begin{aligned}
R^{2} & =0.63 \\
P & =0.01
\end{aligned}
$$

- - - - Linear(Boiled leaves)

$R^{2}=0.96$

$P<0.001$

Figure 4.11 Linear correlations between the concentration of hydroxycinnamic acids and (A) concentration of total phenolic compounds and antioxidant activities measured by (B) ORAC and (C) DPPH techniques for the bioaccessible fraction of Sonchus oleraceus L. raw and boiled leaves during in vitro gastric and intestinal digestion. Data are means $\pm \mathrm{SE}(n=6)$ for $5,15,30$ and 60 min of gastric and 5, 15, 30 and 60 min intestinal digestion. 


\subsection{DISCUSSION}

Our study confirmed previous reports that the leaves of S. oleraceus are a particularly rich source of phenolic antioxidants. We showed that cooking the leaves by boiling them for 5 min did not appreciably diminish these antioxidant activities prior to in vitro gastrointestinal digestion. Significantly, three of the major phenolic compounds (caftaric, chlorogenic, and chicoric acids) were released into solution during gastrointestinal digestion. These compounds were absorbed by human HepG2 cells, whereupon they exhibited apparent antioxidant activity. Collectively, these data argue a compelling case for S. oleraceus as an excellent dietary antioxidant supplement to promote human health.

The high antioxidant potential of untreated $S$. oleraceus leaf extracts was confirmed using both the DPPH and ORAC assays (Table 4.1). DPPH radical scavenging activities were comparable to previous reports for this species (Ellwood, 2007; Yin et al., 2007), though four times weaker than values documented by McDowell et al. (2011) and three times more potent than reported by Simopoulos (2004). Differences are likely due to variation in growing environment and ecotypes on antioxidant activity of S. oleraceus (Section 3.5; Schaffer, 2005; Ellwood, 2007). ORAC values have not been reported previously for $S$. oleraceus leaves. On a dry weight basis, the leaves were richer sources of LMWAs than were blueberry fruit, though the magnitude of the difference varied substantially between the two assays (Table 4.1). Of the two, ORAC is likely to have provided the more reliable estimate of total antioxidant capacities, because steric restrictions to the radical site of DPPH can lead to overestimations of the capacities of the smaller antioxidant molecules (Prior et al., 2005). Phenolic acids in S. oleraceus leaves are small molecules and their percentage in LMWAs pool was three-fold greater than that in blueberries, possibly leading to overestimated DPPH values. The reverse phase HPLC-DPPH profiles confirm that caftaric, chlorogenic and chicoric acid accounted for $89 \%$ of the LMWAs in $S$. oleraceus leaf extracts (Figure 4.1). These hydroxycinnamic acids have been previously documented in S. oleraceus leaves (Gatto et al., 2011; Ou et al., 2013). In contrast, in blueberries, large molecules such as anthocyanins and glycosylated flavonols accounted for $71 \%$ of the phenolic pool while chlorogenic acid accounted for only $29 \%$ (Zheng and Wang, 2002). Nevertheless, the DPPH assay proved useful when used in conjunction with HPLC to measure the activities of known phenolic compounds (Figures 4.1, 4.7, 4.8). 
Boiling leaves for $5 \mathrm{~min}$ sufficiently cooks them (Whyte et al., 2001; Cambie and Ferguson, 2003a), and did not significantly diminish their phenolic compound concentration (Figure 4.2A). Boiling decreased the levels of released chicoric acid (Figure 4.9C), but not chlorogenic (Figure 4.9A) or caftaric acids (Figure 4.9D), which are more resistant to heat degradation than chicoric acid (Chkhikvishvili and Kharebava, 2001; Stuart and Wills, 2003). In other crops, it has been reported that boiling causes either a decline (Chu et al., 2000; Turkmen et al., 2005) or an increase (Doğan et al., 2005; Lee and Scagel, 2009) in the available phenolic compounds. Decreased levels of phenolics are often attributed to polymerisation or decomposition of aromatic rings, which denatures the compounds (Granito et al., 2005), or else to their removal in the water used for boiling (Turkmen et al., 2005). Alternatively, boiling may increase the release of phenolic compounds by enhancing the release of cell wall-bound compounds (Dewanto et al., 2002), and/or by halting polyphenol oxidase driven enzymatic oxidation (Doğan et al., 2005; Lee and Scagel, 2009).

Boiling did not significantly diminish the concentrations of ascorbate measured in methanolic extracts of leaves (Figure 4.3A) even though ascorbate is highly water soluble and heat labile. The ascorbate levels may have been stable because the oxidation of ascorbate into dehydroascorbate (DHA) in water at $100{ }^{\circ} \mathrm{C}$ is reversible (Vieira et al., 2000). Furthermore, the submerged leaves in boiling water may restrict contact between leaf ascorbate and oxygen thus limiting its oxidation; hot air drying of vegetables, for example, caused more ascorbate loss compared to boiling them at the same temperature (Mo et al., 2006; Gupta et al., 2013). Another possibility is that boiling for $5 \mathrm{~min}$ in water is insufficient to cause its loss through leaching into water. For example, vegetables that were boiled for long durations lost ascorbate through leaching but not when boiled for short durations (Lee and Kader, 2000; Oboh, 2005; Cruz et al., 2008). However, irreversible hydrolysis of DHA into 2,3-L-diketo-L-gulonate (2,3-DKG) occurred if incubation was continued for $60 \mathrm{~min}$ at $37{ }^{\circ} \mathrm{C}$ even without gastric or intestinal enzymes (Simpson and Ortwerth, 2000). This may have lowered the ascorbate levels detected in the bioaccessible fraction from boiled leaves compared to raw leaves (Figure 4.9B).

The bioaccessible fraction of the boiled leaves held less antioxidants than did raw leaves as detected by ORAC measurements (Figure 4.2C) and chicoric acid content (Figure 4.9C). However, this difference was not evident in the measurements of DPPH radical 
scavenging (Figure 4.2B), total phenolics (Figure 4.2A), caftaric (Figure 4.9D) or chlorogenic acid content (Figure 4.9A). The boiled leaves released proportionately more caftaric and chlorogenic acids than did raw leaves in the processes of digestion (Figure 4.10). The DPPH assay would, therefore, likely overestimate the antioxidant capacity of boiled leaves (Figure 4.11C) because caftaric and chlorogenic acids are small molecules with coplanar structures than have better access to the radical of the DPPH molecule than chicoric acid (Silva et al., 2000; Huang et al., 2005). For example, the molar volumes of caftaric $\left(184 \mathrm{~cm}^{3} \mathrm{~mol}^{-1}\right)$ and chlorogenic acids $\left(214 \mathrm{~cm}^{3} \mathrm{~mol}^{-1}\right)$ are respectively $60 \%$ and $30 \%$ smaller than that of chicoric acid $\left(289 \mathrm{~cm}^{3} \mathrm{~mol}^{-1}\right)$ according to www.chemspider.com (accessed April 2012). This means that antioxidant activities of the bioaccessible fraction of $S$. oleraceus leaves depend largely on the type and proportion of the compounds, which remain in the bioaccessible fraction; similarly seen during in vitro digestion of Solanum esculentum (Toor et al., 2008).

Temporal changes in antioxidant activities during gastrointestinal digestion recapitulated changes in concentrations of hydroxycinnamic acids, indicating that LMWA activities of S. oleraceus mainly depended on the release and stability of hydroxycinnamic acids during gastrointestinal digestion (Figure 4.11). The release of phenolics during in vitro gastric digestion has been attributed to acidity rather than to pepsin activity in a wide variety of fruits and vegetables (Bermúdez-Soto et al., 2007; Tagliazucchi et al., 2010). The glycosylated and esterified phenolic compounds are hydrolysed by the acidic conditions, which exist during gastric simulations (Liyana-Pathirana and Shahidi, 2005). Pepsin have lower activity or none towards phenolic compounds because pepsin prefer the hydrolysis of peptic bonds in amino acids (Beynon and Bond, 2001). The acid hydrolysis of bound phenolics in leaves (Liyana-Pathirana and Shahidi, 2005) would likely explain why levels of total phenolics released after combined gastric and intestinal digestions were approximately two-fold greater than those in methanolic extracts from untreated leaves (Figure 4.2C).

The reverse phase HPLC-DPPH profiles confirm that caftaric, chlorogenic and chicoric acids retain their stability (i.e. structure and antioxidant activity) following gastrointestinal digestion. There was no evidence that the three phenolics incurred structural transformations due to enzymatic action or $\mathrm{pH}$ variations that extinguished antioxidant activity (Figure 4.8). Gastrointestinal digestion facilitated the release of 
caftaric, chlorogenic and chicoric acids from the leaves. Consistent with these results, chlorogenic acid has been shown to retain its structure in the stomachs of rats (Lafay et $a l ., 2006)$ and in ileostomized humans on a liquid chlorogenic acid supplement (Olthof et al., 2001). Furthermore, chlorogenic acid is rapidly absorbed without structural transformations into the plasma in the stomachs of rats (Lafay et al., 2006), in normal healthy humans (Monteiro et al., 2007) and in ileostomized humans (Olthof et al., 2001). Chlorogenic acid is not hydrolysed by intestinal enzymes during in vitro digestion (Plumb et al., 1999a), though it was found to be transformed into neochlorogenic acid after $2 \mathrm{~h}$ of in vitro pancreatic digestion, attributable to the high $\mathrm{pH}(7.5)$ rather than to activities of pepsin or pancreatin (Bermúdez-Soto et al., 2007). Similar to our results, the physiological $\mathrm{pH}(7.4)$ and temperature $\left(37^{\circ} \mathrm{C}\right)$ had no impact on structure and activity of chicoric acid during in vitro intestinal simulation (Rossetto et al., 2008). Caftaric acid, too, maintains its structural integrity in the stomach of rats, and is rapidly absorbed into their plasma (Vanzo et al., 2007).

The CAA of undigested and digested raw leaves were measured using Caco 2 and HepG2 cells (Figure 4.4) since they are suitable models to study uptake and metabolism of antioxidants by cells, accordingly representing the intestinal epithelium and liver (Bornsek et al., 2012). The S. oleraceus digested leaves were several-fold more effective in CAA (Figure 4.4A) than those values reported for fresh fruits and vegetables including fresh blueberries (Wolfe and Liu, 2007; Wolfe et al., 2008; Song et al., 2010). This indicates the potential of $S$. oleraceus leaves to protect human cells from oxidative stress is much higher than most plant food. Confocal laser scanning microscopy of HepG2 cells treated with $S$. oleraceus leaf extract and stained with Naturstoff reagent has confirmed that antioxidants entered the cells, rather than being bound to the cell membranes (McDowell et al., 2011). Previous reports also verify that chlorogenic acid is readily taken up by human HepG2 cells (Mateos et al., 2005), human Caco2 cells (Sato et al., 2011), and protected human neuroblastoma SH-SY5Y cells from oxidative stress (Sato et al., 2011). In addition, mouse erythrocytes (Ohnishi et al., 1994) and granulocytes (Bouayed et al., 2007) treated with chlorogenic acid were protected from $\mathrm{H}_{2} \mathrm{O}_{2}$ induced haemolysis and lipid peroxidation. Chicoric acid, too, was absorbed by neuron-like PC-12 cells extracted from rat pheochromocytoma, which were than protected from oxidative stress and maintained their viability (Heo et al., 2010). 
Chicoric, chlorogenic and caftaric acids are important dietary LMWAs (Clifford, 1999; Clifford, 2000b) with potent radical scavenging activities in vitro (Thygesen et al., 2007; Rossetto et al., 2008). Chicoric acid is comparable in activity to certain flavonoids and rosmarinic acid, which are efficient antioxidants (Thygesen et al., 2007). It is several times more effective in scavenging peroxyl radicals than ascorbic acid in in vitro human intestinal conditions (Rossetto et al., 2008). Chlorogenic acid was, respectively, threeand seven-fold more potent than ascorbic acid and trolox in simulated human intestinal conditions (Rossetto et al., 2008). Despite their strong antioxidant activities, studies on bioavailability and stability of chicoric acid (Bailly and Cotelle, 2005) and caftaric acid (Nuissier et al., 2010) are far less documented compared to chlorogenic acid. My data confirm that these hydroxycinnamic acids in S. oleraceus leaves were stable following gastrointestinal digestion as quantified by in vitro and cellular measures of antioxidant activity.

In conclusion, gastrointestinal digestion of S. oleraceus leaves resulted in a progressive extraction of hydroxycinnamic acids and ascorbate with corresponding antioxidant activities, where raw leaves were slightly superior to boiled leaves. The antioxidant activities of hydroxycinnamic acids were stable during gastrointestinal digestion, and displayed antioxidant activity inside HepG2 and Caco2 cells. Therefore these in vitro studies demonstrate that $S$. oleraceus raw leaves are an excellent dietary antioxidant source. 
CHAPTER 5: EXTRACTABLE ANTIOXIDANT ACTIVITIES OF CELL SUSPENSION CULTURES OF Sonchus oleraceus L. IN RELATION TO ABIOTIC STRESSORS

A

B

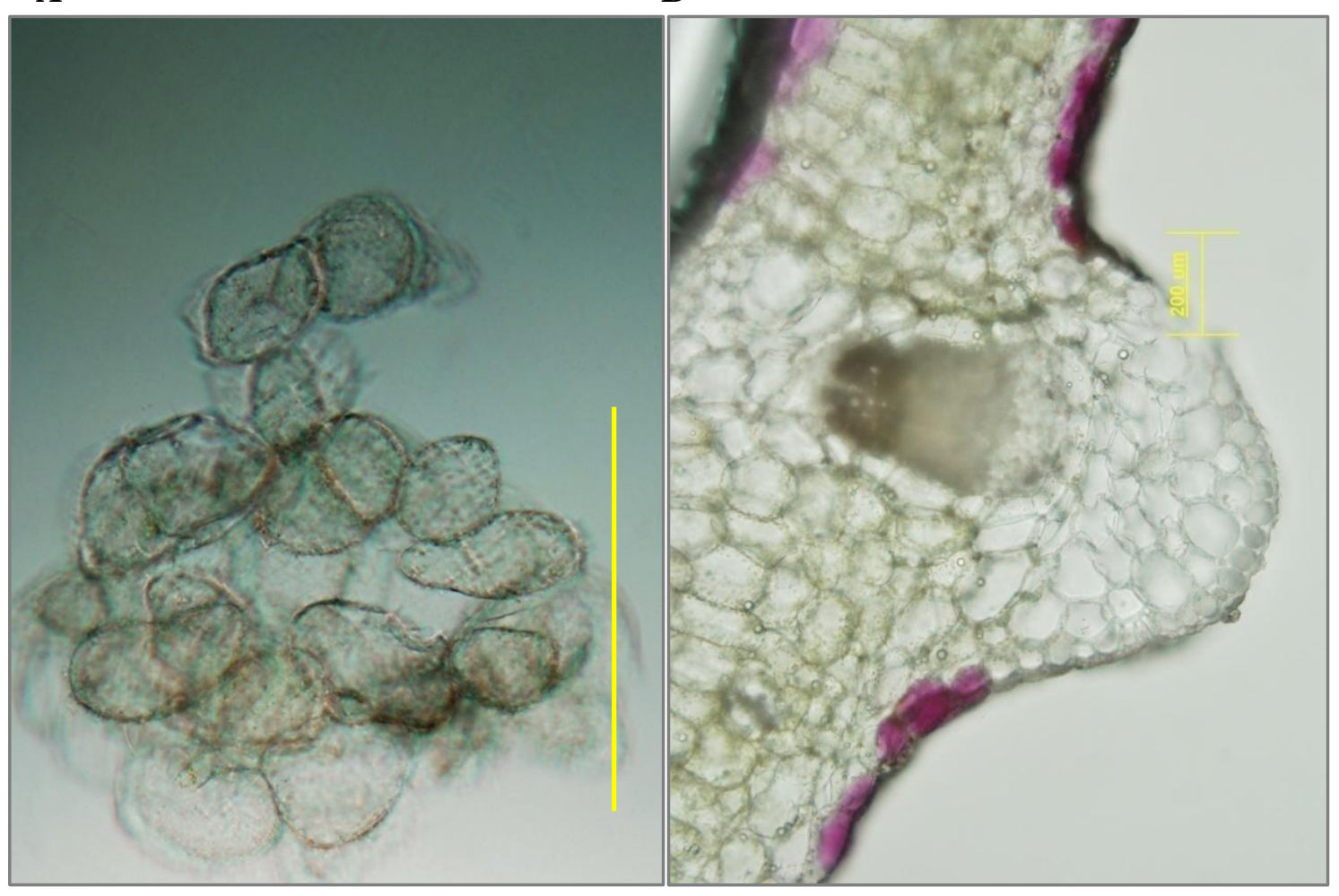

Plate 5.1 Light micrographs of Sonchus oleraceus $\mathrm{L}$. (A) cells in suspension cultures $(\mathrm{bar}=50 \mu \mathrm{m})$ and $(B)$ a transverse section of a leaf from a greenhouse grown plant $(\mathrm{bar}=\mathbf{2 0 0} \mu \mathrm{m})$. 


\subsection{ABSTRACT}

Cell suspension cultures of Sonchus oleraceus L. may provide a continuous, efficient antioxidant production system unhindered by climatic and phenological effects associated with extraction from plants. Therefore the aim of this work was to examine the effects of abiotic stressors on extractable antioxidant activities, and concentrations of ascorbate and phenolic compounds in $S$. oleraceus cell suspension cultures of two ecotypes. Cell suspension cultures were initiated from in vitro shoots of two ecotypes originating from Acacia Bay (ACB) and Oamaru (OAM) in New Zealand. Cells were exposed to chilling, salinity and the combination of both for three weeks, and extractable antioxidant activities, concentrations of ascorbate and phenolic compounds were measured for calli and media. In both ecotypes all stressors increased antioxidant activities, and concentrations of total phenolics, ascorbate and chlorogenic acid compared to the control. The most effective stressor differed between ecotypes; the stressor combination for ACB, and chilling for OAM. Calli of ACB ecotype were more potent than OAM in antioxidant activities, and held higher concentrations of total phenolics, hydroxycinnamic acids and ascorbate irrespective of the stressor. At the stationary phase, calli and media of both ecotypes yielded highest extractable antioxidant activities, concentrations of ascorbate, hydroxycinnamic acids and total phenolics irrespective of the stressor. My data indicate that abiotic stressors can be used to augment antioxidant activities of $S$. oleraceus cells in suspension cultures.

KEYWORDS: Sonchus oleraceus, cell suspension culture, antioxidant, phenolics, chilling, salinity 


\subsection{INTRODUCTION}

Twenty five percent of health-promoting chemicals in all prescribed pharmaceuticals in industrialized countries are still extracted from plants (Namdeo, 2007). Of firms that produced, distributed or sold bioactive compounds, 51\% dealt in plant based LMWAs (Tebbens, 2002). This was because the consumer preference for a particular healthpromoting biochemical was more if they were; plant based rather than of "industrial origin", extracted from a familiar food plant and possessed validated physiological benefits beyond basic nutritional functions (Marriott, 2000; Williams et al., 2004).

However, extraction of the chemicals directly from the plants is problematic since in most cases LMWAs were present at low levels, or accumulated only in a specific tissue and at a specific growth stage or upon certain growth or environmental conditions (Chapter 1; Section 1.10). In Sonchus oleraceus (Compositae) too, yields of LMWAs were variable due to climatic, phenological and genetic factors (Chapter 3). For these reasons cell cultures of $S$. oleraceus may be a more reliable commercial method for the production and extraction of antioxidants since they lack shortcomings associated with extracting from plants. In vitro cell cultures of number of other plant species have already been developed to extract LMWAs successfully (Table 5.1 - 5.2; Chapter 1; Section 1.10). Further, it may be possible to use abiotic stimuli such as chilling and salinity to further enhance LMWA production in S. oleraceus cell cultures. The application of biotic or abiotic stimuli, otherwise known as elicitors, is a proven strategy for increasing secondary metabolite production in some plant cell cultures (Chapter 1; Section 1.10; Table 1.27). An elicitor is defined as a substance which, when introduced in small concentrations to a living cell system, initiates or improves the biosynthesis of specific compounds (Radman et al., 2003). Biotic elicitors are derived from live organisms, for example pectin, chitin and glucan of fungal and yeast origin, while inorganic salts $(\mathrm{NaCl})$, heat shock, chilling, heavy metal ions, UV radiation and ultrasound are classified as abiotic elicitors (Zhou et al., 2011). 
Table 5.1 Selected patents for production of phenolic compounds from plant cell suspension cultures

\begin{tabular}{|l|l|l|l|}
\hline Phenolic compounds & Plant species & Patent number & References \\
\hline Resveratrol & Vitis vinifera & US7309591B2 & $\begin{array}{l}\text { (Martinez } \text { et al., } \\
\text { 2007) }\end{array}$ \\
\hline $\begin{array}{l}\text { Rutin, Quercetin, Quercetin-3- } \\
\text { glucoside, Kaempferol, Kaempferol-3- } \\
\text { rutinoside, Naringenin, Naringenin-7- } \\
\text { glucoside }\end{array}$ & Solanum esculentum & US20030101477A1 & $\begin{array}{l}\text { (Colliver } \text { et al., } \\
\text { 2003) }\end{array}$ \\
\hline $\begin{array}{l}\text { Catechin } \\
\text { Isoflavone }\end{array}$ & Taxus wallichiana & US6620599B1 & $\begin{array}{l}\text { (Chattopadhyay } \\
\text { et al., 2003) }\end{array}$ \\
\hline Procyanidins & Glycine max & US7354765B2 & $\begin{array}{l}\text { (Federici } \text { et al., } \\
\text { 2008) }\end{array}$ \\
\hline Polyphenols & Theobroma spp. & US8568798B2 & (Venkatramesh et \\
& & al., 2013) \\
\hline
\end{tabular}

Table 5.2 Selected commercial applications of plant cell suspension cultures for the production of LMWAs

\begin{tabular}{|c|c|c|c|c|}
\hline LMWAs & $\begin{array}{l}\text { Commercial } \\
\text { product }\end{array}$ & Plant species & Manufacturer & Websites $^{1}$ \\
\hline Procyanidins & Cocovanol & Theobroma cacao & $\begin{array}{l}\text { DianaPlantSciences Inc., } \\
\text { Portland, Oregon, USA }\end{array}$ & $\begin{array}{l}\text { http://plantcellculture. } \\
\text { com/aboutplantcellcul } \\
\text { ture.html }\end{array}$ \\
\hline Ginseng & $\begin{array}{l}\text { Tissue } \\
\text { cultured } \\
\text { ginseng }\end{array}$ & Panax ginseng & $\begin{array}{l}\text { Nitto Denko Medical } \\
\text { Corporation, Osaka, Japan }\end{array}$ & $\begin{array}{l}\text { http://www.nitto.com/ } \\
\text { about_us/corporate/his } \\
\text { tory/ }\end{array}$ \\
\hline $\begin{array}{l}\text { Rosmarinic } \\
\text { acid }\end{array}$ & $\begin{array}{l}\text { Rosmarinic } \\
\text { acid }\end{array}$ & Coleus blumei & $\begin{array}{l}\text { A. Nattermann a Cie } \mathrm{GmbH} \text {, } \\
\text { Cologne, Germany }\end{array}$ & $\begin{array}{l}\underline{\text { http://www.natterman. }} \\
\underline{\text { nl/index.html }}\end{array}$ \\
\hline
\end{tabular}

${ }^{1}$ accessed December 2013

Studies on effect of abiotic stressors on antioxidant activities of $S$. oleraceus cell suspension cultures have not yet been studied. Thus, it was hypothesized that antioxidant activities of calli and media obtained from S. oleraceus cell suspension cultures are promoted by abiotic stressors. 


\subsection{MATERIALS AND METHODS}

\subsubsection{Chemicals}

Murashige and Skoog (MS) medium, $\alpha$-naphthaleneacetic acid (NAA), 6benzylaminopurine (BAP), agar, sucrose, $\mathrm{NaClO}$ and glass vessels were purchased from Sigma-Aldrich (St Louis, MO). All other chemicals are listed at Section 2.1.

\subsubsection{In vitro culture conditions}

Axenically grown plants, callus cultures and cell suspension cultures were maintained in a sterile growth room at $25{ }^{\circ} \mathrm{C}$ and $16 \mathrm{~h}$ photoperiod provided from cool white fluorescent tubes $\left(94 \mu \mathrm{mol} \mathrm{m} \mathrm{m}^{-2}\right)$. All cultures were maintained in cylindrical glass vessels $(6 \mathrm{x} 10$ $\mathrm{cm})$ secured with clear plastic caps.

\subsubsection{Establishment of in vitro plants}

Plants were raised from seeds obtained from selfed F1 generation plants, which were themselves raised from seeds collected from wild populations at Acacia Bay and Oamaru, New Zealand (Chapter 3; Section 3.3.1; Table 3.1). The seeds were surface sterilized by rinsing in $70 \%$ ethanol for $5 \mathrm{~min}$ followed by $10 \% \mathrm{NaClO}$ for $15 \mathrm{~min}$ and then using sterile $\mathrm{ddH}_{2} \mathrm{O}$ for $5 \mathrm{~min}$. The seeds were soaked in sterile $\mathrm{ddH}_{2} \mathrm{O}$ and kept in dark for 12 h. They were seeded at the rate of $10-15$ seeds vessel $^{-1}$ in $50 \mathrm{~mL}$ MS medium supplemented with $6 \mathrm{~g} \mathrm{~L}^{-1}$ agar and $87.7 \mathrm{mM}$ sucrose, devoid of growth regulators.

\subsubsection{Establishment of callus culture}

Callus cultures of Sonchus oleraceus were initiated using leaf explants $(1.0 \times 1.0 \mathrm{~cm})$ excised from 21 day old in vitro plants. The leaf explants were established on $50 \mathrm{~mL} \mathrm{MS}$ medium supplemented with $6 \mathrm{~g} \mathrm{~L}^{-1}$ agar, $87.7 \mathrm{mM}$ sucrose, $5.4 \mathrm{mM}$ NAA and $4.4 \mathrm{mM}$ BAP. The growth regulator concentrations used here were determined through preliminary trials (Appendix B.1). Subculturing was performed at 21 day intervals. 


\subsubsection{Establishment of cell suspension culture and culture conditions}

Suspension cultures were initiated using 21 day old callus. The cultures were maintained in $50 \mathrm{~mL}$ of MS liquid medium supplemented with $87.7 \mathrm{mM}$ sucrose, $10.7 \mathrm{mM}$ NAA and 4.4 mM BAP. The growth regulator concentrations used here were established through preliminary trials (Appendix B.2).

Cultures were maintained on a rotary shaker at $50 \mathrm{rpm}$. Suspension cultures were subcultured at 21 day interval. The sixth subculture was used to initiate suspension cultures used in Section 5.3.6, using 0.5 $\mathrm{g}$ cell FW vessel ${ }^{-1}$.

\subsubsection{Treatments}

Seven day old suspension cultures were exposed to chilling, salinity or the combination of both for three weeks. Control cell suspensions were maintained continuously in the growth room. For the chilling treatment, cell suspensions were repeatedly held at $5{ }^{\circ} \mathrm{C}$ for $8 \mathrm{~h}$ in dark and returned to the light in the growth room. Salinity was imposed by dissolving $\mathrm{NaCl}$ in the medium to obtain $50 \mathrm{mM}$. The fourth group of suspension cultures was given both the chilling and salinity treatments. Aliquots $\left(10 \mathrm{~mL}\right.$ vessel $\left.{ }^{-1}\right)$ were withdrawn from 7, 14, 21 and 28 day old cell suspension cultures.

\subsubsection{Phytochemical extraction}

The aliquots were vacuum filtered to separate cells and extracellular medium. The cell fresh and dry biomass was measured. The relative growth rate (RGR) for cell dry biomass accumulation was calculated as:

$\mathrm{RGR}=\left[\left(\mathrm{W}_{1}-\mathrm{W}_{0}\right) /\left(\mathrm{t}_{1}-\mathrm{t}_{0}\right) \mathrm{W}_{0}\right] \times 100$

Where $\mathrm{W}_{0}$ is the biomass at time $\mathrm{t}_{0}, \mathrm{~W}_{1}$ is biomass at time $\mathrm{t}_{1}$ and $\mathrm{t}_{1}-\mathrm{t}_{0}$ is one week.

Calli intended for phytochemical analysis were prepared according to Section 3.3.3. The extracellular medium was vacuum dried and resuspended in $1.5 \mathrm{~mL}$ of methanol: $\mathrm{ddH}_{2} \mathrm{O}$ : acetic acid (70:23:7, v/v/v). Calli and media extracts were stored under nitrogen at $-20{ }^{\circ} \mathrm{C}$ and phytochemical analyses were performed within $7 \mathrm{~d}$ of extraction. 
The analysis of total phenolic content, 2,2-diphenyl-1-picrylhydrazyl (DPPH) radical scavenging activities, oxygen radical absorbance capacity (ORAC) assay, ascorbate content for cells and medium, were performed as described in Sections $2.2-2.5$. Online reverse phase HPLC was performed for cells and medium as described in Section 2.8 without post column reaction with DPPH reagent.

\subsection{STATISTICAL ANALYSIS}

Repeated measures ANOVA with Bonferroni post hoc tests $(P<0.05)$ were performed to identify significance of treatments. Analyses were performed using SPSS 18.0 statistical software. 


\subsection{RESULTS}

\subsubsection{In vitro plants, callus and suspension cultures of $S$. oleraceus $\mathbf{L}$.}

The seeds germinated rapidly and well developed cotyledons were present in seven day old cultures (Plate 5.2A). The in vitro plant had developed two to four true leaves at day 21 (Plate 5.2B). Callus cultures had rapid proliferation and appeared green and friable at day 21 (Plate 5.2C).
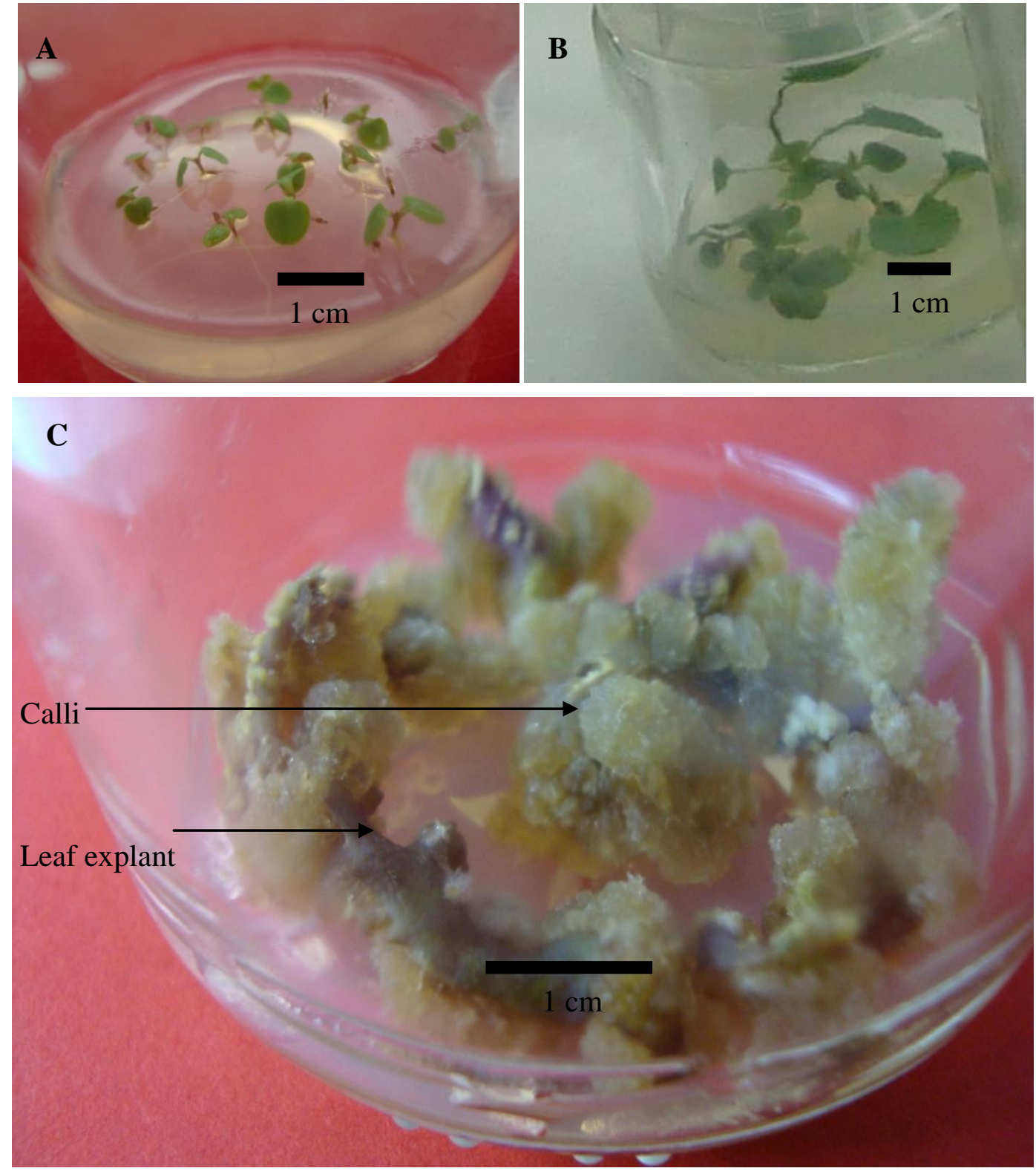

Plate 5.2 Sonchus oleraceus L. (A) 7 day old, (B) 21 day old in vitro plants and (C) 21 day old callus cultures on Murashige and Skoog medium. 
Seven day old suspension cultures appeared turbid and yellowish green (Plate 5.3A) and 28 day old cultures were green and formed cell aggregates (Plate 5.3B).

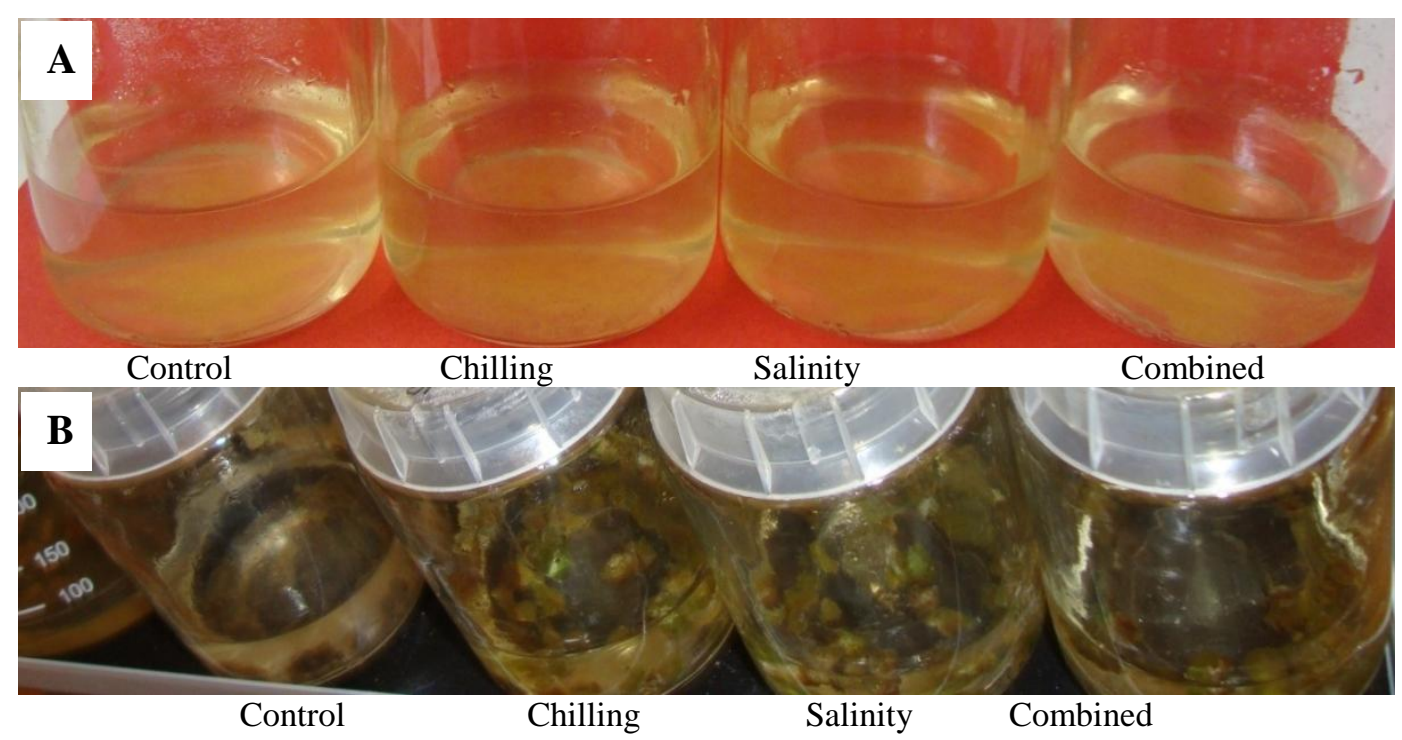

Plate 5.3 Suspension cultures of Sonchus oleraceus L. at (A) 07 and (C) 28 days.

\subsubsection{Biomass of cells from suspension cultures}

Accumulation of cell biomass did not vary significantly across ecotypes or stressor treatments (ANOVA; $P=0.48$; Figure 5.1). At day 21, the cell dry mass of cultures was maximal $\left(0.6 \pm 0.1 \mathrm{mg} \mathrm{mL}^{-1}\right)$, which was double the weight at day $7(P<0.001$; Figure $5.1)$.

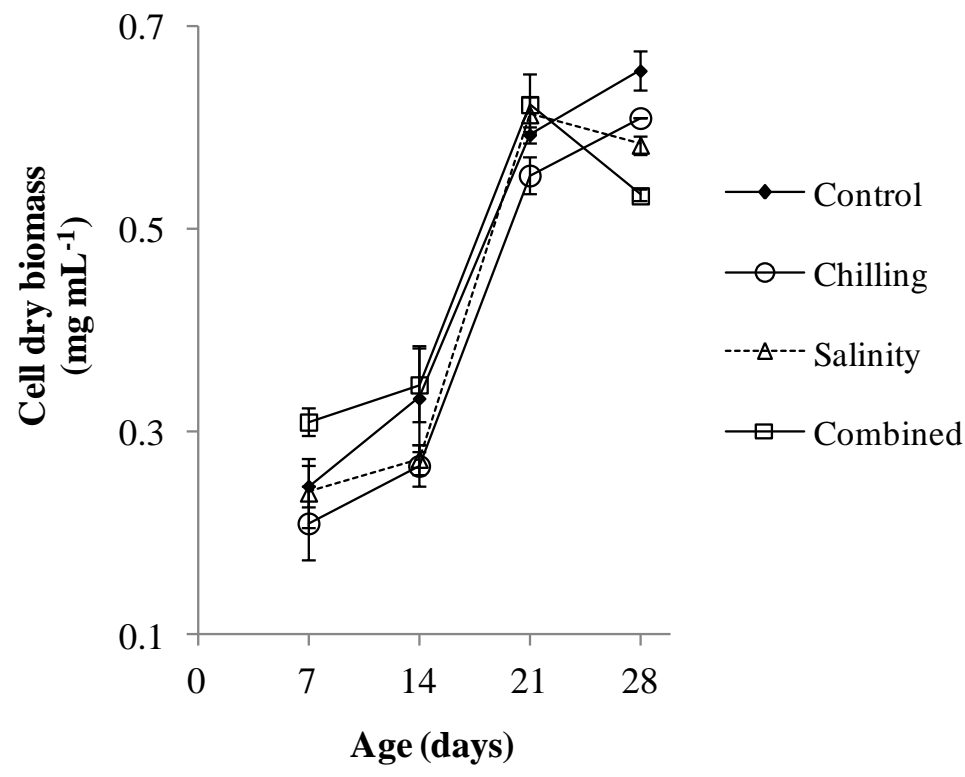

Figure 5.1 Changes in dry biomass of cells from suspension cultures of Sonchus oleraceus L. Means \pm $\mathrm{SE}(n=12)$. 
The growth rate of cultures indicated three distinct growth phases: lag, linear and stationary phases (Table 5.3). During the initial lag phase, cell dry biomass accumulation rate was low. The highest growth rate was during the linear phase. Onset of the stationary growth phase occurred following day 21 . The stationary phase had the lowest growth rate.

Table 5.3 Rates of cell dry biomass accumulation in suspension cultures of Sonchus oleraceus $\mathbf{L}$.

\begin{tabular}{|c|c|c|}
\hline $\begin{array}{c}\text { Culture age } \\
\text { (days) }\end{array}$ & $\begin{array}{l}\text { Relative growth rate } \\
\left(\mathrm{mg} 100 \mathrm{mg}^{a} \text { week }^{-1}\right)\end{array}$ & Growth phase \\
\hline $7-14$ & $28 \pm 7$ & Lag phase \\
\hline $14-21$ & $110 \pm 12$ & Linear phase \\
\hline $21-28$ & $1 \pm 3$ & Stationary phase \\
\hline
\end{tabular}

\subsubsection{Effects of abiotic stressors on extractable antioxidant activities, concentrations of total phenolics, hydroxycinnamic acids and ascorbate}

Stressors increased the extractable antioxidant activities and concentrations of total phenolics, ascorbate and hydroxycinnamic acids excluding chicoric acid (Figures 5.2 5.8). These effects were seen in calli and media of both ecotypes.

In calli, all stressors enhanced the: extractable antioxidant activities measured as DPPH radical scavenging capacities $(P<0.001)$ and ORAC values $(P<0.001)$, concentrations of total phenolics $(P<0.001)$, chlorogenic acid $(P<0.001)$ and ascorbate $(P<0.001)$ compared to the controls (Figures 5.2A,B - 5.5A,B and 5.8A,B). Concentrations of caftaric acid were increased by the stressor combination and by salinity compared to the control, though only in ACB $(P<0.001$; Figure 5.6A); these treatments did not significantly affect caftaric acid levels in OAM (Figure 5.6B). Treatments did not affect concentration of chicoric acid in both ecotypes $(P=0.72$; Figure 5.7A,B). The stressor which caused highest improvement in antioxidant activities and concentrations of LMWAs differed between ecotypes; stressor combination in ACB (Figures 5.2A - 5.6A and 5.8A), and chilling in OAM (Figures 5.2B - 5.5B and 5.8B). The stressor-induced increases compared to their respective controls were greater in ACB (Figures 5.2A - 5.6A and 5.8A) than in OAM (5.2B - 5.5B and 5.8B). 
A

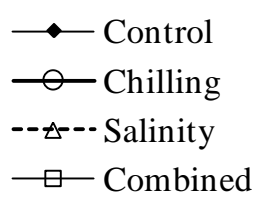

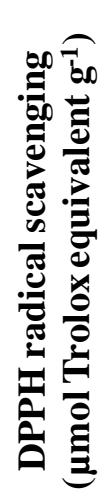

180

150

120

90

60

$\begin{array}{llccc}0 & 7 & 14 & 21 & 28 \\ & & \text { Age (days) }\end{array}$

C

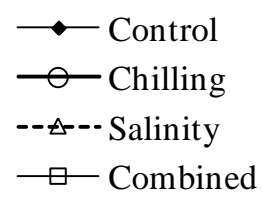

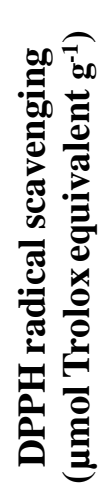

B

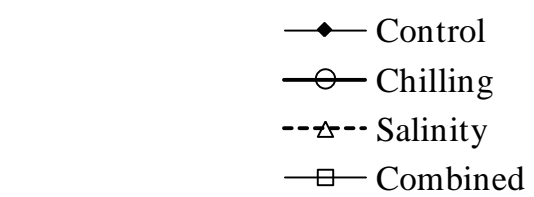

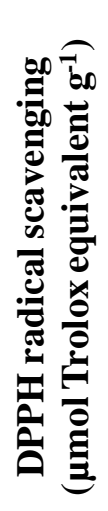

105

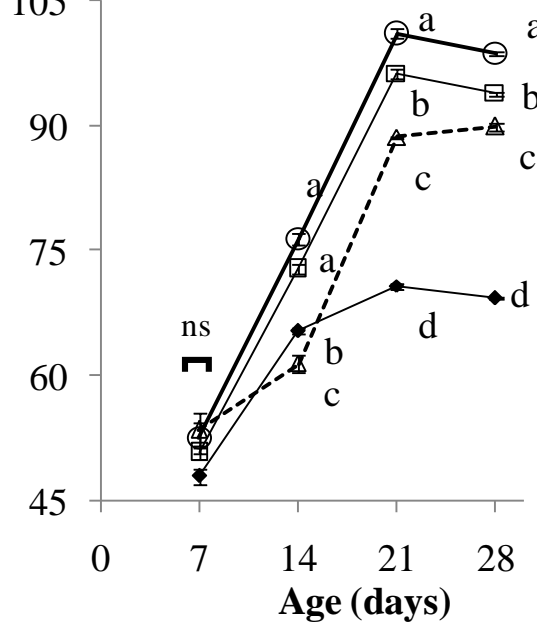

D

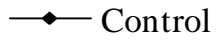

- Chilling

--む-・Salinity

$\square$ Combined

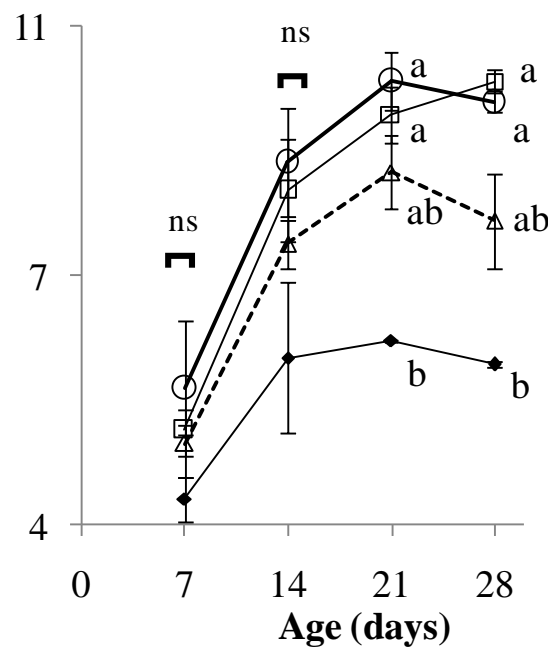

Figure 5.2 Changes in DPPH radical scavenging capacity in calli $(A, B)$ and media $(C, D)$ of $A C B(A, C)$ and OAM (B,D) ecotypes of Sonchus oleraceus $\mathrm{L}$. suspension cultures. Means \pm SE $(n=6)$. Data points with different letters indicate significant differences between treatments within the time point $(P<0.05)$. ns: Treatments are not significantly different within the time point $(P>0.05)$. 
A
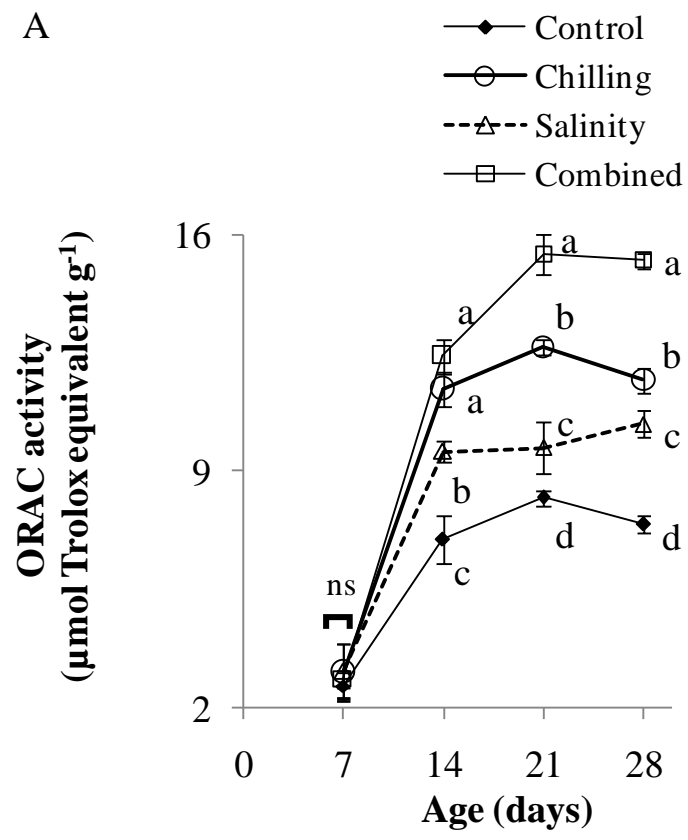

C
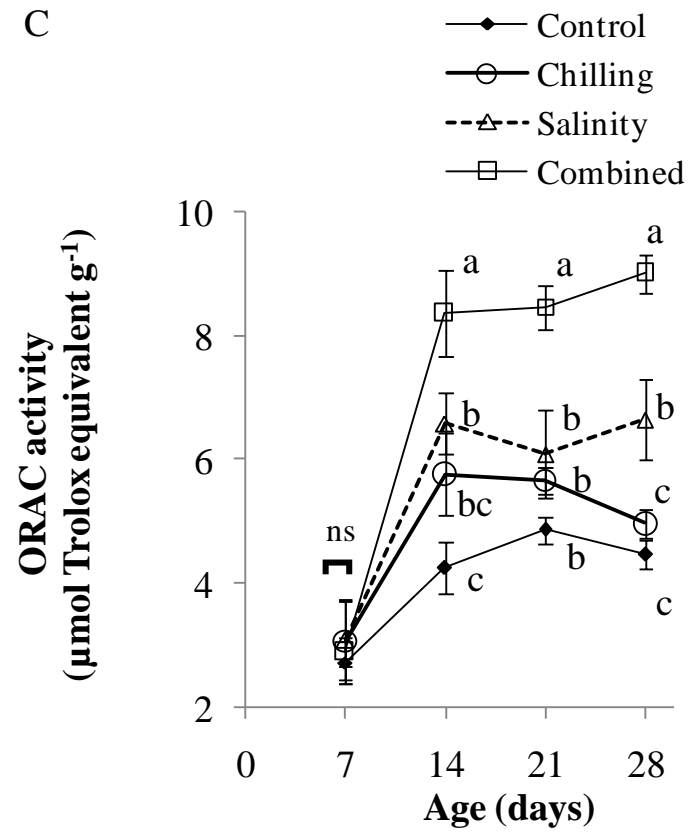

B

$\longrightarrow$ Control

- Chilling

-- -- Salinity

$\square$ Combined

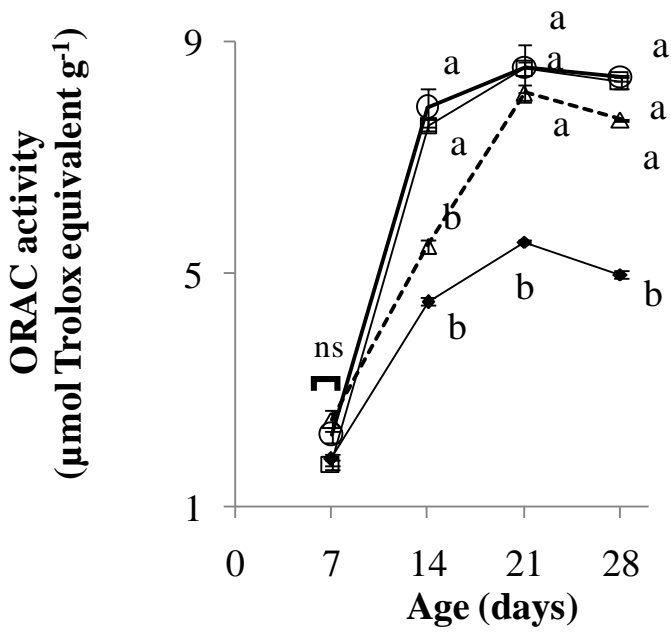

D

$\longrightarrow$ Control

- Chilling

--ઐ-- Salinity

$\square$ Combined

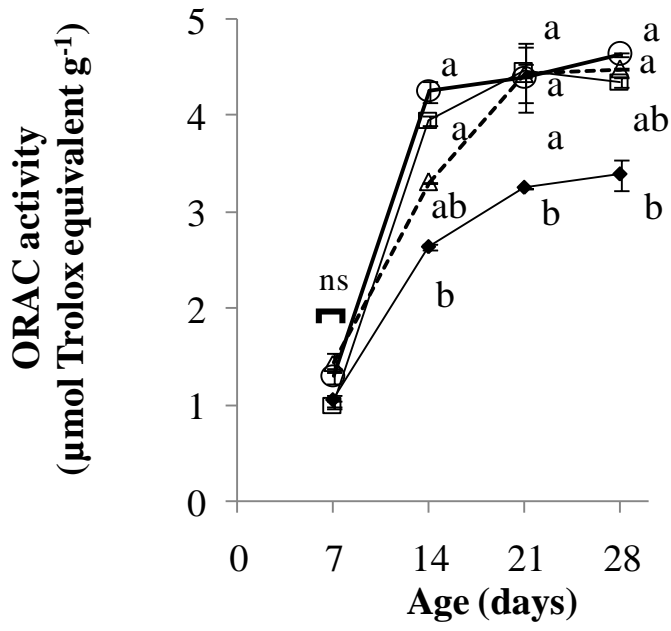

Figure 5.3 Changes in ORAC activity in calli $(\mathrm{A}, \mathrm{B})$ and media $(\mathrm{C}, \mathrm{D})$ of $\mathrm{ACB}(\mathrm{A}, \mathrm{C})$ and OAM (B,D) ecotypes of Sonchus oleraceus L. suspension cultures. Means \pm SE $(n=6)$. Data points with different letters indicate significant differences between treatments within the time point $(P<0.05)$. ns: Treatments are not significantly different within the time point $(P>0.05)$. 


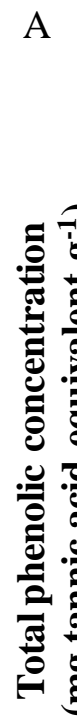

A

-Control

- Chilling

$\cdots-\cdots$ Salinity

曰-Combined

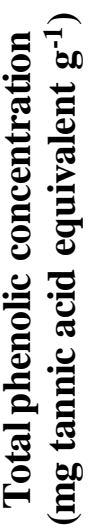

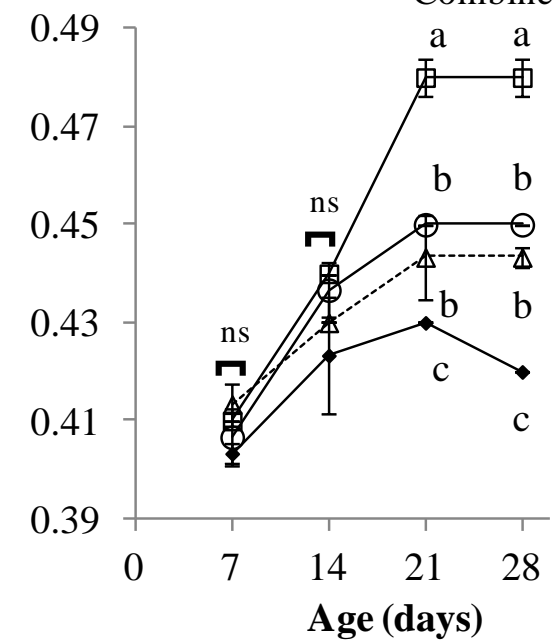

C

$\longrightarrow$ Control

$-\mathrm{C}$ Chilling

--A-- Salinity

曰-Combined

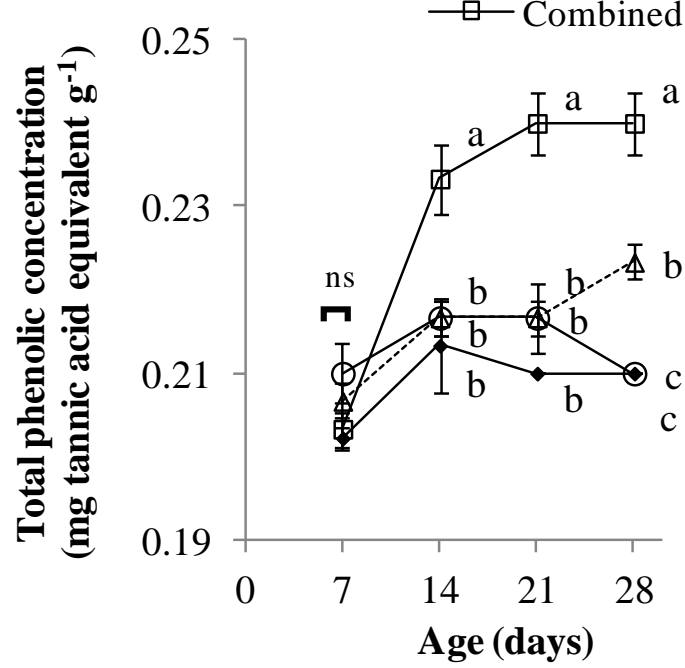

B

$\longrightarrow$ Control

- - Chilling

$\cdots-\cdots$ Salinity

$\square$ Combined
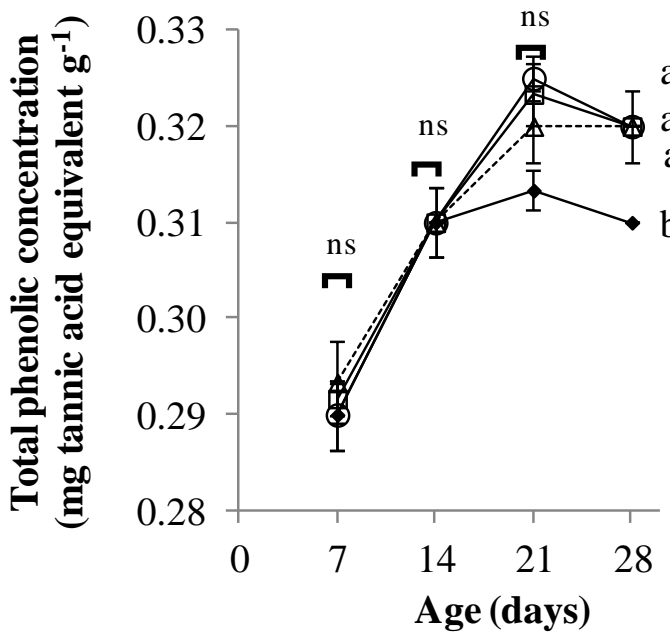

D

$\longrightarrow$ Control

- - Chilling

$\cdots-\cdots$ Salinity

๑-Combined

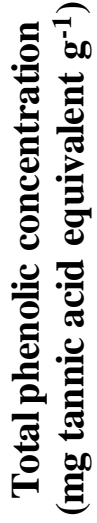

0.20

0.19

0.18

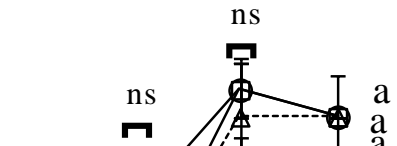

0.17

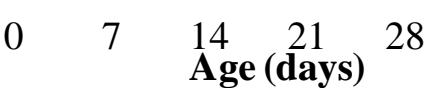

Figure 5.4 Changes in concentration of total phenolics in calli (A,B) and media (C,D) of ACB (A,C) and OAM (B,D) ecotypes of Sonchus oleraceus $L$. suspension cultures. Means \pm SE $(n=6)$. Data points with different letters indicate significant differences between treatments within the time point $(P<0.05)$. ns: Treatments are not significantly different within the time point $(P>0.05)$. 

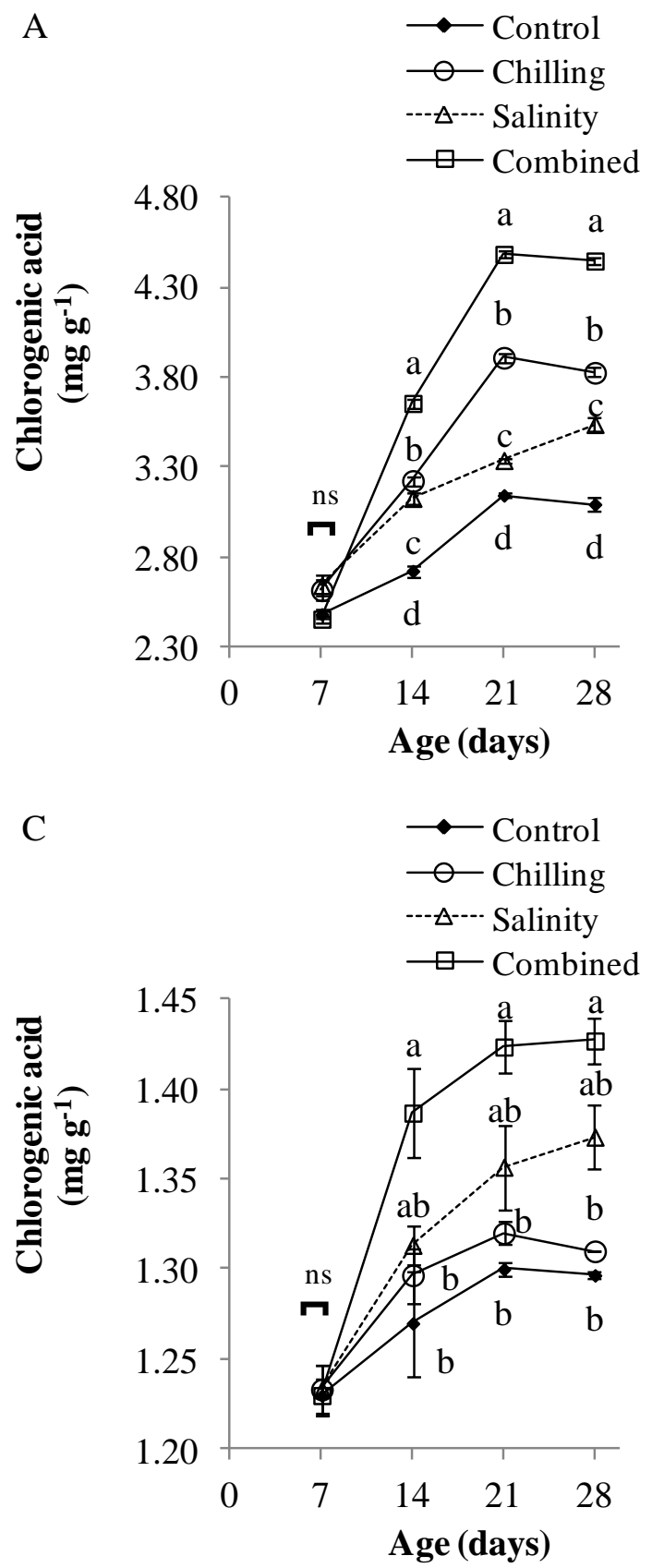
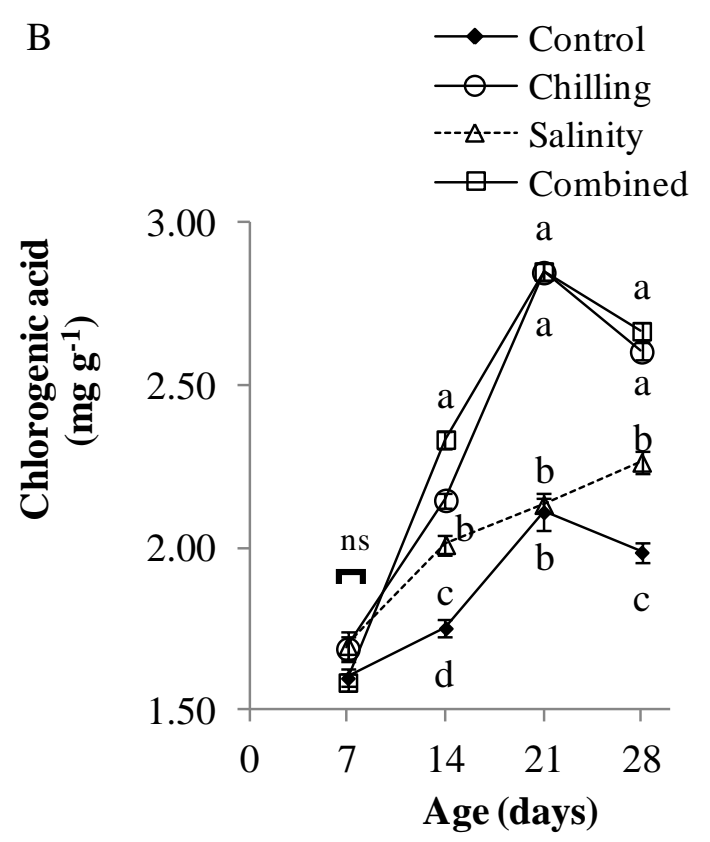

$\mathrm{D}$

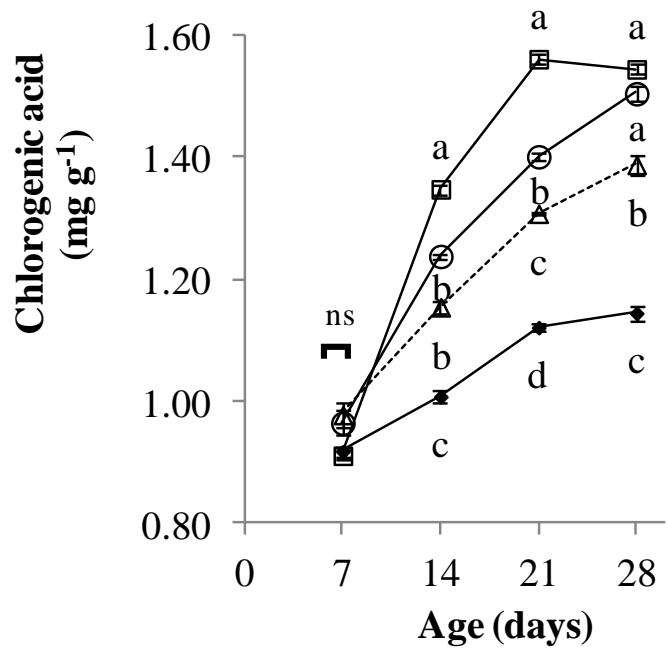

Figure 5.5 Changes in concentration of chlorogenic acid in calli $(A, B)$ and media $(C, D)$ of $A C B(A, C)$ and OAM (B,D) ecotypes of Sonchus oleraceus L. suspension cultures. Means \pm SE $(n=6)$. Data points with different letters indicate significant differences between treatments within the time point $(P<0.05)$. ns: Treatments are not significantly different within the time point $(P>0.05)$. 


$$
\text { A }
$$<smiles>CC=CCC</smiles>

- Chilling

$\cdots--\cdots$ Salinity

七-Combined

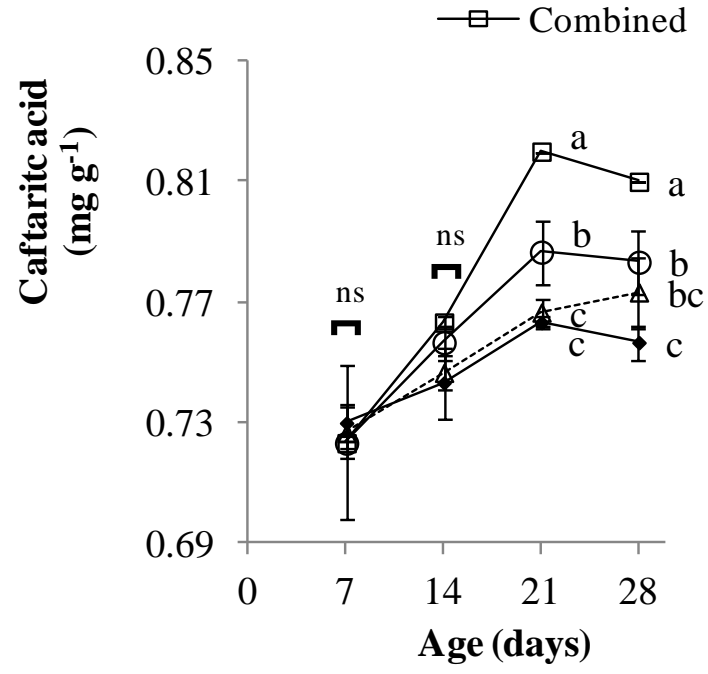

C

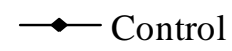

- Chilling

$\cdots----$ Salinity

$\square$ Combined

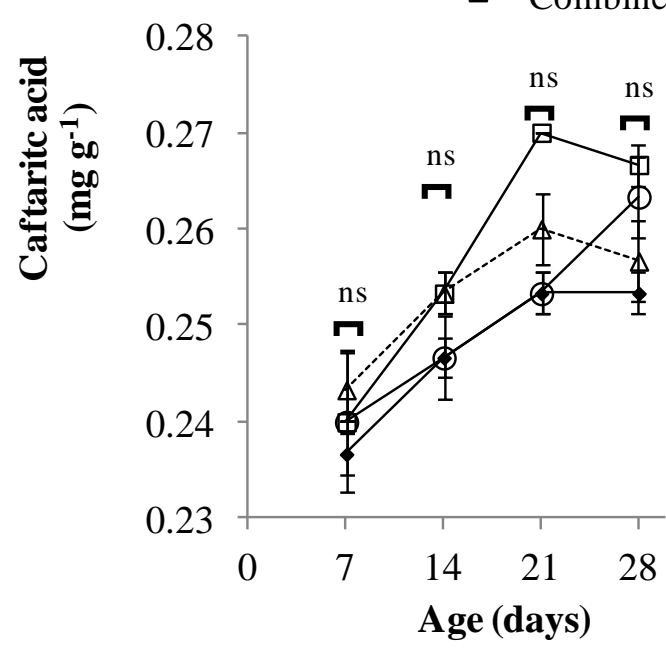

B

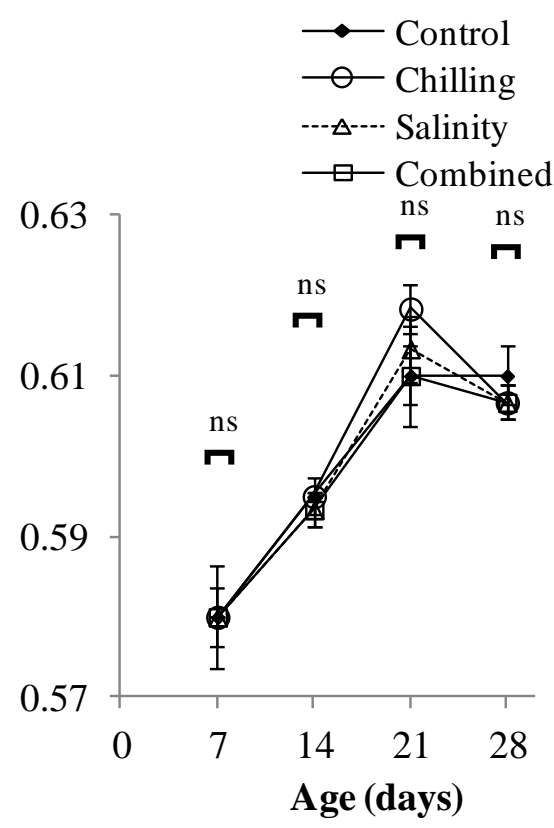

$\mathrm{D}$

$\longrightarrow$ Control

- Chilling

$\cdots-{ }^{-\cdots}$ Salinity

$\square$ Combined

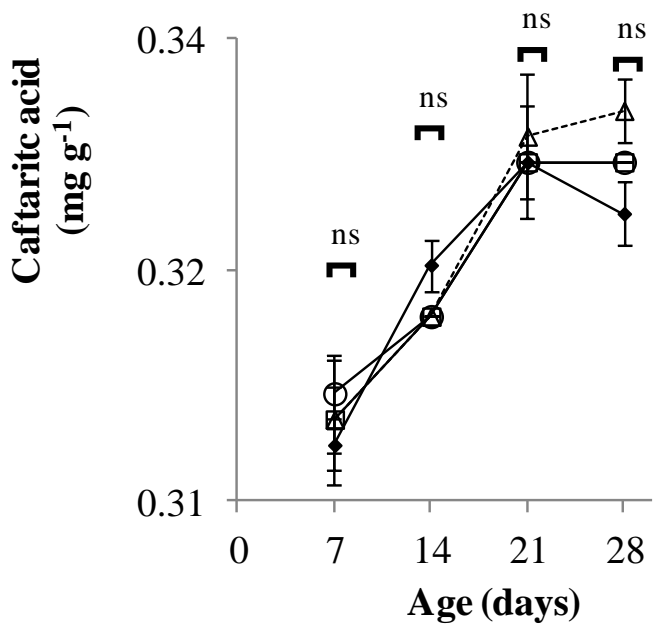

Figure 5.6 Changes in concentration of caftaric acid in calli $(A, B)$ and media $(C, D)$ of $A C B(A, C)$ and OAM (B,D) ecotypes of Sonchus oleraceus $L$. suspension cultures. Means \pm SE $(n=6)$. Data points with different letters indicate significant differences between treatments within the time point $(P<$ 0.05). ns: Treatments are not significantly different within the time point $(P>0.05)$. 

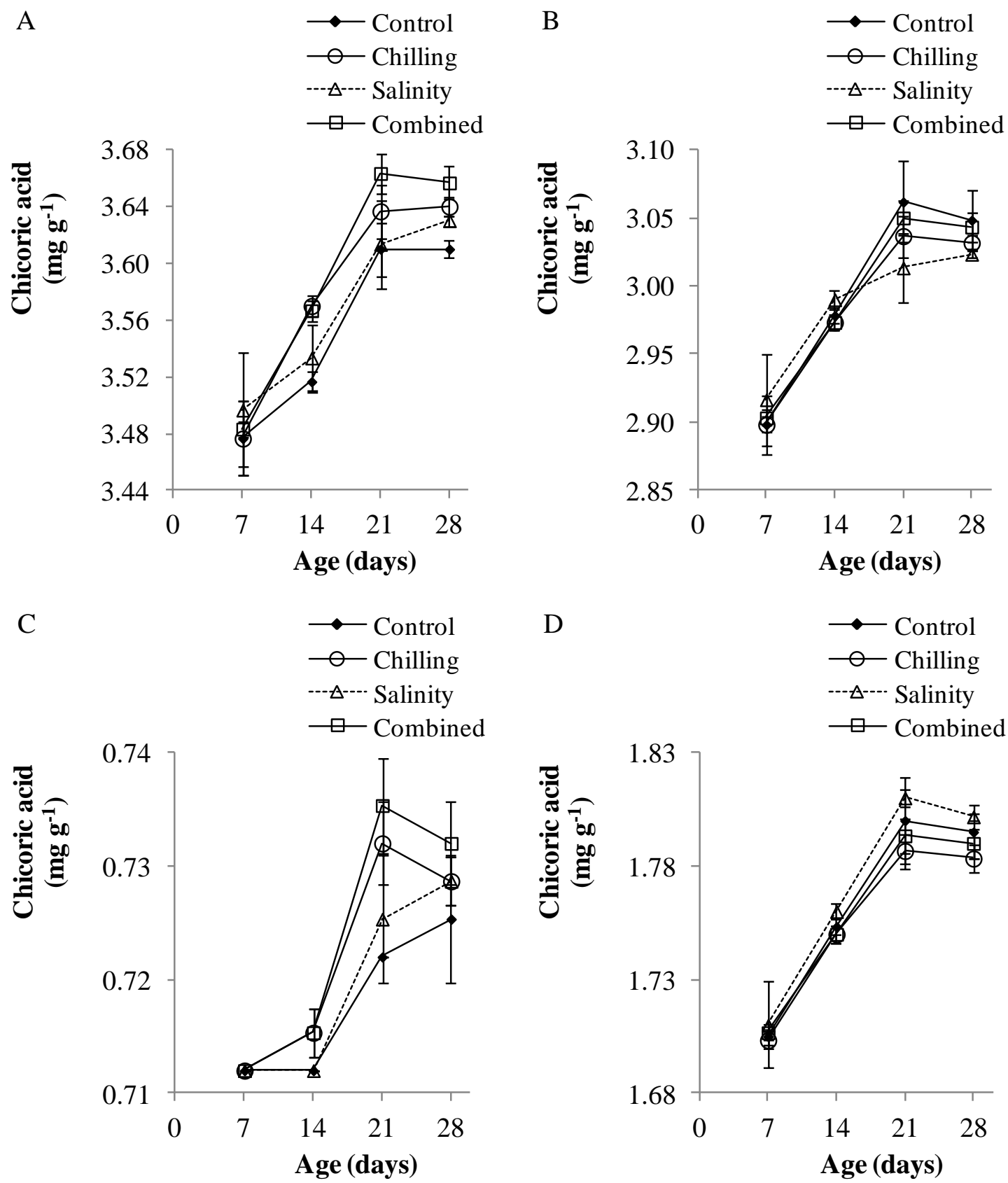

Figure 5.7 Changes in concentration of chicoric acid in calli (A,B) and media (C,D) of ACB (A,C) and OAM (B,D) ecotypes of Sonchus oleraceus L. suspension cultures. Means \pm SE $(n=6)$. Treatments are not significantly different $(P>0.05)$. 
A
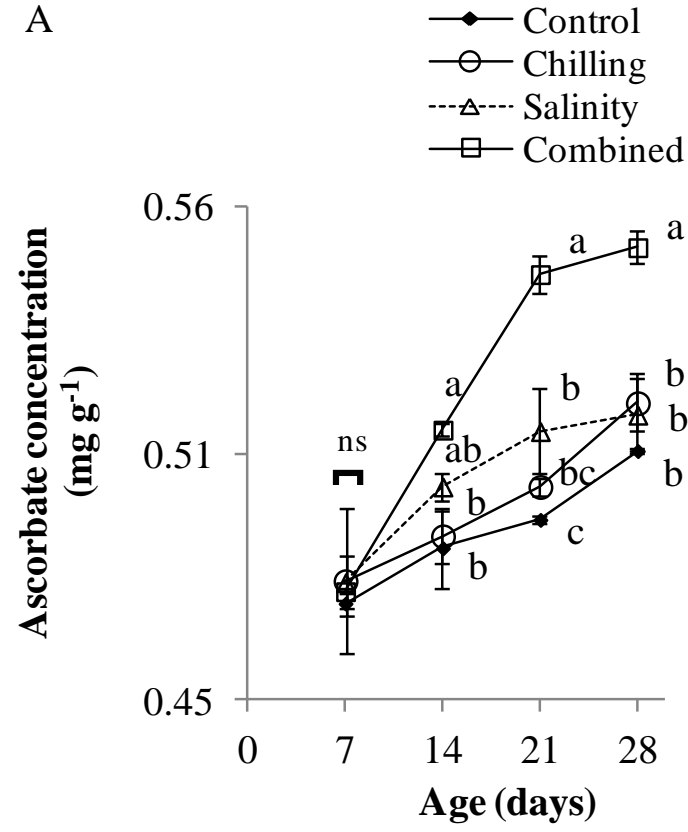

$\mathrm{C}$

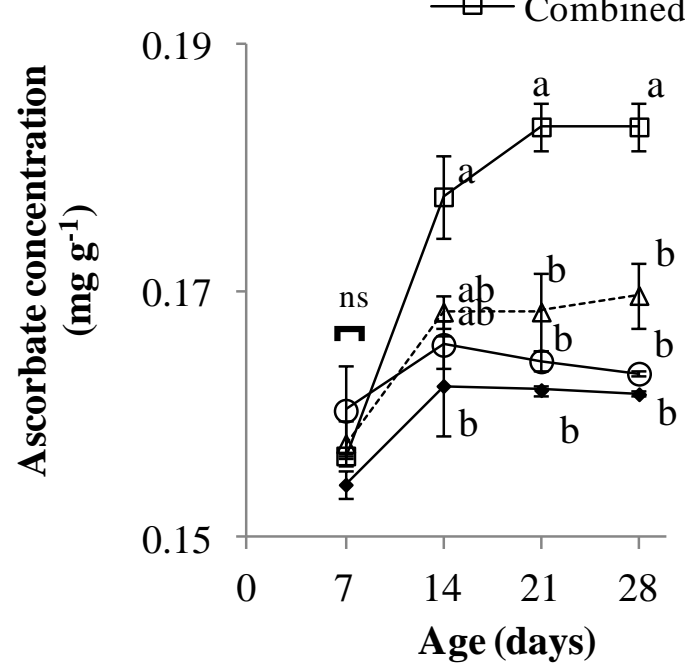

B

$\longrightarrow$ Control

- Chilling

$\cdots-\cdots$ Salinity

$\square-$ Combined

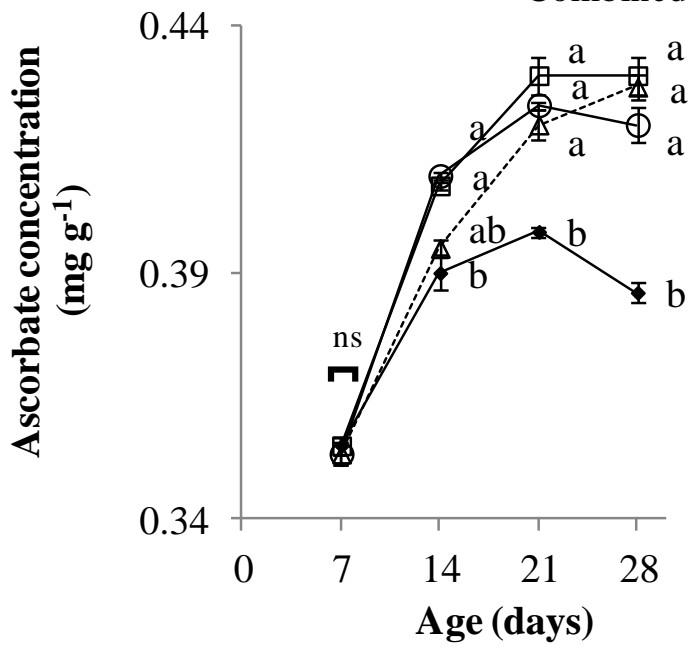

$\mathrm{D}$
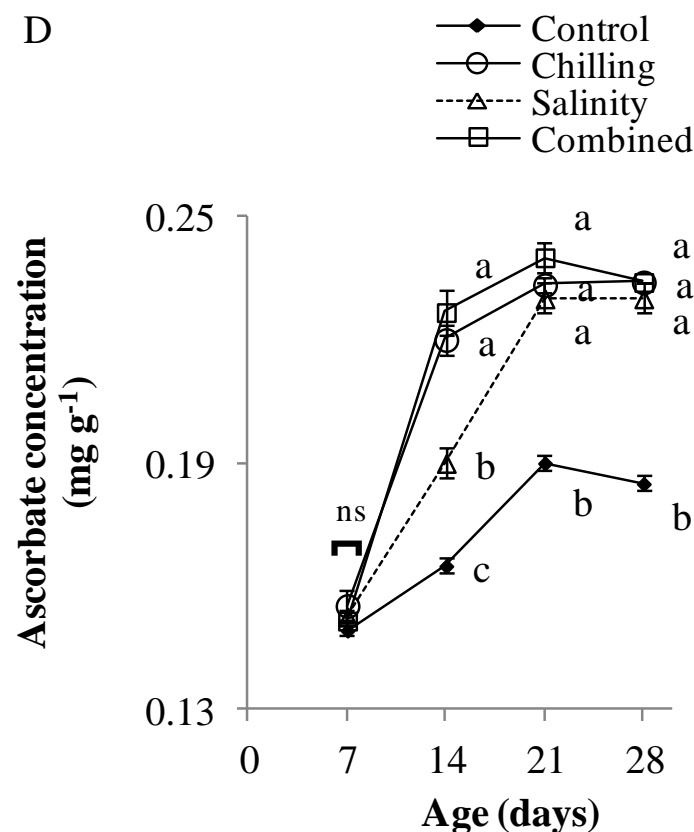

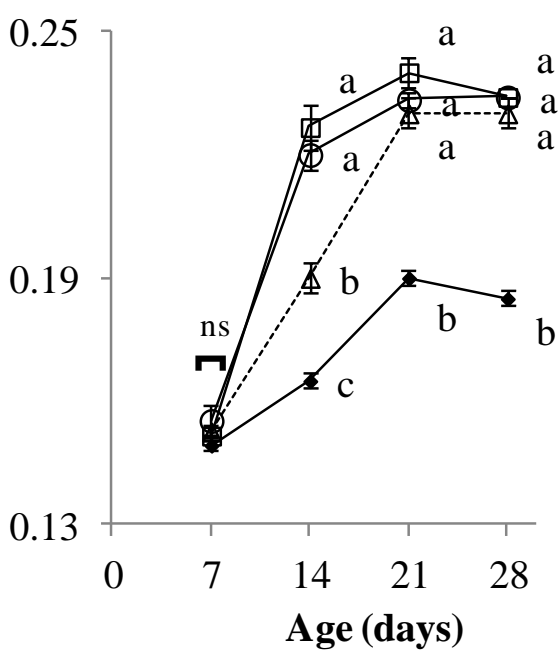

Figure 5.8 Changes in concentration of ascorbate in calli $(A, B)$ and media $(C, D)$ of ACB $(A, C)$ and OAM (B,D) ecotypes of Sonchus oleraceus $L$. suspension cultures. Means \pm SE $(n=6)$. Data points with different letters indicate significant differences between treatments within the time point $(P<$ $0.05)$. ns: Treatments are not significantly different within the time point $(P>0.05)$. 
The culture medium itself displayed higher antioxidant activities and held higher concentrations of total phenolics, chlorogenic acid and ascorbate after treatments of the plant cells (Figures 5.2C,D - 5.5C,D and 5.8C,D). However, these changes were less prominent than those that occurred in the calli (Figures 5.2A,B $-5.5 \mathrm{~A}, \mathrm{~B}$ and 5.8A,B). Treatments did not significantly affect concentrations of caftaric and chicoric acids in the media (Figures 5.6C,D - 5.7C,D).

\subsubsection{Ecotypes differ in extractable antioxidant activities, concentrations of total phenolics, hydroxycinnamic acids and ascorbate}

Calli of ACB were $40-50 \%$ more potent than OAM in antioxidant activities as measured by DPPH radical scavenging $(P<0.001)$ and ORAC activities $(P<0.001)$. ACB calli also had $20-50 \%$ more concentrations of total phenolics $(P<0.001)$, chlorogenic acid $(P<$ 0.001), caftaric acid $(P<0.001)$, chicoric acid $(P<0.001)$ and ascorbate $(P<0.001)$ irrespective of the stressor applied, and across all growth phases (Figures 5.2A,B 5.8A,B).

The culture medium that had contained ACB calli held $20-50 \%$ of the LMWA load of calli whereas media of OAM cultures held $50-60 \%$ LMWA concentrations of its calli (Figures 5.2C,D - 5.8C,D). This was true for all the stressors and growth phases.

\subsubsection{Growth phases differ in extractable antioxidant activities, concentrations of total phenolics, hydroxycinnamic acids and ascorbate}

DPPH radical scavenging $(P<0.001)$, ORAC activities $(P<0.001)$, total phenolics $(P<$ $0.001)$, and concentrations of chlorogenic $(P<0.001)$, caftaric $(P<0.001)$, chicoric $(P<$ $0.001)$ and ascorbic acids $(P<0.001)$ were all greatest at the onset of the stationary phase, both in calli and the culture media for all ecotypes and treatments (Figures 5.2-5.8).

\subsubsection{Extractable antioxidant activities, and concentrations of total phenolics, hydroxycinnamic acids and ascorbate are lower in media than in calli}

The nutrient media from both ecotypes had consistently lower DPPH radical scavenging $(P<0.001)$ and ORAC activities $(P<0.001)$, as well as lower concentrations of total 
phenolics $(P<0.001)$, hydroxycinnamic acids $(P<0.001)$ and ascorbate $(P<0.001)$ compared to the calli themselves (Figures 5.2-5.8).

\subsubsection{Comparison of LMWA concentrations in extracts from calli of suspension cultures and from leaves of greenhouse grown plants}

Stressor-induced concentrations of LMWAs extracted from calli were $30-80 \%$ lower than those from the leaves of similar stressor-imposed greenhouse grown plants (Table 5.4). However, in ACB the concentration of chlorogenic acid in calli extracts were threefold higher than leaf extracts, when controls of youngest suspensions and plants were compared (Table 5.4). The LMWAs accumulated rapidly with lower variability in calli than in leaves (Table 5.4). 
Table 5.4 Comparison of phytochemical concentrations in extracts from calli of suspension cultures and from leaves of greenhouse grown plants of ACB and OAM ecotypes of Sonchus oleraceus L.

following treatments: control, chilling, salinity and combination of the two.

\begin{tabular}{|c|c|c|c|c|c|c|c|c|c|c|}
\hline \multirow{3}{*}{$\begin{array}{c}\text { Age } \\
\text { (weeks) } \\
\text { [Calli/ } \\
\text { plant] }\end{array}$} & \multirow[t]{3}{*}{ Treatment } & \multirow[t]{3}{*}{ Sample } & \multirow{2}{*}{\multicolumn{2}{|c|}{$\begin{array}{c}\text { Ascorbate } \\
\text { concentration } \\
\left(\mathrm{mg} \mathrm{g}^{-1}\right)\end{array}$}} & \multicolumn{6}{|c|}{$\begin{array}{l}\text { Hydroxycinnamic acid concentration } \\
\qquad\left(\mathrm{mg} \mathrm{g}^{-1}\right)\end{array}$} \\
\hline & & & & & \multicolumn{2}{|c|}{ Caftaric } & \multicolumn{2}{|c|}{ Chlorogenic } & \multicolumn{2}{|c|}{ Chicoric } \\
\hline & & & $\mathrm{ACB}$ & OAM & $\mathrm{ACB}$ & OAM & $\mathrm{ACB}$ & OAM & $\mathrm{ACB}$ & OAM \\
\hline \multirow{12}{*}[2/10]{} & Control & Calli $^{1}$ & $0.5 \pm 0.0$ & $0.4 \pm 0.0$ & $0.7 \pm 0.0$ & $0.6 \pm 0.0$ & $2.7 \pm 0.0$ & $1.8 \pm 0.0$ & $3.5 \pm 0.1$ & $3.0 \pm 0.1$ \\
\hline & & Leaf $^{2}$ & $0.2 \pm 0.1$ & $0.3 \pm 0.0$ & $2.0 \pm 0.6$ & $1.2 \pm 0.1$ & $0.9 \pm 0.1$ & $1.1 \pm 0.1$ & $5.4 \pm 1.2$ & $5.2 \pm 0.1$ \\
\hline & & Ratio $^{3}$ & 2.3 & 1.1 & 0.4 & 0.5 & 3.0 & 1.5 & 0.6 & 0.6 \\
\hline & Chilling & Calli & $0.5 \pm 0.0$ & $0.4 \pm 0.0$ & $0.8 \pm 0.0$ & $0.6 \pm 0.0$ & $3.2 \pm 0.0$ & $2.1 \pm 0.0$ & $3.6 \pm 0.0$ & $3.0 \pm 0.0$ \\
\hline & & Leaf & $0.4 \pm 0.0$ & $0.3 \pm 0.0$ & $1.9 \pm 0.2$ & $1.2 \pm 0.1$ & $3.9 \pm 0.4$ & $2.3 \pm 0.1$ & $6.9 \pm 0.8$ & $5.2 \pm 0.3$ \\
\hline & & Ratio & 1.2 & 1.2 & 0.4 & 0.5 & 0.8 & 1.0 & 0.5 & 0.6 \\
\hline & Salinity & Calli & $0.5 \pm 0.0$ & $0.4 \pm 0.0$ & $0.7 \pm 0.0$ & $0.6 \pm 0.0$ & $3.1 \pm 0.0$ & $2.0 \pm 0.0$ & $3.5 \pm 0.0$ & $3.0 \pm 0.0$ \\
\hline & & Leaf & $0.4 \pm 0.0$ & $0.4 \pm 0.0$ & $1.5 \pm 0.2$ & $1.3 \pm 0.1$ & $3.8 \pm 0.3$ & $2.2 \pm 0.1$ & $6.2 \pm 0.7$ & $5.1 \pm 0.2$ \\
\hline & & Ratio & 1.3 & 1.0 & 0.5 & 0.5 & 0.8 & 0.9 & 0.6 & 0.6 \\
\hline & Combined & Calli & $0.5 \pm 0.0$ & $0.4 \pm 0.0$ & $0.8 \pm 0.0$ & $0.6 \pm 0.0$ & $3.7 \pm 0.0$ & $2.3 \pm 0.0$ & $3.6 \pm 0.0$ & $3.0 \pm 0.0$ \\
\hline & & Leaf & $0.3 \pm 0.1$ & $0.4 \pm 0.0$ & $1.7 \pm 0.4$ & $1.3 \pm 0.1$ & $3.9 \pm 1.0$ & $2.1 \pm 0.0$ & $6.0 \pm 1.2$ & $5.2 \pm 0.2$ \\
\hline & & Ratio & 1.8 & 1.2 & 0.5 & 0.5 & 0.9 & 1.1 & 0.6 & 0.6 \\
\hline \multirow{12}{*}{ [3/12] } & Control & Calli & $0.5 \pm 0.0$ & $0.4 \pm 0.0$ & $0.8 \pm 0.0$ & $0.6 \pm 0.0$ & $3.1 \pm 0.0$ & $2.1 \pm 0.1$ & $3.6 \pm 0.0$ & $3.1 \pm 0.0$ \\
\hline & & Leaf & $1.1 \pm 0.0$ & $0.9 \pm 0.1$ & $2.6 \pm 0.2$ & $2.1 \pm 0.2$ & $3.4 \pm 0.2$ & $3.3 \pm 0.0$ & $9.0 \pm 0.2$ & $8.5 \pm 0.3$ \\
\hline & & Ratio & 0.5 & 0.4 & 0.3 & 0.3 & 0.9 & 0.6 & 0.4 & 0.4 \\
\hline & Chilling & Calli & $0.5 \pm 0.0$ & $0.4 \pm 0.0$ & $0.8 \pm 0.0$ & $0.6 \pm 0.0$ & $3.9 \pm 0.0$ & $2.8 \pm 0.0$ & $3.6 \pm 0.0$ & $3.8 \pm 0.0$ \\
\hline & & Leaf & $1.2 \pm 0.1$ & $0.9 \pm 0.1$ & $2.3 \pm 0.3$ & $2.1 \pm 0.2$ & $4.1 \pm 0.2$ & $3.5 \pm 0.1$ & $8.6 \pm 0.8$ & $8.0 \pm 0.5$ \\
\hline & & Ratio & 0.4 & 0.4 & 0.3 & 0.3 & 1.0 & 0.8 & 0.4 & 0.4 \\
\hline & Salinity & Calli & $0.5 \pm 0.0$ & $0.4 \pm 0.0$ & $0.8 \pm 0.0$ & $0.6 \pm 0.0$ & $3.3 \pm 0.0$ & $2.1 \pm 0.0$ & $3.6 \pm 0.0$ & $3.0 \pm 0.0$ \\
\hline & & Leaf & $0.9 \pm 0.1$ & $0.6 \pm 0.1$ & $2.5 \pm 0.4$ & $2.0 \pm 0.3$ & $3.9 \pm 0.2$ & $3.2 \pm 0.2$ & $8.8 \pm 0.3$ & $7.4 \pm 0.6$ \\
\hline & & Ratio & 0.6 & 0.7 & 0.3 & 0.3 & 0.9 & 0.7 & 0.4 & 0.4 \\
\hline & Combined & Calli & $0.5 \pm 0.0$ & $0.4 \pm 0.0$ & $0.8 \pm 0.0$ & $0.6 \pm 0.0$ & $4.5 \pm 0.0$ & $2.9 \pm 0.0$ & $3.7 \pm 0.0$ & $3.1 \pm 0.0$ \\
\hline & & Leaf & $0.9 \pm 0.1$ & $0.7 \pm 0.0$ & $2.2 \pm 0.2$ & $2.0 \pm 0.2$ & $3.3 \pm 0.2$ & $3.1 \pm 0.2$ & $8.3 \pm 0.2$ & $7.9 \pm 0.6$ \\
\hline & & Ratio & 0.6 & 0.6 & 0.4 & 0.3 & 1.3 & 0.9 & 0.4 & 0.4 \\
\hline \multirow{12}{*}{ [4/14] } & Control & Calli & $0.5 \pm 0.0$ & $0.4 \pm 0.0$ & $0.8 \pm 0.0$ & $0.6 \pm 0.0$ & $3.1 \pm 0.0$ & $2.0 \pm 0.0$ & $3.6 \pm 0.0$ & $3.0 \pm 0.0$ \\
\hline & & Leaf & $0.8 \pm 0.1$ & $0.7 \pm 0.1$ & $2.6 \pm 0.2$ & $2.8 \pm 0.3$ & $2.9 \pm 0.1$ & $3.0 \pm 0.2$ & $8.7 \pm 0.3$ & $8.1 \pm 0.5$ \\
\hline & & Ratio & 0.7 & 0.6 & 0.3 & 0.2 & 1.1 & 0.7 & 0.4 & 0.4 \\
\hline & Chilling & Calli & $0.5 \pm 0.0$ & $0.4 \pm 0.0$ & $0.8 \pm 0.0$ & $0.6 \pm 0.0$ & $3.8 \pm 0.0$ & $2.6 \pm 0.0$ & $3.6 \pm 0.0$ & $3.0 \pm 0.0$ \\
\hline & & Leaf & $0.7 \pm 0.0$ & $0.7 \pm 0.0$ & $3.1 \pm 0.3$ & $2.3 \pm 0.1$ & $3.4 \pm 0.1$ & $3.0 \pm 0.1$ & $8.5 \pm 0.5$ & $7.6 \pm 0.2$ \\
\hline & & Ratio & 0.7 & 0.6 & 0.3 & 0.3 & 1.1 & 0.9 & 0.4 & 0.4 \\
\hline & Salinity & Calli & $0.5 \pm 0.0$ & $0.4 \pm 0.0$ & $0.8 \pm 0.0$ & $0.6 \pm 0.0$ & $3.5 \pm 0.0$ & $2.3 \pm 0.0$ & $3.6 \pm 0.0$ & $3.0 \pm 0.0$ \\
\hline & & Leaf & $1.1 \pm 0.2$ & $0.6 \pm 0.1$ & $3.0 \pm 0.2$ & $2.6 \pm 0.2$ & $3.6 \pm 0.1$ & $3.8 \pm 0.2$ & $9.4 \pm 0.5$ & $7.9 \pm 0.6$ \\
\hline & & Ratio & 0.5 & 0.7 & 0.3 & 0.2 & 1.0 & 0.6 & 0.4 & 0.4 \\
\hline & Combined & Calli & $0.6 \pm 0.0$ & $0.4 \pm 0.0$ & $0.8 \pm 0.0$ & $0.6 \pm 0.0$ & $4.4 \pm 0.0$ & $2.7 \pm 0.0$ & $3.7 \pm 0.0$ & $3.0 \pm 0.0$ \\
\hline & & Leaf & $1.1 \pm 0.1$ & $0.8 \pm 0.1$ & $3.1 \pm 0.2$ & $2.4 \pm 0.3$ & $3.6 \pm 0.1$ & $4.3 \pm 0.3$ & $8.1 \pm 0.2$ & $6.8 \pm 0.6$ \\
\hline & & Ratio & 0.5 & 0.6 & 0.4 & 0.3 & 1.2 & 0.6 & 0.5 & 0.4 \\
\hline \multicolumn{11}{|c|}{${ }^{\mathrm{T}}$ Means \pm SE $(n=6)$ from Section 5.5.3 (Figures 5.5A,B $\left.-5.8 \mathrm{~A}, \mathrm{~B}\right)$} \\
\hline${ }^{2}$ Mean & & & $=$ & res 3 . & 3.6 & $3.9 \mathrm{~B})$ & & & & \\
\hline Calli & & & & & & & & & & \\
\hline
\end{tabular}




\subsection{DISCUSSION}

This study shows that antioxidant activities and concentrations of LMWAs in suspension cultures were promoted to different degrees depending on the type of stressor and the ecotype. Of the two ecotypes, ACB was the richer source of LMWAs, and was more potent in antioxidant activity. The stationary phase held the highest concentration of LMWAs and displayed most potent antioxidant activities. These results indicate there is considerable commercial potential of using abiotic stressors as elicitors to elevate antioxidant activities and concentrations of LMWAs of S. oleraceus cells in suspension cultures.

Here, S. oleraceus in vitro cultures showed promising traits that are conducive for commercial application of cell suspension cultures to produce LMWAs: they produced comparable levels of LMWAs with lower variability in a shorter duration compared to plant leaves (Table 5.4). This maybe due to the optimum concentrations of plant growth regulators in the $S$. oleraceus cell cultures favoured the production of LMWAs. However, in other plant species, the commercial application of plant cell cultures to produce LMWAs was constrained by low yield and variability (Kolewe et al., 2008; Lee et al., 2010). The poor synthesis and variability of LMWAs in plant cell cultures were due to chromosomal aberrations caused by accelerated the rates of cellular-deprogramming and reprogramming brought upon by supra-optimal plant growth regulator concentrations in the medium (Whitmer et al., 2003; Morcillo et al., 2006; Ekiert et al., 2009; Dubrovina and Kiselev, 2012; Cheruvathur et al., 2013; Szopa et al., 2013).

All of the tested stressors resulted in higher concentrations and activities of LMWAs extractable from $S$. oleraceus calli in suspension cultures, than in control cultures and did not compromise cell growth (Figures 5.1 - 5.6 and 5.8). This is desirable if these abiotic stressors were to be used commercially to increase antioxidants. Usually, growth and secondary metabolite production are negatively correlated with one another, though it is possible to increase secondary metabolite production without compromising biomass accumulation by optimising elicitation conditions such as: type of elicitor, severity, the stage of application and the duration of application (Zhao et al., 2010; Cai et al., 2012a; Cai et al., 2012b). 
The combination of chilling and salinity were not synergistic on LMWA concentrations and activities in cell cultures (Figures 5.2 - 5.6 and 5.8). These results were similar to the effects of this stressor combination on intact plants (Section 3.5). Similarities in stressorresponses between whole plants and calli were reported when calli were initiated from leaf explants (Rus et al., 2001).

The stressors increased the concentrations of chlorogenic acid to a greater or lesser extent, but did not affect chicoric acid (Figures 5.5 and 5.7). Differential chlorogenic acid accumulation across stressors is possible because different stressors induce differential transcription and activity of genes for the cytochrome P450 monooxygenases, as discussed in detail in Chapter 3 (Section 3.6).

The concentration of chlorogenic acid in calli extracts was three-fold higher compared to leaf extracts (Table 5.4). This indicates higher carbon: nitrogen ratio and near optimal plant growth regulator concentrations in the medium may have been conducive for chlorogenic acid synthesis. Similarly higher C:N ratio in Cecropia obtusifolia in vitro cultures enhanced chlorogenic acid accumulation by three-fold compared to leaves of trees (Fritz et al., 2006; Nicasio-Torres et al., 2012). Further, aloesin production was three times higher in Aloe vera callus cultures, than leaves from plants which was attributed to optimum plant growth regulator concentrations (Matos Acurero, 2008).

The extent to which ascorbate concentration varied between ecotypes after stressor treatments (Figure 5.8) may be explained by their different rates of ascorbate biosynthesis, recycling, oxidation and catabolism. This is because transcription of genes encoding enzymes, which regulate ascorbate biosynthesis, recycling and degradation are variably increased or decreased depending on the stressor and cultivar (Cruz-Rus et al., 2011; Zhang et al., 2011b; Mellidou et al., 2012; Alós et al., 2013; Li et al., 2013). For example, accessions of Fragaria ananassa with higher stressor-induced ascorbate content had upregulated transcription of genes for ascorbate biosynthetic and recycling enzymes (Cruz-Rus et al., 2011; Li et al., 2013). In Solanum esculentum and Capsicum annuum, too, cultivars with higher stressor-induced fruit ascorbate content was attributed to enhanced transcription of ascorbate biosynthetic and recycling enzymes and lower transcription of ascorbate degradation enzymes (Mellidou et al., 2012; Alós et al., 2013). 
The calli of two ecotypes differed in ability to increase caftaric acid accumulation in response to stressors (Figure 5.6A,B). This may imply differences in stressor-inducible genes encoding enzymes and transcription factors in phenylpropanoid pathway between ecotypes. Differences in founding genotypes and their geographic isolation between the two $S$. oleraceus populations from which the ecotypes originated may have lead to this (St John-Sweeting, 2011). For example, in certain accessions of Zea mays, complete or partial loss of either, one or both anthocyanin and flavonone biosynthetic pathways occurred (Zhang et al., 2011b).

Calli of ACB were richer in LMWAs and had more potent antioxidant activities, than OAM (Figures 5.2A,B - 5.8A,B) possibly due to a strong genetic component controlling S. oleraceus antioxidant traits across ecotypes. The direction of the difference between ecotypes was consistent with that for greenhouse grown plants (Section 3.5; Figure 3.4), and with the unpublished results by Ellwood (2007). As discussed in detail in Section 3.6, this may be due to differential expression of PAL multigene family across plant accessions.

$\mathrm{ACB}$ is more tolerant to abiotic stressor in in vitro cultures than OAM. Of the two ecotypes, ACB had greater stressor-induced LMWAs levels and better cell membrane integrity indicated by proportionally lower LMWAs level in the media (Figures 5.2 5.8). Similarly, a lower efflux of cell contents from calli of a cadmium-tolerant Populus nigra ecotype, compared to that of a sensitive ecotype, was attributed to higher Cdinduced intracellular LMWAs accumulation in the tolerant ecotype aiding its cell membrane integrity by scavenging excess ROS efficiently (Iori et al., 2012). In Phoenix dactylifera and Triticum aestivum too, these traits have been associated with the stress tolerant genotypes in in vitro cultures (Daayf et al., 2003; Moheb et al., 2011; Iori et al., 2012).

The stationary phase held the highest ascorbate, hydroxycinnamic and total phenolic concentrations compared to any other growth phase (Figures 5.4-5.8), which may due to higher cell numbers at stationary phase compared to other growth stages. The onset of the stationary phase occurs once the cell cultures reach maximum carrying capacity (Naill and Roberts, 2005; Cacho et al., 2010). Further, at stationary phase, the $G_{0} / G_{1}$ cell ratio exceeds $90 \%$ and the $\mathrm{G}_{0}$ cells have higher capacity and rates of secondary metabolism 
than $\mathrm{G}_{1}$ cells (Cheng et al., 2006; Zhao et al., 2010). In suspension cultures of other species, too, phenolic compound accumulation is maximal at the stationary phase (Jeong et al., 2009; Cacho et al., 2010; Cai et al., 2012b; Karwasara and Dixit, 2012; NicasioTorres et al., 2012; Yin et al., 2012).

These results indicate the significant features of LMWAs production in S. oleraceus cell suspension cultures, which were: highly stressor-induced, lower in variability and accumulation within shorter culture duration compared to leaves of whole plants. Additionally, the growth of cell cultures was unchallenged by stressors. These basic traits are highly preferable in developing large scale commercial production and extraction systems of LMWAs from plant cell cultures. 


\section{CHAPTER 6: GENERAL DISCUSSION}

\subsection{CONCLUSIONS}

This study confirmed that vegetative shoots of Sonchus oleraceus L. are rich in LMWAs as shown by in vitro chemical and cellular antioxidant activity (CAA) measures (Chapter 4). The antioxidant activities and concentration of LMWAs of S. oleraceus leaves and calli significantly increased with maturation of plants and cell cultures (Chapters 3 and 5; Table 6.1). Furthermore, as shown in Chapters 3 and 5, the ecotype differences in antioxidant activities were largely maintained across progenies and in cell cultures indicating the heritability and genetic stability of antioxidant potential in S. oleraceus (Table 6.1).

Chapters 3 and 5 showed that, the degree of stressor-induced antioxidant activities compared to controls, were greater in plant cell cultures than in whole plants (Chapter 5: Table 5.4). Furthermore, of the two ecotypes tested here, the antioxidant activities and LMWAs content of the superior ecotype were enhanced to a greater degree by imposing stressors to plants and cell cultures (Chapters 3 and 5). Chapter 5 also demonstrated that for calli from suspension cultures, the most effective stressor differed between ecotypes; the stressor combination for ACB, and chilling for OAM. As shown in Chapter 3, leaves with highest antioxidant activities and concentrations of LMWAs were obtained from 14 week old plants originating from Acacia Bay (ACB) that had been exposed to two weeks of chilling night temperatures and salinity. Chapter 3 also showed that infusion of HepG2 cells with extracts from leaves with stressor-promoted antioxidant activities protected the cultured human cells from oxidative stress to a greater degree.

Furthermore, as shown in Chapter 4, cooking leaves, diminished the levels of some LMWAs in the bioaccessible fraction obtained through in vitro gastrointestinal digestion. Also, antioxidants from uncooked leaves that were digested in in vitro gastrointestinal conditions were absorbed into human cells in vitro and protected them from oxidative stress (Chapter 4). 
Table 6.1 Simplified summary of results from Chapters 3 - 5 showing factors affecting antioxidant activities in Sonchus oleraceus L. leaves and cell cultures

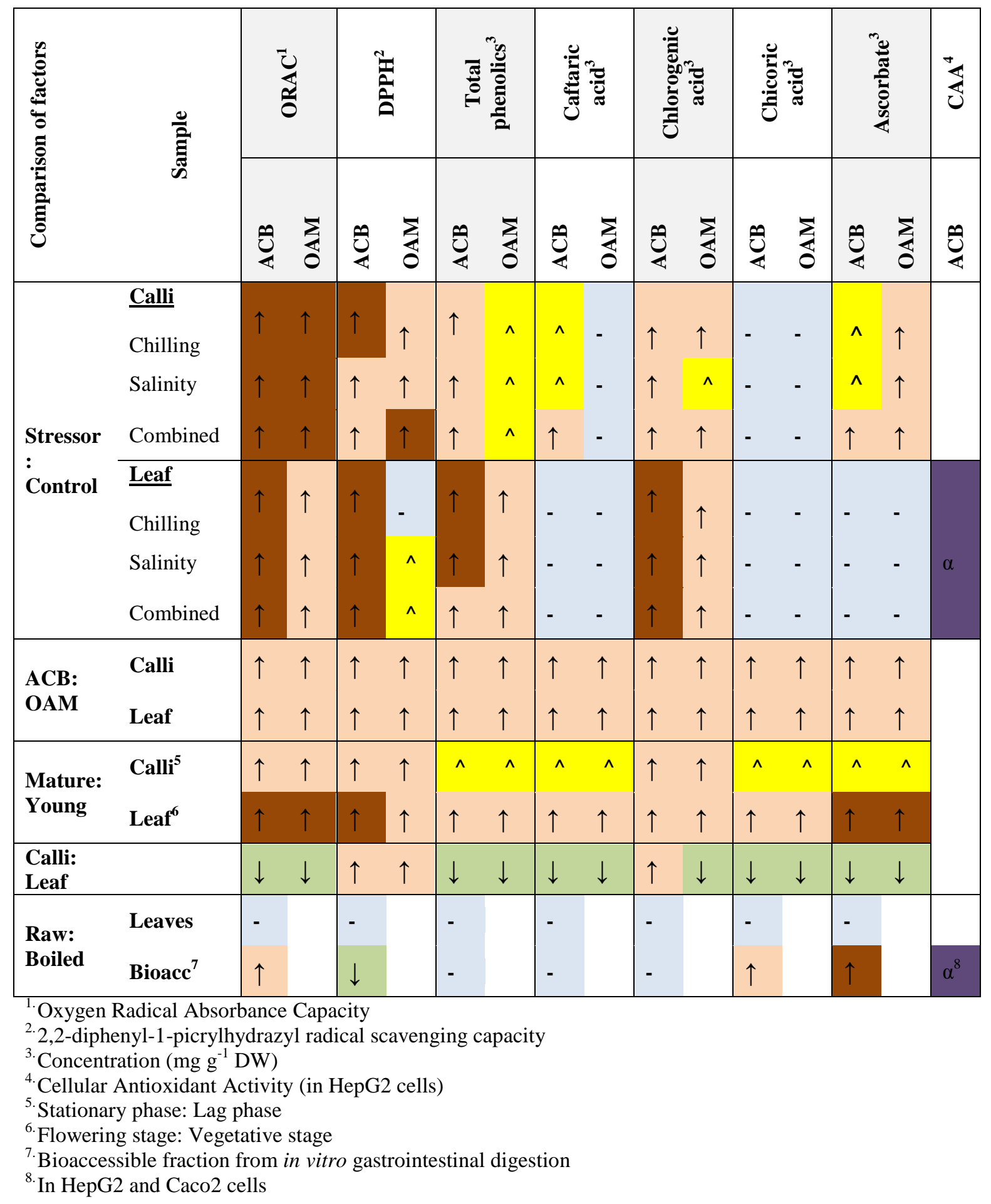

Key

\begin{tabular}{llc} 
Key & & \\
\hline Symbol & Change/result & Fold change \\
\hline$\uparrow$ & Large increase & $1.50-6.00$ \\
$\uparrow$ & Moderate increase & $1.10-1.49$ \\
$\wedge$ & Very small increase & $1.00-1.09$ \\
$\downarrow$ & Decrease & $<0.99$ \\
- & No change & 0.00 \\
$\alpha$ & Significant positive linear correlation & Not applicable \\
\hline
\end{tabular}




\subsection{DISCUSSION}

There has been a recent drive to produce plants rich in LMWAs to promote consumer health. Consequently, increasingly more research is being done on the antioxidant properties of food plants (Kaur and Kapoor, 2001; García-Mier et al., 2013). However, to commercialise a food plant as a antioxidant source, systematic research is required, focused on; (1) enhancing the levels of LMWAs in field grown plants; (2) developing commercially applicable in vitro culture techniques for efficient and effective LMWAs extraction; (3) the effects of food preparation on LMWAs; and (4) bioaccessibility, bioactivity, bioavailability and stability of LMWAs (Figure 6.1). My study on the antioxidant activities of $S$. oleraceus followed the scheme given in Figure 6.1 following recent recommendations on using plants as health promoting phytochemical sources (Finley, 2005; Rea et al., 2011; Traka and Mithen, 2011; Tounekti and Munné-Bosch, 2012).

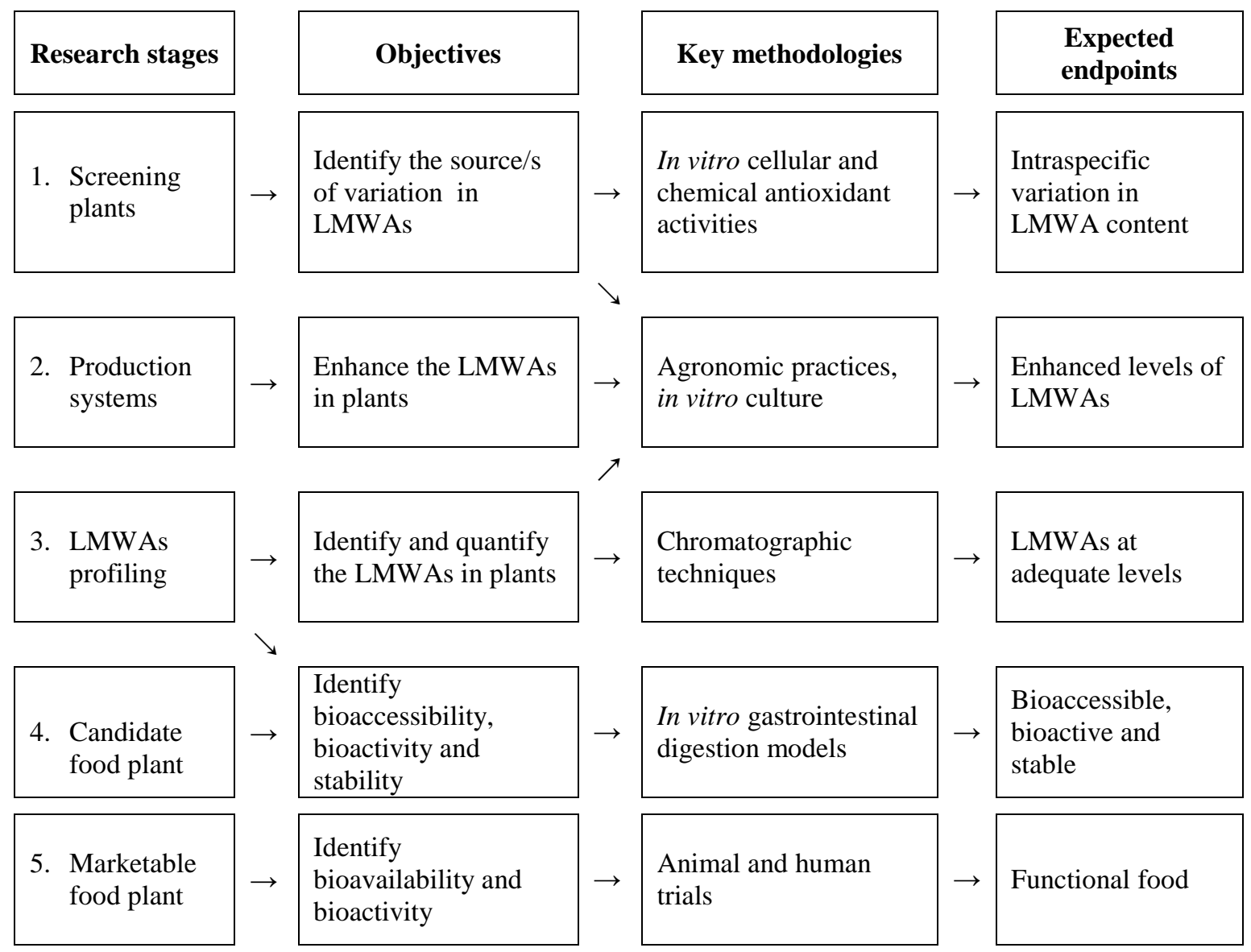

Figure 6.1 Process for validating a food plant as a valuable source of dietary LMWAs with evidence of health benefits developed based on recommendations of Finley (2005); Rea et al. (2011); Traka and Mithen (2011); Tounekti and Munné-Bosch (2012). 
My work, demonstrated that extractable antioxidant activities of $S$. oleraceus leaves were superior to most commonly consumed food (Table 6.2). This was particularly true when leaves were selected from flowering plants of the more potent ecotype (ACB) that were exposed to stressors (Table 6.2). These results indicates the commercial potential of selecting potent ecotypes and practising correct agronomy to further improve extractable antioxidant activities of $S$. oleraceus leaves.

Table 6.2 Sonchus oleraceus L. leaves and common food categorized into six groups ranked by their extractable antioxidant activities

\begin{tabular}{|c|c|c|c|c|c|}
\hline ORAC $^{1}$ & S. oleraceus leaves ${ }^{2}$ & Fruits $^{3}$ & Vegetables $^{3}$ & $\begin{array}{l}\text { Dried fruits } \\
\text { and nuts }\end{array}$ & Other food $^{3}$ \\
\hline \multirow{12}{*}{$\mathbf{0}-\mathbf{2 0}$} & Vegetative plants of & Watermelon & Cucumber & Brazil nut & Bread \\
\hline & both ecotypes & Cantaloupe & Beans & Macadamia & Ready-to-eat \\
\hline & & Nectarine & Green peas & Cashews & breakfast cereals \\
\hline & & Pineapple & Celery & & \\
\hline & & Banana & Corn & & \\
\hline & & Grapes & Cauliflower & & \\
\hline & & Apricot & Onion & & \\
\hline & & Avocado & Potato & & \\
\hline & & Tangerine & Pepper & & \\
\hline & & Oranges & Carrot & & \\
\hline & & Peach & Broccoli & & \\
\hline & & Pears & Lettuce & & \\
\hline \multirow{4}{*}{$21-40$} & & Apple & Cabbage & Peanut & \\
\hline & & Cherry & Spinach & Dates & \\
\hline & & Strawberry & Beet & Raisin & \\
\hline & & & Asparagus & Figs & \\
\hline \multirow{2}{*}{$41-60$} & Flowering plants of & Raspberry & & Almond & \\
\hline & OAM ecotype & Blackberry & & & \\
\hline \multirow{2}{*}{$61-80$} & Flowering, ACB & Blueberry & & Pistachio & Milk chocolate \\
\hline & without a stressor & Plum & & & \\
\hline $81-90$ & Flowering, $\mathrm{ACB}^{4}$ & & & Prunes & \\
\hline $91-96$ & Flowering, $\mathrm{ACB}^{5}$ & Cranberry & Artichoke & Hazelnut & \\
\hline $97-100$ & Flowering, $\mathrm{ACB}^{6}$ & & & & \\
\hline 1031 & & & & & Baking chocolate \\
\hline \multicolumn{6}{|c|}{${ }^{1}$ Oxygen Radical Absorbance Capacity $\left(\mu \mathrm{mol} \mathrm{TE} \mathrm{g}^{-1}\right)$} \\
\hline \multicolumn{6}{|c|}{${ }^{2}$ Results from Chapter 3} \\
\hline \multicolumn{6}{|c|}{${ }^{3}$ Source: Wu et al., 2004} \\
\hline Stressors & ling, ${ }^{5}$ salinity and ${ }^{6}$ & bined & & & \\
\hline
\end{tabular}


Here, extraction of LMWAs from S. oleraceus in vitro cultures showed advantages over leaves because produced LMWA levels were; (1) higher or comparable, (2) had low variability and (3) accumulated rapidly (Chapter 5; Table 5.4). These significant features displayed by $S$. oleraceus in vitro cultures have been considered essential first steps in commercial projects, such as the European Union project 'Nutra-Snack'. Nutra-Snack aimed to develop large scale pre-industrial production of antioxidants from cells and in vitro cultures of Ocimum basilicum, Mentha piperita, Trifolium heldreichianum, Glycine max, Taraxacum officinale and Salvia officinalis. The ultimate goal of the projects was to manufacture novel ready-to-eat snacks enriched with antioxidants of plant origin (Rea et al., 2011). Further, plant cell cultures are gaining popularity as biofactories of bioactive phytochemicals (Lindsay, 2000; Jacobo-Velázquez et al., 2011; Becerra-Moreno et al., 2012; Jacobo-Velázquez and Cisneros-Zevallos, 2012; Tounekti and Munné-Bosch, 2012). Thus $S$. oleraceus cell cultures have the potential to be developed into commercial bioreactors to biosynthesise antioxidants that maybe developed into botanical antioxidant food products.

The in vitro cultures of $S$. oleraceus produced all three major hydroxycinnamic acids to lesser or comparable levels that were present in leaves harvested from plants (Chapter 5; Section 5.5.3; Table 5.4). This is of particular importance since some other plant species altogether lacked the capability to accumulate these hydroxycinnamic acids when they were grown as in vitro cell cultures than as whole plants (Table 6.3). Organ cultures too, can produce secondary metabolites at levels that are similar to those synthesized in whole plants. However, organ cultures unlike cell cultures are expensive and complex to maintain in bioreactors at large scale (Verpoorte et al., 2002). Therefore $S$. oleraceus cell suspension cultures have economic feasibility of scaling-up to produce hydroxycinnamic acids.

Further, the abiotic stressors that were used here have the potential to be used as elicitors particularly the combined stressor in commercial in vitro culture systems (Table 6.4). Fold increase in hydroxycinnamic acid levels due to elicitation of in vitro cultures of $S$. oleraceus was comparable with values obtained for other plant species that were in the experimental stages of developing into commercialised systems (Table 6.4). 
Table 6.3 Comparison of concentrations of hydroxycinnamic acids extracted from calli of suspension cultures and leaves of greenhouse grown plants of Sonchus oleraceus L. and other selected plant species

\begin{tabular}{|c|c|c|c|c|c|}
\hline \multirow[t]{2}{*}{ Species } & & \multicolumn{3}{|c|}{$\begin{array}{c}\text { Hydroxycinnamic acid concentration } \\
\left(\mathrm{mg} \mathrm{g}^{-1} \mathrm{DW}\right)\end{array}$} & \multirow[t]{2}{*}{ References } \\
\hline & & Caftaric & Chlorogenic & Chicoric & \\
\hline Sonchus oleraceus & Calli $^{1}$ & 0.8 & 3.5 & 3.6 & (Chapter 5; Section 5.5.3) \\
\hline \multirow[t]{2}{*}{ ACB ecotype } & Leaf $^{2}$ & 2.4 & 3.4 & 7.8 & (Chapter 3; Section 3.5.2) \\
\hline & Ratio $^{3}$ & 0.3 & 1.0 & 0.5 & \\
\hline \multirow[t]{3}{*}{ OAM ecotype } & Calli & 0.6 & 2.3 & 3.0 & (Chapter 5; Section 5.5.3) \\
\hline & Leaf & 1.9 & 2.9 & 6.9 & (Chapter 3; Section 3.5.2) \\
\hline & Ratio & 0.3 & 0.8 & 0.4 & \\
\hline \multirow[t]{3}{*}{ Lactuca virosa } & Calli & 0.1 & 0.1 & 0.6 & (Stojakowska et al., 2012) \\
\hline & Leaf & 2.0 & 3.9 & 1.5 & \\
\hline & Ratio & 0.1 & $\mathbf{0 . 0}$ & 0.4 & \\
\hline \multirow[t]{3}{*}{ Eucommia ulmoides } & Calli & - & 2.2 & - & (Wang et al., 2003) \\
\hline & Leaf & - & 2.6 & - & \\
\hline & Ratio & - & 0.8 & - & \\
\hline \multirow[t]{3}{*}{ Lavandula viridis } & Calli & - & 1.8 & - & (Costa et al., 2013). \\
\hline & Leaf & - & 2.3 & - & \\
\hline & Ratio & - & 0.8 & - & \\
\hline \multirow[t]{3}{*}{ Echinacea angustifolia } & Calli & - & - & - & (Lucchesini et al., 2009) \\
\hline & Leaf & 4.3 & 1.2 & 1.5 & \\
\hline & Ratio & - & - & - & \\
\hline
\end{tabular}

${ }^{1}$ Means $(n=72)$ pooled for ages and stressors

${ }^{2}$ Means $(n=96)$ pooled for ages and stressors

${ }^{3}$ Calli: Leaf

- Compound is not detected 
Table 6.4 Effects of abiotic elicitors on concentrations of hydroxycinnamic acids extracted from calli of suspension cultures of Sonchus oleraceus L. and selected plant species

\begin{tabular}{llcccl}
\hline Species & $\begin{array}{l}\text { Abiotic } \\
\text { elicitors }\end{array}$ & $\begin{array}{c}\text { Hydroxycinnamic acid concentration } \\
\left(\mathbf{m g ~ g}^{-1} \mathbf{~ D W}\right)\end{array}$ & References \\
& & Caftaric & $\begin{array}{c}\text { Chlorogenic } \\
\text { Chicoric }\end{array}$ & \\
\hline Sonchus oleraceus $^{1}$ & Combined & 0.8 & 4.5 & 3.7 & (Chapter 5; Figure \\
& Control & 0.8 & 3.1 & 3.6 & 5.3A,C,E) \\
& Ratio $^{2}$ & $\mathbf{1 . 1}$ & $\mathbf{1 . 5}$ & $\mathbf{1 . 0}$ & \\
\hline Echinacea purpurea & $20^{\circ} \mathrm{C}$ & 4.7 & 5.2 & 28.4 & (Wu et al., 2007) \\
& $10^{\circ} \mathrm{C}$ & 4.4 & 4.9 & 29.1 & \\
& Ratio & $\mathbf{1 . 1}$ & $\mathbf{1 . 1}$ & $\mathbf{1 . 0}$ & \\
\cline { 2 - 6 } & Light & 6.1 & 2.3 & 27 & (Abbasi et al., 2007) \\
& Dark & 4.1 & 1.0 & 20 & \\
& Ratio & $\mathbf{1 . 5}$ & $\mathbf{2 . 3}$ & $\mathbf{1 . 4}$ & \\
\cline { 2 - 6 } & Ultrasound & 10.2 & 1.4 & 23.4 & (Liu et al., 2012) \\
& Control & 7.7 & 1.0 & 16.6 & \\
& Ratio & $\mathbf{1 . 3}$ & $\mathbf{1 . 4}$ & $\mathbf{1 . 4}$ & \\
\hline
\end{tabular}

${ }^{1}$ Means $(n=6)$ calli at stationary phase

${ }^{2}$ Abiotic elicitor: Control

Combined stressor enhanced the extractable antioxidant activities of calli of suspension cultures to a greater degree whereas in leaves of greenhouse grown plants they were not improved, compared to their respective controls (Table 6.1). This indicates the possible differences between the responses at whole plant and cellular level to abiotic stressors. Cells in in vitro cultures may rely on elevated antioxidant activities to mitigate combined effects of chilling and salinity, more than whole plants. This is because once chilling injures the cell membranes; the increased cell membrane permeability will enhance the movement of inorganic ions into cells (Liu et al., 2013). The degree of ion movement into undifferentiated cells in suspension cultures would be more compared to whole plants in which roots exclude the salts. For example, in Sesuvium portulacastrum salinity-elevated antioxidant activities were higher in undifferentiated cells than in whole plants (Lokhande et al., 2010).

The discovery of heritable and genetically stable ecotype difference in LMWA activities may be significant for growers and breeders (Chapter 3 and 4). Growers may use selfed 
seeds from superior accessions to produce LMWA-rich leaves across cropping cycles. Crop breeding and improvement techniques can be used to further augment their levels in leaves once their genetic basis for higher LMWAs content is understood. Presently, crop breeding programmes focus on identifying heritable differences in LMWA properties in their breeding stock and progenies, and on prioritizing genotypes with improved antioxidant properties beneficial to consumer health (Connor et al., 2002; Stushnoff et al., 2008; Cantín et al., 2009; Yousef et al., 2013). An example is Solanum esculentum for which hybrids with four-fold higher fruit lycopene content have been developed by the selective elimination of low lycopene-genes and by backcrossing which incorporated high lycopene-genes into progenies (Anon, 1998). In addition, the chlorogenic acid content in the fruit was doubled in Solanum esculentum through genetic engineering in which overexpression of hydroxycinnamoyl-CoA quinate: hydroxycinnamoyl transferase (HQT) enzyme was achieved (Niggeweg et al., 2004).

My work has shown that stressor-enhanced LMWAs in S. oleraceus leaves provide improved antioxidant protection to human cells in cultures (Chapter 3; Figures 3.16-3.17). This finding is a significant first step because it demonstrates that agronomic efforts to increase LMWAs would likely translate into an improvement in the antioxidant status of live human cells if treated with LMWAs enriched plant extracts. Much research has focused on imposing stress on plants to improve in vitro antioxidant activities and to test the cellular antioxidant activities of plant foods, but few attempts have been made to correlate the two (Prior et al., 1998; Wolfe et al., 2008; Song et al., 2010; Tsormpatsidis et al., 2010; McDowell et al., 2011; Zhang et al., 2011a; Avena-Bustillos et al., 2012; Bornsek et al., 2012; Jacobo-Velázquez and Cisneros-Zevallos, 2012).

Here I identified how pre- and post-harvest factors: plant age, ecotype, abiotic stressors and cooking, contribute to variation in LMWAs and antioxidant activities of leaves (Chapter 3; Chapter 4; Table 6.1). This knowledge is the basis for developing good cropping and processing practices to obtain leaves enriched with LMWAs. These findings are particularly important, because modern day humans greatly prefer minimally processed plant food to fulfil their nutritional and health needs than the formulated merchandise such as capsules or tablets (Lindsay, 2000; Williams et al., 2004; Herath et al., 2008; Jacobo-Velázquez et al., 2011; Becerra-Moreno et al., 2012; Jacobo-Velázquez and Cisneros-Zevallos, 2012; Tounekti and Munné-Bosch, 2012). 
Contemporary definition of food security by the Food and Agriculture Organization (FAO), recognises the importance of consuming food that would promote human health (Nestel et al., 2006; FAO, 2008). However, even in European countries and USA, the average fruit and vegetable intake is below the World Health Organisation (WHO) recommendation ( of $\geq 400 \mathrm{~g} \mathrm{~d}^{-1}$ person $^{-1}$ ) for the prevention of diet-related chronic diseases (Anon, 2003; Ashfield-Watt et al., 2004). To counteract the problem of low fruit and vegetable per capita intake, the Nutritional Enhancement of Plant Foods in European Trade (NEODIET) programme advocates a shift in public health strategy towards promoting the consumption of plants rich in LMWAs (Lindsay, 2000). In these contexts, there is a demand for plant produce that are highly concentrated in LMWAs. S. oleraceus can fulfill these expectations by following the basic guidelines provided in this study.

\subsection{FUTURE DIRECTIONS}

Elevated concentrations of LMWAs in S. oleraceus leaves do not automatically guarantee higher bioactivity in live organisms since the these compounds need to be stable through the interaction with plasma proteins and metabolism in the liver. Thus, bioactivity studies require animal and human trials (Schreiner et al., 2012). The antioxidant capacity of plant food as measured by in vitro chemical assays and by cellular antioxidant activities following in vitro gastrointestinal simulation, may still differ from in vivo antioxidant activities, because of: (1) phenolic-microbiota interactions in the sigmoid colon; (2) phenolic-plasma protein interactions in the blood; and (3) hepatic metabolism (Rohn et al., 2004; Silberberg et al., 2006; Selma et al., 2009). To understand the in vivo fate of phenolic compounds in S. oleraceus leaves would require animal and human intervention studies, because: (1) the colonic microbial diversity vary between individuals and continuously modified depending on the ingested phenolic compounds; (2) the diffusion of phenolic compounds from blood to target tissues depends on the degree of binding between phenolic compound and the plasma protein; and (3) hepatic metabolism of phenolic compounds depends on the location of the metabolizing enzymes in a liver's acini (Ballinger et al., 1995; Requena et al., 2010; Duarte and Farah, 2011; Xiao and Kai, 2011). For those reasons, bioactivity studies require intact live animal organs thus necessitating animal models prior to human clinical trials. 
Studies of the in vivo transformation of phenolic compounds in S. oleraceus can done using leaves with ${ }^{14} \mathrm{C}$-labelled phenolic compounds obtained from plants grown in ${ }^{14} \mathrm{CO}_{2}$ supplied growth chambers. The leaves with radiolabeled phenolic compounds can be either administered orally or their leaf extracts can be perfused in situ to the colon and/or liver of rats. Time course monitoring of the quantitative and qualitative profiles of the radiolabeled compounds in target tissues (intestines, blood and liver) would provide information on in vivo transformation of phenolic compounds. The bioactivity can be quantified by measuring time course changes in cellular antioxidant activities in tissues and by antioxidant activities of blood and tissue lysates from sacrificed animals.

In conclusion, this study focused on the leaves of Sonchus oleraceus that are exceptionally rich in extractable antioxidants, since they have the potential to protect humans cells from oxidative stress. I identified the factors that caused significant variation in antioxidant properties of $S$. oleraceus, namely: maturation (of cell cultures and plants), genetic heredity, abiotic stressors, propagation method (whole plants versus cells), and cooking. Furthermore, it was observed that cultured human cells infused with leaf extracts were protected from oxidative stress even after the leaves had been digested in simulated gastrointestinal conditions. Importantly, human cells were more protected from oxidative damage if the leaves had stressor-augmented extractable antioxidant activities. Collectively, the data provide a compelling argument to explore the commercial potential of growing S. oleraceus as a functional food crop. 


\section{REFERENCES}

Anonymous (1988). British pharmacopoeia 1988, Her Majesty's Stationery Office, London, United Kingdom.

Anonymous (1998). Role and control of antioxidants in the tomato processing industry. European Commission Concerted Action Programme, EU FAIR Project (FAIR CT97-3233): 24.

Anonymous (2003). Population nutrient intake goals for preventing diet-related chronic diseases. Diet, nutrition and the prevention of chronic diseases. Report of a Joint WHO/FAO Expert Consultation. WHO technical report series (TRS 916). Geneva, Switzerland, World Health Oraganisation: 148.

Abbasi, B., C.-L. Tian, S. Murch, P. Saxena and C.-Z. Liu (2007). Light-enhanced caffeic acid derivatives biosynthesis in hairy root cultures of Echinacea purpurea. Plant Cell Reports $26: 1367-1372$.

Abreu, I. N., A. L. M. Porto, A. J. Marsaioli and P. Mazzafera (2004). Distribution of bioactive substances from Hypericum brasiliense during plant growth. Plant Science 167: 949-954.

Acamovic, T. and J. D. Brooker (2005). Biochemistry of plant secondary metabolites and their effects in animals. Proceedings of the Nutrition Society 64: 403-412.

Adams III, W. W., C. R. Zarter, K. E. Mueh, V. e. Amiard and B. Demmig-Adams (2006). Energy dissipation and photoinhibition: A continuum of photoprotection. In Photoprotection, photoinhibition, gene regulation, and environment. B. Demmig-Adams, W. W. Adams and A. K. Mattoo, Springer-Verlag Inc., New York, USA. 21: 49-64.

Ader, P., B. Grenacher, P. Langguth, E. Scharrer and S. Wolffram (1996). Cinnamate uptake by rat small intestine: Transport kinetics and transepithelial transfer. Experimental Physiology 81: 943-955.

Ahmed, I. M., F. Cao, Y. Han, U. A. Nadira, G. Zhang and F. Wu (2013a). Differential changes in grain ultrastructure, amylase, protein and amino acid profiles between Tibetan wild and cultivated barleys under drought and salinity alone and combined stress. Food Chemistry 141: 2743-2750.

Ahmed, I. M., H. Dai, W. Zheng, F. Cao, G. Zhang, D. Sun and F. Wu (2013b). Genotypic differences in physiological characteristics in the tolerance to drought and salinity combined stress between Tibetan wild and cultivated barley. Plant Physiology and Biochemistry 63: 49-60.

Akdemir, Z. Ş., İ. İrem Tatlı, İ. Saracoğlu, U. B. İsmailoğlu, İ. Şahin-Erdemli and İ. Çalış (2001). Polyphenolic compounds from Geranium pratense and their free radical scavenging activities. Phytochemistry 56: 189-193.

Alós, E., M. J. Rodrigo and L. Zacarías (2013). Transcriptomic analysis of genes involved in the biosynthesis, recycling and degradation of L-ascorbic acid in pepper fruits (Capsicum annuum L.). Plant Science 207: 2-11.

Andersson, B. and E.-M. Aro (2004). Photodamage and D1 protein turnover in photosystem ii regulation of photosynthesis. advances in photosynthesis and respiration. In Advances in Photosynthesis and Respiration. E. M. Aro and B. Andersson, Springer, Netherlands. 11: 377-393.

Aroca, R., J. J. Irigoyen and M. Sánchez-Díaz (2003). Drought enhances maize chilling tolerance. II. Photosynthetic traits and protective mechanisms against oxidative stress. Physiologia Plantarum 117: 540-549. 
Arora, A., T. M. Byrem, M. G. Nair and G. M. Strasburg (2000). Modulation of liposomal membrane fluidity by flavonoids and isoflavonoids. Archives of Biochemistry and Biophysics 373: 102-109.

Asada, K. (1999). The water-water cycle in chloroplasts: Scavenging of active oxygens and dissipation of excess photons. Annual Review of Plant Biology 50: 601-639.

Ashfield-Watt, P., A. Welch, N. Day and S. Bingham (2004). Is 'five-a-day' an effective way of increasing fruit and vegetable intakes? Public Health Nutrition 7: 257-261.

Aura, A.-M. (2008). Microbial metabolism of dietary phenolic compounds in the colon. Phytochemistry Reviews 7: 407-429.

Avena-Bustillos, R. J., W.-X. Du, R. Woods, D. Olson, A. P. Breksa and T. H. McHugh (2012). Ultraviolet-B light treatment increases antioxidant capacity of carrot products. Journal of the Science of Food and Agriculture 92: 2341-2348.

Ayan, A., C. Çirak and O. Yanar (2006). Variations in total phenolics during ontogenetic, morphogenetic, and diurnal cycles in Hypericum species from Turkey. Journal of Plant Biology 49: 432-439.

Bailly, F. and P. Cotelle (2005). Anti-HIV activities of natural antioxidant caffeic acid derivatives: Toward an antiviral supplementation diet. Current Medicinal Chemistry 12: 1811-1818.

Ballinger, L. N., S. E. Cross and M. S. Roberts (1995). Availability and mean transit times of phenol and its metabolites in the isolated perfused rat liver: Normal and retrograde studies using tracer concentrations of phenol Journal of Pharmacy and Pharmacology 47: 949-956.

Bartoli, C. G., J. J. Guiamet, G. U. Y. Kiddle, G. M. Pastori, R. Di Cagno, F. L. Theodoulou and C. H. Foyer (2005). Ascorbate content of wheat leaves is not determined by maximal L-galactono-1,4-lactone dehydrogenase (GalLDH) activity under drought stress. Plant, Cell \& Environment 28: 1073-1081.

Bartoli, C. G., M. Simontacchi, E. Tambussi, J. Beltrano, E. Montaldi and S. Puntarulo (1999). Drought and watering-dependent oxidative stress: Effect on antioxidant content in Triticum aestivum L. leaves. Journal of Experimental Botany 50: 375383.

Barton, K. E. (2007). Early ontogenetic patterns in chemical defense in Plantago (Plantaginaceae): Genetic variation and trade-offs. American Journal of Botany 94: 56-66.

Basu, A., N. M. Betts, J. Ortiz, B. Simmons, M. Wu and T. J. Lyons (2011). Low-energy cranberry juice decreases lipid oxidation and increases plasma antioxidant capacity in women with metabolic syndrome. Nutrition Research 31: 190-196.

Baynes, J. W. and S. R. Thorpe (1999). Role of oxidative stress in diabetic complications: A new perspective on an old paradigm. Diabetes 48: 1-9.

Bazzocco, S., I. Mattila, S. Guyot, C. G. C. Renard and A.-M. Aura (2008). Factors affecting the conversion of apple polyphenols to phenolic acids and fruit matrix to short-chain fatty acids by human faecal microbiota in vitro. European Journal of Nutrition 47: 442-452.

Becerra-Moreno, A., J. Benavides, L. Cisneros-Zevallos and D. A. Jacobo-Velázquez (2012). Plants as biofactories: Glyphosate-induced production of shikimic acid and phenolic antioxidants in wounded carrot tissue. Journal of Agricultural and Food Chemistry 60: 11378-11386.

Ben Ahmed, C., B. Ben Rouina, S. Sensoy, M. Boukhriss and F. B. Abdullah (2009). Saline water irrigation effects on antioxidant defense system and proline accumulation in leaves and roots of field-grown olive. Journal of Agricultural and Food Chemistry 57: 11484-11490. 
Bermúdez-Soto, M. J., F. A. Tomás-Barberán and M. T. García-Conesa (2007). Stability of polyphenols in chokeberry (Aronia melanocarpa) subjected to in vitro gastric and pancreatic digestion. Food Chemistry 102: 865-874.

Beynon, R. J. and J. S. Bond (2001). Proteolytic enzymes: A practical approach, IRL Press at Oxford University Press, Oxford, United Kingdom.

Bilger, W., T. Johnsen and U. Schreiber (2001). UV excited chlorophyll fluorescence as a tool for the assessment of UV protection by the epidermis of plants. Journal of Experimental Botany 52: 2007-2014.

Blount, J., S. Masoud, L. Sumner, D. Huhman and R. Dixon (2002). Over-expression of cinnamate 4-hydroxylase leads to increased accumulation of acetosyringone in elicited tobacco cell-suspension cultures. Planta 214: 902-910.

Blount, J. W., K. L. Korth, S. A. Masoud, S. Rasmussen, C. Lamb and R. A. Dixon (2000). Altering expression of cinnamic acid 4-hydroxylase in transgenic plants provides evidence for a feedback loop at the entry point into the phenylpropanoid pathway. Plant Physiology 122: 107-116.

Bohnert, H. J. and E. Sheveleva (1998). Plant stress adaptations - Making metabolism move. Current Opinion in Plant Biology 1: 267-274.

Bornsek, S. M., L. Ziberna, T. Polak, A. Vanzo, N. P. Ulrih, V. Abram, F. Tramer and S. Passamonti (2012). Bilberry and blueberry anthocyanins act as powerful intracellular antioxidants in mammalian cells. Food Chemistry 134: 1878-1884.

Botting, K. J., M. M. Young, A. E. Pearson, P. J. Harris and L. R. Ferguson (1999). Antimutagens in food plants eaten by polynesians: Micronutrients, phytochemicals and protection against bacterial mutagenicity of the heterocyclic amine 2-amino-3-methylimidazo[4,5-f]quinoline. Food and Chemical Toxicology 37: $95-103$.

Bouayed, J., H. Rammal, A. Dicko, C. Younos and R. Soulimani (2007). Chlorogenic acid, a polyphenol from Prunus domestica (Mirabelle), with coupled anxiolytic and antioxidant effects. Journal of the Neurological Sciences 262: 77-84.

Brand-Williams, W., M. E. Cuvelier and C. Berset (1995). Use of a free radical method to evaluate antioxidant activity. LWT - Food Science and Technology 28: 25-30.

Britton, G. (1995). Structure and properties of carotenoids in relation to function. The FASEB Journal 9: 1551-1558.

Buchanan, B. B., W. Gruissem and R. L. Jones (2000). Biochemistry and Molecular Biology of Plants, John Wiley \& Sons, Oxford, United Kingdom.

Burda, S. and W. Oleszek (2001). Antioxidant and antiradical activities of flavonoids. Journal of Agricultural and Food Chemistry 49: 2774-2779.

Burdette, J. E., S.-n. Chen, Z.-Z. Lu, H. Xu, B. E. P. White, D. S. Fabricant, J. Liu, H. H. S. Fong, N. R. Farnsworth, A. I. Constantinou, R. B. van Breemen, J. M. Pezzuto and J. L. Bolton (2002). Black cohosh (Cimicifuga racemosa L.) protects against menadione-induced DNA damage through scavenging of reactive oxygen species:

Bioassay-directed isolation and characterization of active principles. Journal of Agricultural and Food Chemistry 50: 7022-7028.

Cacho, M., A. Torres Domínguez and J.-A. Elena-Rosselló (2010). Are polyamines directly involved in silymarin production in the milk thistle [Silybum marianum (L.) Gaernt]?. Plant Cell, Tissue and Organ Culture (PCTOC) 103: 361-368.

Cai, Z., A. Kastell, I. Mewis, D. Knorr and I. Smetanska (2012a). Polysaccharide elicitors enhance anthocyanin and phenolic acid accumulation in cell suspension cultures of Vitis vinifera. Plant Cell, Tissue and Organ Culture (PCTOC) 108: 401-409.

Cai, Z., D. Knorr and I. Smetanska (2012b). Enhanced anthocyanins and resveratrol production in Vitis vinifera cell suspension culture by indanoyl-isoleucine, N- 
linolenoyl-l-glutamine and insect saliva. Enzyme and Microbial Technology 50: 29-34.

Cai, Z., H. Riedel, N. M. M. T. Saw, I. Mewis, K. Reineke, D. Knorr and I. Smetanska (2011). Effects of elicitors and high hydrostatic pressure on secondary metabolism of Vitis vinifera suspension culture. Process Biochemistry 46: 1411-1416.

Cambie, R. C. and L. R. Ferguson (2003a). Potential functional foods in the traditional Maori diet. Mutation Research 523-524: 109-117.

Cambie, R. C. and L. R. Ferguson (2003b). Potential functional foods in the traditional Māori diet. Mutation Research/Fundamental and Molecular Mechanisms of Mutagenesis 523-524: 109-117.

Cantín, C. M., M. a. A. Moreno and Y. Gogorcena (2009). Evaluation of the antioxidant capacity, phenolic compounds, and vitamin $\mathrm{C}$ content of different peach and nectarine [Prunus persica (L.) Batsch] breeding progenies. Journal of Agricultural and Food Chemistry 57: 4586-4592.

Cao, G., E. Sofic and R. L. Prior (1997). Antioxidant and prooxidant behavior of flavonoids: Structure-activity relationships. Free Radical Biology and Medicine 22: 749-760.

Cerda, B., C. Soto, M. D. Albaladejo, P. Martinez, F. Sanchez-Gascon, F. TomasBarberan and J. C. Espin (2005). Pomegranate juice supplementation in chronic obstructive pulmonary disease: a 5-week randomized, double-blind, placebocontrolled trial. European Journal of Clinical Nutrition 60: 245-253.

Chang, J.-L., G. Chen, C. M. Ulrich, J. Bigler, I. B. King, Y. Schwarz, S. Li, L. Li, J. D. Potter and J. W. Lampe (2010). DNA damage and repair: fruit and vegetable effects in a feeding trial. Nutrition and Cancer 62: 329-335.

Chattopadhyay, A., P. Subba, A. Pandey, D. Bhushan, R. Kumar, A. Datta, S. Chakraborty and N. Chakraborty (2011). Analysis of the grasspea proteome and identification of stress-responsive proteins upon exposure to high salinity, low temperature, and abscisic acid treatment. Phytochemistry 72: 1293-1307.

Chattopadhyay, S. K., S. Banerjee, S. Agarwal, M. Kulshrestha, R. P. Sharma, V. K. Mehta, and S. Kumar (2003) Process for the production of a biologically active phenolic compound (+) catechin. United States Patent and Trademark Office.

Chauhan, B. S., G. Gill and C. Preston (2006). Factors affecting seed germination of annual sowthistle (Sonchus oleraceus) in southern Australia. Weed Science 54: 854-860.

Chavan, S., V. Lokhande, K. Nitnaware and T. Nikam (2011). Influence of growth regulators and elicitors on cell growth and $\alpha$-tocopherol and pigment productions in cell cultures of Carthamus tinctorius L. Applied Microbiology and Biotechnology 89: 1701-1707.

Cheng, X.-Y., H.-Y. Zhou, X. Cui, W. Ni and C.-Z. Liu (2006). Improvement of phenylethanoid glycosides biosynthesis in Cistanche deserticola cell suspension cultures by chitosan elicitor. Journal of Biotechnology 121: 253-260.

Cheruvathur, M., J. Abraham and T. D. Thomas (2013). Plant regeneration through callus organogenesis and true-to-type conformity of plants by RAPD analysis in Desmodium gangeticum (Linn.) DC. Applied Biochemistry and Biotechnology 169: 1799-1810.

Chinnusamy, V., J. Zhu and J.-K. Zhu (2007). Cold stress regulation of gene expression in plants. Trends in Plant Science 12: 444-451.

Chkhikvishvili, I. D. and G. I. Kharebava (2001). Chicoric and chlorogenic acids in plant species from Georgia. Applied Biochemistry and Microbiology 37: 188-191. 
Choi, J. and J.-H. James Ou (2006). Mechanisms of liver injury. III. oxidative stress in the pathogenesis of hepatitis $\mathrm{C}$ virus. American Journal of Physiology Gastrointestinal and Liver Physiology 290: G847-G851.

Christensen, K. Y., A. Naidu, M.-É. Parent, J. Pintos, M. Abrahamowicz, J. Siemiatycki and A. Koushik (2012). The risk of lung cancer related to dietary intake of flavonoids. Nutrition and Cancer 64: 964-974.

Chu, Y.-H., C.-L. Chang and H.-F. Hsu (2000). Flavonoid content of several vegetables and their antioxidant activity. Journal of the Science of Food and Agriculture 80: 561-566.

Cici, S. Z.-H., S. Adkins and J. Hanan (2009). Modelling the morphogenesis of annual sowthistle, a common weed in crops. Computers and Electronics in Agriculture 69: 40-45.

Cilla, A., S. Perales, M. J. Lagarda, R. Barberá, G. Clemente and R. Farré (2011). Influence of storage and in vitro gastrointestinal digestion on total antioxidant capacity of fruit beverages. Journal of Food Composition and Analysis 24: 87-94.

Çirak, C., J. Radušienè, L. Ivanauskas and V. Janulis (2007). Variation of bioactive secondary metabolites in Hypericum origanifolium during its phenological cycle. Acta Physiologiae Plantarum 29: 197-203.

Çirak, C., B. Sağlam, A. K. Ayan and K. Kevseroğlu (2006). Morphogenetic and diurnal variation of hypericin in some Hypericum species from Turkey during the course of ontogenesis. Biochemical Systematics and Ecology 34: 1-13.

Clifford, M. N. (1999). Chlorogenic acids and other cinnamates - Nature, occurrence and dietary burden. Journal of the Science of Food and Agriculture 79: 362-372.

Clifford, M. N. (2000a). Anthocyanins - Nature, occurrence and dietary burden. Journal of the Science of Food and Agriculture 80: 1063-1072.

Clifford, M. N. (2000b). Chlorogenic acids and other cinnamates - Nature, occurrence, dietary burden, absorption and metabolism. Journal of the Science of Food and Agriculture 80: 1033-1043.

Clifford, M. N., K. L. Johnston, S. Knight and N. Kuhnert (2003). Hierarchical scheme for LC-MS identification of chlorogenic acids. Journal of Agricultural and Food Chemistry 51: 2900-2911.

Colliver, S., S. Hughes, S. Muir, A. Tunen, and M. Verhoeyen (2003) Process for increasing the flavonoid content of a plant and plants obtainable thereby. United States Patent and Trademark Office.

Conforti, F., S. Sosa, M. Marrelli, F. Menichini, G. A. Statti, D. Uzunov, A. Tubaro, and F. Menichini (2009). The protective ability of Mediterranean dietary plants against the oxidative damage: The role of radical oxygen species in inflammation and the polyphenol, flavonoid and sterol contents. Food Chemistry 112:587-594.

Connor, A. M., J. J. Luby and C. B. S. Tong (2002). Variation and heritability estimates for antioxidant activity, total phenolic content, and anthocyanin content in blueberry progenies. Journal of the American Society for Horticultural Science 127: 82-88.

Costa, P., S. Gonçalves, P. Valentão, P. B. Andrade and A. Romano (2013). Accumulation of phenolic compounds in in vitro cultures and wild plants of Lavandula viridis L'Hér and their antioxidant and anti-cholinesterase potential. Food and Chemical Toxicology 57: 69-74.

Couceiro, M. A., F. Afreen, S. M. A. Zobayed and T. Kozai (2006). Variation in concentrations of major bioactive compounds of St. John's wort: Effects of harvesting time, temperature and germplasm. Plant Science 170: 128-134. 
Cruz-Rus, E., I. Amaya, J. F. Sánchez-Sevilla, M. A. Botella and V. Valpuesta (2011). Regulation of L-ascorbic acid content in strawberry fruits. Journal of Experimental Botany 62: 4191-4201.

Cruz, R. M. S., M. C. Vieira and C. L. M. Silva (2008). Effect of heat and thermosonication treatments on watercress (Nasturtium officinale) vitamin $\mathrm{C}$ degradation kinetics. Innovative Food Science \& Emerging Technologies 9: 483488.

Cui, X., Y. Jin, U. P. Singh, A. A. Chumanevich, B. Harmon, P. Cavicchia, A. B. Hofseth, V. Kotakadi, D. Poudyal, B. Stroud, S. R. Volate, T. G. Hurley, J. R. Hebert and L. J. Hofseth (2012). Suppression of DNA damage in human peripheral blood lymphocytes by a juice concentrate: A randomized, double-blind, placebo-controlled trial. Molecular Nutrition \& Food Research 56: 666-670.

Cui, Y., H. Morgenstern, S. Greenland, D. P. Tashkin, J. T. Mao, L. Cai, W. Cozen, T. M. Mack, Q.-Y. Lu and Z.-F. Zhang (2008). Dietary flavonoid intake and lung cancer-A population-based case-control study. Cancer 112: 2241-2248.

Cutler, G. J., J. A. Nettleton, J. A. Ross, L. J. Harnack, D. R. Jacobs, C. G. Scrafford, L. M. Barraj, P. J. Mink and K. Robien (2008). Dietary flavonoid intake and risk of cancer in postmenopausal women: The Iowa Women's Health Study. International Journal of Cancer 123: 664-671.

Daayf, F., M. El Bellaj, M. El Hassni, F. J'Aiti and I. El Hadrami (2003). Elicitation of soluble phenolics in date palm (Phoenix dactylifera) callus by Fusarium oxysporum f. sp. albedinis culture medium. Environmental and Experimental Botany 49: 41-47.

Dávalos, A., C. Gómez-Cordovés and B. Bartolomé (2003). Extending applicability of the oxygen radical absorbance capacity (ORAC-fluorescein) assay. Journal of Agricultural and Food Chemistry 52: 48-54.

De La Torre-Carbot, K., J. L. Chávez-Servín, O. Jaúregui, A. I. Castellote, R. M. Lamuela-Raventós, T. Nurmi, H. E. Poulsen, A. V. Gaddi, J. Kaikkonen, H.-F. Zunft, H. Kiesewetter, M. Fitó, M.-I. Covas and M. C. López-Sabater (2010). Elevated circulating LDL phenol levels in men who consumed virgin rather than refined olive oil are associated with less oxidation of plasma LDL. The Journal of Nutrition 140: 501-508.

De Mejía, E. G., E. Castaño-Tostado and G. Loarca-Piña (1999). Antimutagenic effects of natural phenolic compounds in beans. Mutation Research/Genetic Toxicology and Environmental Mutagenesis 441: 1-9.

DeEll, J. R. and P. M. A. Toivonen (2003). Practical applications of chlorophyll fluorescence in plant biology, Kluwer Academic Publishers, Boston, USA.

Devaraj, S., R. Tang, B. Adams-Huet, A. Harris, T. Seenivasan, J. A. de Lemos and I. Jialal (2007). Effect of high-dose $\alpha$-tocopherol supplementation on biomarkers of oxidative stress and inflammation and carotid atherosclerosis in patients with coronary artery disease. The American Journal of Clinical Nutrition 86: 13921398.

Dewanto, V., X. Wu, K. K. Adom and R. H. Liu (2002). Thermal processing enhances the nutritional value of tomatoes by increasing total antioxidant activity. Journal of Agricultural and Food Chemistry 50: 3010-3014.

Diaz, M. N., B. Frei, J. A. Vita and J. F. Keaney (1997). Antioxidants and atherosclerotic heart disease. New England Journal of Medicine 337: 408-416.

Dickson, G., C. W. Cunningham and S. Parry (2010). The prevalence of colorectal adenomas in Māori and New Zealand Europeans parallels colorectal cancer rates. Journal of the New Zealand Medical Association 123: 45-49. 
Dinnella, C., P. Minichino, A. M. D’Andrea and E. Monteleone (2007). Bioaccessibility and antioxidant activity stability of phenolic compounds from extra-virgin olive oils during in vitro digestion. Journal of Agricultural and Food Chemistry 55: 8423-8429.

Doğan, S., P. Turan, M. Doğan, O. Arslan and M. Alkan (2005). Purification and characterization of Ocimum basilicum L. polyphenol oxidase. Journal of Agricultural and Food Chemistry 53: 10224-10230.

Dörmann, P. (2007). Functional diversity of tocochromanols in plants. Planta 225: 269276.

Duarte, G. S. and A. Farah (2011). Effect of simultaneous consumption of milk and coffee on chlorogenic acids' bioavailability in humans. Journal of Agricultural and Food Chemistry 59: 7925-7931.

Dubrovina, A. S. and K. V. Kiselev (2012). Effect of long-term cultivation on resveratrol accumulation in a high-producing cell culture of Vitis amurensis. Acta Physiologiae Plantarum 34: 1101-1106.

Dumas, Y., M. Dadomo, G. Di Lucca and P. Grolier (2003). Effects of environmental factors and agricultural techniques on antioxidantcontent of tomatoes. Journal of the Science of Food and Agriculture 83: 369-382.

Dunne, R. (2010). Synergy or antagonism-Interactions between stressors on coral reefs. Coral Reefs 29: 145-152.

Eberhardt, M. V., K. Kobira, A.-S. Keck, J. A. Juvik and E. H. Jeffery (2005). Correlation analyses of phytochemical composition, chemical, and cellular measures of antioxidant activity of broccoli (Brassica oleracea L. var. italica). Journal of Agricultural and Food Chemistry 53: 7421-7431.

Ehlenfeldt, M. K. and R. L. Prior (2001). Oxygen radical absorbance capacity (ORAC) and phenolic and anthocyanin concentrations in fruit and leaf tissues of highbush blueberry. Journal of Agricultural and Food Chemistry 49: 2222-2227.

Ehlting, J., B. Hamberger, R. Million-Rousseau and D. Werck-Reichhart (2006). Cytochromes P450 in phenolic metabolism. Phytochemistry Reviews 5: 239-270.

Eilers, P. H. C. and J. C. H. Peeters (1988). A model for the relationship between light intensity and the rate of photosynthesis in phytoplankton. Ecological Modelling 42: 199-215.

Ekiert, H., A. Szewczyk, Ku and A. (2009). Free phenolic acids in Ruta graveolens L. in vitro culture. Die Pharmazie - An International Journal of Pharmaceutical Sciences 64: 692-694.

Ellwood, R. H. A. (2007). Variation in antioxidant activities of puha (Sonchus spp.) extracts., Department of Botany, University of Otago, New Zealand. Unpublished honours thesis.

Emmons, C. L. and D. M. Peterson (2001). Antioxidant activity and phenolic content of oat as affected by cultivar and location. Crop Science 41: 1676-1681.

Erlund, I. (2004). Review of the flavonoids quercetin, hesperetin, and naringenin. Dietary sources, bioactivities, bioavailability, and epidemiology. Nutrition Research 24: 851-874.

Fahn, S. (1992). A pilot trial of high-dose alpha-tocopherol and ascorbate in early Parkinson's disease. Annals of Neurology 32: S128-S132.

Faller, A. L. K., E. Fialho and R. H. Liu (2012). Cellular antioxidant activity of feijoada whole meal coupled with an in vitro digestion. Journal of Agricultural and Food Chemistry 60: 4826-4832.

FAO (2008). An introduction to the basic concepts of food security. Rome, Food and Agriculture Organization (FAO). 
Fazzari, M., L. Fukumoto, G. Mazza, M. A. Livrea, L. Tesoriere and L. D. Marco (2008). In vitro bioavailability of phenolic compounds from five cultivars of frozen sweet cherries (Prunus avium L.). Journal of Agricultural and Food Chemistry 56: 35613568.

Federici, E., A. Touche, D. Courtois, and V. Petiard (2008) Soya cell strains with high isoflavone content. United States Patent and Trademark Office.

Federico, A., F. Morgillo, C. Tuccillo, F. Ciardiello and C. Loguercio (2007). Chronic inflammation and oxidative stress in human carcinogenesis. International Journal of Cancer 121: 2381-2386.

Ferguson, L. R., R. L. Yee, R. Scragg, P. A. Metcalf and P. J. Harris (1995). Differences in intake of specific food plants by Polynesians may explain their lower incidence of colorectal cancer compared with Europeans in New Zealand. Nutrition and Cancer 23: 33-42.

Fernandez, M. A., M. T. Saenz and M. D. Garcĺa (1998). Natural products: antiinflammatory activity in rats and mice of phenolic acids isolated from Scrophularia frutescens. Journal of Pharmacy and Pharmacology 50: 1183-1186.

Fernandez, P., J. Di Rienzo, L. Fernandez, H. E. Hopp, N. Paniego and R. Heinz (2008). Transcriptomic identification of candidate genes involved in sunflower responses to chilling and salt stresses based on cDNA microarray analysis. BMC Plant Biology 8: 11.

Finley, J. W. (2005). Proposed criteria for assessing the efficacy of cancer reduction by plant foods enriched in carotenoids, glucosinolates, polyphenols and selenocompounds. Annals of Botany 95: 1075-1096.

Ford, E. S. and W. H. Giles (2000). Serum vitamins, carotenoids, and angina pectoris: Findings from the national health and nutrition examination survey III. Annals of Epidemiology 10: 106-116.

Foyer, C. H. and G. Noctor (2003). Redox sensing and signalling associated with reactive oxygen in chloroplasts, peroxisomes and mitochondria. Physiologia Plantarum 119: 355-364.

Foyer, C. H. and G. Noctor (2005). Redox homeostasis and antioxidant signaling: a metabolic interface between stress perception and physiological responses. The Plant Cell Online 17: 1866-1875.

Fraire-Velázquez, S., R. Rodríguez-Guerra and L. Sánchez-Calderón (2011). Abiotic and biotic stress response crosstalk in plants. In Abiotic stress response in plants physiological, biochemical and genetic perspectives. A. Shanker and B. Venkateswarlu, InTech, Rijeka, Croatia: 3 - 26.

Franz, C., R. Chizzola, J. Novak and S. Sponza (2011). Botanical species being used for manufacturing plant food supplements (PFS) and related products in the EU member states and selected third countries. Food \& Function 2: 720-730.

Fritz, C., N. Palacios-Rojas, R. Feil and M. Stitt (2006). Regulation of secondary metabolism by the carbon-nitrogen status in tobacco: Nitrate inhibits large sectors of phenylpropanoid metabolism. The Plant Journal 46: 533-548.

Fritz, R., C. Hochwender, D. Lewkiewicz, S. Bothwell and C. Orians (2001). Seedling herbivory by slugs in a willow hybrid system: Developmental changes in damage, chemical defense, and plant performance. Oecologia 129: 87-97.

Fujita, M., Y. Fujita, Y. Noutoshi, F. Takahashi, Y. Narusaka, K. Yamaguchi-Shinozaki and K. Shinozaki (2006). Crosstalk between abiotic and biotic stress responses: A current view from the points of convergence in the stress signaling networks. Current Opinion in Plant Biology 9: 436-442. 
Funes, L., S. Fernández-Arroyo, O. Laporta, A. Pons, E. Roche, A. Segura-Carretero, A. Fernández-Gutiérrez and V. Micol (2009). Correlation between plasma antioxidant capacity and verbascoside levels in rats after oral administration of lemon verbena extract. Food Chemistry 117: 589-598.

García-Mier, L., R. Guevara-González, V. Mondragón-Olguín, B. del Rocío VerduzcoCuellar and I. Torres-Pacheco (2013). Agriculture and bioactives: Achieving both crop yield and phytochemicals. International Journal of Molecular Sciences 14: 4203-4222.

Gatto, M. A., A. Ippolito, V. Linsalata, N. A. Cascarano, F. Nigro, S. Vanadia and D. Di Venere (2011). Activity of extracts from wild edible herbs against postharvest fungal diseases of fruit and vegetables. Postharvest Biology and Technology 61: $72-82$.

Gautier, H., V. Diakou-Verdin, C. Bénard, M. Reich, M. Buret, F. Bourgaud, J. L. Poëssel, C. Caris-Veyrat and M. Génard (2008). How does tomato quality (sugar, acid, and nutritional quality) vary with ripening stage, temperature, and irradiance? Journal of Agricultural and Food Chemistry 56: 1241-1250.

Genty, B., J.-M. Briantais and N. R. Baker (1989). The relationship between the quantum yield of photosynthetic electron transport and quenching of chlorophyll fluorescence. Biochimica et Biophysica Acta (BBA) - General Subjects 990: 8792.

Gil-Izquierdo, A., M. I. Gil, F. Ferreres and F. A. Tomás-Barberán (2001). In vitro availability of flavonoids and other phenolics in orange juice. Journal of Agricultural and Food Chemistry 49: 1035-1041.

Gillespie, K. M., J. M. Chae and E. A. Ainsworth (2007). Rapid measurement of total antioxidant capacity in plants. Nature Protocols 2: 867-870.

Gould, K. S. (2003). Free radicals, oxidative stress and antioxidants. In Encyclopedia of applied plant sciences. B. Thomas, D. J. Murphy and B. G. Murray, Elsevier Academic Press, Amsterdam, Netherlands. 1: 9-16.

Gould, K. S. (2004). Nature's Swiss army knife: The diverse protective roles of anthocyanins in leaves. Journal of Biomedicine and Biotechnology 2004: 314320.

Gould, K. S., K. Thodey, M. Philpott and L. R. Ferguson (2006). Antioxidant activities of extracts from traditional Māori food plants. New Zealand Journal of Botany 44: 14.

Goupy, P., C. Dufour, M. Loonis and O. Dangles (2002). Quantitative kinetic analysis of hydrogen transfer reactions from dietary polyphenols to the DPPH radical. Journal of Agricultural and Food Chemistry 51: 615-622.

Grace, S. C. and B. A. Logan (2000). Energy dissipation and radical scavenging by the plant phenylpropanoid pathway. Philosophical Transactions of the Royal Society of London. Series B: Biological Sciences 355: 1499-1510.

Grajek, W., Olejnik, A., \& Sip, A. (2005). Probiotics, prebiotics and antioxidants as functional foods. Acta Biochimica Polonica 52: 665-671.

Granito, M., A. Torres, J. Frias, M. Guerra and C. Vidal-Valverde (2005). Influence of fermentation on the nutritional value of two varieties of Vigna sinensis. European Food Research and Technology 220: 176-181.

Grant, M., I. Brown, S. Adams, M. Knight, A. Ainslie and J. Mansfield (2000). The RPM1 plant disease resistance gene facilitates a rapid and sustained increase in cytosolic calcium that is necessary for the oxidative burst and hypersensitive cell death. The Plant Journal 23: 441-450. 
Grassmann, J., S. Hippeli and E. F. Elstner (2002). Plant's defence and its benefits for animals and medicine: Role of phenolics and terpenoids in avoiding oxygen stress. Plant Physiology and Biochemistry 40: 471-478.

Gray, D. E., S. G. Pallardy, H. E. Garret and G. E. Rottinghaus (2003). Effect of acute drought stress and time of harvest on phytochemistry and dry weight of St. John's wort leaves and flowers. Planta Medlica 69: 1024-1030.

Guil-Guerrero, J. L., A. Giménez-Giménez, I. Rodríguez-García and M. E. Torija-Isasa (1998). Nutritional composition of Sonchus species (S. asper L., S. oleraceus L. and S. tenerrimus L.). Journal of the Science of Food and Agriculture 76: 628632.

Guil-Guerrero, J. L. and M. M. Rebolloso-Fuentes (2009). Nutrient composition and antioxidant activity of eight tomato (Lycopersicon esculentum) varieties. Journal of Food Composition and Analysis 22: 123-129.

Gupta, M., V. K. Sehgal and S. Arora (2013). Optimization of drying process parameters for cauliflower drying. Journal of Food Science and Technology 50: 62-69.

Hahlbrock, K. and D. Scheel (1989). Physiology and molecular-biology of phenylpropanoid metabolism. Annual Review of Plant Physiology and Plant Molecular Biology 40: 347-369.

Halliwell, B. (2007). Oxidative stress and cancer: Have we moved forward? Biochemical Journal 401: 1-11.

Halliwell, B. and J. M. C. Gutteridge (2007). Free radicals in biology and medicine, Oxford University Press Inc., New York, USA.

Hartikainen, K., J. Riikonen, A.-M. Nerg, M. Kivimäenpää, V. Ahonen, A. Tervahauta, S. Kärenlampi, M. Mäenpää, M. Rousi, S. Kontunen-Soppela, E. Oksanen and T. Holopainen (2012). Impact of elevated temperature and ozone on the emission of volatile organic compounds and gas exchange of silver birch (Betula pendula Roth). Environmental and Experimental Botany 84: 33-43.

Hasan, M. M., M. Cha, V. Bajpai and K.-H. Baek (2012). Production of a major stilbene phytoalexin, resveratrol in peanut (Arachis hypogaea) and peanut products: A mini review. Reviews in Environmental Science and Bio/Technology 11: 1-13.

Hedren, E., V. Diaz and U. Svanberg (2002). Estimation of carotenoid accessibility from carrots determined by an in vitro digestion method. European Journal of Clinical Nutrition 56: 425-430.

Heo, H. J., S.-E. Im, D.-O. Kim, C. Y. Lee, T.-G. Nam and H. Yoon (2010). Antineurodegenerative effect of phenolic extracts and caffeic acid derivatives in romaine lettuce on neuron-like PC-12 cells. Journal of Medicinal Food 13: 779+.

Herath, D., J. Cranfield and S. Henson (2008). Who consumes functional foods and nutraceuticals in Canada?: Results of cluster analysis of the 2006 survey of Canadians' Demand for Food Products Supporting Health and Wellness. Appetite 51: 256-265.

Herbinger, K., M. Tausz, A. Wonisch, G. Soja, A. Sorger and D. Grill (2002). Complex interactive effects of drought and ozone stress on the antioxidant defence systems of two wheat cultivars. Plant Physiology and Biochemistry 40: 691-696.

Hernández-Ramírez, R. U., M. V. Galván-Portillo, M. H. Ward, A. Agudo, C. A. González, L. F. Oñate-Ocaña, R. Herrera-Goepfert, O. Palma-Coca and L. LópezCarrillo (2009). Dietary intake of polyphenols, nitrate and nitrite and gastric cancer risk in Mexico City. International Journal of Cancer 125: 1424-1430.

Hernández, I., L. Alegre, F. Van Breusegem and S. Munné-Bosch (2009). How relevant are flavonoids as antioxidants in plants? Trends in Plant Science 14: 125-132. 
Hernández, I. and F. Van Breusegem (2010). Opinion on the possible role of flavonoids as energy escape valves: Novel tools for nature's Swiss army knife? Plant Science 179: 297-301.

Hollman, P. C. H. and I. C. W. Arts (2000). Flavonols, flavones and flavanols - Nature, occurrence and dietary burden. Journal of the Science of Food and Agriculture 80: 1081-1093.

Holm, L. R. G. and E.-W. Center (1977). The World's worst weeds: distribution and biology, Published for the East-West Center by the University Press of Hawaii, Hawaii.

Howles, P. A., V. Sewalt, N. L. Paiva, Y. Elkind, N. J. Bate, C. Lamb and R. A. Dixon (1996). Overexpression of Overexpression of L-phenylalanine ammonia-lyase in transgenic tobacco plants reveals control points for flux into phenylpropanoid biosynthesis. Plant Physiology 112: 1617-1624.

$\mathrm{Hu}$, O. Y.-P. (1998). Dissolution apparatus simulating physiological gastrointestinal conditions United States Patent and Trademark Office. United States: 17.

Huang, D., B. Ou and R. L. Prior (2005). The chemistry behind antioxidant capacity assays. Journal of Agricultural and Food Chemistry 53: 1841-1856.

Hutchinson, I. A. N., J. Colosi and R. A. Lewin (1984). The biology of Canadian weeds: Sonchus asper (L.) Hill and S. oleraceus L. Canadian Journal of Plant Science 64: 731-744.

Incerti, A., R. Izzo, A. Belligno and F. Navari-Izzo (2008). Seawater effects on antioxidant production in berries of three cultivars of tomato (Lycopersicon esculentum mill.). In Biosaline Agriculture and High Salinity Tolerance. C. Abdelly, M. Öztürk, M. Ashraf and C. Grignon, Die Deutsche Bibliothek, Basel, Switzerland: 43-51.

Iori, V., F. Pietrini, A. Massacci and M. Zacchini (2012). Induction of metal binding compounds and antioxidative defence in callus cultures of two black poplar $(P$. nigra) clones with different tolerance to cadmium. Plant Cell, Tissue and Organ Culture (PCTOC) 108: 17-26.

Iranshahi, M. and Y. Amanzadeh (2008). Rapid isocratic HPLC analysis of caffeic acid derivatives from Echinacea purpurea cultivated in Iran. Chemistry of Natural Compounds 44: 190-193.

Jacob, J. K., K. Tiwari, J. Correa-Betanzo, A. Misran, R. Chandrasekaran and G. Paliyath (2012). Biochemical basis for functional ingredient design from fruits. Annual Review of Food Science and Technology 3: 79-104.

Jacobo-Velázquez, D. A. and L. Cisneros-Zevallos (2012). An alternative use of horticultural crops: stressed plants as biofactories of bioactive phenolic compounds. Agriculture 2: 259-271.

Jacobo-Velázquez, D. A., G. s. B. Martínez-Hernández, S. del C. Rodríguez, C.-M. Cao and L. Cisneros-Zevallos (2011). Plants as biofactories: Physiological role of reactive oxygen species on the accumulation of phenolic antioxidants in carrot tissue under wounding and hyperoxia stress. Journal of Agricultural and Food Chemistry 59: 6583-6593.

Jaganath, I. B. and A. Crozier (2010). Dietary flavonoids and phenolic compounds. In Plant Phenolics and Human Health: Biochemistry, Nutrition, and Pharmacology. C. G. Fraga, John Wiley \& Sons, New Jersey, USA: 1-49.

Jaleel, C. A., R. Gopi, P. Manivannan and R. Panneerselvam (2007). Antioxidative potentials as a protective mechanism in Catharanthus roseus (L.): Plants under salinity stress. Turkish Journal of Botany 31: 245-251. 
Janas, K. M., M. Cvikrová, A. Pałągiewicz and J. Eder (2000). Alterations in phenylpropanoid content in soybean roots during low temperature acclimation. Plant Physiology and Biochemistry 38: 587-593.

Jeong, J.-A., C.-H. Wu, H. Murthy, E.-J. Hahn and K.-Y. Paek (2009). Application of an airlift bioreactor system for the production of adventitious root biomass and caffeic acid derivatives of Echinacea purpurea. Biotechnology and Bioprocess Engineering 14: 91-98.

Jeong, S.-M., S.-Y. Kim, D.-R. Kim, S.-C. Jo, K. C. Nam, D. U. Ahn, and S.-C. Lee (2004) Effect of heat treatment on the antioxidant activity of extracts from citrus peels. Journal of Agricultural and Food Chemistry 52:3389-3393.

Johnson, E. J. (2002). The role of carotenoids in human health. Nutrition in Clinical Care 5: 56-65.

Kahle, K., W. Huemmer, M. Kempf, W. Scheppach, T. Erk and E. Richling (2007). Polyphenols are intensively metabolized in the human gastrointestinal tract after apple juice consumption. Journal of Agricultural and Food Chemistry 55: 1060510614.

Karakaya, S. (2004). Bioavailability of phenolic compounds. Critical Reviews in Food Science and Nutrition 44: 453-464.

Karray-Bouraoui, N., R. Ksouri, H. Falleh, M. Rabhi, C. A. Jaleel, C. Grignon and M. LachaÂL (2010). Effects of environment and development stage on phenolic content and antioxidant activities of Mentha pulegium L. Journal of Food Biochemistry 34: 79-89.

Karwasara, V. and V. Dixit (2012). Culture medium optimization for improved puerarin production by cell suspension cultures of Pueraria tuberosa (Roxb. ex Willd.) DC. In Vitro Cellular \& Developmental Biology - Plant 48: 189-199.

Kaur, C. and H. C. Kapoor (2001). Antioxidants in fruits and vegetables - The millennium's health. International Journal of Food Science \& Technology 36: 703-725.

Keppler, K. and H.-U. Humpf (2005). Metabolism of anthocyanins and their phenolic degradation products by the intestinal microflora. Bioorganic \&amp; Medicinal Chemistry 13: 5195-5205.

Keutgen, A. J. and E. Pawelzik (2007). Modifications of strawberry fruit antioxidant pools and fruit quality under $\mathrm{NaCl}$ stress. Journal of Agricultural and Food Chemistry 55: 4066-4072.

Kim, S. H., Y. O. Ahn, M.-J. Ahn, H.-S. Lee and S.-S. Kwak (2012). Down-regulation of $\beta$-carotene hydroxylase increases $\beta$-carotene and total carotenoids enhancing salt stress tolerance in transgenic cultured cells of sweetpotato. Phytochemistry 74 : 69-78.

Kirakosyan, A., E. Seymour, P. B. Kaufman, S. Warber, S. Bolling and S. C. Chang (2003). Antioxidant capacity of polyphenolic extracts from leaves of Crataegus laevigata and Crataegus monogyna (hawthorn) subjected to drought and cold stress. Journal of Agricultural and Food Chemistry 51: 3973-3976.

Kitao, M., H. Utsugi, S. Kuramoto, R. Tabuchi, K. Fujimoto and S. Lihpai (2003). Lightdependent photosynthetic characteristics indicated by chlorophyll fluorescence in five mangrove species native to Pohnpei Island, Micronesia. Physiologia Plantarum 117: 376-382.

Koc, E., C. Dslek and A. Sülün Üstün (2010). Effect of cold on protein, proline, phenolic compounds and chlorophyll content of two pepper (Capsicum annuum L.) varieties. Gazi University Journal of Science 23: 1-6. 
Kolewe, M. E., V. Gaurav and S. C. Roberts (2008). Pharmaceutically active natural product synthesis and supply via plant cell culture technology. Molecular Pharmaceutics 5: 243-256.

Kornyeyev, D., B. A. Logan and A. S. Holaday (2002). A chlorophyll fluorescence analysis of the allocation of radiant energy absorbed in photosystem 2 antennae of cotton leaves during exposure to chilling. Photosynthetica 40: 77-84.

Koti, S., K. R. Reddy, V. G. Kakani, D. Zhao and W. Gao (2007). Effects of carbon dioxide, temperature and ultraviolet-B radiation and their interactions on soybean (Glycine max L.) growth and development. Environmental and Experimental Botany 60: 1-10.

Kováčik, J., B. Klejdus, M. Bačkor and M. Repčák (2007). Phenylalanine ammonia-lyase activity and phenolic compounds accumulation in nitrogen-deficient Matricaria chamomilla leaf rosettes. Plant Science 172: 393-399.

Kregel, K. C. and H. J. Zhang (2007). An integrated view of oxidative stress in aging: basic mechanisms, functional effects, and pathological considerations. American Journal of Physiology - Regulatory, Integrative and Comparative Physiology 292: R18-R36.

Krüger, E., H. Dietrich, E. Schöpplein, S. Rasim and P. Kürbel (2011). Cultivar, storage conditions and ripening effects on physical and chemical qualities of red raspberry fruit. Postharvest Biology and Technology 60: 31-37.

Ksouri, R., W. Megdiche, A. Debez, H. Falleh, C. Grignon and C. Abdelly (2007). Salinity effects on polyphenol content and antioxidant activities in leaves of the halophyte Cakile maritima. Plant Physiology and Biochemistry 45: 244-249.

Lafay, S., A. Gil-Izquierdo, C. Manach, C. Morand, C. Besson and A. Scalbert (2006). Chlorogenic acid is absorbed in its intact form in the stomach of rats. The Journal of Nutrition 136: 1192-1197.

Lamb, C. and R. A. Dixon (1997). The oxidative burst in plant disease resistance. Annual Review of Plant Physiology and Plant Molecular Biology 48: 251-275.

Langmead, L., R. M. Feakins, S. Goldthorpe, H. Holt, E. Tsironi, A. De Silva, D. P. Jewell and D. S. Rampton (2004). Randomized, double-blind, placebo-controlled trial of oral Aloe vera gel for active ulcerative colitis. Alimentary Pharmacology \& Therapeutics 19: 739-747.

Laurent, C., P. Besançon, and B. Caporiccio (2007) Flavonoids from a grape seed extract interact with digestive secretions and intestinal cells as assessed in an in vitro digestion/Caco-2 cell culture model. Food Chemistry 100:1704-1712.

Lee, J. and C. F. Scagel (2009). Chicoric acid found in basil (Ocimum basilicum L.) leaves. Food Chemistry 115: 650-656.

Lee, K. W., H. J. Hur, H. J. Lee and C. Y. Lee (2005). Antiproliferative effects of dietary phenolic substances and hydrogen peroxide. Journal of Agricultural and Food Chemistry 53: 1990-1995.

Lee, S. K. and A. A. Kader (2000). Preharvest and postharvest factors influencing vitamin C content of horticultural crops. Postharvest Biology and Technology 20: 207220.

Leonard, D. B. (1998) "Medicine at your feet: healing plants of the Hawaiian kingdom: Sonchus oleraceus."

Leyva, A., J. A. Jarillo, J. Salinas and J. M. Martinez-Zapater (1995). Low temperature induces the accumulation of phenylalanine ammonia-lyase and chalcone synthase mRNAs of Arabidopsis thaliana in a light-dependent manner. Plant Physiology 108: 39-46. 
Li, J., M. Cui, M. Li, X. Wang, D. Liang and F. Ma (2013). Expression pattern and promoter analysis of the gene encoding GDP-d-mannose $3^{\prime}, 5^{\prime}$-epimerase under abiotic stresses and applications of hormones by kiwifruit. Scientia Horticulturae 150: 187-194.

Li, N., J.-H. Liu, J. Zhang and B.-Y. Yu (2008). Comparative evaluation of cytotoxicity and antioxidative activity of 20 flavonoids. Journal of Agricultural and Food Chemistry 56: 3876-3883.

Lim, J.-H., K.-J. Park, B.-K. Kim, J.-W. Jeong and H.-J. Kim (2012). Effect of salinity stress on phenolic compounds and carotenoids in buckwheat (Fagopyrum esculentum M.) sprout. Food Chemistry 135: 1065-1070.

Lindsay, D. G. (2000). The nutritional enhancement of plant foods in Europe 'NEODIET'. Trends in Food Science \& Technology 11: 145-151.

Liu, H.-H., X. Tian, Y.-J. Li, C.-A. Wu and C.-C. Zheng (2008). Microarray-based analysis of stress-regulated microRNAs in Arabidopsis thaliana. RNA 14: 836843.

Liu, J.-F., Y.-H. Liu, C.-M. Chen, W.-H. Chang and C. Y. O. Chen (2012). The effect of almonds on inflammation and oxidative stress in Chinese patients with type 2 diabetes mellitus: a randomized crossover controlled feeding trial. European Journal of Nutrition 51: 1-9.

Liu, L., P. Howe, Y.-F. Zhou, C. Hocart and R. E. N. Zhang (2002). Fatty acid profiles of leaves of nine edible wild plants: an Australian study. Journal of Food Lipids 9: 65-71.

Liu, M.-q., Y.-y. Chen, C.-f. Lu, H. Zhang and W.-1. Yin (2007). Cold acclimation induced accumulation of phenolic compounds and freezing tolerance in Ammopiptanthus mongolicus. Forestry Studies in China 9: 203-207.

Liu, R., W. Li, L.-Y. Sun and C.-Z. Liu (2012). Improving root growth and cichoric acid derivatives production in hairy root culture of Echinacea purpurea by ultrasound treatment. Biochemical Engineering Journal 60: 62-66.

Liu, W., K. Yu, T. He, F. Li, D. Zhang, and J. Liu (2013) The low temperature induced physiological responses of Avena nuda L., a cold-tolerant plant species. The Scientific World Journal 2013: 1-7.

Liyana-Pathirana, C. M. and F. Shahidi (2005). Antioxidant activity of commercial soft and hard wheat (Triticum aestivum L.) as affected by gastric $\mathrm{pH}$ conditions. Journal of Agricultural and Food Chemistry 53: 2433-2440.

LoNostro, P., G. Capuzzi, P. Pinelli, N. Mulinacci, A. Romani and F. F. Vincieri (2000). Self-assembling and antioxidant activity of some vitamin $\mathrm{C}$ derivatives. Colloids and Surfaces A: Physicochemical and Engineering Aspects 167: 83-93.

López Pérez, L., N. Fernández García, E. Olmos and M. Carvajal (2007). The phi thickening in roots of broccoli plants: An acclimation mechanism to salinity? International Journal of Plant Sciences 168: 1141-1149.

Løvdal, T., K. M. Olsen, R. Slimestad, M. Verheul and C. Lillo (2010). Synergistic effects of nitrogen depletion, temperature, and light on the content of phenolic compounds and gene expression in leaves of tomato. Phytochemistry 71: 605-613.

Lucchesini, M., A. Bertoli, A. Mensuali-Sodi and L. Pistelli (2009). Establishment of in vitro tissue cultures from Echinacea angustifolia D.C. adult plants for the production of phytochemical compounds. Scientia Horticulturae 122: 484-490.

Lushchak, V. I. (2011). Adaptive response to oxidative stress: Bacteria, fungi, plants and animals. Comparative Biochemistry and Physiology Part C: Toxicology \& Pharmacology 153: 175-190. 
Machowetz, A., H. E. Poulsen, S. Gruendel, A. Weimann, M. Fitó, J. Marrugat, R. de la Torre, J. T. Salonen, K. Nyyssönen, J. Mursu, S. Nascetti, A. Gaddi, H. Kiesewetter, H. Bäumler, H. Selmi, J. Kaikkonen, H.-J. F. Zunft, M.-I. Covas and C. Koebnick (2007). Effect of olive oils on biomarkers of oxidative DNA stress in Northern and Southern Europeans. The FASEB Journal 21: 45-52.

Madamanchi, N. R., A. Vendrov and M. S. Runge (2005). Oxidative stress and vascular disease. Arteriosclerosis, Thrombosis, and Vascular Biology 25: 29-38.

Maggio, A., S. De Pascale, M. Fagnano and G. Barbieri (2007). Can salt stress-induced physiological responses protect tomato crops from ozone damages in Mediterranean environments? European Journal of Agronomy 26: 454-461.

Maiani, G., M. J. Periago Castón, G. Catasta, E. Toti, I. G. Cambrodón, A. Bysted, F. Granado-Lorencio, B. Olmedilla-Alonso, P. Knuthsen, M. Valoti, V. Böhm, E. Mayer-Miebach, D. Behsnilian, and U. Schlemmer (2009) Carotenoids: Actual knowledge on food sources, intakes, stability and bioavailability and their protective role in humans. Molecular Nutrition \& Food Research 53:S194-S218.

Mamelak, M. (2007). Alzheimer' s disease, oxidative stress and gammahydroxybutyrate. Neurobiology of Aging 28: 1340-1360.

Mandalari, G., C. Bisignano, A. Filocamo, S. Chessa, M. Sarò, G. Torre, R. M. Faulks and P. Dugo (2013). Bioaccessibility of pistachio polyphenols, xanthophylls, and tocopherols during simulated human digestion. Nutrition 29: 338-344.

Mandalari, G., A. Tomaino, T. Arcoraci, M. Martorana, V. L. Turco, F. Cacciola, G. T. Rich, C. Bisignano, A. Saija, P. Dugo, K. L. Cross, M. L. Parker, K. W. Waldron and M. S. J. Wickham (2010). Characterization of polyphenols, lipids and dietary fibre from almond skins (Amygdalus communis L.). Journal of Food Composition and Analysis 23: 166-174.

Mann, J. C. and S. R. Pygall (2012). A formulation case study comparing the dynamic gastric model with conventional dissolution methods. Dissolution Technologies 19: 14-19.

Mano, Y. M. and T. K. Komatsuda (2002). Identification of QTLs controlling tissueculture traits in barley (Hordeum vulgare L.). TAG Theoretical and Applied Genetics 105: 708-715.

Martinez, R. B., and M. del los A. P. Garcia (2007) Method for the production of resveratrol in cell cultures. United States Patent and Trademark Office.

Mateos, R., L. Goya and L. Bravo (2005). Metabolism of the olive oil phenols hydroxytyrosol, tyrosol, and hydroxytyrosyl acetate by human hepatoma HepG2 cells. Journal of Agricultural and Food Chemistry 53: 9897-9905.

Mateos, R., L. Goya and L. Bravo (2006). Uptake and metabolism of hydroxycinnamic acids (chlorogenic, caffeic, and ferulic acids) by HepG2 cells as a model of the human liver. Journal of Agricultural and Food Chemistry 54: 8724-8732.

Matos Acurero, Á. (2008). Aloesin, aloin and aloe-emodin production in Aloe vera L. calli. Ciencia 16: 389-395.

Maxwell, K. and G. N. Johnson (2000). Chlorophyll fluorescence-A practical guide. Journal of Experimental Botany 51: 659-668.

McDougall, G. J., P. Dobson, P. Smith, A. Blake and D. Stewart (2005a). Assessing potential bioavailability of raspberry anthocyanins using an in vitro digestion system. Journal of Agricultural and Food Chemistry 53: 5896-5904.

McDougall, G. J., S. Fyffe, P. Dobson and D. Stewart (2005b). Anthocyanins from red wine - Their stability under simulated gastrointestinal digestion. Phytochemistry 66: $2540-2548$. 
McDowell, A., S. Thompson, M. Stark, Z.-Q. Ou and K. S. Gould (2011). Antioxidant activity of puha (Sonchus oleraceus L.) as assessed by the cellular antioxidant activity (CAA) assay. Phytotherapy Research 25: 1876-1882.

Medeiros, K. C. P., C. A. V. Figueiredo, T. B. Figueredo, K. R. L. Freire, F. A. R. Santos, N. M. Alcantara-Neves, T. M. S. Silva and M. R. Piuvezam (2008). Anti-allergic effect of bee pollen phenolic extract and myricetin in ovalbumin-sensitized mice. Journal of Ethnopharmacology 119: 41-46.

Mediani, A., F. Abas, T. Ping, A. Khatib and N. Lajis (2012). Influence of growth stage and season on the antioxidant constituents of Cosmos caudatus. Plant Foods for Human Nutrition 67: 344-350.

Mehta, J. L., N. Rasouli, A. K. Sinha and B. Molavi (2006). Oxidative stress in diabetes: A mechanistic overview of its effects on atherogenesis and myocardial dysfunction. The International Journal of Biochemistry \&amp; Cell Biology 38: 794-803.

Meléndez-Martínez, A. J., G. Britton, I. M. Vicario and F. J. Heredia (2007). Relationship between the colour and the chemical structure of carotenoid pigments. Food Chemistry 101: 1145-1150.

Mellidou, I., J. Keulemans, A. K. Kanellis and M. W. Davey (2012). Regulation of fruit ascorbic acid concentrations during ripening in high and low vitamin $\mathrm{C}$ tomato cultivars. BMC Plant Biology 12: 239.

Mercadante, A. Z. and D. B. Rodriguez-Amaya (1990). Carotenoid composition and vitamin $A$ value of some native Brazilian green leafy vegetables. International Journal of Food Science \& Technology 25: 213-219.

Meyers, K. J., C. B. Watkins, M. P. Pritts and R. H. Liu (2003). Antioxidant and antiproliferative activities of strawberries. Journal of Agricultural and Food Chemistry 51: 6887-6892.

Miles, E. A., P. Zoubouli and P. C. Calder (2005). Differential anti-inflammatory effects of phenolic compounds from extra virgin olive oil identified in human whole blood cultures. Nutrition (Burbank, Los Angeles County, Calif.) 21: 389-394.

Miller, G., V. Shulaev and R. Mittler (2008). Reactive oxygen signaling and abiotic stress. Physiologia Plantarum 133: 481-489.

Mittler, R. (2002). Oxidative stress, antioxidants and stress tolerance. Trends in Plant Science 7: 405-410.

Mittler, R. (2006). Abiotic stress, the field environment and stress combination. Trends in Plant Science 11: 15-19.

Mittler, R., E. Merquiol, E. Hallak-Herr, S. Rachmilevitch, A. Kaplan and M. Cohen (2001). Living under a 'dormant' canopy: a molecular acclimation mechanism of the desert plant Retama raetam. The Plant Journal 25: 407-416.

Mittler, R., S. Vanderauwera, M. Gollery and F. Van Breusegem (2004). Reactive oxygen gene network of plants. Trends in Plant Science 9: 490-498.

Mo, H., M. Zhang and J. Sun (2006). Effect of drying process parameters on dehydrated cabbage enriched with selenium. Drying Technology 24: 1657-1663.

Moheb, A., R. K. Ibrahim, R. Roy and F. Sarhan (2011). Changes in wheat leaf phenolome in response to cold acclimation. Phytochemistry 72: 2294-2307.

Monagas, M., B. Bartolome and C. Gomez-Cordoves (2005). Updated knowledge about the presence of phenolic compounds in wine. Critical Reviews in Food Science and Nutrition 45: 85-118.

Monagas, M., N. Khan, C. Andres-Lacueva, R. Casas, M. Urpí-Sardà, R. Llorach, R. M. Lamuela-Raventós and R. Estruch (2009). Effect of cocoa powder on the 
modulation of inflammatory biomarkers in patients at high risk of cardiovascular disease. The American Journal of Clinical Nutrition 90: 1144-1150.

Mondolot, L., P. La Fisca, B. Buatois, E. Talansier, A. De Kochko and C. Campa (2006). Evolution in Evolution in caffeoylquinic acid content and histolocalization during Coffea canephora leaf development. Annals of Botany 98: 33-40.

Montanari, M., E. Degl'Innocenti, R. Maggini, S. Pacifici, A. Pardossi and L. Guidi (2008). Effect of nitrate fertilization and saline stress on the contents of active constituents of Echinacea angustifolia. Food Chemistry 107: 1461-1466.

Monteiro, M., A. Farah, D. Perrone, L. C. Trugo and C. Donangelo (2007). Chlorogenic acid compounds from coffee are differentially absorbed and metabolized in humans. The Journal of Nutrition 137: 2196-2201.

Morand, C., C. Dubray, D. Milenkovic, D. Lioger, J. F. Martin, A. Scalbert and A. Mazur (2011). Hesperidin contributes to the vascular protective effects of orange juice: a randomized crossover study in healthy volunteers. The American Journal of Clinical Nutrition 93: 73-80.

Morcillo, F., C. Gagneur, H. Adam, F. Richaud, R. Singh, S.-C. Cheah, A. Rival, Y. Duval and J. W. Tregear (2006). Somaclonal variation in micropropagated oil palm. Characterization of two novel genes with enhanced expression in epigenetically abnormal cell lines and in response to auxin. Tree Physiology 26: 585-594.

Moreda-Piñeiro, J., A. Moreda-Piñeiro, V. Romarís-Hortas, C. Moscoso-Pérez, P. LópezMahía, S. Muniategui-Lorenzo, P. Bermejo-Barrera and D. Prada-Rodríguez (2011). In-vivo and in-vitro testing to assess the bioaccessibility and the bioavailability of arsenic, selenium and mercury species in food samples. TrAC Trends in Analytical Chemistry 30: 324-345.

Munné-Bosch, S. and L. Alegre (2000). The significance of carotene \& tocopherol and the xanthophyll cycle in droughted Melissa officinalis plants. Functional Plant Biology 27: 139-146.

Munné-Bosch, S. and L. Alegre (2002). The function of tocopherols and tocotrienols in plants. Critical Reviews in Plant Sciences 21: 31-57.

Munné-Bosch, S. and L. Alegre (2003). Drought-induced changes in the redox state of $\alpha-$ tocopherol, ascorbate, and the diterpene carnosic acid in chloroplasts of Labiatae species differing in carnosic acid contents. Plant Physiology 131: 1816-1825.

Munné-Bosch, S. and J. Peñuelas (2004). Drought-induced oxidative stress in strawberry tree (Arbutus unedo L.) growing in Mediterranean field conditions. Plant Science 166: 1105-1110.

Munné-Bosch, S., K. Schwarz and L. Alegre (1999). Enhanced formation of $\alpha$-tocopherol and highly oxidized abietane diterpenes in water-stressed rosemary plants. Plant Physiology 121: 1047-1052.

Munné-Bosch, S., K. Schwarz and L. Alegre (2001). Water deficit in combination with high solar radiation leads to midday depression of tocopherol in field-grown lavender (Lavandula stoechas) plants. Functional Plant Biology 28: 315-321.

Mursu, J., T. Nurmi, T.-P. Tuomainen, J. T. Salonen, E. Pukkala and S. Voutilainen (2008). Intake of flavonoids and risk of cancer in Finnish men: The Kuopio Ischaemic Heart Disease Risk Factor Study. International Journal of Cancer 123: 660-663.

Murthy, V. K., J. C. Shipp, C. Hanson and D. M. Shipp (1992). Delayed onset and decreased incidence of diabetes in BB rats fed free radical scavengers. Diabetes Research and Clinical Practice 18: 11-16. 
Nacif de Abreu, I. and P. Mazzafera (2005). Effect of water and temperature stress on the content of active constituents of Hypericum brasiliense Choisy. Plant Physiology and Biochemistry 43: 241-248.

Naill, M. C. and S. C. Roberts (2005). Cell cycle analysis of Taxus suspension cultures at the single cell level as an indicator of culture heterogeneity. Biotechnology and Bioengineering 90: 491-500.

Namdeo, A (2007) Plant cell elicitation for production of secondary metabolites: A review. Pharmacognosy reviews 1:69-79.

Narusaka, Y., M. Narusaka, M. Seki, T. Umezawa, J. Ishida, M. Nakajima, A. Enju and K. Shinozaki (2004). Crosstalk in the responses to abiotic and biotic stresses in Arabidopsis : Analysis of gene expression in cytochrome P450 gene superfamily by cDNA microarray. Plant Molecular Biology 55: 327-342.

Navarro, J. M., P. Flores, C. Garrido and V. Martinez (2006). Changes in the contents of antioxidant compounds in pepper fruits at different ripening stages, as affected by salinity. Food Chemistry 96: 66-73.

Ndhlala, A. R., M. Moyo and J. Van Staden (2010). Natural antioxidants: Fascinating or mythical biomolecules? Molecules 15: 6905-6930.

Nenadis, N., H.-Y. Zhang and M. Z. Tsimidou (2003). Structure-antioxidant activity relationship of ferulic acid derivatives: Effect of carbon side chain characteristic groups. Journal of Agricultural and Food Chemistry 51: 1874-1879.

Nestel, P., H. E. Bouis, J. V. Meenakshi and W. Pfeiffer (2006). Biofortification of staple food crops. The Journal of Nutrition 136: 1064-1067.

Nicasio-Torres, M. d., M. Meckes-Fischer, L. Aguilar-Santamaría, M. Garduño-Ramírez, V. Chávez-Ávila and F. Cruz-Sosa (2012). Production of chlorogenic acid and isoorientin hypoglycemic compounds in Cecropia obtusifolia calli and in cell suspension cultures with nitrate deficiency. Acta Physiologiae Plantarum 34: 307316.

Nicolle, C., A. Carnat, D. Fraisse, J.-L. Lamaison, E. Rock, H. Michel, P. Amouroux and C. Remesy (2004). Characterisation and variation of antioxidant micronutrients in lettuce (Lactuca sativa folium). Journal of the Science of Food and Agriculture 84: 2061-2069.

Niggeweg, R., A. J. Michael and C. Martin (2004). Engineering plants with increased levels of the antioxidant chlorogenic acid. Nat Biotech 22: 746-754.

Niki, E. (2013). Role of vitamin E as a lipid-soluble peroxyl radical scavenger: In vitro and in vivo evidence. Free Radical Biology and Medicine.

NIWA (2012). National Climate Database. http://cliflo.niwa.co.nz/.

Noguer, M., A. B. Cerezo, M. Rentzsch, P. Winterhalter, A. M. Troncoso and M . C. García-Parrilla (2008). Simulated digestion and antioxidant activity of red wine fractions separated by high speed countercurrent chromatography. Journal of Agricultural and Food Chemistry 56: 8879-8884.

Nuissier, G., B. Rezzonico and M. Grignon-Dubois (2010). Chicoric acid from Syringodium filiforme. Food Chemistry 120: 783-788.

Oboh, G. (2005). Effect of blanching on the antioxidant properties of some tropical green leafy vegetables. LWT - Food Science and Technology 38: 513-517.

Oh, M.-M., E. Carey and C. B. Rajashekar (2011). Antioxidant phytochemicals in lettuce grown in high tunnels and open field. Horticulture, Environment, and Biotechnology 52: 133-139.

Oh, M.-M., E. E. Carey and C. B. Rajashekar (2009). Environmental stresses induce health-promoting phytochemicals in lettuce. Plant Physiology and Biochemistry 47: $578-583$ 
Ohnishi, M., H. Morishita, H. Iwahashi, S. Toda, Y. Shirataki, M. Kimura and R. Kido (1994). Inhibitory effects of chlorogenic acids on linoleic acid peroxidation and haemolysis. Phytochemistry 36: 579-583.

Olenichenko, N., V. Ossipov and N. Zagoskina (2006). Effect of cold hardening on the phenolic complex of winter wheat leaves. Russian Journal of Plant Physiology 53: 495-500.

Olthof, M. R., P. C. H. Hollman and M. B. Katan (2001). Chlorogenic acid and caffeic acid are absorbed in humans. The Journal of Nutrition 131: 66-71.

Oquist, G., V. M. Hurry and N. Huner (1993). Low-temperature effects on photosynthesis and correlation with freezing tolerance in spring and winter cultivars of wheat and rye. Plant Physiology 101: 245-250.

Orozco-Cardenas, M. and C. A. Ryan (1999). Hydrogen peroxide is generated systemically in plant leaves by wounding and systemin via the octadecanoid pathway. Proceedings of the National Academy of Sciences 96: 6553-6557.

Ortega-García, F., S. Blanco, M. Á. Peinado and J. Peragón (2008). Polyphenol oxidase and its relationship with oleuropein concentration in fruits and leaves of olive (Olea europaea) cv. 'Picual' trees during fruit ripening. Tree Physiology 28: 4554.

Ou, B., M. Hampsch-Woodill and R. L. Prior (2001). Development and validation of an improved oxygen radical absorbance capacity assay using fluorescein as the fluorescent probe. Journal of Agricultural and Food Chemistry 49: 4619-4626.

Ou, Z.-Q., D. M. Schmierer, T. Rades, L. Larsen and A. McDowell (2012). Application of an online post-column derivatization HPLC-DPPH assay to detect compounds responsible for antioxidant activity in Sonchus oleraceus L. leaf extracts. Journal of Pharmacy and Pharmacology: n/a-n/a.

Ou, Z.-Q., D. M. Schmierer, T. Rades, L. Larsen and A. McDowell (2013). Application of an online post-column derivatization HPLC-DPPH assay to detect compounds responsible for antioxidant activity in Sonchus oleraceus L. leaf extracts. Journal of Pharmacy and Pharmacology 65: 271-279.

Pääkkönen, E., M. S. Günthardt-Goerg and T. Holopainen (1998). Responses of leaf processes in a sensitive birch (Betula pendula Roth) clone to ozone combined with drought. Annals of Botany 82: 49-59.

Papageorgiou, V., A. Mallouchos and M. Komaitis (2008). Investigation of the antioxidant behavior of air- and freeze-dried aromatic plant materials in relation to their phenolic content and vegetative cycle. Journal of Agricultural and Food Chemistry 56: 5743-5752.

Paredes-López, O., M. Cervantes-Ceja, M. Vigna-Pérez and T. Hernández-Pérez (2010). Berries: improving human health and healthy aging, and promoting quality lifeA review. Plant Foods for Human Nutrition 65: 299-308.

Parola, M. and G. Robino (2001). Oxidative stress-related molecules and liver fibrosis. Journal of hepatology 35: 297-306.

Pellati, F., S. Benvenuti, L. Magro, M. Melegari and F. Soragni (2004). Analysis of phenolic compounds and radical scavenging activity of Echinacea spp. Journal of Pharmaceutical and Biomedical Analysis 35: 289-301.

Pennycooke, J. C., S. Cox and C. Stushnoff (2005). Relationship of cold acclimation, total phenolic content and antioxidant capacity with chilling tolerance in petunia $($ Petunia $\times$ hybrida $)$. Environmental and Experimental Botany 53: 225-232.

Pereira, G. E., J. P. Gaudillere, P. Pieri, G. Hilbert, M. Maucourt, C. Deborde, A. Moing and D. Rolin (2006). Microclimate influence on mineral and metabolic profiles of grape berries. Journal of Agricultural and Food Chemistry 54: 6765-6775. 
Pérez-Vicente, A., A. Gil-Izquierdo and C. García-Viguera (2002). In vitro gastrointestinal digestion study of pomegranate juice phenolic compounds, anthocyanins, and vitamin C. Journal of Agricultural and Food Chemistry 50: 2308-2312.

Perry, N. B., E. J. Burgess and V. 1. Glennie (2001). Echinacea standardization: Analytical methods for phenolic compounds and typical levels in medicinal species. Journal of Agricultural and Food Chemistry 49: 1702-1706.

Peterson, J. J., G. R. Beecher, S. A. Bhagwat, J. T. Dwyer, S. E. Gebhardt, D. B. Haytowitz and J. M. Holden (2006a). Flavanones in grapefruit, lemons, and limes: A compilation and review of the data from the analytical literature. Journal of Food Composition and Analysis 19, Supplement: S74-S80.

Peterson, J. J., J. T. Dwyer, G. R. Beecher, S. A. Bhagwat, S. E. Gebhardt, D. B. Haytowitz and J. M. Holden (2006b). Flavanones in oranges, tangerines (mandarins), tangors, and tangelos: A compilation and review of the data from the analytical literature. Journal of Food Composition and Analysis 19, Supplement: S66-S73.

Petridis, A., I. Therios, G. Samouris and C. Tananaki (2012). Salinity-induced changes in phenolic compounds in leaves and roots of four olive cultivars (Olea europaea L.) and their relationship to antioxidant activity. Environmental and Experimental Botany 79: 37-43.

Philpott, M., K. S. Gould, K. R. Markham, S. L. Lewthwaite and L. R. Ferguson (2003). Enhanced coloration reveals high antioxidant potential in new sweetpotato cultivars. Journal of the Science of Food and Agriculture 83: 1076-1082.

Pietta, P.-G. (2000). Flavonoids as antioxidants. Journal of Natural Products 63: 10351042.

Plumb, G. W., M. T. Garcia-Conesa, P. A. Kroon, M. Rhodes, S. Ridley and G. Williamson (1999a). Metabolism of chlorogenic acid by human plasma, liver, intestine and gut microflora. Journal of the Science of Food and Agriculture 79: 390-392.

Plumb, G. W., K. R. Price and G. Williamson (1999b). Antioxidant properties of flavonol glycosides from tea. Redox Report 4: 13-16.

Pociecha, E., A. Płażek, F. Janowiak and Z. Zwierzykowski (2008). ABA level, proline and phenolic concentration, and PAL activity induced during cold acclimation in androgenic Festulolium forms with contrasting resistance to frost and pink snow mould (Microdochium nivale). Physiological and Molecular Plant Pathology 73: 126-132.

Prior, R. L., G. Cao, A. Martin, E. Sofic, J. McEwen, C. O'Brien, N. Lischner, M. Ehlenfeldt, W. Kalt, G. Krewer and C. M. Mainland (1998). Antioxidant capacity as influenced by total phenolic and anthocyanin content, maturity, and variety of Vaccinium species. Journal of Agricultural and Food Chemistry 46: 2686-2693.

Prior, R. L., X. Wu and K. Schaich (2005). Standardized methods for the determination of antioxidant capacity and phenolics in foods and dietary supplements. Journal of Agricultural and Food Chemistry 53: 4290-4302.

Radhakrishnan, R., T. Leelapriya and B. D. R. Kumari (2012). Effects of pulsed magnetic field treatment of soybean seeds on calli growth, cell damage, and biochemical changes under salt stress. Bioelectromagnetics 33: 670-681.

Radman, R., T. Saez, C. Bucke and T. Keshavarz (2003). Elicitation of plants and microbial cell systems. Biotechnology and Applied Biochemistry 37: 91-102. 
Raffo, A., G. L. Malfa, V. Fogliano, G. Maiani and G. Quaglia (2006). Seasonal variations in antioxidant components of cherry tomatoes (Lycopersicon esculentum cv. Naomi F1). Journal of Food Composition and Analysis 19: 11-19.

Ranga Rao, A., R. L. Raghunath Reddy, V. Baskaran, R. Sarada and G. A. Ravishankar (2010). Characterization of microalgal carotenoids by mass spectrometry and their bioavailability and antioxidant properties elucidated in rat model. Journal of Agricultural and Food Chemistry 58: 8553-8559.

Rao, C. V., A. Rivenson, B. Simi and B. S. Reddy (1995). Chemoprevention of colon carcinogenesis by dietary curcumin, a naturally occurring plant phenolic compound. Cancer Research 55: 259-266.

Rao, R. S. and G. A. Ravishankar (2002). Plant cell cultures: Chemical factories of secondary metabolites. Biotechnology Advances 20: 101-153.

Raoa, A. V. and L. G. Raob (2007). Carotenoids and human health. Pharmacological Research 55 207-216.

Rea, G., A. Antonacci, M. Lambreva, S. Pastorelli, A. Tibuzzi, S. Ferrari, D. Fischer, U. Johanningmeier, W. Oleszek, T. Doroszewska, A. M. Rizzo, P. V. R. Berselli, B. Berra, A. Bertoli, L. Pistelli, B. Ruffoni, C. Calas-Blanchard, J. L. Marty, S. C. Litescu, M. Diaconu, E. Touloupakis, D. Ghanotakis and M. T. Giardi (2011). Integrated plant biotechnologies applied to safer and healthier food production: The Nutra-Snack manufacturing chain. Trends in Food Science \& Technology 22: 353-366.

Record, I. R. and J. M. Lane (2001). Simulated intestinal digestion of green and black teas. Food Chemistry 73: 481-486.

Reddivari, L., A. L. Hale and J. C. Miller (2007). Genotype, location, and year influence antioxidant activity, carotenoid content, phenolic content, and composition in specialty potatoes. Journal of Agricultural and Food Chemistry 55: 8073-8079.

Remorini, D., J. C. Melgar, L. Guidi, E. Degl'Innocenti, S. Castelli, M. L. Traversi, R. Massai and M. Tattini (2009). Interaction effects of root-zone salinity and solar irradiance on the physiology and biochemistry of Olea europaea. Environmental and Experimental Botany 65: 210-219.

Requena, T., M. Monagas, M. A. Pozo-Bayón, P. J. Martín-Álvarez, B. Bartolomé, R. del Campo, M. Ávila, M. C. Martínez-Cuesta, C. Peláez and M. V. Moreno-Arribas (2010). Perspectives of the potential implications of wine polyphenols on human oral and gut microbiota. Trends in Food Science \& Technology 21: 332-344.

Rice-Evans, C. A., N. J. Miller and G. Paganga (1996). Structure-antioxidant activity relationships of flavonoids and phenolic acids. Free Radical Biology and Medicine 20: 933-956.

Rimm, E. B., M. J. Stampfer, A. Ascherio, E. Giovannucci, G. A. Colditz and W. C. Willett (1993). Vitamin E influence on mineral and metabolic profiles of grape berries. New England Journal of Medicine 328: 1450-1456.

Rivero, R. M., J. M. Ruiz, P. C. García, L. R. López-Lefebre, E. Sánchez and L. Romero (2001). Resistance to cold and heat stress: Accumulation of phenolic compounds in tomato and watermelon plants. Plant Science 160: 315-321.

Robbin, R (2003) Phenolic acids in foods: An overview of analytical methodology. Journal of Agricultural and Food Chemistry 51:2866-2887.

Roberts II, L. J., J. A. Oates, M. F. Linton, S. Fazio, B. P. Meador, M. D. Gross, Y. Shyr and J. D. Morrow (2007). The relationship between dose of vitamin E and suppression of oxidative stress in humans. Free Radical Biology and Medicine 43: 1388-1393. 
Rodríguez-Roque, M. J., M. A. Rojas-Graü, P. Elez-Martínez, and O. Martín-Belloso (2013) Changes in vitamin C, phenolic, and carotenoid profiles throughout in vitro gastrointestinal digestion of a blended fruit juice. Journal of Agricultural and Food Chemistry 61:1859-1867.

Rohn, S., H. M. Rawel and J. Kroll (2004). Antioxidant activity of protein-bound quercetin. Journal of Agricultural and Food Chemistry 52: 4725-4729.

Ros, E., I. Núñez, A. Pérez-Heras, M. Serra, R. Gilabert, E. Casals and R. Deulofeu (2004). A walnut diet improves endothelial function in hypercholesterolemic subjects. Circulation 109: 1609-1614.

Rossetto, M., P. Vanzani, V. De Marco, L. Zennaro, M. Scarpa and A. Rigo (2008). Fast and simple method for the simultaneous evaluation of the capacity and efficiency of food antioxidants in trapping peroxyl radicals in an intestinal model system. Journal of Agricultural and Food Chemistry 56: 3486-3492.

Roy, M. K., M. Takenaka, S. Isobe and T. Tsushida (2007). Antioxidant potential, antiproliferative activities, and phenolic content in water-soluble fractions of some commonly consumed vegetables: Effects of thermal treatment. Food Chemistry 103: 106-114.

Rus, A. M., M. T. Estañ, C. Gisbert, B. Garcia-Sogo, R. Serrano, M. Caro, V. Moreno and M. C. Bolarín (2001). Expressing the yeast HAL1 gene in tomato increases fruit yield and enhances $\mathrm{K}+\mathrm{Na}+$ selectivity under salt stress. Plant, Cell \& Environment 24: 875-880.

Rush, E. C., E. Hsi, L. R. Ferguson, M. H. Williams and D. Simmons (2010). Traditional foods reported by a Māori community in 2004. MAI Review 2.

Sajc, L., D. Grubisic and G. Vunjak-Novakovic (2000). Bioreactors for plant engineering: an outlook for further research. Biochemical Engineering Journal 4: 89-99.

Sato, Y., S. Itagaki, T. Kurokawa, J. Ogura, M. Kobayashi, T. Hirano, M. Sugawara and K. Iseki (2011). In vitro and in vivo antioxidant properties of chlorogenic acid and caffeic acid. International Journal of Pharmaceutics 403: 136-138.

Saw, N., H. Riedel, Z. Cai, O. Kütük and I. Smetanska (2012). Stimulation of anthocyanin synthesis in grape (Vitis vinifera) cell cultures by pulsed electric fields and ethephon. Plant Cell, Tissue and Organ Culture (PCTOC) 108: 47-54.

Schaffer, S., Schmitt-Schillig, S., Müller, W.E. and Eckert, G.P. (2005). Antioxidant properties of Mediterranean food plant extracts: Geographical differences. Journal of physiology and pharmacology 56: 115-124.

Schreiner, M., I. Mewis, S. Huyskens-Keil, M. A. K. Jansen, R. Zrenner, J. B. Winkler, N. O'Brien and A. Krumbein (2012). UV-B-induced secondary plant metabolites Potential benefits for plant and human health. Critical Reviews in Plant Sciences 31: 229-240.

Schwartz, E., R. Tzulker, I. Glazer, I. Bar-Ya'akov, Z. Wiesman, E. Tripler, I. Bar-Ilan, H. Fromm, H. Borochov-Neori, D. Holland and R. Amir (2009). Environmental conditions affect the color, taste, and antioxidant capacity of 11 pomegranate accessions. Journal of Agricultural and Food Chemistry 57: 9197-9209.

Selma, M. a. V., J. C. Espín and F . A. Tomás-Barberán (2009). Interaction between phenolics and gut microbiota: Role in human health. Journal of Agricultural and Food Chemistry 57: 6485-6501.

Serra, A., A. Macià, M.-P. Romero, J. Reguant, N. Ortega and M.-J. Motilva (2012). Metabolic pathways of the colonic metabolism of flavonoids (flavonols, flavones and flavanones) and phenolic acids. Food Chemistry 130: 383-393. 
Sgherri, C., Z. Kadlecová, A. Pardossi, F. Navari-Izzo and R. Izzo (2008). Irrigation with diluted seawater improves the nutritional value of cherry tomatoes. Journal of Agricultural and Food Chemistry 56: 3391-3397.

Sgherri, C., F. Navari-Izzo, A. Pardossi, G. P. Soressi and R. Izzo (2007). The influence of diluted seawater and ripening stage on the content of antioxidants in fruits of different tomato genotypes. Journal of Agricultural and Food Chemistry 55: 24522458 .

Shahidi, F., P. K. Janitha and P. D. Wanasundara (1992). Phenolic antioxidants. Critical Reviews in Food Science and Nutrition 32: 67-103.

Shen, X., Y. Zhou, L. Duan, Z. Li, A. E. Eneji and J. Li (2010). Silicon effects on photosynthesis and antioxidant parameters of soybean seedlings under drought and ultraviolet-B radiation. Journal of Plant Physiology 167: 1248-1252.

Sies, H. and W. Stahl (1995). Vitamins E and C, beta-carotene, and other carotenoids as antioxidants. The American Journal of Clinical Nutrition 62: 1315S-1321S.

Silberberg, M., C. Morand, T. Mathevon, C. Besson, C. Manach, A. Scalbert and C. Remesy (2006). The bioavailability of polyphenols is highly governed by the capacity of the intestine and of the liver to secrete conjugated metabolites. European Journal of Nutrition 45: 88-96.

Silva, E. N., S. L. Ferreira-Silva, A. d. V. Fontenele, R. V. Ribeiro, R. A. Viégas and J. A. G. Silveira (2010). Photosynthetic changes and protective mechanisms against oxidative damage subjected to isolated and combined drought and heat stresses in Jatropha curcas plants. Journal of Plant Physiology 167: 1157-1164.

Silva, F. A. M., F. Borges, C. Guimarães, J. L. F. C. Lima, C. Matos and S. Reis (2000). Phenolic acids and derivatives: Studies on the relationship among structure, radical scavenging activity, and physicochemical parameters. Journal of Agricultural and Food Chemistry 48: 2122-2126.

Simons, C. C. J. M., L. A. E. Hughes, I. C. W. Arts, R. A. Goldbohm, P. A. van den Brandt and M. P. Weijenberg (2009). Dietary flavonol, flavone and catechin intake and risk of colorectal cancer in the Netherlands Cohort Study. International Journal of Cancer 125: 2945-2952.

Simopoulos, A. P. (2004). Omega-3 fatty acids and antioxidants in edible wild plants. Biological Research 37: 263-277.

Simpson, G. L. W. and B. J. Ortwerth (2000). The non-oxidative degradation of ascorbic acid at physiological conditions. Biochimica et Biophysica Acta (BBA) Molecular Basis of Disease 1501: 12-24.

Singal, P. K., N. Khaper, V. Palace and D. Kumar (1998). The role of oxidative stress in the genesis of heart disease. Cardiovascular Research 40: 426-432.

Singh, U. and I. Jialal (2006). Oxidative stress and atherosclerosis. Pathophysiology 13: 129-142.

Siracusa, L., T. Kulisic-Bilusic, O. Politeo, I. Krause, B. Dejanovic and G. Ruberto (2011). Phenolic composition and antioxidant activity of aqueous infusions from Capparis spinosa L. and Crithmum maritimum L. before and after submission to a two-step in vitro digestion model. Journal of Agricultural and Food Chemistry 59: 12453-12459.

Šircelj, H., M. Tausz, D. Grill and F. Batič (2005). Biochemical responses in leaves of two apple tree cultivars subjected to progressing drought. Journal of Plant Physiology 162: 1308-1318.

Smirnoff, N. (1993). The role of active oxygen in the response of plants to water deficit and desiccation. New Phytologist 125: 27-58. 
Smirnoff, N. (2011). Chapter 4 - Vitamin C: The metabolism and functions of ascorbic acid in plants. In Advances in Botanical Research: Vitamins B6, B8, B9, C, E, K, Part 2. R. Fabrice and D. Roland, Academic Press, London, United Kingdom. 59: 107-177.

Solecka, D., A.-M. Boudet and A. Kacperska (1999). Phenylpropanoid and anthocyanin changes in low-temperature treated winter oilseed rape leaves. Plant Physiology and Biochemistry 37: 491-496.

Soler-Rivas, C., F. R. Marín, S. Santoyo, M. n. R. García-Risco, F. J. Señoráns and G . Reglero (2009a). Testing and enhancing the in vitro bioaccessibility and bioavailability of Rosmarinus officinalis extracts with a high level of antioxidant abietanes. Journal of Agricultural and Food Chemistry 58: 1144-1152.

Soler-Rivas, C., A. C. Ramírez-Anguiano, G. Reglero and S. Santoyo (2009b). Effect of cooking, in vitro digestion and Caco-2 cells absorption on the radical scavenging activities of edible mushrooms. International Journal of Food Science \& Technology 44: 2189-2197.

Song, W., C. M. Derito, M. K. Liu, X. He, M. Dong and R. H. Liu (2010). Cellular antioxidant activity of common vegetables. Journal of Agricultural and Food Chemistry 58: 6621-6629.

Spencer, J. P. E., M. M. Abd El Mohsen and C. Rice-Evans (2004). Cellular uptake and metabolism of flavonoids and their metabolites: Implications for their bioactivity. Archives of Biochemistry and Biophysics 423: 148-161.

Spencer, J. P. E., G. Chowrimootoo, R. Choudhury, E. S. Debnam, S. K. Srai and C. Rice-Evans (1999). The small intestine can both absorb and glucuronidate luminal flavonoids. FEBS Letters 458: 224-230.

Sreenivasulu, N., B. Grimm, U. Wobus and W. Weschke (2000). Differential response of antioxidant compounds to salinity stress in salt-tolerant and salt-sensitive seedlings of foxtail millet (Setaria italica). Physiologia Plantarum 109: 435-442.

St John-Sweeting, R. S. (2011). Dispersal and genetic variability of Sonchus oleraceus L. in relation to its resistance to ALS-inhibiting herbicides. Doctoral dissertation, School of Agriculture, Food and Wine, The University of Adelaide, Australia.

Stahl, W., U. Heinrich, S. Wiseman, O. Eichler, H. Sies and H. Tronnier (2001). Dietary tomato paste protects against ultraviolet light-induced erythema in humans. The Journal of Nutrition 131: 1449-1451.

Stevenson, D. E., and R. D. Hurst (2007) Polyphenolic phytochemicals - just antioxidants or much more? Cellular and Molecular Life Sciences 64:2900-2916.

Stojakowska, A., J. Malarz, A. Szewczyk and W. Kisiel (2012). Caffeic acid derivatives from a hairy root culture of Lactuca virosa. Acta Physiologiae Plantarum 34: 291298.

Strauss, A. J., G. H. J. Krüger, R. J. Strasser and P. D. R. Van Heerden (2007). The role of low soil temperature in the inhibition of growth and PSII function during dark chilling in soybean genotypes of contrasting tolerance. Physiologia Plantarum 131: $89-105$.

Stuart, D. L. and R. B. H. Wills (2003). Effect of drying temperature on alkylamide and cichoric acid concentrations of Echinacea purpurea. Journal of Agricultural and Food Chemistry 51: 1608-1610.

Stushnoff, C., D. Holm, M. D. Thompson, W. Jiang, H. J. Thompson, N. I. Joyce and P. Wilson (2008). Antioxidant properties of cultivars and selections from the Colorado potato breeding program. American Journal of Potato Research 85: $267-$ 276. 
Suárez, B., Á. L. Álvarez, Y. D. García, G. d. Barrio, A. P. Lobo and F. Parra (2010). Phenolic profiles, antioxidant activity and in vitro antiviral properties of apple pomace. Food Chemistry 120: 339-342.

Szopa, A., H. Ekiert and B. Muszyńska (2013). Accumulation of hydroxybenzoic acids and other biologically active phenolic acids in shoot and callus cultures of Aronia melanocarpa (Michx.) Elliott (black chokeberry). Plant Cell, Tissue and Organ Culture (PCTOC) 113: 323-329.

Tabart, J., C. Kevers, J. Pincemail, J.-O. Defraigne and J. Dommes (2009). Comparative antioxidant capacities of phenolic compounds measured by various tests. Food Chemistry 113: 1226-1233.

Tagliazucchi, D., E. Verzelloni, D. Bertolini and A. Conte (2010). In vitro bioaccessibility and antioxidant activity of grape polyphenols. Food Chemistry 120: 599-606.

Tarko, T., A. Duda-Chodak and T. Tuszyński (2009). Simulation of phenolic compounds transformations and interactions in an in vitro model of the human alimentary tract. Food Science and Technology International 15: 235-241.

Tattersall, E., J. Grimplet, L. DeLuc, M. Wheatley, D. Vincent, C. Osborne, A. Ergül, E. Lomen, R. Blank, K. Schlauch, J. Cushman and G. Cramer (2007). Transcript abundance profiles reveal larger and more complex responses of grapevine to chilling compared to osmotic and salinity stress. Functional \& Integrative Genomics 7: 317-333.

Tausz, M., H. Šircelj and D. Grill (2004). The glutathione system as a stress marker in plant ecophysiology: Is a stress-response concept valid? Journal of Experimental Botany 55: 1955-1962.

Tavares, L., I. Figueira, D. Macedo, G. J. McDougall, M. C. Leitão, H. L. A. Vieira, D. Stewart, P. M. Alves, R. B. Ferreira and C. N. Santos (2012). Neuroprotective effect of blackberry (Rubus sp.) polyphenols is potentiated after simulated gastrointestinal digestion. Food Chemistry 131: 1443-1452.

Tebbens, J (2005) Functional foods and nutraceuticals: the development of value-added food by Canadian firms. Statistics Canada, Science Innovation and Electronic Information Division.

Thomson, B., and Shaw, I. (2002). Comparison of risk and protective factors for colorectal cancer in the diet of New Zealand Māori and non-Māori. Asian Pacific Journal of Cancer Prevention 3: 319-324.

Thygesen, L., J. Thulin, A. Mortensen, L. H. Skibsted and P. Molgaard (2007). Antioxidant activity of cichoric acid and alkamides from Echinacea purpurea, alone and in combination. Food Chemistry 101: 74-81.

Tomás-Barberán, F. A. and M. N. Clifford (2000). Dietary hydroxybenzoic acid derivatives - Nature, occurrence and dietary burden. Journal of the Science of Food and Agriculture 80: 1024-1032.

Toor, R. K., G. P. Savage and C. E. Lister (2008). Release of antioxidant components from tomatoes determined by an in vitro digestion method. International Journal of Food Sciences and Nutrition 60: 119-129.

Torres, P., P. Galleguillos, E. Lissi and C. López-Alarcón (2008). Antioxidant capacity of human blood plasma and human urine: Simultaneous evaluation of the ORAC index and ascorbic acid concentration employing pyrogallol red as probe. Bioorganic \&amp; Medicinal Chemistry 16: 9171-9175.

Tounekti, T. and S. Munné-Bosch (2012). Enhanced phenolic diterpenes antioxidant levels through non-transgenic approaches. Critical Reviews in Plant Sciences 31: 505-519. 
Traka, M. H. and R. F. Mithen (2011). Plant science and human nutrition: Challenges in assessing health-promoting properties of phytochemicals. The Plant Cell Online 23: 2483-2497.

Treutter, D. (2006). Significance of flavonoids in plant resistance: A review. Environmental Chemistry Letters 4: 147-157.

Tsormpatsidis, E., R. G. C. Henbest, N. H. Battey and P. Hadley (2010). The influence of ultraviolet radiation on growth, photosynthesis and phenolic levels of green and red lettuce: Potential for exploiting effects of ultraviolet radiation in a production system. Annals of Applied Biology 156: 357-366.

Tuan, P. A., J. K. Kim, S. Lee, S. C. Chae and S. U. Park (2013). Molecular characterization of carotenoid cleavage dioxygenases and the effect of gibberellin, abscisic acid, and sodium chloride on the expression of genes involved in the carotenoid biosynthetic pathway and carotenoid accumulation in the callus of Scutellaria baicalensis Georgi. Journal of Agricultural and Food Chemistry 61: 5565-5572.

Tuck, K. L. and P. J. Hayball (2002). Major phenolic compounds in olive oil: Metabolism and health effects. The Journal of Nutritional Biochemistry 13: 636-644.

Tulipani, S., B. Mezzetti, F. Capocasa, S. Bompadre, J. Beekwilder, C. H. R. de Vos, E. Capanoglu, A. Bovy and M. Battino (2008). Antioxidants, phenolic compounds, and nutritional quality of different strawberry genotypes. Journal of Agricultural and Food Chemistry 56: 696-704.

Turkmen, N., F. Sari and Y. S. Velioglu (2005). The effect of cooking methods on total phenolics and antioxidant activity of selected green vegetables. Food Chemistry 93: 713-718.

Vallejo, F., C. García-Viguera and F. A. Tomás-Barberán (2003a). Changes in broccoli (Brassica oleracea L. var. italica) health-promoting compounds with inflorescence development. Journal of Agricultural and Food Chemistry 51: 37763782.

Vallejo, F., A. Gil-Izquierdo, A. Pérez-Vicente and C. García-Viguera (2003b). In vitro gastrointestinal digestion study of broccoli inflorescence phenolic compounds, glucosinolates, and vitamin C. Journal of Agricultural and Food Chemistry 52: 135-138.

Vanzo, A., R. Cecotti, U. Vrhovsek, A. M. Torres, F. Mattivi and S. Passamonti (2007). The fate of trans-caftaric acid administered into the rat stomach. Journal of Agricultural and Food Chemistry 55: 1604-1611.

Venkatramesh, M., D. R. Wagner, S. Lall, F. Y. Lejard, and S.-Y. H. Yoon (2013) Production and extraction of procyanidins from plant cell cultures. United States Patent and Trademark Office.

Vermaak, I., A. M. Viljoen, J. H. Hamman and S. F. Van Vuuren (2009). Effect of simulated gastrointestinal conditions and epithelial transport on extracts of green tea and sage. Phytochemistry Letters 2: 166-170.

Verpoorte, R., A. Contin and J. Memelink (2002). Biotechnology for the production of plant secondary metabolites. Phytochemistry Reviews 1: 13-25.

Versari, A., G. P. Parpinello, G. B. Tornielli, R. Ferrarini and C. Giulivo (2001). Stilbene compounds and stilbene synthase expression during ripening, wilting, and UV treatment in grape cv. Corvina. Journal of Agricultural and Food Chemistry 49: 5531-5536.

Vieira, M. C., A. A. Teixeira and C. L. M. Silva (2000). Mathematical modeling of the thermal degradation kinetics of vitamin $\mathrm{C}$ in cupuaçu (Theobroma grandiflorum) nectar. Journal of Food Engineering 43: 1-7. 
Villaño, D., M. S. Fernández-Pachón, A. M. Troncoso and M. C. García-Parrilla (2005). Comparison of antioxidant activity of wine phenolic compounds and metabolites in vitro. Analytica Chimica Acta 538: 391-398.

Vinokur, Y., V. Rodov, N. Reznick, G. Goldman, B. Horev, N. Umiel and H. Friedman (2006). Rose petal tea as an antioxidant-rich beverage: Cultivar effects. Journal of Food Science 71: S42-S47.

Vol'eva, V. B., N. S. Domnina, O. Y. Sergeeva, E. A. Komarova, I. S. Belostotskaya and N. L. Komissarova (2011). Structural factors responsible for the activity of macromolecular phenolic antioxidants. Russian Journal of Organic Chemistry 47: 480-485.

Wahle, K. J., I. Brown, D. Rotondo and S. Heys (2010). Plant phenolics in the prevention and treatment of cancer. bio-farms for nutraceuticals. In Bio-Farms for Nutraceuticals. M. Giardi, G. Rea and B. Berra, Springer US. 698: 36-51.

Wang, J., X. Liao, H. Zhang, J. Du and P. Chen (2003). Accumulation of chlorogenic acid in cell suspension cultures of Eucommia ulmoides. Plant Cell, Tissue and Organ Culture 74: 193-195.

Wang, Y. and M. Frei (2011). Stressed food - The impact of abiotic environmental stresses on crop quality. Agriculture, Ecosystems \& Environment 141: 271-286.

Ward, N. C., J. M. Hodgson, K. D. Croft, V. Burke, L. J. Beilin and I. B. Puddey (2005). The combination of vitamin $\mathrm{C}$ and grape-seed polyphenols increases blood pressure: a randomized, double-blind, placebo-controlled trial. Journal of Hypertension 23: 427-434.

Warren, J. M., J. H. Bassman, J. K. Fellman, D. S. Mattinson and S. Eigenbrode (2003). Ultraviolet-B radiation alters phenolic salicylate and flavonoid composition of Populus trichocarpa leaves. Tree Physiology 23: 527-535.

Waterhouse, A. L. (2001). Determination of total phenolics. In Current Protocols in Food Analytical Chemistry, John Wiley \& Sons, Inc., New York, USA.

Whitmer, S., C. Canel, R. van der Heijden and R. Verpoorte (2003). Long-term instability of alkaloid production by stably transformed cell lines of Catharanthus roseus. Plant Cell, Tissue and Organ Culture (PCTOC) 74: 73-80.

Whyte, R., J. A. Hudson, S. Hasell, M. Gray and R. O'Reilly (2001). Traditional Māori food preparation methods and food safety. International Journal of Food Microbiology 69: 183-190.

Williams, E., B. Stewart-Knox and I. Rowland (2004). A qualitative analysis of consumer perceptions of mood, food and mood-enhancing functional foods. Journal of nutraceuticals, functional \& medical foods 4: 61-83.

Wilson, S. A. and S. C. Roberts (2012). Recent advances towards development and commercialization of plant cell culture processes for the synthesis of biomolecules. Plant Biotechnology Journal 10: 249-268.

Wolfe, K., X. Wu and R. H. Liu (2003). Antioxidant activity of apple peels. Journal of Agricultural and Food Chemistry 51: 609-614.

Wolfe, K. L., X. Kang, X. He, M. Dong, Q. Zhang and R. H. Liu (2008). Cellular antioxidant activity of common fruits. Journal of Agricultural and Food Chemistry 56: 8418-8426.

Wolfe, K. L. and R. H. Liu (2007). Cellular antioxidant activity (CAA) assay for assessing antioxidants, foods, and dietary supplements. Journal of Agricultural and Food Chemistry 55: 8896-8907.

Wolfe, K. L. and R. H. Liu (2008). Structure-activity relationships of flavonoids in the cellular antioxidant activity assay. Journal of Agricultural and Food Chemistry 56: 8404-8411. 
Wolucka, B. A., A. Goossens and D. Inzé (2005). Methyl jasmonate stimulates the de novo biosynthesis of vitamin $\mathrm{C}$ in plant cell suspensions. Journal of Experimental Botany 56: 2527-2538.

Wootton-Beard, P. C., A. Moran and L. Ryan (2011). Stability of the total antioxidant capacity and total polyphenol content of 23 commercially available vegetable juices before and after in vitro digestion measured by FRAP, DPPH, ABTS and Folin-Ciocalteu methods. Food Research International 44: 217-224.

Wu, C.-H., H. N. Murthy, E.-J. Hahn and K.-Y. Paek (2007). Enhanced production of caftaric acid, chlorogenic acid and cichoric acid in suspension cultures of Echinacea purpurea by the manipulation of incubation temperature and photoperiod. Biochemical Engineering Journal 36: 301-303.

Wu, J. and L. Lin (2002). Elicitor-like effects of low-energy ultrasound on plant (Panax ginseng) cells: induction of plant defense responses and secondary metabolite production. Applied Microbiology and Biotechnology 59: 51-57.

Wu, J., C. Wang and X. Mei (2001). Stimulation of taxol production and excretion in Taxus spp cell cultures by rare earth chemical lanthanum. Journal of Biotechnology 85: 67-73.

Wu, W.-M., L. Lu, Y. Long, T. Wang, L. Liu, Q. Chen and R. Wang (2007). Free radical scavenging and antioxidative activities of caffeic acid phenethyl ester (CAPE) and its related compounds in solution and membranes: A structure-activity insight. Food Chemistry 105: 107-115.

Wu, X., G. R. Beecher, J. M. Holden, D. B. Haytowitz, S. E. Gebhardt, and R. L. Prior (2004) Lipophilic and hydrophilic antioxidant capacities of common foods in the United States. Journal of Agricultural and Food Chemistry 52:4026-4037.

Wünsche, J. N., D. H. Greer, W. A. Laing and J. W. Palmer (2005). Physiological and biochemical leaf and tree responses to crop load in apple. Tree Physiology 25: 1253-1263.

Xiao, J. and G. Kai (2011). A review of dietary polyphenol-plasma protein interactions: Characterization, influence on the bioactivity, and structure-affinity relationship. Critical Reviews in Food Science and Nutrition 52: 85-101.

Ye, Z. (2009). Metabolism of herbal phenolics in gut/oral microbiota or CaCo-2 cells and bioavailability associated efficacy of caffeic acid in mouse colitis. Doctoral thesis, Department of Toxicology, Iowa State University, USA.

Yin, J., G. J. Kwon and M. H. Wang (2007). The antioxidant and cytotoxic activities of Sonchus oleraceus L. extracts. Nutrition research and practice 1: 189-194.

Yin, J., C. Si and M. Wang (2008). Antioxidant activity of flavonoids and their glucosides from Sonchus oleraceus L. Journal of Applied Biology Chemistry 51: 57-60.

Yin, Y., G. Borges, M. Sakuta, A. Crozier and H. Ashihara (2012). Effect of phosphate deficiency on the content and biosynthesis of anthocyanins and the expression of related genes in suspension-cultured grape (Vitis sp.) cells. Plant Physiology and Biochemistry 55: 77-84.

Yoon, S. H., R. E. B. Ketchum, and C. G. Caldwell (2013) Polyphenol, terpenoid, glycoside, and alkaloid production by Crocus sativus cell cultures. Patent Cooperation Treaty.

Yousef, G. G., A. F. Brown, Y. Funakoshi, F. Mbeunkui, M. H. Grace, J. R. Ballington, A. Loraine and M. A. Lila (2013). Efficient quantification of the health-relevant anthocyanin and phenolic acid profiles in commercial cultivars and breeding selections of blueberries (Vaccinium spp.). Journal of Agricultural and Food Chemistry. 
Zandi, P., A. J. C and K. A. S (2004). Reduced risk of alzheimer disease in users of antioxidant vitamin supplements: The cache county study. Archives of Neurology 61: 82-88.

Zhang, J., L. Melton, A. Adaim and M. Skinner (2008). Cytoprotective effects of polyphenolics on $\mathrm{H}_{2} \mathrm{O}_{2}$-induced cell death in SH-SY5Y cells in relation to their antioxidant activities. European Food Research and Technology 228: 123-131.

Zhang, L., A. S. Ravipati, S. R. Koyyalamudi, S. C. Jeong, N. Reddy, P. T. Smith, J. Bartlett, K. Shanmugam, G. Münch and M. J. Wu (2011a). Antioxidant and antiinflammatory activities of selected medicinal plants containing phenolic and flavonoid compounds. Journal of Agricultural and Food Chemistry 59: 1236112367.

Zhang, X. and R. E. Schmidt (2000). Hormone-containing products' impact on antioxidant status of tall fescue and creeping bentgrass subjected to drought. Crop Science 40: 1344-1349.

Zhang, Y.-H., J.-J. Zhong and J.-T. Yu (1995). Effect of osmotic pressure on cell growth and production of ginseng saponin and polysaccharide in suspension cultures of Panax notoginseng. Biotechnology Letters 17: 1347-1350.

Zhang, Y., H. Li, W. Shu, C. Zhang, W. Zhang and Z. Ye (2011b). Suppressed expression of ascorbate oxidase gene promotes ascorbic acid accumulation in tomato fruit. Plant Molecular Biology Reporter 29: 638-645.

Zhao, J.-L., L.-G. Zhou and J.-Y. Wu (2010). Effects of biotic and abiotic elicitors on cell growth and tanshinone accumulation in Salvia miltiorrhiza cell cultures. Applied Microbiology and Biotechnology 87: 137-144.

Zhao, Z. and M. Moghadasian (2010). Bioavailability of hydroxycinnamates: A brief review of in vivo and in vitro studies. Phytochemistry Reviews 9: 133-145.

Zheng, W. and S. Y. Wang (2002). Oxygen radical absorbing capacity of phenolics in blueberries, cranberries, chokeberries, and lingonberries. Journal of Agricultural and Food Chemistry 51: 502-509.

Zhou, M.-L., X.-M. Zhu, J.-R. Shao, Y.-X. Tang and Y.-M. Wu (2011). Production and metabolic engineering of bioactive substances in plant hairy root culture. Applied Microbiology and Biotechnology 90: 1229-1239.

Zibadi, S., P. J. Rohdewald, D. Park and R. R. Watson (2008). Reduction of cardiovascular risk factors in subjects with type 2 diabetes by Pycnogenol supplementation. Nutrition Research 28: 315-320.

Zobayed, S. M. A., F. Afreen and T. Kozai (2007). Phytochemical and physiological changes in the leaves of St. John's wort plants under a water stress condition. Environmental and Experimental Botany 59: 109-116.

Zushi, K. and N. Matsuzoe (2007). Seasonal and cultivar differences in salt-induced change in ascorbic acid and dehydroascorbic acid contents of tomato fruit. Environment Control in Biology 45: 165-171. 


\section{APPENDIX A}

\section{A.1 Optimum concentration of $\mathrm{NaCl}$ that enhances the DPPH radical scavenging activities of leaf extracts}

A pilot study was conducted (October - January 2009) to determine, which salinity levels are most likely to enhance the DPPH radical scavenging activities of plants. ACB and OAM were exposed to two salinity levels (50 and $200 \mathrm{mM} \mathrm{NaCl}$ ) using eight week old plants. Leaf phytochemical analysis for DPPH radical scavenging was performed according to 3.3.1 and 3.3.3. Results (Figure A.1) indicated antioxidant activities were highest with $50 \mathrm{mM} \mathrm{NaCl}$ at 14 weeks in both ecotypes.

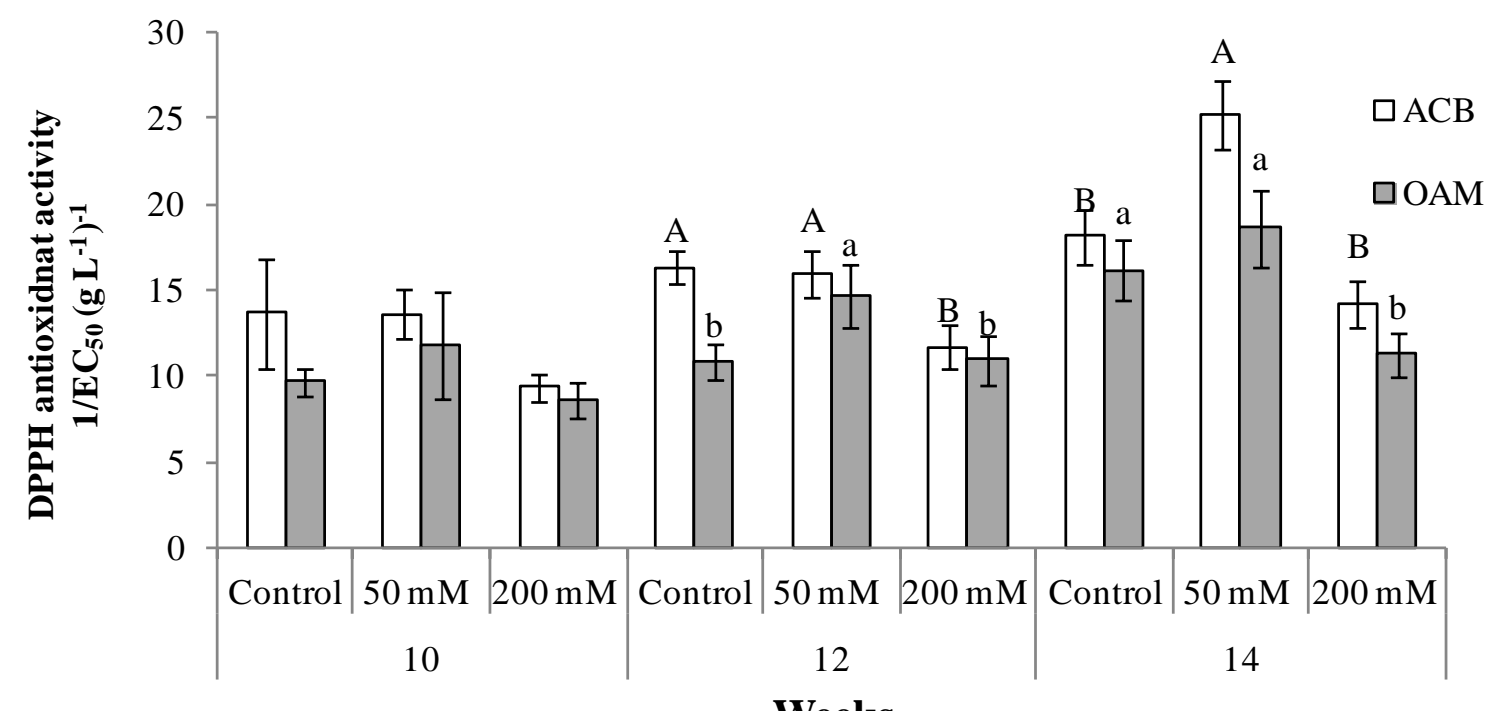

Weeks

Figure A.1 Treatment effects on DPPH scavenging in methanolic extracts of leaves from 10, 12 and 14 week old plants of ACB and OAM ecotypes of Sonchus oleraceus L. Means \pm SE $(n=9)$. Bars with different letters of the same case indicate significant differences across treatments within an ecotype, and bars without letters indicate no significant effects of stressors within an ecotype $(P<0.05)$. 


\section{A.2 Stressors that enhances the DPPH radical scavenging activities of leaf extracts}

A pilot study was conducted (April - July 2010) to determine, which stressors are most likely to enhance the extractable antioxidant activities of plants. ACB and OAM were exposed to chilling $\left(5^{0} \mathrm{C}\right.$ for $12 \mathrm{~h}$ overnight per week), salinity (50 $\left.\mathrm{mM} \mathrm{NaCl}\right)$, drought (withholding irrigation until wilting, followed by re-watering) and chilling in low light during daytime $\left(5^{0} \mathrm{C}\right.$ for $12 \mathrm{~h}$ at $\left.96 \mu \mathrm{mol} \mathrm{m} \mathrm{s}^{-2} \mathrm{PAR}\right)$ using eight week old plants. Leaf phytochemical analysis was performed according to Sections $2.2-2.4$ and 3.3.1. Results (Figure A.2) indicated antioxidant activities and levels of total phenolics nearly doubled in week 14 compared to week 10 regardless of treatment or ecotype. Chilling doubled DPPH radical scavenging activities in week 14 compared to the control. Salinity doubled ORAC activities in week 14 compared to the control. Antioxidant activities and total phenolics content were reduced by $70 \%$ by chilling in low light during daytime compared to the control in week 14 

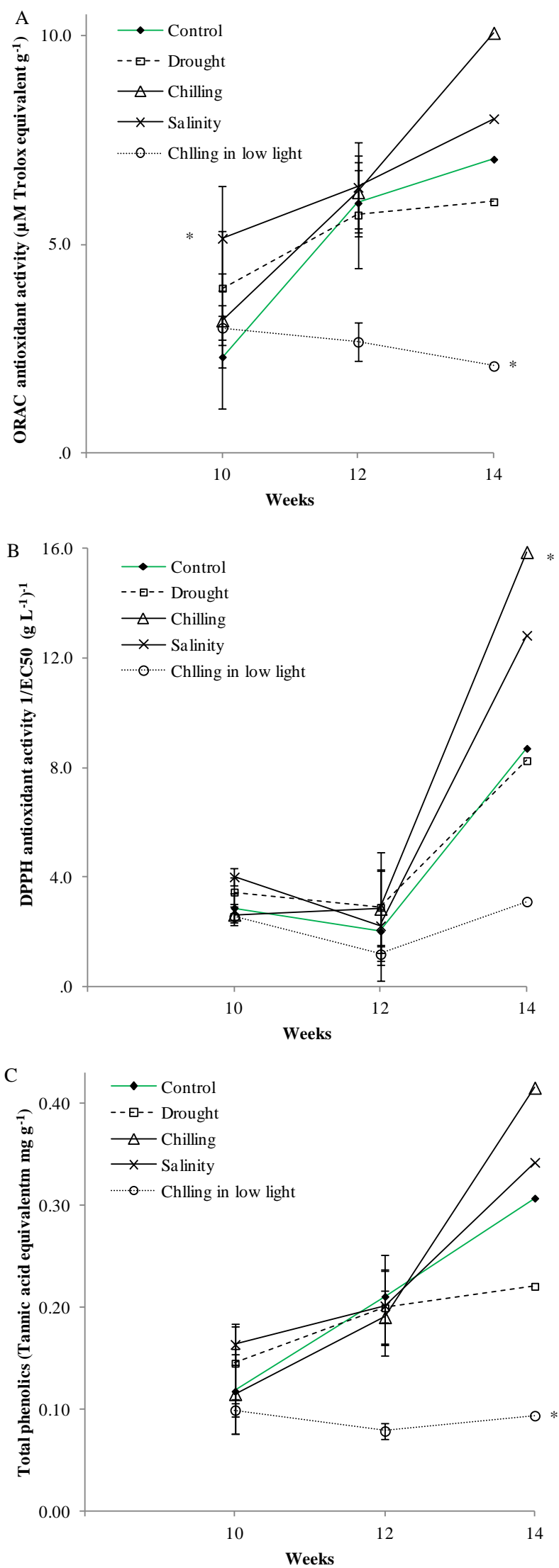

Figure A.2 Effects of age and stressors on (A) ORAC, (B) DPPH scavenging, (C) total phenolic content, in methanolic extracts of Sonchus oleraceus L. leaves. Means \pm SE $(n=5)$. ${ }^{*}$ Significant difference compared to control $(P<\mathbf{0 . 0 5})$. 


\section{APPENDIX B}

\section{B.1 Effects of age, ecotype and stressor on antioxidant activity, total phenolic content, hydroxycinnamic acid content}

Table B.1 ANOVA results ( $F$ values) for effects of age, ecotype and stressor on antioxidant activity, total phenolic content, hydroxycinnamic acid content of Sonchus oleraceus L. leaf methanolic

extracts $^{a}$

\begin{tabular}{|c|c|c|c|c|c|c|c|c|}
\hline \multirow{3}{*}{$\begin{array}{l}\text { Sources of } \\
\text { variation }\end{array}$} & \multirow[t]{3}{*}{$d f^{1}$} & \multicolumn{7}{|c|}{ F values } \\
\hline & & \multicolumn{3}{|c|}{ Antioxidant activity } & \multicolumn{4}{|c|}{ Hydroxycinnamic acids $^{2}$} \\
\hline & & $\begin{array}{c}\text { ORAC } \\
\text { technique }^{3}\end{array}$ & $\begin{array}{c}\text { DPPH } \\
\text { technique }^{4}\end{array}$ & $\begin{array}{c}\text { Total } \\
\text { phenolic } \\
\text { content }^{5}\end{array}$ & $\begin{array}{c}\text { Caftaric } \\
\text { acid }\end{array}$ & $\begin{array}{c}\text { Chlorogenic } \\
\text { acid }\end{array}$ & $\begin{array}{c}\text { Chicoric } \\
\text { acid }\end{array}$ & Total \\
\hline Age (A) & 2 & $74^{*}$ & $128 *$ & $80 *$ & $47 *$ & $31 *$ & $55^{*}$ & $56^{*}$ \\
\hline Ecotype (E) & 1 & $22 *$ & $4^{\mathrm{ns}}$ & $30 *$ & $17 *$ & $19 *$ & $15^{*}$ & $23 *$ \\
\hline Stressor (S) & 3 & $0^{\mathrm{ns}}$ & $3 *$ & $4^{*}$ & $0^{\mathrm{ns}}$ & $18 *$ & $1^{\mathrm{ns}}$ & $1^{\mathrm{ns}}$ \\
\hline$A * E$ & 2 & $4^{*}$ & $9 *$ & $4 *$ & $0^{\mathrm{ns}}$ & $12 *$ & $0^{\mathrm{ns}}$ & $0^{\mathrm{ns}}$ \\
\hline$A * S$ & 6 & $6^{*}$ & $4^{*}$ & $5 *$ & $0^{\mathrm{ns}}$ & $8 *$ & $1^{\mathrm{ns}}$ & $1^{\mathrm{ns}}$ \\
\hline$E^{*} S$ & 3 & $2^{\mathrm{ns}}$ & $2^{\mathrm{ns}}$ & $1^{\mathrm{ns}}$ & $0^{\mathrm{ns}}$ & $3 *$ & $1^{\mathrm{ns}}$ & $1^{\mathrm{ns}}$ \\
\hline$A * E * S$ & 6 & $1^{\mathrm{ns}}$ & $0^{\mathrm{ns}}$ & $1^{\mathrm{ns}}$ & $1^{\mathrm{ns}}$ & $2 *$ & $0^{\mathrm{ns}}$ & $0^{\mathrm{ns}}$ \\
\hline Error & 168 & $559^{\mathrm{b}}$ & $20^{\mathrm{b}}$ & $0.1^{\mathrm{b}}$ & $1^{\mathrm{b}}$ & $1^{\mathrm{b}}$ & $3^{\mathrm{b}}$ & $7^{\mathrm{b}}$ \\
\hline \multicolumn{9}{|c|}{${ }^{a}$ The factors were age (three levels), ecotype (two) and stressor (four) with eight plants for each } \\
\hline \multicolumn{9}{|c|}{${ }^{\mathrm{b}}$ Mean error squared } \\
\hline \multicolumn{9}{|c|}{${ }^{1}$ Degrees of freedom } \\
\hline \multicolumn{9}{|c|}{${ }^{2}$ Concentration $\left(\mathrm{mg} \mathrm{g}^{-1}\right)$} \\
\hline \multicolumn{9}{|c|}{${ }^{3}$ Oxygen radical absorbance capacity expressed as $\mu$ mol Trolox equivalent $\mathrm{g}^{-1}$} \\
\hline \multicolumn{9}{|c|}{${ }^{4}$ 2,2-diphenyl-1-picrylhydrazyl radical scavenging activity expressed as $1 / \mathrm{EC}_{50}\left(\mathrm{~g} \mathrm{~L}^{-1}\right)^{-1}$} \\
\hline \multicolumn{9}{|c|}{${ }^{5} \mathrm{mg}$ tannic acid equivalent $\mathrm{g}^{-1}$} \\
\hline$* P<0.05 ;{ }^{n}$ & $P>0$ & & & & & & & \\
\hline
\end{tabular}




\section{B.2 Effects of age, ecotype and stressor on ascorbate concentration}

Table B.2 ANOVA results (F values) for effects of age, ecotype and stressor on ascorbate concentration of Sonchus oleraceus L. leaf methanolic extracts ${ }^{a}$

\begin{tabular}{lcc}
\hline Sources of variation & $\boldsymbol{d f}^{\mathbf{1}}$ & F values $^{2}$ \\
& & \\
\hline Age (A) & 2 & $126^{*}$ \\
Ecotype (E) & 1 & $19^{*}$ \\
Stressor (S) & 3 & $1^{\mathrm{ns}}$ \\
A*E & 2 & $8^{*}$ \\
A*S & 6 & $7^{*}$ \\
E*S & 3 & $2^{\mathrm{ns}}$ \\
A*E*S & 6 & $1^{\mathrm{ns}}$ \\
Error & 168 & $0.05^{\mathrm{b}}$ \\
\hline
\end{tabular}

$a$ The factors were age (three levels), ecotype (two) and stressor (four) with eight plants for each combination of factors.

\footnotetext{
${ }^{\mathrm{b}}$ Mean error squared

${ }^{1}$ Degrees of freedom

${ }^{2}$ Ascorbate concentration $\left(\mathrm{mg} \mathrm{g}^{-1}\right)$

* $P<0.05 ;{ }^{\mathrm{ns}} P>0.05$
} 


\section{APPENDIX C \\ C.1 Optimum concentrations of NAA and BAP for callus initiation and growth}

Callus induction and dry biomass were measured using various concentrations of NAA $(1,2,4)$ and $\operatorname{BAP}(0,1,2)$. Results (Figure B.1) indicated the best hormone combination as NAA $1.0 \mathrm{mg} \mathrm{L}^{-1}(5.4 \mathrm{mM})$ and BAP $1.0 \mathrm{mg} \mathrm{L}^{-1}(4.4 \mathrm{mM})$.

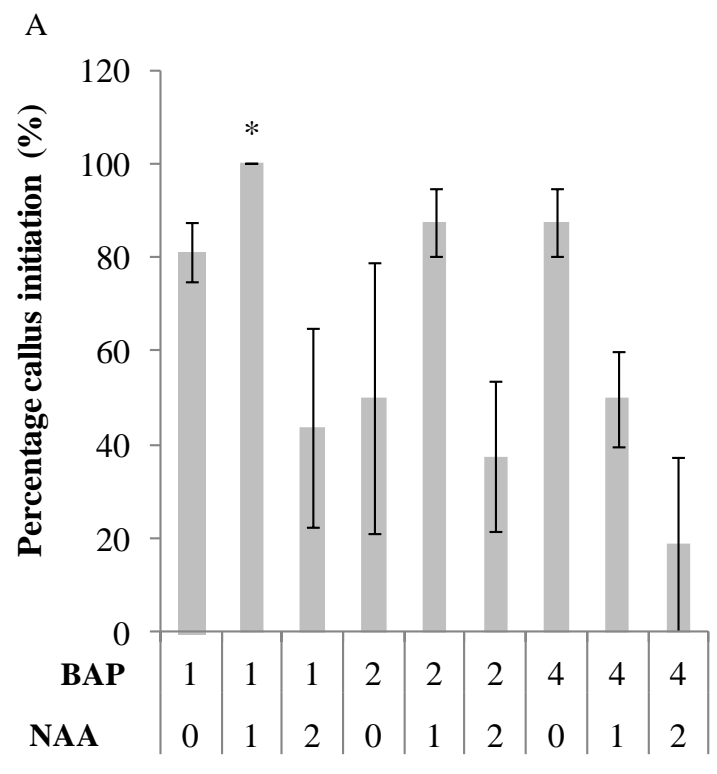

Concentration $\left(\mathrm{mg} \mathrm{L}^{-1}\right)$

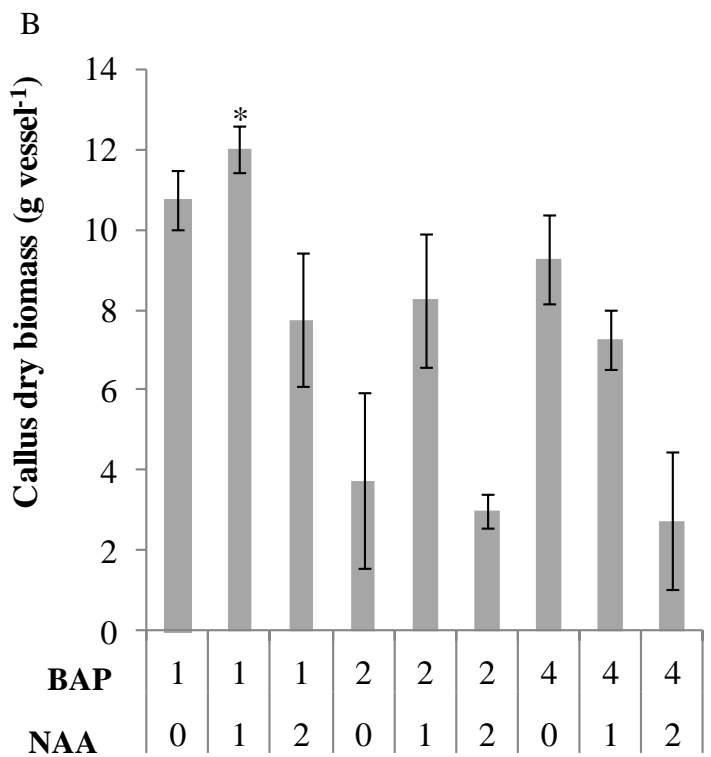

Concentration $\left(\mathrm{mg} \mathrm{L}^{-1}\right)$

Figure C.1 Different hormone concentrations on callus initiation and callus dry biomass of Sonchus oleraceus L. after 21 days of culture. Means \pm SE $(n=8)$. *Selected hormone concentration. 


\section{C.2 Optimum concentrations of NAA and BAP for growth of suspension cultures}

The dry biomass of calli was measured in suspension cultures maintained on variable concentrations of NAA $(0.5,1.0,2.0)$ and $\operatorname{BAP}(0.5,1.0)$. Results indicated best hormone combination as NAA $2 \mathrm{mg} \mathrm{L}^{-1}(10.7 \mathrm{mM})$ and BAP $1 \mathrm{mg} \mathrm{L}^{-1}(4.4 \mathrm{mM})$ based on biomass accumulation (Figure B.2).

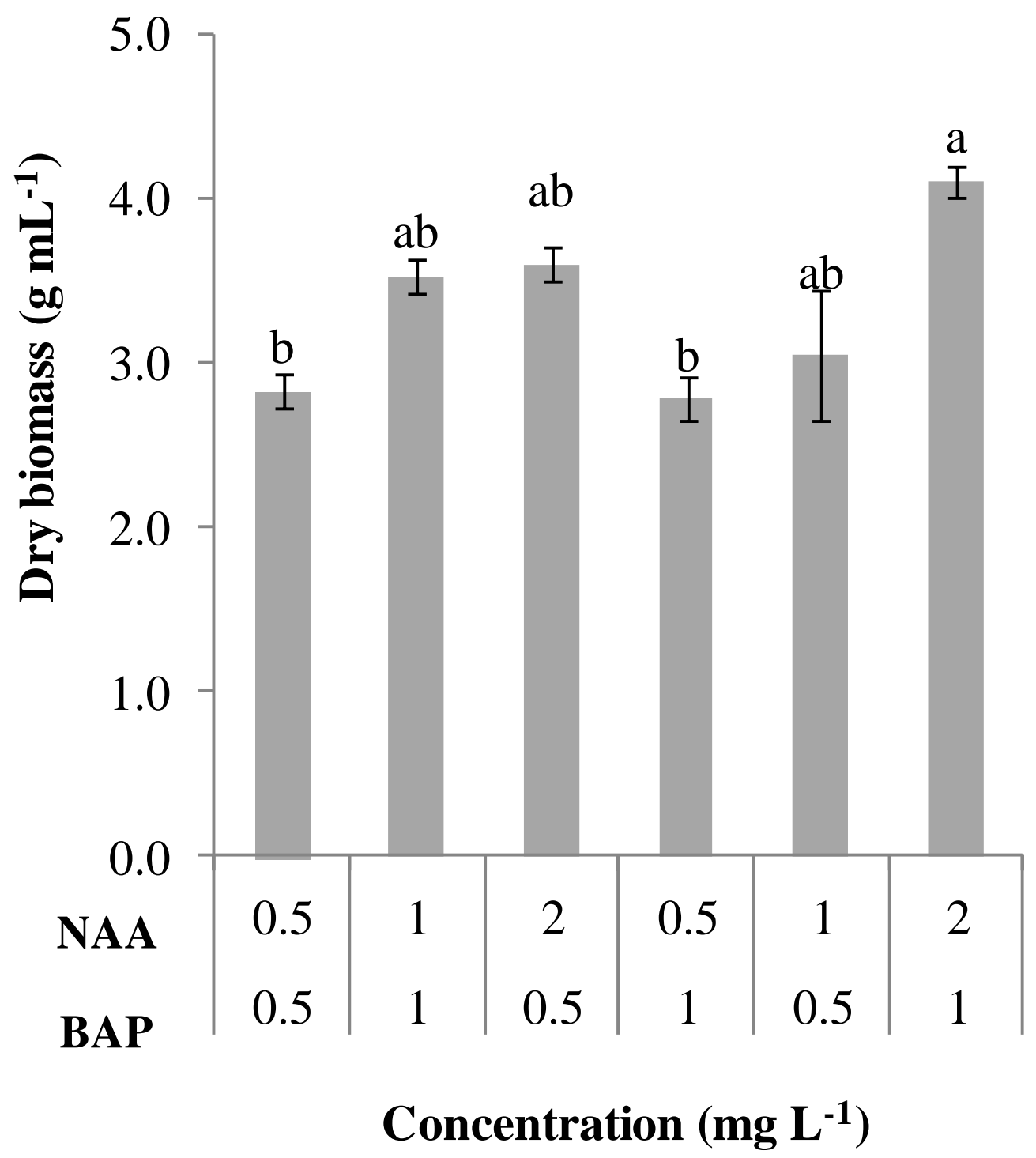

Figure C.2 Different hormone concentrations on dry biomass of Sonchus oleraceus L. suspension cultures after 21 days of culture. Means $\pm S E(n=10)$. Bars with different letters indicate significant differences of treatments $(P<\mathbf{0 . 0 5})$. 